\title{
A PROBABIISTIC TECHNIQUE FOR OPERATING RESERVE ASSESSMENT USING SYSTEM OPERATING STATES
}

\author{
A Thesis \\ Submitted to the College of Graduate Studies and Research \\ in partial fulfillment of the requirements \\ for the Degree of \\ Master of Science \\ in the \\ Department of Electrical Engineering \\ University of Saskatchewan \\ by \\ MAHMUD FOTUHI-FIRUZABAD \\ Saskatoon, Saskatchewan \\ March 1993
}

Copyright @ 1993

The author claims copyright. Use shall not be made of the material contained herein without proper acknowledgment, as indicated on the copyright page. 


\section{DEDICATED TO MY PARENTS}

Mirza Mohammad and Massoumeh 


\section{COPYRIGHT}

The author has agreed that the library, University of Saskatchewan, may make this thesis freely available for inspection. Moreover, the author has agree that permission for extensive copying of this thesis for scholarly purposes may be granted by the Professor who supervised the thesis work recorded herein or, in his absence, by the Head of Department or the Dean of the College in which the thesis work was done. It is understood that due recognition will be given to the author of this thesis and to the University of Saskatchewan in any use of the material in this thesis. Copying or publication or any other use of this thesis for financial gain without approval by the University of Saskatchewan and the author's written permission is prohibited.

Requests for permission to copy or to make any other use of the material in this thesis in whole or in part should be addressed to:

Head of the Department of Electrical Engineering

University of Saskatchewan

Saskatoon, Canada S7N OWO. 


\section{ACKNOWLEDGEMENTS}

The author would like to express his sincere gratitude and appreciation to Dr. Roy Billinton for his guidance and consistent encouragement through-out the entire course of this research project. The author would also like to acknowledge Dr. Billinton's patience, perceptive criticism and helpful suggestions in the preparation of this thesis.

The author is indebted to his parents and all other family members who have provided encouragement and moral support for the duration of his studies. Special thanks are extended to his wife, Parvaneh, for her patience and continuous moral support.

This work was financed by the Ministry of Culture and Higher Education of Iran and by Dr. Billinton in the form of research assistantship from the Natural Sciences and Engineering Research Council of Canada. Both financial supports are thankfully acknowledged. 


\title{
UNIVERSITY OF SASKATCHEWAN
}

Electrical Engineering Abstract No.93A373

\section{A PROBABILISTIC TECHNIQUE FOR OPERATING RESERVE ASSESSMENT USING SYSTEM OPERATING STATES}

\author{
Student: Mahmud Fotuhi-Firuzabad Supervisor: Dr. Roy Billinton \\ M.Sc. Thesis Presented to the \\ College of Graduate Studies and Research \\ March 1993
}

\begin{abstract}
Operating reserve assessment in an electric power system is normally performed using deterministic criteria. Deterministic approaches do not include an assessment of the actual system reliability as they do not take into account the probabilistic or stochastic nature of system behavior and component failures. Probabilistic techniques, however, respond to the significant factors which affect the reliability of a system. Deterministic criteria are, however, easier for the system operator to understand, than a risk index determined using probabilistic techniques. In order to alleviate the difficulty in interpreting the risk index and provide more applicable information for the system operator, deterministic considerations can be included in the probabilistic assessment.
\end{abstract}


A probabilistic technique is illustrated in this thesis to assess the operating reserve requirements in a system. This technique combines deterministic criteria with probabilistic indices to monitor the system wellbeing. In this approach, the generation system is classified into different system operating states. A risk index designated as the Generating System Operating State Risk (GSOSR) is defined in this thesis as the probability of residing in an undesirable operating state. The technique together with the effect on the GSOSR and the system operating state probabilities of factors such as lead time, system peak load, load forecast uncertainty and generating unit derated states are illustrated in this thesis. The inclusion of rapid start and hot reserve units and interruptible loads in the analysis can affect the GSOSR and the system operating state probabilities. The effects of these factors have been incorporated in the operating reserve assessment using the concept of area risk curves. The effect of various degrees of postponability on the GSOSR and the system operating state probabilities are also discussed. Two reliability test systems, the RBTS and the IEEE-RTS, have been utilized in the wide range of studies presented in this thesis. 


\section{Table of Contents}

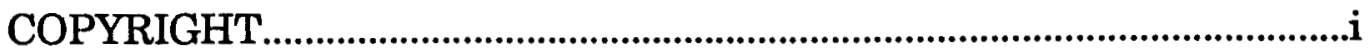

ACKNOWLEDGEMENTS ...................................................................

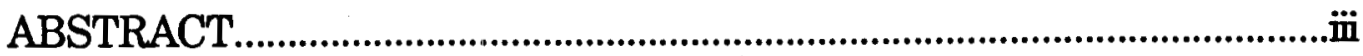

Table of Contents .............................................................................................

List of Figures ................................................................................................ viii

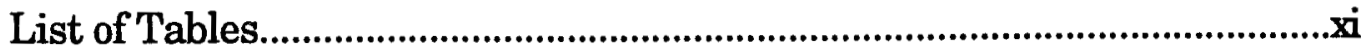

List of Symbols .................................................................................................. . Xv

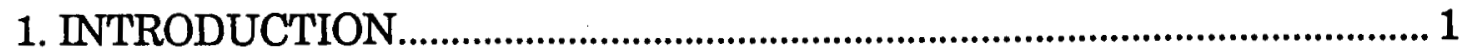

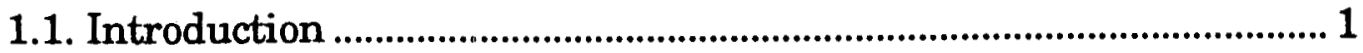

1.2. Reliability Evaluation At HL I............................................................ 4

1.3. Scope and Objective of the Thesis........................................................ 6

1.4. Thesis Outline........................................................................................... 9

2. BASIC CONCEPTS OF OPERATING RESERVE ASSESSMENT......12

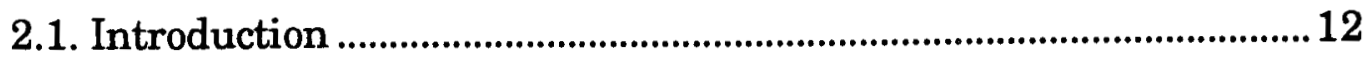

2.2. State-space Representation of Generating Units ............................ 14

2.2.1. Two-state Model ......................................................................... 14

2.2.2. Derated-state Model ............................................................18

2.3. Capacity Outage Probability Table ..................................................... 22

2.4. Basic Concepts of the PJM Method...................................................23

2.4.1. Unit Commitment................................................................25

2.5. Description of the Roy Billinton Test System ( RBTS) ..................26

2.6. Application to the RBTS.....................................................................27

2.6.1. Effect of Lead Time Variation on the Unit Commitment..31

2.6.2. Effect of Peak Load Variation on the Unit Commitment ..32

2.6.3. Effect of Variation in Acceptable Risk Level on the Unit Commitment..............................................................................33

2.7. The Security Function Approach ....................................................... 33

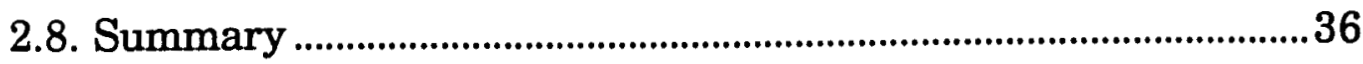

3. A PROBABILISTIC TECHNIQUE FOR OPERATING RESERVE ASSESSMENT USING SYSTEM OPERATING STATES.....................37

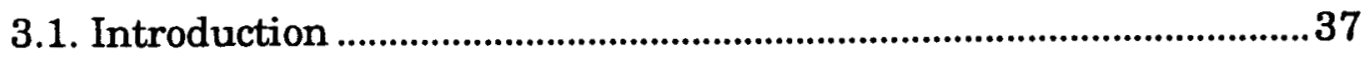

3.2. Classification Of System Operating States.......................................39 
3.2.1. System Model and State Definitions in Composite System

3.2.2. System Model and State Definitions for Operating Reserve Studies at HLI...........................................................41

3.3. Unit Commitment and Evaluation Procedure. .46

3.4. Comparison of the Proposed Probabilistic Technique with the PJM Method. 50

3.5. Load Forecast Uncertainty ...............................................................53

3.6. Selected Studies.................................................................................54

3.6.1. Effect of Lead Time Variation ..................................................55

3.6.1.1. Base Case....................................................................55

3.6.1.2. Inclusion of Derated States Into the Analysis......58

3.6.1.3. Inclusion of Load Forecast Uncertainty .62

3.6.1.4. Inclusion of Both Derated States and Load Forecast Uncertainty .66

3.6.2. Effect of Peak Load Variation .................................................66

3.6.3. Sensitivity Analysis............................................................72

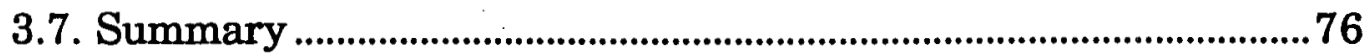

4. OPERATING RESERVE ASSESSMENT CONSIDERING STAND-BY UNITS 78

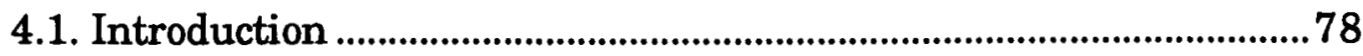

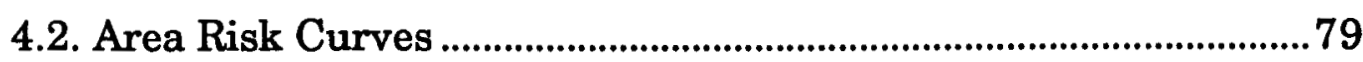

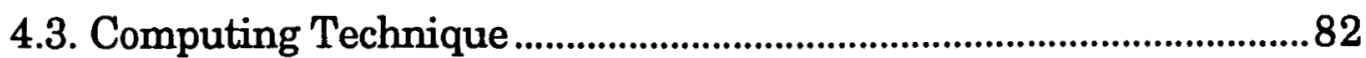

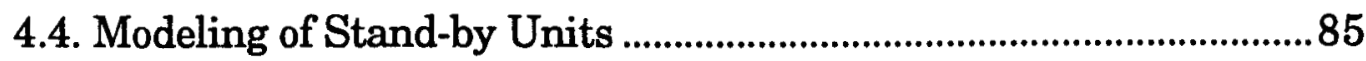

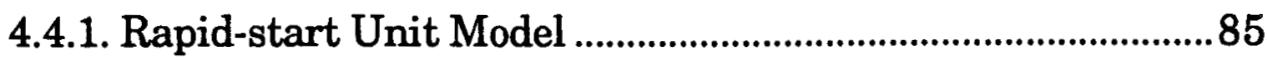

4.4.2. Hot Reserve Unit Model..........................................................88

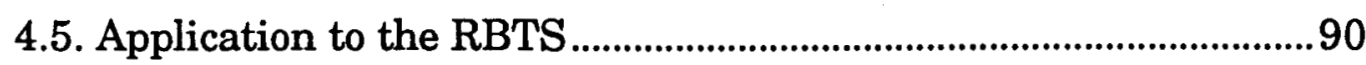

4.5.1. Unit Commitment for a Specified GSOSR.............................91

4.5.2. Unit Commitment for a Specified GSOSR and a Specified Normal State Probability

4.5.3. Effect on the System Operating States and GSOSR of Increasing the Number of Rapid Start and Hot Reserve Units. 94

4.6. Postponable Outages 99

4.6.1. Model and Evaluation Technique for Postponable

Outages. 


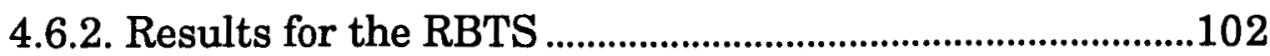

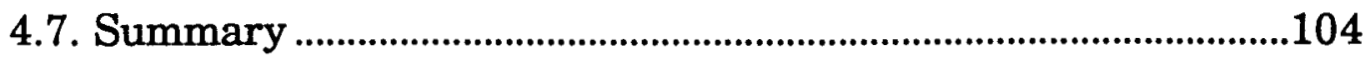

5. OPERATING RESERVE ASSESSMENT CONSIDERING INTERRUPTIBLE LOADS ..............................................................109

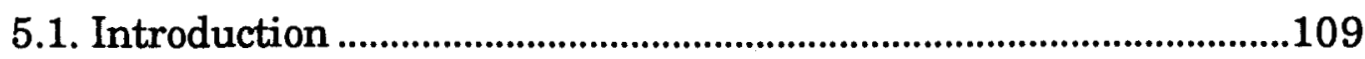

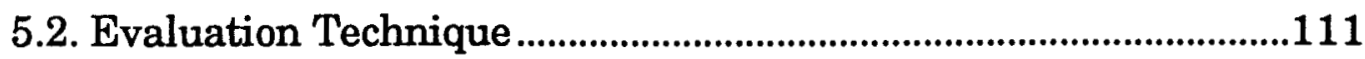

5.3. Unit Commitment.......................................................................116

5.4. Effect of Variation in the Available Interruptible Load................119

5.5. Effect of Variation in the Lead Time of Interruptible Load .........123

5.6. Additional Load/Interruptible Load Carrying Capability of a System

5.7. Comparison of the Effect of Interruptible Loads and Rapid Start Units

5.8. Summary

6. APPLICATION TO THE IEEE-RELIABILITY TEST SYSTEM

6.1. Introduction

6.2. Description of the IEEE-Reliability Test System (IEEE-RTS) 138

6.3. Unit Commitment for the Hourly Peak Load .140

6.4. Effect of Lead Time Variation .140

6.5. Effect of Peak Load Variation.. .147

6.6. Effect of Inclusion of Rapid Start and Hot Reserve Units 152

6.7. Effect of Outage Postponability 158

6.8. Effect of Interruptible Loads. 163

6.9. Summary .167

7. SUMMARY AND CONCLUSIONS .170

REFERENCES. 


\section{List of Figures}

Figure 1.1: Subdivision of System Reliability .........................2

Figure 1.2: Hierarchical Levels............................................3

Figure 1.3: Model for Hierarchical Level I. .............................4

Figure 2.1: Basic Two-state Model............................................. 15

Figure 2.2: $\quad$ Simplified Two-state Model Used in Operating Reserve Evaluation....................................................... 17

Figure 2.3: Three-state Model of a Generating Unit. .................... 19

Figure 2.4: Three-state Model of a Generating Unit Without Repair

Process. ..........................................................20

Figure 2.5: Three-state Model of a Generating Unit Used in

Operating Reserve Evaluation.................................20

Figure 2.6: Multi-state Model of a Generating Unit Used in

Operating Reserve Evaluation...................................21

Figure 2.7: Single Line Diagram of the RBTS......................... 28

Figure 3.1: Diagram of System Operating States........................... 40

Figure 3.2: Modified Diagram of the System Operating States....... 45

Figure 3.3: $\quad$ System Operating Domains................................52

Figure 3.4: Seven-step Approximation of the Normal Distribution

of Uncertainty in Load Forecasting............................. 54

Figure 3.5: Three State-model of the $40 \mathrm{MW}$ Thermal Units...........58

Figure 3.6: Variation of Probabilities of the Normal and Alert

States with Lead Time............................................59

Figure 3.7: Variation of Probabilities of the Emergency and

Extreme Emergency States with Lead Time..................60

Figure 3.8: Variation of the GSOSR with Lead Time. .................61

Figure 3.9: $\quad$ Probabilities of the Normal and Alert States. ..............69

Figure 3.10: Probabilities of the Emergency and Extreme Emergency States............................................. 70

Figure 3.11: Variation of the GSOSR with the System Peak Load.......71

Figure 3.12: Effect of Peak Load Variation on the Number of

Committed Units................................................72 
Figure 3.13: Probabilities of the Normal and Alert States with

Standard Deviation.

Figure 3.14: Probabilities of the Emergency and Extreme

Emergency States with Standard Deviation ................75

Figure 4.1: Area Risk Curve Without Stand-by Units.

Figure 4.2: $\quad$ Area Risk Curve with Rapid Start and Hot Reserve

Units.

Figure 4.3: Four-state Model for Rapid Start Units........................ 86

Figure 4.4: Five-state Model for Hot Reserve Units.....................89

Figure 4.5: Variation of Number of Required Units Versus Load.....93

Figure 4.6: Probabilities of the Normal and Alert States..............97

Figure 4.7: Probabilities of the Emergency and Extreme

Emergency States............................................98

Figure 4.8: Variation of GSOSR with Number of Rapid Start

Units. .......................................................99

Figure 4.9: Postponable Outage Model. .................................100

Figure 4.10: Variation of the Normal and Alert State Probabilities

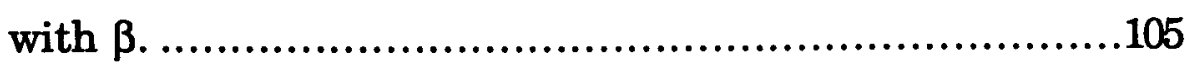

Figure 4.11: Variation of the Emergency and Extreme emergency

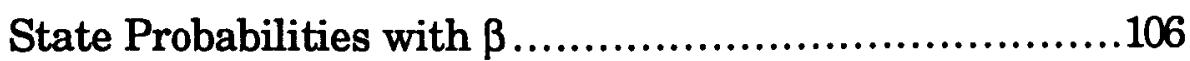

Figure 4.12: Variation of GSOSR with $\beta$................................107

Figure 5.1: Area Risk Curve for Load Interruption....................112

Figure 5.2: Equivalent Load Approach for Load Interruption.........113

Figure 5.3: Equivalent Unit Approach for Load Interruption. ........113

Figure 5.4: Probabilities of the Normal and Alert States with the

Magnitude of Interruptible Load .............................121

Figure 5.5: Probabilities of the Emergency and Extreme

Emergency States with the Magnitude of Interruptible

Load .

Figure 5.6: Variation of the GSOSR with the Magnitude of

Interruptible Load............................................123

Figure 5.7: Probabilities of the Normal and Alert States with the

Interruptible Load Lead Time.................................125

Figure 5.8: Probabilities of the Emergency and Extreme

Emergency States with the Interruptible Load Lead

Time. 
Figure 5.9: Variation of the GSOSR with the Interruptible Load Lead Time.......................................................127

Figure 5.10: Probabilities of the Normal and Alert States. .............133

Figure 5.11: Probabilities of the Emergency and Extreme Emergency States...............................................134

Figure 5.12: Variation of Generating System Operating State Risk...135

Figure 6.1: Single Line Diagram of the IEEE-RTS. 139

Figure 6.2: Probabilities of the Normal and Alert States with Lead Time

Figure 6.3: Probabilities of the Emergency and Extreme Emergency States with Lead Time. 146

Figure 6.4: Probabilities of the Normal and Alert States with Peak Load.

Figure 6.5: Probabilities of the Emergency and Extreme Emergency States with Peak Load

Figure 6.6: Variation of the Number of Required Generating Units and the GSOSR with Peak Load.

Figure 6.7: Probabilities of the Normal and Alert States with Rapid Start Units. .156

Figure 6.8: Probabilities of the Emergency and Extreme Emergency States with Rapid Start Units 157

Figure 6.9: Probabilities of the Normal and Alert States with $\beta \ldots . . . . .161$

Figure 6.10: Probabilities of the Emergency and Extreme Emergency States with $\beta$

Figure 6.11: Probabilities of the Normal and Alert States with the Magnitude of Interruptible Load .165

Figure 6.12: Probabilities of the Emergency and Extreme Emergency States with the Magnitude of Interruptible Load .166

Figure 6.13: Probabilities of the Normal and Alert States with Interruptible Load Lead Time. .168

Figure 6.14: Probabilities of the Emergency and Extreme Emergency States with Interruptible Load Lead Time ..169 


\section{List of Tables}

Table 2.1: Generating Unit Data of the RBTS...........................29

Table 2.2: Capacity Outage Probability Table for the First Eight Units of the RBTS. .............................................. 30

Table 2.3: Unit Commitment at Different Lead Times..................... 31

Table 2.4: Unit Commitment at Different Load Levels...................... 32

Table 2.5: Unit Commitment at Different Specified Risk Levels........ 33

Table 3.1: Unit Commitment with a Specified Risk of $0.01 \ldots \ldots \ldots \ldots . . .48$

Table 3.2: Unit Commitment with a Specified Risk of 0.01 and a Desired Level of Normal State Probability of 0.9 ............ 49

Table 3.3: Unit Commitment and System Operating State Probabilities (Base Case)...........................................56

Table 3.4: Unit Commitment and System Operating State Probabilities Considering the Effects of Derated States (Case 2). 62

Table 3.5: System Operating State Probabilities for a Load Level of $111 \mathrm{MW}$ and a Lead Time of 30 Minutes. 64

Table 3.6: Unit Commitment and System Operating State Probabilities for Different Lead Times and with Load Forecast Uncertainty (Case 3).

Table 3.7: Unit Commitment and System Operating State Probabilities Considering the Effects of both Derated States and Load Forecast Uncertainty (Case 4)................67

Table 3.8: Effect of Variation in Standard Deviation....................... 73

Table 4.1: Transition Rates ( occ/hr) of the Rapid Start and Hot Reserve Unit.

Table 4.2: Unit Commitment and System Operating State Probabilities Without Stand-by Units.........................92

Table 4.3: Unit Commitment and System Operating State Probabilities Including one Rapid Start and one Hot Reserve Unit. 
Table 4.4: Unit Commitment and System Operating State Probabilities Including one Rapid Start and one Hot Reserve Unit with

Table 4.5: $\quad$ System Operating State Probabilities for Different Numbers of Rapid Start Units and no Hot Reserve Units. .96

Table 4.6: System Operating State Probabilities for Different Numbers of Rapid Start Units and one Hot Reserve Unit. .96

Table 4.7: Unit Commitment and System Operating State Probabilities for Different Values of $\beta$. 103

Table 4.8: Unit Commitment and System Operating State Probabilities for Different Values of $\beta$ with Load Forecast Uncertainty. 104

Table 5.1: Unit Commitment and System Operating State Probabilities Considering Interruptible Load.

Table 5.2: Number of Committed Units for Three Different Cases...118

Table 5.3: Unit Commitment and System Operating State Probabilities for a Load Level of $160 \mathrm{MW}$ with Variable Interruptible Load Capability.

Table 5.4: System Operating State Probabilities for a Load Level of $160 \mathrm{MW}$ and Spinning Capacity of $210 \mathrm{MW}$

Considering Variable Interruptible Load Capability.

Table 5.5: Unit Commitment and System Operating State

Probabilities for Various Interruptible Load Lead

Times.

Table 5.6: Additional Load/Interruptible Load for Spinning

Capacity of $210 \mathrm{MW}$ and Corresponding System

Operating State Probabilities.

Table 5.7: System Operating State Probabilities for Different

Numbers of Rapid Start Units.

Table 5.8: System Operating State Probabilities for Various

Interruptible Load Capabilities.

Table 6.1: Generation Unit Data for the IEEE-RTS. .138 
Table 6.2: Unit Commitment and system Operating State Probabilities for the Hourly Peak Load Variations in a 24 Hours Scheduling Period. ...................................141

Table 6.3: Unit Commitment and System Operating State Probabilities for Different Lead Times When the System Load is $1995 \mathrm{MW}$ .142

Table 6.4: Unit Commitment and System Operating State Probabilities for Different Lead Times and a Load Level of $1995 \mathrm{MW}$ with Load Forecast Uncertainty

Table 6.5: System Operating State Probabilities for a Load Level of 1995 MW when the Number of Committed Units is Fixed at 13 .

Table 6.6: System Operating State Probabilities for a Load Level of 1995 MW When the Number of Committed Units is Fixed at 13 and with Load Forecast Uncertainty............147

Table 6.7: Unit Commitment and System Operating State Probabilities for Different Load Levels. 148

Table 6.8: Unit Commitment and System Operating State Probabilities for Different Load Levels Considering Load Forecast Uncertainty. .......................................152

Table 6.9: Unit Commitment and System Operating State Probabilities with one Rapid Start and one Hot reserve Unit. 153

Table 6.10: System Operating State Probabilities with Different Numbers of Rapid Start Units and no Hot Reserve Units .154

Table 6.11: System Operating State Probabilities with Different Numbers of Rapid Start Units and One Hot Reserve Unit. .155

Table 6.12: System Operating State Probabilities with Different Numbers of Rapid Start and Two Hot Reserve Units. ......155

Table 6.13: Data for Considering Postponable Outage Units............158

Table 6.14: Unit Commitment and System Operating State Probabilities for Different Values of $\beta$. 
Table 6.15: Unit Commitment and System Operating State Probabilities for Different Values of $\beta$ Considering Load Forecast Uncertainty.

Table 6.16: System Operating State Probabilities for Different Values of $\beta$ and Fixed Number of Units, Considering Load Forecast Uncertainty .160

Table 6.17: Effect of the Magnitude of Interruptible Loads on the System Operating State Probabilities. .164

Table 6.18: Effect of Interruptible Load Lead time on the System Operating State Probabilities. 


\section{List of Symbols}

LOLE Loss of Load Expectation

LOEE Loss of Energy Expectation

HL I Hierarchical Level I

HL II Hierarchical Level II

HL III Hierarchical Level III

GSOSR Generating System Operating State Risk

LFU Load Forecast Uncertainty

RBTS Roy Billinton Test System

IEEE-RTS IEEE-Reliability Test System

LI Load Interruption

F(R) Risk Function

NRS Number of Rapid Start units

NHR Number of Hot Reserve units

$\lambda \quad$ Failure rate

$\mu \quad$ Repair rate 


\section{INTRODUCTION}

\subsection{Introduction}

The importance of electricity in our economy and in our lives is constantly growing and it is therefore obvious that a high level of reliability is of the utmost importance. This can only be achieved by focusing on all aspects of an electric power system from the generating units through the transmission system down to the customer at the end of the distribution system. Modern society because of its pattern of social and working habits, has come to expect the supply to be continuously available on demand[1]. In practice, however, it is neither economically nor technically possible to design and construct a power system with one hundred percent reliability. Power system engineers have always attempted to respond to societies' expectations and to achieve the highest possible reliability at an affordable cost. In this regard, it is generally agreed that reliability assessments must be applied to both the planning and operating domains of a power system.

The term reliability has several definitions. The one most often used is that "reliability is a measure of the overall ability of a system to perform its intended function"[1,2]. The concept of power system reliability is extremely broad and covers all aspects of the ability of the system to satisfy 
the consumer requirements $[1,3]$. The term reliability as applied to power systems can be divided into two general categories: system adequacy and system security as shown in Figure 1.1.

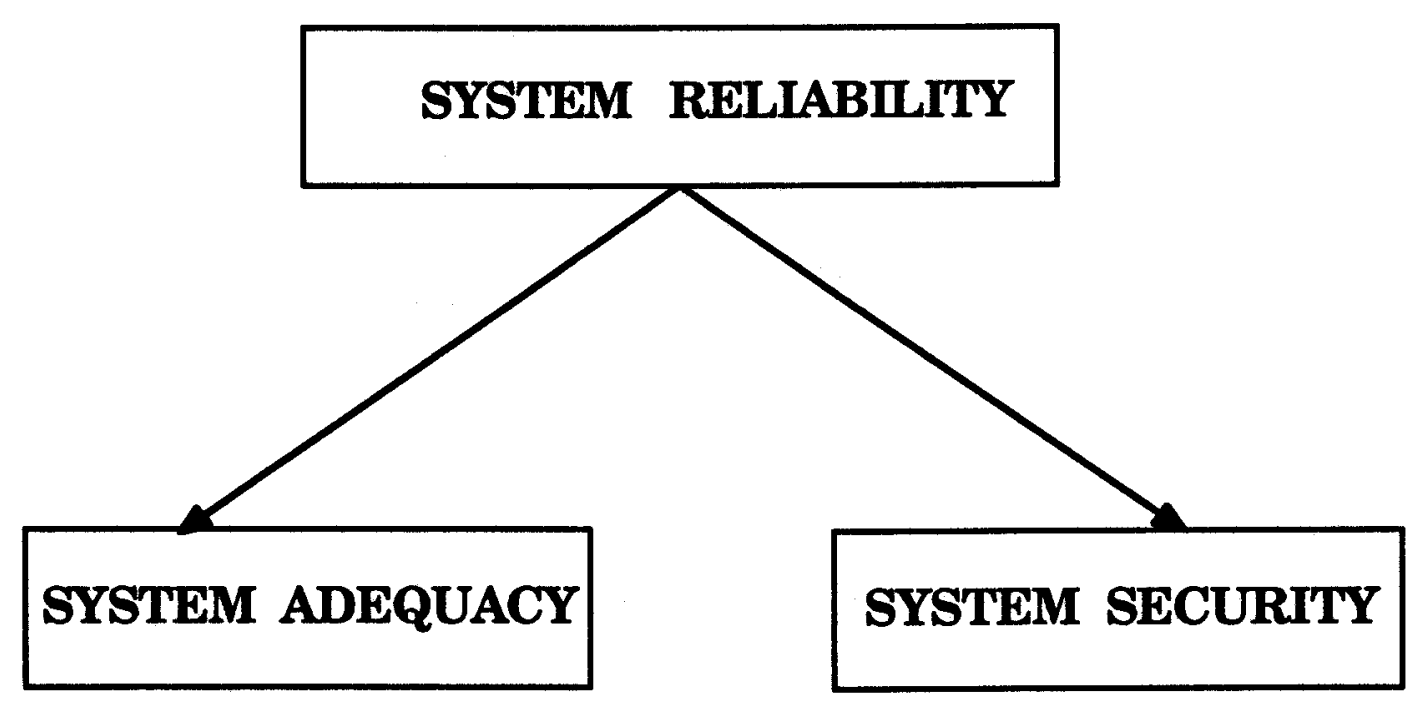

Figure 1.1: Subdivision of System Reliability.

System adequacy relates to the existence of sufficient facilities within the system to satisfy the consumer load demand. Adequacy is therefore concerned with static conditions which do not include system disturbances. System security, on the other hand, relates to the ability of the system to cope with perturbations arising within it.

Indices, commonly used in generating-planning studies such as the Loss of Load Expectation(LOLE) and the Loss of Energy Expectation(LOEE) are adequacy parameters. Quantification of spinning or operating capacity requirements falls in the domain of security assessment which is the subject of this thesis. 
Due to their complexity and size power systems are generally divided into generation, transmission, and distribution functional zones, as shown in Figure 1.2. These functional zones can be combined to form a series of hierarchical levels for the purpose of conducting system reliability analysis. Reliability assessment at HL I is concerned only with the generation facilities. Evaluation of the composite generation and transmission facilities is designated as an Hierarchical Level II (HL II) study. The evaluation of the entire system is designated as Hierarchical Level III (HL III) assessment. This thesis is concentrated on security evaluation at HL I.

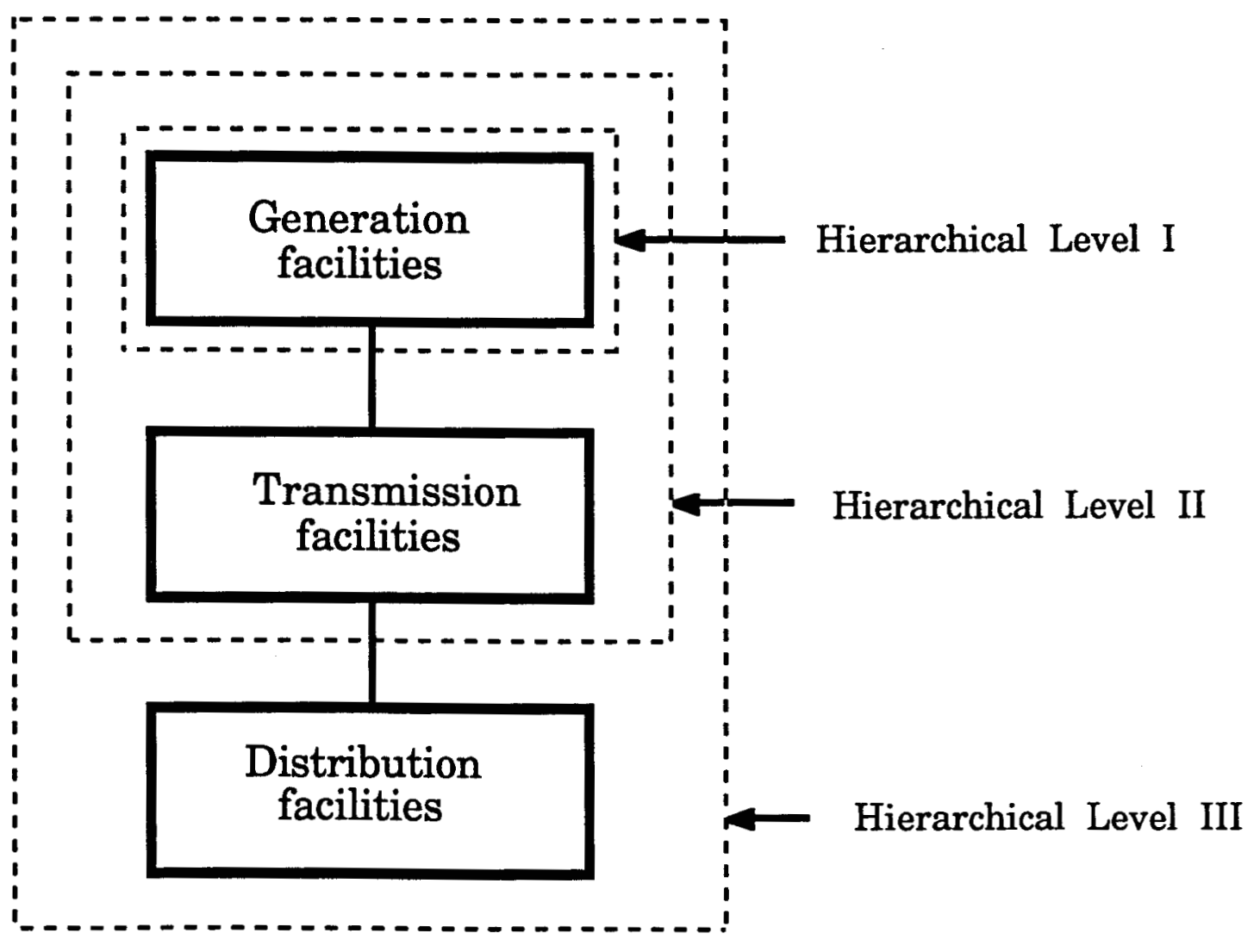

Figure 1.2: Hierarchical Levels. 


\subsection{Reliability Evaluation At HL I}

Reliability evaluation at HL I provides a quantitative assessment of the ability of the generation system to satisfy the total system demand. The basic system model is one in which all the generating units and loads are connected to a single bus as shown in Figure 1.3. This area of application can be divided into the two basic forms of static capacity assessment and operating reserve assessment [3].

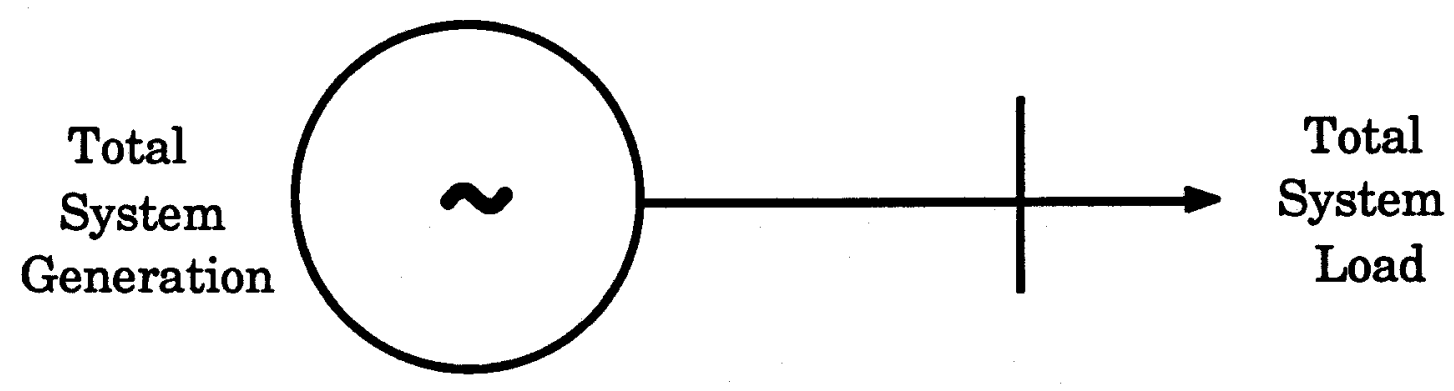

Figure 1.3: Model for Hierarchical Level I.

Static capacity assessment is conducted at the planning stage in order to decide how much, and when additional generating plant needs to be installed. Operating capacity assessment is conducted at an operational planning stage or in actual operation in order to decide how much of the existing plant needs to be committed to meet the forecast load. The theoretical techniques presented in this thesis and the illustrated applications are limited to the domain of operating reserve evaluation at HL I.

There are a number of methods in general use to evaluate the 
operating reserve requirements in a power system. These methods can be classified into the two categories of deterministic and probabilistic approaches. Deterministic techniques such as those shown below recommend that the reserve capacity in a system should be equal to a:
i) Percentage of system load or operating capacity,
ii) Fixed capacity margin,
iii) Largest unit contingency, or
iv) Any combination of the above methods.

The most common deterministic criterion relates the reserve margin to the size of the largest unit or to some percentage of the peak load. Most Canadian utilities use the "largest unit contingency" method and some utilities complement this reserve assessment technique with an additional margin of some form [4]. The basic objective of deterministic approaches in determining the required operating reserve is to minimize the total operating cost $[5,6,7,8]$ and in doing so a system faces different degrees of risk throughout the day. The essential weakness of deterministic approaches is that they do not assess the actual system risk by ignoring the probabilistic or stochastic nature of system behavior and component failures [9].

Probabilistic techniques can be used to recognize the stochastic nature of system components and to incorporate these factors in the operating reserve assessment in a consistent manner [10]. The first major probabilistic technique, known as the PJM method, was proposed in 1963 [11]. This method evaluates the probability of the committed generation just 
satisfying or failing to satisfy the expected demand during a specified time into the future, known as the lead time. The lead time is the time required to commit additional generation capacity into service. The method was further extended to accommodate more accurate generating models [12]. In the original PJM method it was assumed that the reserve in the system is in the form of synchronized reserve. The method has been modified by including the effect of rapid start and hot reserve units in [13].

A more general probabilistic approach known as the "Security Function Approach" was proposed by Patton[14,15,16]. This approach evaluates the probability of a breach of a system security at times in the near term future given a known operating condition at the time the calculations are made. A breach of security is defined to be some intolerable or undesirable operating condition in a system[3]. In an operating reserve evaluation at HL I, a breach of security is defined to be inadequate spinning reserve capacity. In this constrained application, the security function approach therefore, is identical to the PJM method.

\subsection{Scope and Objective of the Thesis}

This thesis is strictly concerned with the application of probability concepts to operating reserve assessment. The basic objective in using a probabilistic technique is to maintain the system risk at a level which is less than or equal to a specified value. The magnitude of the required operating reserve can therefore be determined on the basis of the assigned system risk. The system risk is expressed as: 


$$
R(t)=\sum_{i=1}^{N} P_{i}(t) Q_{i}(t)
$$

Where,

$$
\begin{aligned}
& R(t)=\text { System risk at time } t, \\
& P_{i}(t)=\text { Probability that the generation system is in state } i \text { at time } t, \\
& Q_{i}(t)=\text { Probability that the system load will be equal to or greater } \\
& \quad \text { than the generation in state } i \text { at time } t, \\
& N \quad=\text { total number of generation states. }
\end{aligned}
$$

As noted earlier, the basic probabilistic technique presently used in operating reserve assessment is the PJM method. On the basis of the PJM method, units are committed in such a way that the unit commitment risk is less than or equal to a specified value. Using this method, system performance for a given load and set of committed units can be identified as being in the acceptable or the unacceptable domains. The system is in the acceptable domain if the operating capacity is greater than the load, otherwise it is in the unacceptable domain. The unit commitment risk and its complementary value, i.e. probability of the acceptable performance, are the only information available to the system operator. There are two disadvantages in regard to the PJM method. The first is the restricted information it provides and the second is the problem faced by the system operator in interpreting this information. Most utilities prefer using a deterministic technique rather than probabilistic methods because of those two disadvantages. 
A new probabilistic technique is illustrated in this thesis to assess the operating reserve requirements in a system. The related theoretical and computational basis of the technique are described in detail. In this approach, the generation system is classified into different system operating states designated as normal, alert, emergency and extreme emergency. The state definitions are presented in Chapter 3. A computer program has been developed to quantify the well-being of the operating system in terms of the defined states. The system is considered to be acceptable in regard to the system generation and load in the normal and the alert states. The complement of the summation of these two state probabilities is considered as the basic risk index and is designated as the Generating System Operating State Risk (GSOSR). Commitment of units to meet load changes can be done by satisfying a specified GSOSR. The probability associated with the normal state can also be utilized as a criterion to extend the concepts of operating reserve evaluation. This is discussed in Chapter 3 of this thesis.

The proposed technique combines deterministic considerations with probabilistic indices in order to monitor the system well-being. This combination is achieved by recognizing that the system operating states created by incorporating the system deterministic criteria can be categorized as being healthy, marginal or at risk. These divisions are defined as the system operating zones and quantified using the probabilities of the system operating states. The operating health, margin and risk zones are also presented and defined in Chapter 3. It is generally believed that the developed technique overcomes the major difficulties associated with the PJM method. The reliability indices provided by the proposed technique, are 
easy to understand and can be easily interpreted by the system operator. This method also provides more information to the system operator compared to that available from the basic PJM method. This information not only informs the operator of the risk in the system but, more importantly, provides information on the degree of system comfortability, which can not be achieved by the basic PJM method.

\subsection{Thesis Outline}

The thesis is structured as follows. Chapter 2 describes the basic concepts of operating reserve evaluation. This chapter provides a review of the probabilistic techniques currently used for spinning reserve assessment. Unit commitment should be such that the unit commitment risk is less than or equal to a specified level. The effect of variation in the specified risk on the number of committed units are illustrated. The effect of lead time and peak load variations on the unit commitment risk and the required spinning reserve are also illustrated in this chapter.

Chapter 3 describes the proposed probabilistic method for spinning reserve assessment. The system operating state framework is examined in this chapter. A risk index designated as the Generating System Operating State Risk (GSOSR) is obtained from the probability of the normal and the alert states. Unit commitment can be done by satisfying the operating criteria which could be a specified level of GSOSR or a specified probability of being in the normal state. The effect of lead time and peak load variation on the unit commitment and probabilities of the system operating states are examined in this chapter. An approach to consider load forecast 
uncertainty in operating reserve assessment using the new probabilistic technique is presented. The effects of generating unit derated states are also examined in Chapter 3.

The reserve in the system can be in the form of synchronized spinning reserve or non-synchronized unit reserve such as rapid start and hot reserve units. An approach is illustrated in Chapter 4 to incorporate the effect of rapid start and hot reserve units in the evaluation of the system operating state probabilities. The conventional definition of a forced outage includes both sudden removal from service and non-sudden removal in those cases in which the unit can continue to operate for a limited but specified period of time. The effects of various degrees of outage postponability on the system operating states and GSOSR are presented in this chapter.

In addition to generating capacity adjustments, some systems have loads which can be curtailed within a specified period of time with no utility penalty. Area risk curve concepts [3] have been utilized in Chapter 5 to illustrate the effect of interruptible loads on the GSOSR and the system operating state probabilities. The effects of variation in the magnitude of interruptible loads and the corresponding lead times are also examined in this chapter.

The developed methods and techniques presented in this thesis have been applied to the two reliability test systems, Roy Billinton Test System(RBTS) and the IEEE-Reliability Test System(IEEE-RTS). The results obtained by utilizing the RBTS are illustrated in Chapters 2,3,4 and 5 . 
Chapter 6 of this thesis presents the results obtained by utilizing the IEEERTS.

Chapter 7 presents a summary and the conclusions to this research work. 


\section{BASIC CONCEPTS OF OPERATING RESERVE ASSESSMENT}

\subsection{Introduction}

Reliability evaluation at HL I is concerned with the problem of determining the amount of system generating capacity required in order to maintain the desired level of system reliability. This area of study can be divided into the two categories of static capacity assessment and operating reserve assessment. Static generating capacity assessment is used to determine the amount of installed reserve capacity required to maintain a desired level of reliability. Operating reserve assessment, on the other hand, is related to the short-term evaluation of the actual capacity required to meet a given load demand [3]. Considerable efforts have been devoted to static capacity assessment $[20,21,22]$. There is, however, relatively little published material in the area of operating reserve assessment.

In a practical power system, the load demand varies considerably between weekdays and on-peak and off-peak hours. It is, therefore, not economical to continuously keep all the generating units on line. The task of forecasting the load for a short time in the future and scheduling the appropriate and necessary operating capacity is a complex one. Sufficient 
capacity should be scheduled in order that the system is capable of handling deviations in customer demands and the possible loss of operating generating units. The system reliability can be improved by increasing the system generating reserve. This, however, will increase the system operating cost. The reserve in the system, therefore, should be scheduled in such a way that both reliability and economic constraints are satisfied.

There is a wide range of available approaches in regard to how the operating reserve is actually maintained. It may be in the form of synchronized spinning reserve or non-synchronized reserve such as rapid start and hot reserve units. Both deterministic and probabilistic techniques can be utilized to determine the required level of capacity reserve to be maintained by a system. Deterministic approaches do not specifically recognize the probability of component failures in the assessment of operating reserve. Probabilistic techniques can be used to take into account the random outages of system components and other stochastic component behavior. The basic goal of a probabilistic technique is to maintain the system risk as close as possible but lower than an allowable risk at all times.

Static capacity assessment and operating reserve assessment, though related, are conceptually different. They deal with different reliability issues and therefore different evaluation techniques are required. This chapter presents some basic generating unit models and discusses the unit statistics required in operating reserve assessments. Two basic probabilistic techniques for operating reserve assessment namely, the "PJM" method and the "Security Function Approach" are also briefly 
illustrated in this chapter.

\subsection{State-space Representation of Generating Units}

Each component in a power system reliability study is represented by an appropriate model. This model can be quite simple or quite complicated depending upon the application. Generating units are the basic components in an HL I analysis. Different generating unit models such as two-state, three-state and multi-state have been proposed. The decision on what model to use depends on a number of factors. The two most important factors are: the size of the generating unit and the accuracy required in the power system reliability study. In some cases, using the simplest model is quite adequate, however, in other cases, it is necessary to use a more exact model. Utilizing a more exact model increases the system accuracy, but it also invariably increases the system size which in turn increases the required computation time to conduct the system reliability evaluation. Some of the important generating unit models and related spinning reserve concepts are reviewed in the following sections.

\subsubsection{Two-state Model}

Most generating unit models used in power system reliability evaluation, neglect the residence times in partial outage states and reduce the generator failure and repair processes into the two state model shown in Figure 2.1.

This is the simplest possible model of a generating unit and assumes 
that the unit resides in either the up state or the down state. The parameters $\lambda$ (failure rate) and $\mu$ (repair rate) are state transition rates and

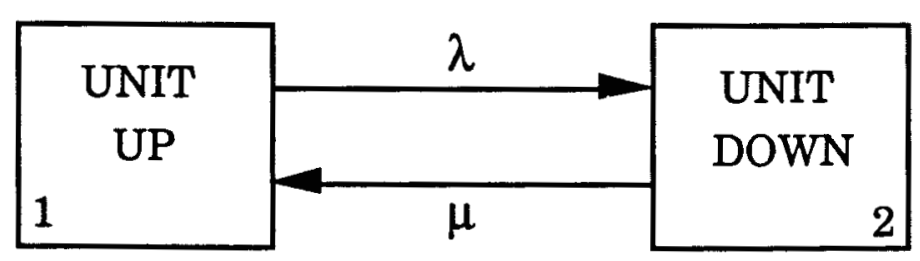

Figure 2.1: Basic Two-state Model.

represent the rates at which the unit transits from one state to another [23]. The major assumption made in Figure 2.1 is that the generator up and down state times are exponentially distributed and therefore the transition rates from the up state to the down state and vice-versa are constant.

The time dependent state probabilities can be calculated using differential equations or by the matrix multiplication method [23]. The state probabilities of a generating unit, represented by a two state model, utilizing the differential equations approach, are shown below :

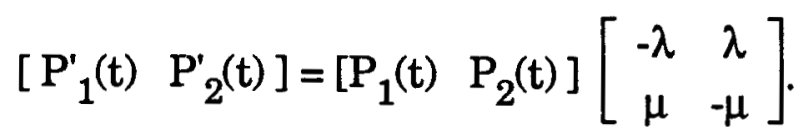

If the unit is in the operating state at time $t=0$, then :

$$
\begin{aligned}
& \mathrm{P}_{1}(\mathrm{t})=\frac{\mu}{\lambda+\mu}+\frac{\lambda}{\lambda+\mu} \mathrm{e}^{-(\lambda+\mu) \mathrm{t}} \\
& \mathrm{P}_{2}(\mathrm{t})=\frac{\lambda}{\lambda+\mu}-\frac{\lambda}{\lambda+\mu} \mathrm{e}^{-(\lambda+\mu) \mathrm{t} .}
\end{aligned}
$$


Where,

$$
\begin{aligned}
& P_{1}(t)=\text { Probability that the unit is in the up state at time } t \\
& P_{2}(t)=\text { Probability that the unit is in the down state at time } t .
\end{aligned}
$$

The limiting state or steady-state probabilities can be evaluated from Equation 2.2 by letting $t \rightarrow \infty$. If the limiting state probabilities are defined as $P_{1}$ and $P_{2}$ for the operating and the failed states, respectively, then :

$$
\begin{aligned}
& \mathrm{P}_{1}=\mathrm{P}_{1}(\infty)=\frac{\mu}{\lambda+\mu}, \\
& \mathrm{P}_{2}=\mathrm{P}_{2}(\infty)=\frac{\lambda}{\lambda+\mu} .
\end{aligned}
$$

The steady state probabilities given by Equation 2.3 are utilized in static reserve assessment. Equation $2.3 \mathrm{~b}$ is the probability of finding the unit in the down state for a distant time into the future, and is known as the "Forced Outage Rate"(FOR ). As noted earlier, the basic difference between static and operating capacity evaluation is the future time period considered. The former is related to long-term assessment and the latter is related to short-term evaluation. The probability of finding the unit in the down state at a given time $\mathrm{T}$ in the future can be found by substituting $\mathrm{T}$ for $t$ in Equation 2.2b, and is :

$$
\mathrm{P}(\text { down })=\frac{\lambda}{\lambda+\mu}-\frac{\lambda}{\lambda+\mu} \mathrm{e}^{-(\lambda+\mu) \mathrm{T}}
$$

The time period $\mathrm{T}$ used in operating capacity assessment is relatively 
short and known as the lead time. This parameter is the time in the future during which no capacity increases can be made and no additional units can be brought into service. If $\mathrm{T}$ is relatively short it can be assumed that the probability of a repair is negligible. Applying this approximation, the model, shown in Figure 2.1 is changed to the more simple model shown in Figure 2.2.

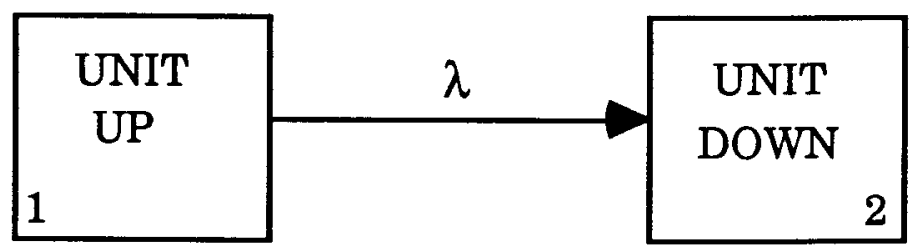

Figure 2.2: Simplified Two-state Model Used in Operating Reserve Evaluation.

Equation 2.4 becomes,

$$
\mathrm{P}(\text { down })=1-\mathrm{e}^{-\lambda \mathrm{T}}
$$

If $\lambda T \ll 1$, Equation 2.5 can be approximated [3] by:

$$
\mathrm{P}(\text { down }) \approx \lambda \mathrm{T}
$$

The product $\lambda \mathrm{T}$ is known as the "Outage Replacement Rate" (O.R.R). This is the basic statistic used in operating reserve evaluation and can be defined as the probability that a unit fails and is not replaced during the lead time T. A two-state model is generally quite adequate for small generating units, since the total time spent in partial outage states is much smaller than the total residence time in the up and the down states. This is 
not usually true for large generating units in which the partial outage times may be quite considerable and therefore should not be ignored.

\subsubsection{Derated-state Model}

A generating unit is arguably the most complex component in a power system as it contains many auxiliary components [24]. This complexity usually increases with the size of the unit. The failure of certain components can result in different unit partial outages, and therefore the two state model can be a very simplified representation for a large generating unit as big units can contain a large number of possible derated capacity states. Incorporating detailed derating states in a reliability assessment will increase the accuracy of the results, but it will also increase the required computation time.

The simplest model for a large thermal unit considering partial outages is a three-state model. This representation was proposed in Reference 25, where the three states are operating at full capacity, operating at less than full capacity and the full forced outage state. In this model which is shown in Figure 2.3 all the partial outage states are lumped into a single derated state. The time dependent probabilities can be found by solving the system differential equations or by the matrix multiplication method [3]. It is time consuming and difficult to obtain the exact time-dependent solution for a model including all possible transition rates. Under certain assumptions, these complications can be reduced as shown in the following example. 


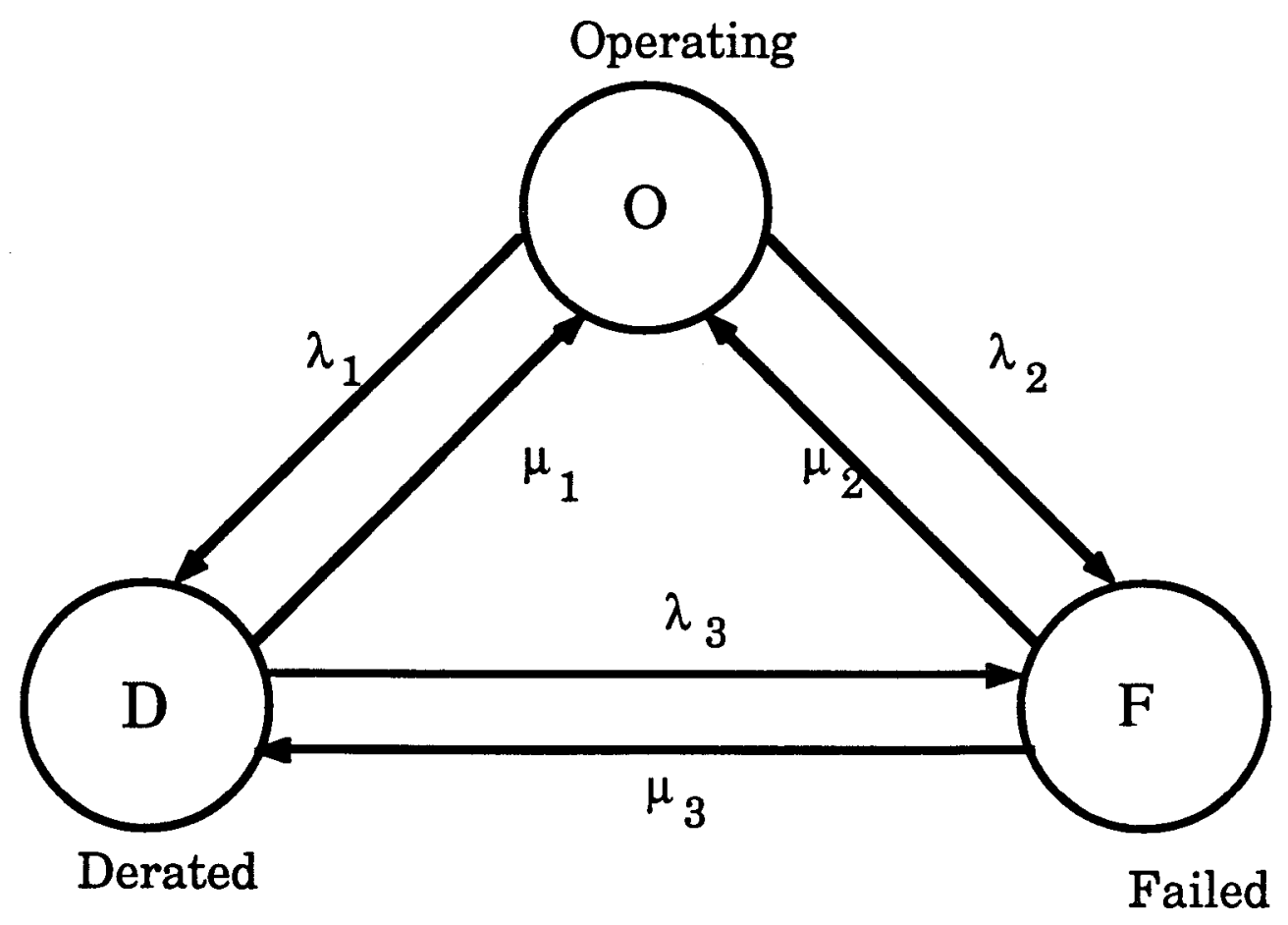

Figure 2.3: Three-state Model of a Generating Unit.

If the average repair time of the unit is much longer than the lead time, it is acceptable to neglect the repair process. Under this condition, the model shown in Figure 2.3 is reduced to that shown in Figure 2.4. Also, if the probability of more than one failure occurring during the small delay time is negligible, then the three-state model reduces to that of Figure 2.5. Considering the model shown in Figure 2.5 and assuming that $\left(\lambda_{1}+\lambda_{2}\right) \ll 1$, it follows from Equation 2.6 that [3],

$$
\begin{aligned}
& \mathrm{P}(\text { down }) \approx \lambda_{2} \mathrm{~T}, \\
& \mathrm{P}(\text { derated }) \approx \lambda_{1} \mathrm{~T}, \\
& \mathrm{P}(\text { operating }) \approx 1-\left(\lambda_{1}+\lambda_{2}\right) \mathrm{T} .
\end{aligned}
$$


Where,

$\lambda_{1}$ and $\lambda_{2}$ are the failure rates and $\mathrm{T}$ is the lead time.

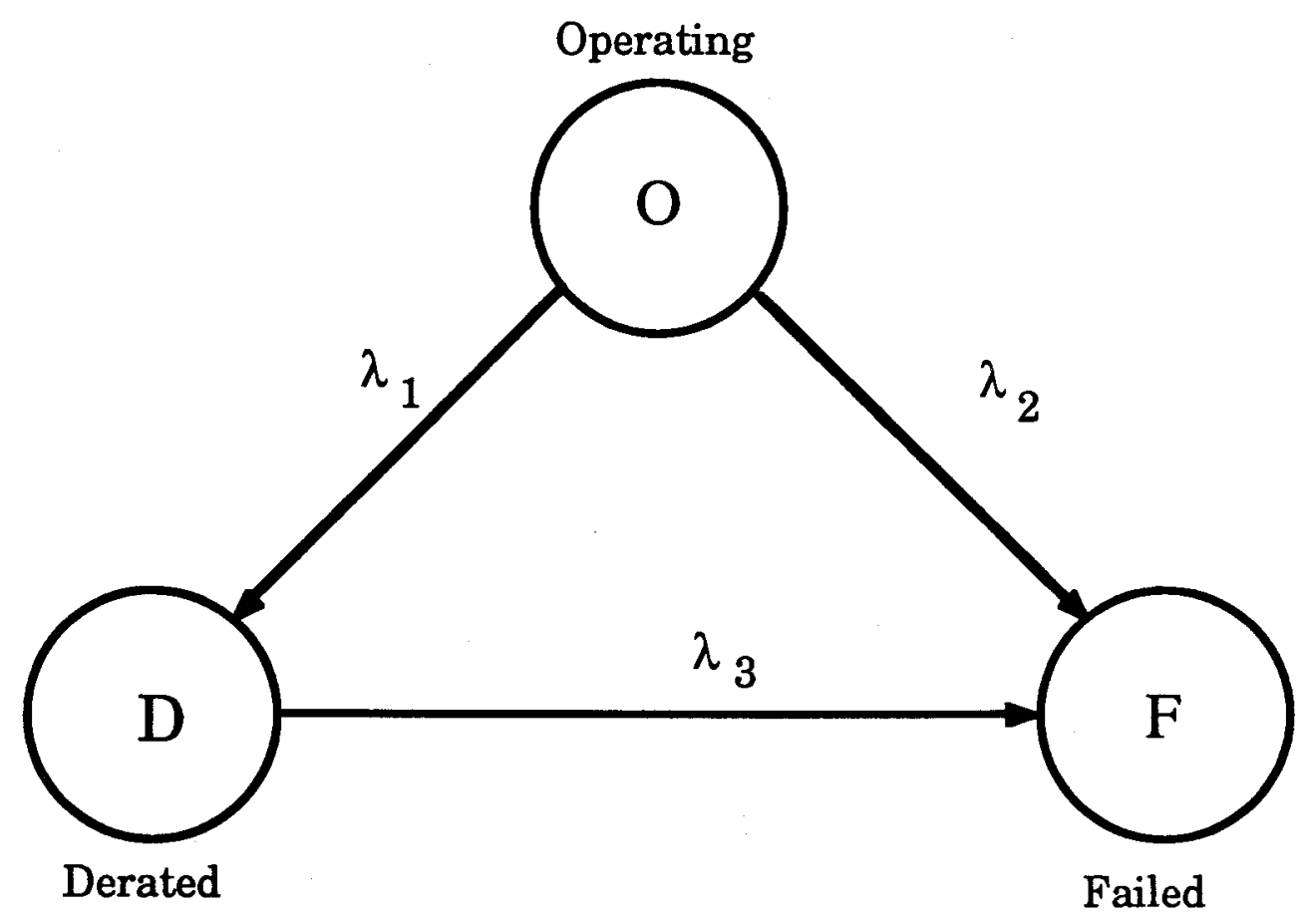

Figure 2.4: Three-state Model of a Generating Unit Without Repair Process.

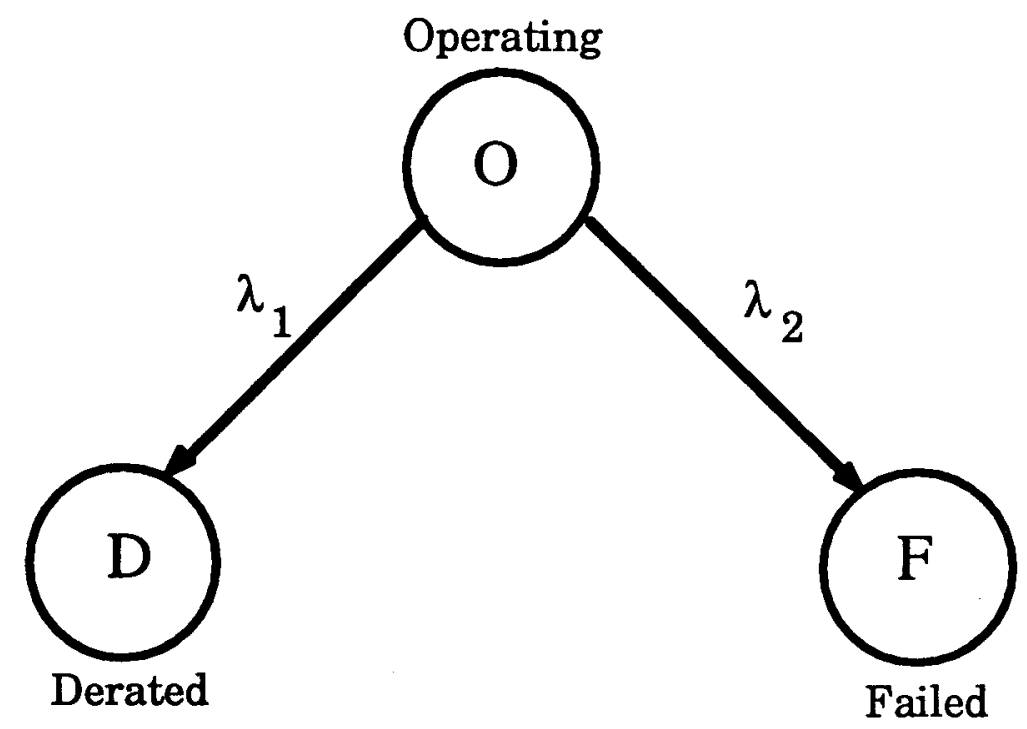

Figure 2.5: Three-state Model of a Generating Unit Used in Operating Reserve Evaluation. 
Given that the conditions described above are satisfied, the time dependent probability of each state for a unit with $\mathbf{n}$ derated states can be approximated by Equation 2.8. A simplified state-space model of a unit with $\mathrm{n}$ derated states is illustrated in Figure 2.6.

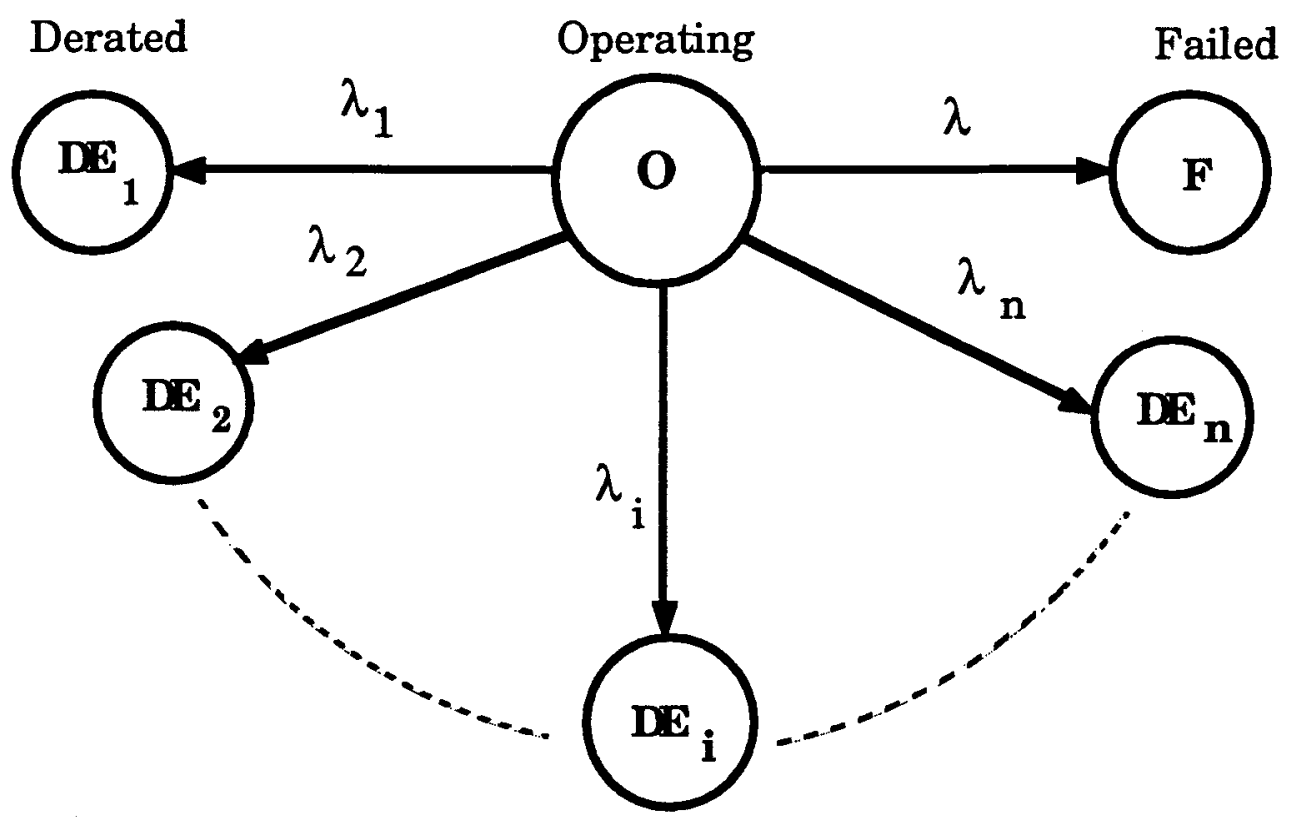

Figure 2.6: Multi-state Model of a Generating Unit Used in Operating Reserve Evaluation.

For a relatively short lead time of $\mathrm{T}[26]$,

$$
\begin{aligned}
& \mathrm{P}(\text { down }) \approx \lambda T, \\
& \mathrm{P}\left(\mathrm{de}_{\mathbf{i}}\right) \approx \lambda_{\mathrm{i}} \mathrm{T}, \quad \mathrm{i}=1,2,3, \ldots, \mathrm{n} \\
& \mathrm{P}(\text { up }) \approx 1-\left(\lambda+\sum_{\mathrm{i}=1}^{\mathrm{n}} \lambda_{\mathrm{i}}\right) \mathrm{T} .
\end{aligned}
$$




\subsection{Capacity Outage Probability Table}

Only generating units are considered in reliability evaluation at $\mathrm{HL}$ I. The system generating units can be modeled by an equivalent generating source in the form of a capacity outage probability table. This model will have different capacity output states depending on the capacity outage states and corresponding probabilities of the individual generating units. The basic statistic, designated as the O.R.R, used in operating capacity evaluation was defined in the previous sections. Using these statistics, a capacity outage probability table can be created which provides the probabilities of having various amounts of capacity on outage for the lead time considered. The table can be created using the recursive approach [3] given in Equation 2.9 .

$$
p(X)=\sum_{i=1}^{n} p^{\prime}\left(X-C_{i}\right) p_{i},
$$

where,

$\mathrm{C}_{\mathbf{i}}$ = Capacity outage of state $\mathrm{i}$ for the unit being added,

$p_{i}=$ Probability of existence of the unit in state $i$,

n = number of states of the unit being added,

$p(X)=$ Individual probability of the capacity outage state of exactly $X$ MW out after the unit is added,

$\mathrm{p}^{\prime}\left(\mathrm{X}-\mathrm{C}_{\mathrm{i}}\right)=0$ if $\mathrm{X}<\mathrm{C}_{\mathrm{i}} \quad$ or there is no state corresponding to the capacity outage of exactly $\left(X-C_{i}\right) M W$ out before the unit is added. 
$\mathbf{p}^{\prime}\left(\mathrm{X}-\mathrm{C}_{\mathbf{i}}\right)=$ Individual state probability of the capacity outage state of exactly $\left(X-C_{i}\right) M W$ out before the unit is added, if $X \geq C_{j}$.

The cumulative state probabilities can be calculated using the following equations :

$$
\begin{aligned}
& P_{N}=p_{N}, \\
& P_{i}=P_{i+1}+p_{i} \quad i=1,2, \ldots, N-1
\end{aligned}
$$

where

$\mathrm{N}$ = Total number of states in the capacity outage probability table,

$P_{i}=$ Cumulative probability of the ith state,

$p_{i}=$ Individual probability of the ith state.

\subsection{Basic Concepts of the PJM Method}

Operating reserve assessment is usually done on the basis of deterministic approaches which do not take into account the stochastic behavior of system components in the determination of spinning reserve requirements [10]. A fundamental probabilistic approach, was proposed in 1963 in order to evaluate the required spinning reserve for the Pennsylvania-New Jersey-Maryland Interconnected system This approach is generally known as the PJM method [11]. The main objective of this method is to calculate the probability of the operating units just carrying or failing to carry the system demand for a specified time period, known as the lead time. This is the time for which no additional units can come into 
service. In other words, the on-line capacity can not be replaced or added to in the case of an increase in the system load demand or the loss of some generating capacity. The lead time can be a few minutes to several hours depending on the type and the size of the units to be brought into service.

One of the problems faced by a system operator is to make on-line decisions based on the available information. The system condition is deterministically known at time $t=0$. The system risk is either zero or one depending on whether the load is less than or greater than the on line capacity. The system operator therefore must calculate the risk for the period of time into the future needed for starting up and loading additional generating units. This risk is defined as the probability of the system generation just satisfying or failing to satisfy the load demand during the lead time [3]. This risk index is known as the unit commitment risk, and can be calculated using a capacity outage probability table. The risk is given by Equation 2.11 .

$$
R(t)=\sum_{i=1}^{N} P_{i}(t) Q_{i}(t)
$$

where,

$$
\begin{aligned}
R(t)= & \text { system risk at time } t, \\
P_{i}(t)= & \text { Individual probability that the generation system is in state } i \\
& \text { at time } t, \\
\mathrm{Q}_{\mathbf{i}}(\mathrm{t})= & \text { Probability that the system load will be equal to or greater } \\
& \text { than the generation in state } i \text { at time } t, \\
N \quad= & \text { total number of generation states. }
\end{aligned}
$$


In operating reserve assessment and in the case of zero load forecast uncertainty, $Q_{\mathbf{i}}(t)$ is either zero or unity.

$$
\begin{array}{lll}
Q_{i}(t)=0 & \text { when } & \text { Load }<C_{i}(t), \\
Q_{i}(t)=1 & \text { when } & \operatorname{Load} \geq C_{i}(t) .
\end{array}
$$

Where,

$$
\mathrm{C}_{\mathbf{i}}(\mathrm{t})=\text { total spinning capacity of the generation system in state } \mathbf{i} \text {. }
$$

By arranging the capacity states in descending order in the capacity outage probability table, Equation 2.11 can be expressed as :

$$
R(t)=\sum_{i=n}^{N} P_{i}(t) .
$$

Where $n$ is an integer such that : $C_{n-1}>$ Load $\geq C_{n}$, and $R(t)$ is the cumulative probability of the nth state in the capacity outage probability table.

\subsubsection{Unit Commitment}

In a practical power system, the load demand changes continuously. It is, therefore, not economical to continuously keep all generating units on line. Units are put into service or removed from service at different periods of time depending on the load demand. Adequate capacity should be 
committed in order to make the system capable of handling deviations in customer demands and forced fluctuations in the generation capacity. Using the PJM method, the unit commitment should be done in such a way that the unit commitment risk should be less than or equal to an allowable risk level at all times. Therefore, the required number of committed units depends on the unit failure rates, unit sizes, the system lead time, the system load demand and the allowable risk level. The selection of an allowable system operating risk level is an extremely difficult problem and depends on the desired level of reliability, past experience, corresponding costs and the optimum benefits. The system reliability can be increased by committing more generating units for a given load level.

Generating units are usually committed individually according to a predetermined loading order [27] such that the specified unit commitment risk is satisfied. Units are removed from service as the load decreases using the reverse priority order. The determination of such a unit priority order is the first step in the unit commitment. This priority list can be prepared based on economic and system operating factors. In this research, methods for determining a priority order list have not been examined and it is assumed that a priority order list is available for the two test systems utilized.

\subsection{Description of the Roy Billinton Test System ( RBTS)}

The Roy Billinton Test System is an educational test system which was developed at the University of Saskatchewan. The basic objective in designing the RBTS is to make it sufficiently small to permit a large 
number of reliability studies with reasonable solution time but sufficiently detailed to reflect the actual complexities involved in a practical reliability analysis [28].

The single line diagram of this system is shown in Figure 2.7. The system has 6 buses, 9 transmission lines and 11 generating units, ranging from $5 \mathrm{MW}$ to $40 \mathrm{MW}$. The system peak load is $185 \mathrm{MW}$ and the total installed generating capacity is $240 \mathrm{MW}$.

\subsection{Application to the RBTS}

The concepts described in the previous sections have been applied to the Roy Billinton Test System (RBTS). As noted earlier, this system has 11 generating units. The generating unit data and the system priority loading order are shown in Table 2.1. Two different studies have been conducted on the spinning reserve requirements in the RBTS. The objective of the first study is to determine the system risk for a given set of operating units. In the second study, the number of generating units required to satisfy an acceptable risk level is determined. The results of these studies are given in the following section.

Consider a set of eight committed generation units and lead times of 2 hours and 4 hours. Each unit is represented by a two state model. A generation model in the form of a capacity outage probability table can be built using the technique described in Section 2.3. The capacity outage probability table for the committed units is shown in Table 2.2. The table is truncated at a cumulative probability value of $10^{-8}$. In this table, columns 3 


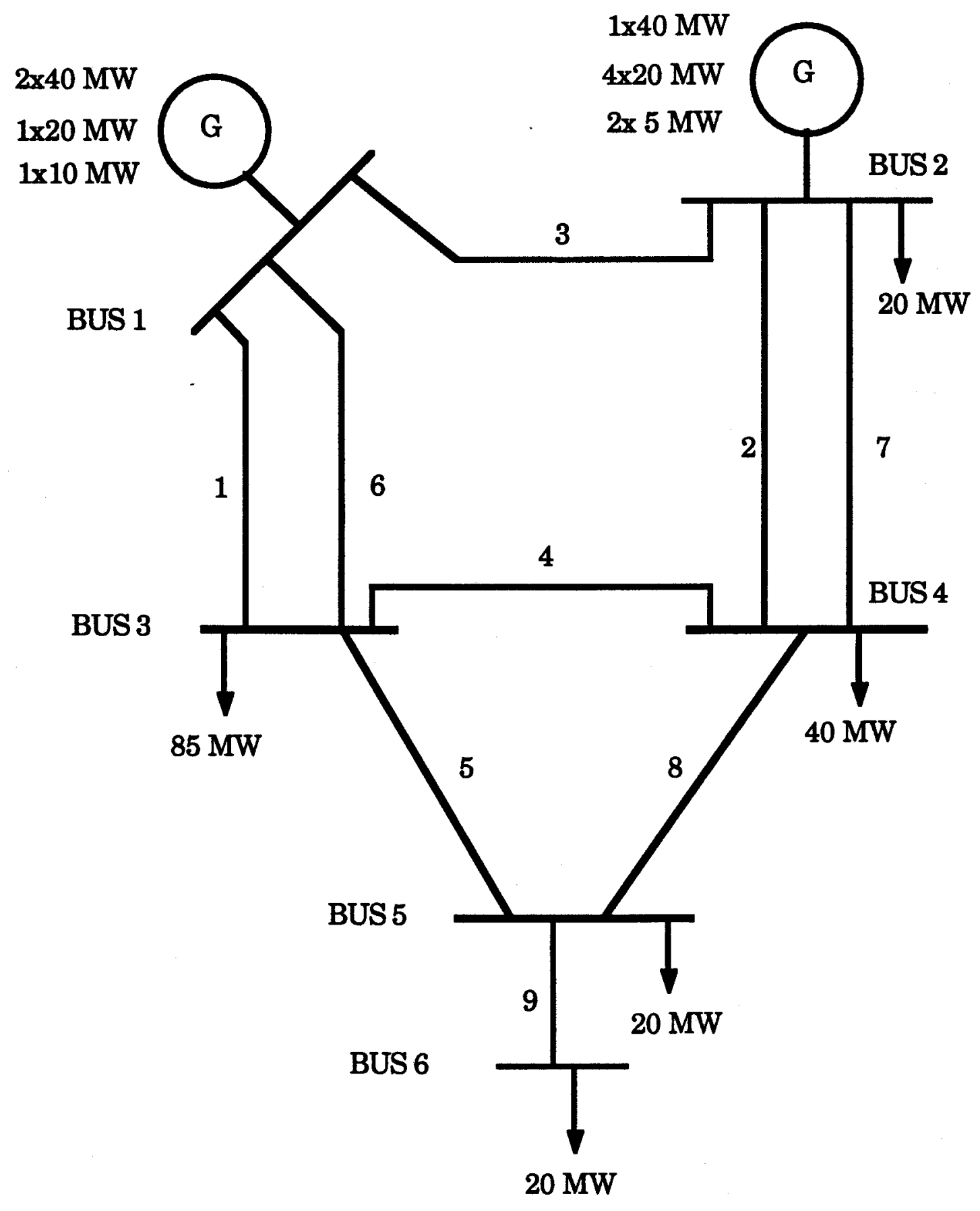

Figure 2.7: Single Line Diagram of the RBTS. 
Table 2.1: Generating Unit Data of the RBTS.

\begin{tabular}{|c|c|c|c|}
\hline $\begin{array}{c}\text { Priority } \\
\text { Loading } \\
\text { Order }\end{array}$ & $\begin{array}{c}\text { Unit } \\
\text { Size } \\
{[\mathrm{MW}]}\end{array}$ & $\begin{array}{c}\text { Unit } \\
\text { Type }\end{array}$ & $\begin{array}{c}\text { Failure } \\
\text { Rate } \\
{[\mathrm{f} / \mathrm{Yr}]}\end{array}$ \\
\hline 1 & 40 & Hydro & 3 \\
\hline $2-3$ & 20 & Hydro & 2.4 \\
\hline $4-5$ & 40 & Thermal & 6 \\
\hline 6 & 20 & Thermal & 5 \\
\hline 7 & 10 & Thermal & 4 \\
\hline $8-9$ & 20 & Hydro & 2.4 \\
\hline $10-11$ & 5 & Hydro & 2 \\
\hline & & &
\end{tabular}

and 4 show the state cumulative probabilities for the system lead times of 2 hours and 4 hours respectively. The unit commitment risk and the spinning reserve for a given load level can be found from the capacity outage table. The unit commitment risk is the probability of the generating capacity just carrying or failing to carry the load.

From Table 2.2, it can be observed that at the system peak load of 185 MW the unit commitment risk is 0.00342620 and 0.00685539 when additional capacity is made available to the system within 2 hours and 4 hours, respectively. The system can carry a load of $185 \mathrm{MW}$ with a spinning reserve of $25 \mathrm{MW}$, with an acceptable risk of 0.0035 when the lead time is 2 hours. However, if the lead time increases to 4 hours the required spinning reserve increases to $50 \mathrm{MW}$ and a load of only $160 \mathrm{MW}$ can be carried. Therefore, for a lead time of 4 hours and a specified risk of 0.0035 more than eight units must be committed to satisfy a load of $185 \mathrm{MW}$. The unit commitment risk decreases to 0.00001824 and 0.00007276 for lead times of 2 
hours and 4 hours respectively, when the system has nine operating units. If a risk level of 0.001 is selected as the acceptable risk level, then a system with eight units and a lead time of 4 hours can carry a load of $160 \mathrm{MW}$.

Table 2.2: Capacity Outage Probability Table for the First Eight Units of the RBTS.

\begin{tabular}{|c|c|c|c|}
\hline \multirow{2}{*}{$\begin{array}{c}\text { Capacity } \\
\text { Out } \\
{[\mathrm{MW}]}\end{array}$} & \multirow{2}{*}{$\begin{array}{c}\text { Capacity } \\
\text { In } \\
{[\mathrm{MW}]}\end{array}$} & \multicolumn{2}{|c|}{ Cumulative Probability } \\
\hline & & $\begin{array}{c}\text { Lead time } \\
2 \text { Hours }\end{array}$ & $\begin{array}{c}\text { Lead time } \\
4 \text { Hours }\end{array}$ \\
\hline 0 & 210 & 1 & 1 \\
\hline 10 & 200 & 0.00710159 & 0.01415993 \\
\hline 20 & 190 & 0.00619401 & 0.01235601 \\
\hline 30 & 180 & 0.00342620 & 0.00685539 \\
\hline 40 & 170 & 0.00342367 & 0.00684533 \\
\hline 50 & 160 & 0.00001637 & 0.00006532 \\
\hline 60 & 150 & 0.00001326 & 0.00005291 \\
\hline 70 & 140 & 0.00000377 & 0.00001514 \\
\hline 80 & 130 & 0.00000376 & 0.00001507 \\
\hline 90 & 120 & 0.00000002 & 0.00000012 \\
\hline 100 & 110 & 0.00000001 & 0.00000009 \\
\hline 110 & 100 & 0 & 0.00000001 \\
\hline 120 & 90 & 0 & 0.00000001 \\
\hline
\end{tabular}

From the above results, it can be inferred that the required spinning reserve depends on a number of factors, including the system lead time, the system load and the specified risk level. The effects of these factors are further illustrated in the following examples. 


\subsubsection{Effect of Lead Time Variation on the Unit Commitment}

In the evaluation of spinning reserve, it is assumed that there is always sufficient generating capacity available to the system to meet the load demand. Therefore, it is only a matter of time before additional capacity can be brought into service. The number of generators to be committed for a particular load are taken from the priority unit loading order as shown in Table 2.1. Using this priority order list, the number of generators required for $70 \%$ of the peak load, i.e. $130 \mathrm{MW}$, and an acceptable unit commitment risk of 0.001 are shown in Table 2.3 for lead times from 0.5 to 15 hours. The actual risk is shown in each case. It can be seen from Table 2.3 that the number of committed units increases from 5 to 6 as the lead time increases from 0.5 hour to 1 hour. The required number of generating units is unchanged as the lead time increases from 1 hour to

Table 2.3: Unit Commitment at Different Lead Times.

\begin{tabular}{|c|c|c|c|c|c|c|}
\hline $\begin{array}{c}\text { Load } \\
{[\mathrm{MW}]}\end{array}$ & $\begin{array}{c}\text { Specified } \\
\text { Risk }\end{array}$ & $\begin{array}{c}\text { Lead } \\
\text { Time } \\
{[\mathrm{hr}]}\end{array}$ & $\begin{array}{c}\text { No.Of } \\
\text { Units }\end{array}$ & $\begin{array}{c}\text { Spinning } \\
\text { Capacity } \\
{[\mathrm{MW}]}\end{array}$ & $\begin{array}{c}\text { Spinning } \\
\text { Reserve } \\
{[\mathrm{MW}]}\end{array}$ & $\begin{array}{c}\text { Actual } \\
\text { Risk }\end{array}$ \\
\hline 130 & 0.001 & 0.5 & 5 & 160 & 30 & 0.00085595 \\
\hline 130 & 0.001 & 1 & 6 & 180 & 50 & 0.00000285 \\
\hline 130 & 0.001 & 2 & 6 & 180 & 50 & 0.00001139 \\
\hline 130 & 0.001 & 3 & 6 & 180 & 50 & 0.00002560 \\
\hline 130 & 0.001 & 4 & 6 & 180 & 50 & 0.00004547 \\
\hline 130 & 0.001 & 5 & 6 & 180 & 50 & 0.00007097 \\
\hline 130 & 0.001 & 6 & 6 & 180 & 50 & 0.00010208 \\
\hline 130 & 0.001 & 8 & 6 & 180 & 50 & 0.00018110 \\
\hline 130 & 0.001 & 10 & 6 & 180 & 50 & 0.00028236 \\
\hline 130 & 0.001 & 12 & 6 & 180 & 50 & 0.00040573 \\
\hline 130 & 0.001 & 15 & 6 & 180 & 50 & 0.00063192 \\
\hline
\end{tabular}


15 hours, while the corresponding unit commitment risk increases. These results show that the unit commitment and the corresponding unit commitment risk are sensitive to the generating capacity lead time.

\subsubsection{Effect of Peak Load Variation on the Unit Commitment}

The number of units required at a specified unit commitment risk of 0.001 for different load levels are shown in Table 2.4. The lead time is fixed at 4 hours and the system load level varies from $40 \%$ to $100 \%$ of the system peak load. It can be seen that the number of committed units increases as the system load increases. The corresponding spinning reserve in each case is calculated by subtracting the load from the on-line capacity. The required spinning reserve as a percentage of the load varies between $24.3 \%$ and $73 \%$. It can be noted from the above results that under certain conditions the unit commitment risk is also a function of the system load demand.

Table 2.4: Unit Commitment at Different Load Levels.

\begin{tabular}{|c|c|c|c|c|c|c|c|}
\hline $\begin{array}{c}\text { Load } \\
{[\mathrm{MW}]}\end{array}$ & $\begin{array}{c}\text { Load } \\
\text { Level } \\
{[\%]}\end{array}$ & $\begin{array}{c}\text { Specified } \\
\text { Risk }\end{array}$ & $\begin{array}{c}\text { Lead } \\
\text { Time } \\
{[\mathrm{hr}]}\end{array}$ & $\begin{array}{c}\text { No.Of } \\
\text { Units }\end{array}$ & $\begin{array}{c}\text { Spinning } \\
\text { Capacity } \\
{[\mathrm{MW}]}\end{array}$ & $\begin{array}{c}\text { Spinning } \\
\text { Reserve } \\
{[\mathrm{MW}]}\end{array}$ & $\begin{array}{c}\text { Actual } \\
\text { Risk }\end{array}$ \\
\hline 74 & $40 \%$ & 0.001 & 4 & 4 & 120 & 46 & 0.00001274 \\
\hline 92.5 & $50 \%$ & 0.001 & 4 & 5 & 160 & 67.5 & 0.00001500 \\
\hline 111 & $60 \%$ & 0.001 & 4 & 5 & 160 & 49 & 0.00002993 \\
\hline 129.5 & $70 \%$ & 0.001 & 4 & 6 & 180 & 50.5 & 0.00004547 \\
\hline 148 & $80 \%$ & 0.001 & 4 & 7 & 190 & 42 & 0.00005788 \\
\hline 166.5 & $90 \%$ & 0.001 & 4 & 8 & 210 & 43.5 & 0.00006532 \\
\hline 185 & $100 \%$ & 0.001 & 4 & 9 & 230 & 45 & 0.00007276 \\
\hline
\end{tabular}


2.6.3. Effect of Variation in Acceptable Risk Level on the Unit

Commitment

In the previous studies, the acceptable risk level was fixed at 0.001 and the system load and the lead time were varied. In this study, it is assumed that the system lead time is fixed at 4 hours and the system load is $70 \%$ of the peak load, i.e. $130 \mathrm{MW}$. The allowable risk level was varied from 0.15 to 0.0001 and the results are shown in Table 2.5. It can be seen from Table 2.5, that as the specified risk level decreases, the number of required generating units increase.

Table 2.5: Unit Commitment at Different Specified Risk Levels.

\begin{tabular}{|c|c|c|c|c|c|c|}
\hline $\begin{array}{c}\text { Load } \\
{[\mathrm{MW}]}\end{array}$ & $\begin{array}{c}\text { Specified } \\
\text { Risk }\end{array}$ & $\begin{array}{c}\text { Lead } \\
\text { Time } \\
{[\mathrm{hr}]}\end{array}$ & $\begin{array}{c}\text { No.Of } \\
\text { Units }\end{array}$ & $\begin{array}{c}\text { Spinning } \\
\text { Capacity } \\
{[\mathrm{MW}]}\end{array}$ & $\begin{array}{c}\text { Spinning } \\
\text { Reserve } \\
{[\mathrm{MW}]}\end{array}$ & $\begin{array}{c}\text { Actual } \\
\text { Risk }\end{array}$ \\
\hline 130 & 0.1500 & 240 & 5 & 160 & 30 & 0.00683551 \\
\hline 130 & 0.1000 & 240 & 5 & 160 & 30 & 0.00683551 \\
\hline 130 & 0.0500 & 240 & 5 & 160 & 30 & 0.00683551 \\
\hline 130 & 0.0100 & 240 & 5 & 160 & 30 & 0.00683551 \\
\hline 130 & 0.0050 & 240 & 6 & 180 & 50 & 0.00004547 \\
\hline 130 & 0.0010 & 240 & 6 & 180 & 50 & 0.00004547 \\
\hline 130 & 0.0005 & 240 & 6 & 180 & 50 & 0.00004547 \\
\hline 130 & 0.0001 & 240 & 6 & 180 & 50 & 0.00004547 \\
\hline
\end{tabular}

\subsection{The Security Function Approach}

The probabilistic techniques developed in the area of operating capacity assessment can in general be divided into two categories, the basic PJM method and the security function approach. The PJM method is 
discussed in some detail in Section 2.4. The security function approach is a general technique which has been proposed in terms of various breaches of security. A breach of security is defined as an intolerable or undesirable operating condition, such as an inadequacy of spinning generation capacity, unacceptable low system voltage, transmission line over-load or system instability [3]. The first step in any assessment of system security is the development of a set of events whose occurrence would be considered to be a breach of security. The probability of insecurity is displayed as a time function called the "security function". The general form of the security function is [14] :

$$
S(t)=\sum_{i=1}^{M} P_{i}(t) Q_{i}(t)
$$

where,

$\mathrm{P}_{\mathrm{i}}(\mathrm{t})=$ Individual probability that the system is in state $\mathrm{i}$ at time $t$,

$\mathrm{Q}_{\mathbf{i}}(\mathrm{t})=$ Conditional probability that state $\mathrm{i}$ constitutes a breach of system security at time $t$,

M = Number of all possible system states.

There is a large number of possible system states in a practical power system network. A state can be defined as an outage combination of generating units, transmission lines and other facilities in the system. Each state has a probability of existence and given the state, the probability of it constituting a violation of the system operating conditions can be determined. The security function, $\mathrm{S}(\mathrm{t})$, can be calculated and compared 
with a maximum tolerable insecurity or risk level to determine if and when some control action is required to maintain the risk of system insecurity at an acceptable level. The major problem in the application of this method to operating capacity assessment is that it is a time-consuming and exhaustive evaluation process especially for a large system with many possible operating states. The literature does not provide any practical application of the general method.

In the application of this method to HL I spinning reserve studies, the only concern is whether or not sufficient generating capacity is available to carry the load. In this case, $P_{i}(t)$ is the individual probability of residing in the ith capacity state and $\mathrm{Q}_{\mathbf{i}}(\mathrm{t})$ is the conditional probability that the available capacity associated with state $i$ is less than or equal to the load at time $t$. For a constant load, $Q_{\mathbf{i}}(t)$ is either zero when the load is less than the ith state capacity or unity when the load is greater than or equal to the ith state capacity. Under this condition, Equation 2.13 reduces to Equation 2.14 .

$$
S(t)=\sum_{i=n}^{N} P_{i}(t),
$$

where,

$\mathrm{N}$ is the total number of generation states and $\mathrm{n}$ is an integer such that, $\mathrm{C}_{\mathrm{n}-1}>$ Load $\geq \mathrm{C}_{\mathrm{n}}$. Therefore, $\mathrm{S}(\mathrm{t})$ is equal to the cumulative probability of the nth state in the capacity outage probability table.

From the above discussion it can be concluded that the security 
function approach, when applied to HL I spinning reserve evaluation, is identical to the PJM method and $S(t)$ has the same magnitude as the unit commitment risk.

\subsection{Summary}

The general concepts associated with reliability evaluation at HL I are briefly defined in this chapter. The basic generating unit models and related operating reserve concepts are discussed. The recursive algorithm for building a generation model in the form of a capacity outage table is introduced and discussed. These concepts are then utilized to evaluate the number of generating units which should be committed to the system to meet a given load level at a specified risk.

The number of units committed should satisfy the predetermined acceptable system risk level. The required number of units is a complex function of the system lead time, the system load and the specified risk levels. The effects of these factors on the unit commitment and the corresponding unit commitment risk are illustrated by application to a reliability test system (RBTS). 


\section{A PROBABIISTIC TECHNIQUE FOR OPERATING RESERVE ASSESSMENT USING SYSTEM OPERATING STATES}

\subsection{Introduction}

Operating reserve provides a power system with the capability to handle unforeseen load changes and sudden generation outages. Operating reserve assessment is, historically, done by deterministic approaches[3]. Procedures such as ensuring that the system has a reserve margin equal to the size of the largest unit or to some percentage of the peak load are usually used. Deterministic approaches do not have the ability to determine the actual system reliability due to the fact that they do not specifically take into account the probabilistic or stochastic nature of system behavior and component failures. Probabilistic techniques provide a more comprehensive and realistic evaluation of the operating reserve by incorporating the stochastic nature of system components.

A major task of a power system operator is to make rapid on-line decisions based on the available information. This information should be easy to understand and easy to interpret by the system operator and therefore more realistic and understandable information will help the 
operator to make the appropriate decision. The concepts of the basic probabilistic technique known as the PJM method were illustrated in Chapter 2. On the basis of this method, the system operator can make a decision regarding the required capacity based on the existing risk, the forecast load and the specified risk criterion. A survey described in Reference [17] shows that no Canadian utility uses probabilistic techniques to assess operating reserve requirements at the present time. The two most important reasons for this are the difficulty in interpreting the risk index and the lack of system operating information contained in the use of a single risk value.

A new probabilistic technique is illustrated in this chapter which overcomes these difficulties by incorporating system operating states in operating reserve assessment. In this approach, the generation system is classified into several operating states. A framework for the system operating states and associated definitions based on a composite system were proposed in Reference [18]. This framework is examined and redefined in this chapter for application to HL I operating reserve assessment. An evaluation procedure for unit commitment and system risk evaluation are presented in this chapter. The effects of lead time and peak load variation on the unit commitment and the probabilities associated with different system operating states are illustrated. The effects of load forecast uncertainty and generating unit derated states are also examined. The benefits of the proposed method are compared in this chapter with those of the PJM method. 


\subsection{Classification Of System Operating States}

The control objectives of a power system are related to the level of security, and as this level decreases below an acceptable value, preventive controls must be taken to restore the system to a robust state. However, before such controls can be taken, the general operating states of a system should be recognized[19].

Overall power system performance can be divided into several operating states in terms of the degree to which reliability constraints are satisfied. These operating states are designated as normal, alert, emergency, and extreme emergency as shown in Figure $3.1[18,19]$. The system model and state definitions should be based on the purpose behind the study. In the following subsections, the state definitions are examined. In the first subsection, the state definitions based on composite system evaluation proposed in the EPRI report [18] are illustrated. The states are redefined in Subsection 3.2.2 based on operating reserve evaluation at HLI.

\subsubsection{System Model and State Definitions in Composite System}

The following definitions are taken from the EPRI report [18].

The normal state is defined as follows:

"In the normal state, all equipment and operating constraints are within limits, indicating that the generation is adequate to supply the load (total demand), with no equipment over-loaded. In the normal 


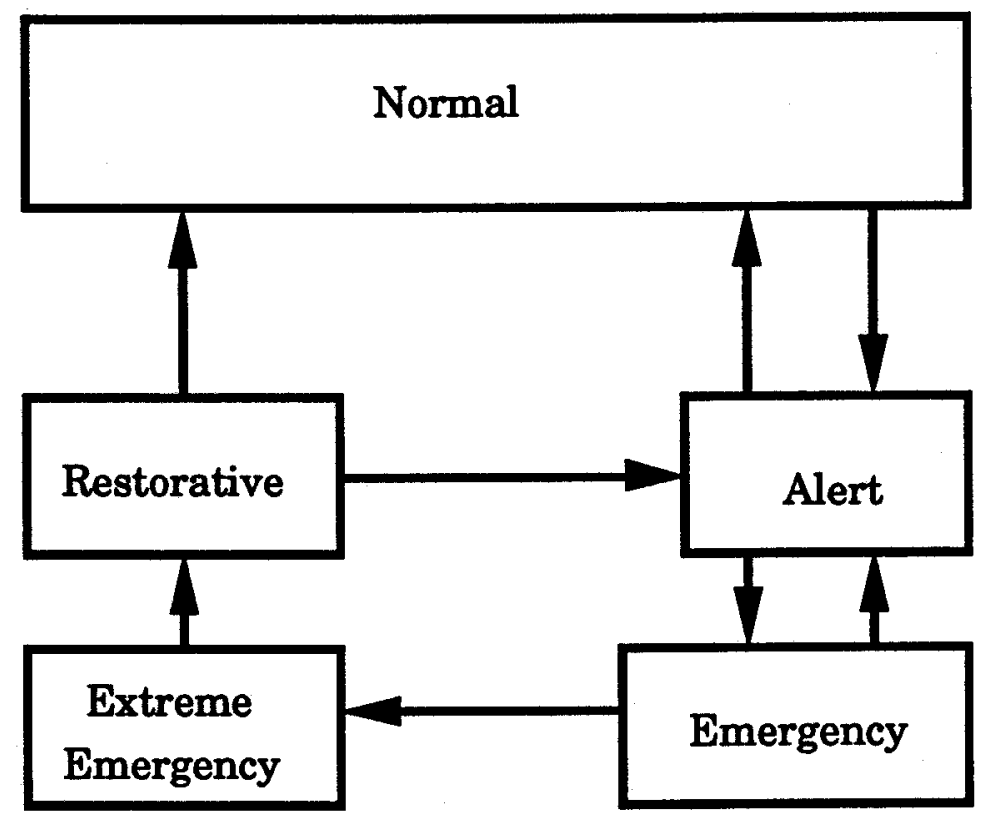

Figure 3.1: Diagram of System Operating States.

state, there is sufficient margin such that the loss of any elements, specified by some criteria, will not result in a limit being violated. The particular criteria, such as all single elements, will depend on the planning and operating philosophy of a particular utility".

The alert state is defined as follows:

"If a system enters a condition where the loss of some elements covered by the operating criteria will result in a current or voltage violation, then the system is in the alert state. The alert state is similar to the normal state in that all constraints are satisfied, but there is no longer sufficient margin to withstand some outages (disturbances). The system can enter the alert state by the outage of equipment, by a change in generation schedule, or a growth in the system load." 
The emergency state is defined as follows:

"If a contingency occurs or the generation and the load changes before corrective action can be (or is) taken, the system will enter the emergency state. No load is curtailed in the emergency state, but equipment or operating constraints have been violated. If control measures are not taken in time to restore the system to the alert state, the system will transfer from the emergency state to the extreme emergency state ."

The extreme emergency state is defined as follows:

"In the extreme emergency state, the equipment and operating constraints are violated and load is not supplied."

The system model shown in Figure 3.1 does not have all the possible transitions between the states. The system has been modified in Reference [29] by adding a connection between the normal and extreme emergency states and a connection between the alert and extreme emergency states.

\subsubsection{System Model and State Definitions for Operating Reserve Studies at HLI}

The proposed definitions of the system operating states in the EPRI report [18] are based on security constraints in composite system reliability evaluation. The security constraints are basically the operating limits which have to be satisfied for acceptable operation of a power system. These 
constraints depend mainly on the purpose behind the study. There are several constraints that govern power system operation. Composite system security constraints such as voltage magnitude constraints, line flow constraints and real power generation constraints are discussed in Reference [29].

Only generating units are included in an HLI evaluation. In these studies, security constraints refer to the generation and total load demand. The effects of transmission lines and the actual physical location of the generating units are neglected. In an operating reserve evaluation at HLI, the only constraint is that the total operating capacity should be greater than the system load. The operating states are redefined in the following paragraphs in order to make them applicable to operating reserve assessment at HLI.

The definition of the normal state is :

In the normal state, the generation is adequate to supply the existing total load demand. In this state there is sufficient margin such that the loss of any generating units, specified by some criterion, will not result in load curtailment. The particular criterion, such as the loss of any single generating unit will depend on the planning and operating philosophy of the particular utility.

The specified criterion used in this thesis is that the loss of any single unit can be tolerated. It can be seen from the definition that in the normal state the system not only has the ability to supply the load, but also has 
enough reserve such that the loss of any single unit will not result in load curtailment.

The definition of the alert state is :

If a system enters a condition where the loss of generating capacity covered by the operating criteria will result in load curtailment then the system is in the alert state. The alert state is similar to the normal state in that the constraint is satisfied, but there is no longer sufficient margin to withstand some outages. The system can enter the alert state by the outage of generation unit(s), or by a growth in the system load.

In the alert state, the operating capacity is sufficient to supply the load. The loss of certain units could, however, result in load curtailment. Corrective action such as the start up of additional unit(s) could restore the system to the normal state.

The definition of the emergency state is :

If a contingency occurs or the load changes before a corrective action can be (or is) taken, the system will enter the emergency state. There is no reserve margin and no load is curtailed in the emergency state.

In this state the operating capacity is exactly equal to the load. If control measures are not taken in time to restore the system to the alert state, the system will transfer from the emergency state to the extreme 
emergency state.

The definition of the extreme emergency state is :

In this state, the system constraint is violated; and some portion of the system load is curtailed.

The system operator should commit additional generation into service to transfer the system from the extreme emergency state to the normal or alert state and reconnect the curtailed load through the restorative state.

The system model shown in Figure 3.1 should be modified in order to be applicable to operating reserve assessment at HLI. One difficulty with the model is that there is no connection between the normal and the emergency and the extreme emergency states. The system state can go directly from the normal to the emergency or extreme emergency states by the loss of some on-line generating units or by a sudden increase in the system load. The system also can transfer from the alert state to the extreme emergency state depending on the outage and the system. For example, the RBTS should commit 5 units, i.e. $3 * 40 \mathrm{MW}$ and $2 * 20 \mathrm{MW}$, for a load of $111 \mathrm{MW}$ to satisfy a specified risk of 0.001 when additional units are made available within 4 hours. The total spinning capacity is $160 \mathrm{MW}$. If two generating units ( $1 * 20 \mathrm{MW}$ and $1 * 40 \mathrm{MW}$ or $2 * 40 \mathrm{MW}$ ) are removed from service, the system will go directly from the normal state to the extreme emergency state. If one $20 \mathrm{MW}$ unit is removed from service, the system will go from the normal state to the alert state and the loss of 
another $40 \mathrm{MW}$ will cause the system to go to the extreme emergency state. If the required spinning capacity for the load of $111 \mathrm{MW}$ is $120 \mathrm{MW}$, i.e. 4 units, the system is initially in the alert state and loss of any single unit will cause the system to go to the extreme emergency state. In order to overcome these deficiencies the system model has been modified as shown in Figure 3.2.

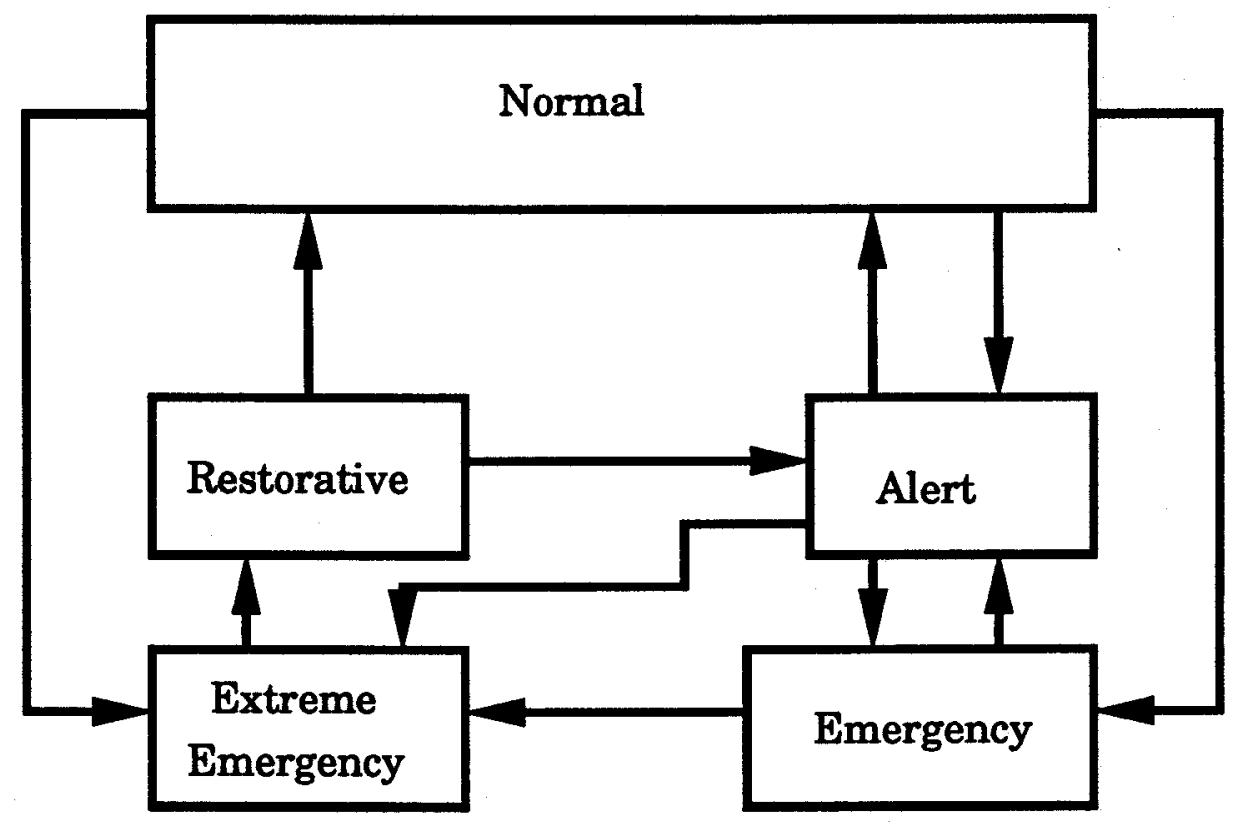

Figure 3.2: Modified Diagram of the System Operating States.

For a given set of generating units and by considering all the possible contingencies:

$$
P_{n}+P_{a}+P_{e m}+P_{\text {exem }}=1
$$


Where,

$\mathrm{P}_{\mathrm{n}} \quad=$ probability of being in the normal state,

$\mathrm{P}_{\mathrm{a}} \quad$ = probability of being in the alert state,

$\mathrm{P}_{\mathrm{em}}=$ probability of being in the emergency state,

$\mathrm{P}_{\text {exem }}=$ probability of being in the extreme emergency state.

A contingency can be defined as a combination of generating unit outages. For $\mathbf{n}$ generating units and assuming that each unit is represented by a two state model, the total number of contingencies is $2^{\mathrm{n}}$. Each contingency can be associated with one of the operating states. Once the probability of each contingency is calculated, the next step is to determine which operating state it belongs to according to the different operating state definitions.

\subsection{Unit Commitment and Evaluation Procedure}

From the system operating state definitions discussed in Section 3.2.2, it can be seen that no constraint is violated or load curtailed in either the normal or the alert states. A system operating objective is therefore to operate the system with a high probability of being in these two states. The summation of the two probabilities of the normal and the alert states provides an assessment of the favorable conditions associated with the system. The complement of the sum of these two probabilities represents the unfavorable conditions and therefore constitutes the system risk level. A risk index designated as the Generating System Operating State Risk (GSOSR) can be calculated using Equation 3.2. 


$$
\operatorname{GSOSR}=1-P_{n}-P_{a}
$$

or

$$
\text { GSOSR }=\mathrm{P}_{\mathrm{em}}+\mathrm{P}_{\mathrm{exem}}
$$

This risk index is identical to the unit commitment risk obtained in the PJM method and can be identified as the probability that the system will fail to meet the load or just be able to meet the load for a given lead time.

Once an operating criterion is adopted, the goal is to satisfy the criterion throughout the various stages of system operation. Using the PJM method, units should be committed such that a specified risk is satisfied at all hours of the day. The operating criteria could be an acceptable level of GSOSR, an acceptable probability of the normal state or both, depending on the required level of reliability.

As noted earlier, the GSOSR is identical to the risk evaluated by the PJM method. If unit commitment is performed using a specified risk then the number of committed units and the corresponding GSOSR will be identical to those obtained by the PJM method, provided that the specified risk and all other system parameters are the same. The operating criterion might be to operate the system such that the probability of the normal state and the system risk are both at acceptable levels. In this case, units should first be committed to satisfy the specified risk. The number of committed units may or may not meet the acceptable normal state probability in which case additional unit(s) should be committed until the probability of the normal state exceeds or equals the specified value. The required number of units therefore depends on the desired level of normal state probability and 
the specified GSOSR.

In order to illustrate the above procedure, a unit commitment schedule has been developed using a seven step load model of the RBTS assuming that the system lead time is four hours. Table 3.1 shows the required number of committed units and the corresponding probabilities of the different operating states when a specified risk of 0.01 is selected as the unit commitment criterion. It can be seen that the probability of the normal state is zero for all load levels. The reason for this is that the system with the designated number of committed units and at the corresponding load level does not have sufficient spinning reserve to tolerate any single unit outage. If an acceptable level of normal state probability is required then the number of committed units must be increased.

Table 3.1: Unit Commitment with a Specified Risk of 0.01 .

\begin{tabular}{|c|c|c|c|c|c|c|}
\hline $\begin{array}{c}\text { Load } \\
\text { Level } \\
\text { [MW] }\end{array}$ & $\begin{array}{c}\text { No.of } \\
\text { units }\end{array}$ & Normal & Alert & Emergency & $\begin{array}{c}\text { Extreme } \\
\text { Emergency }\end{array}$ & GSOSR \\
\hline 74 & 3 & 0 & 0.99644254 & 0 & 0.00355746 & 0.00355746 \\
\hline 92.5 & 4 & 0 & 0.99589297 & 0 & 0.00410703 & 0.00410703 \\
\hline 111 & 4 & 0 & 0.99371256 & 0 & 0.00628744 & 0.00628744 \\
\hline 129.5 & 5 & 0 & 0.99316449 & 0 & 0.00683551 & 0.00683551 \\
\hline 148 & 5 & 0 & 0.99099006 & 0 & 0.00900994 & 0.00900994 \\
\hline 166.5 & 7 & 0 & 0.99315143 & 0 & 0.00684857 & 0.00684857 \\
\hline 185 & 8 & 0 & 0.99314461 & 0 & 0.00685539 & 0.00685539 \\
\hline
\end{tabular}

Table 3.2 shows the number of committed units and system operating state probabilities when the system is required to satisfy both a specified risk and a specified normal state probability. Assume that the risk should 
be less than or equal to 0.01 and the probability of the system being in the normal state should be greater than or equal to 0.9 . It can be seen from Table 3.2 that the system should commit one or two units in addition to the previously committed units to satisfy both criteria. In this study, the required number of units is dominated by the desired level of normal state probability rather than the specified risk. If a single specified risk of 0.001 is selected as the criterion for unit commitment, the results will be the same as those given in Table 3.2. Therefore, it can be concluded that one of these criteria is the dominant condition, depending upon the acceptable levels of risk and the normal state. If a low GSOSR value is selected as the operating criterion, it drives the unit commitment process and in doing so creates an acceptable normal state probability. This is a general observation and actual values for any specific system can only be obtained by detailed analysis.

Table 3.2: Unit Commitment with a Specified Risk of 0.01 and a Desired Level of Normal State Probability of 0.9 .

\begin{tabular}{|c|c|c|c|c|c|c|}
\hline $\begin{array}{c}\text { Load } \\
\text { Level } \\
\text { [MW] }\end{array}$ & $\begin{array}{l}\text { No.of } \\
\text { units }\end{array}$ & Normal & Alert & Emergency & $\begin{array}{c}\text { Extreme } \\
\text { Emergency }\end{array}$ & GSOSR \\
\hline 74 & 4 & 0.99371256 & 0.00627470 & 0 & 0.00001274 & 0.00001274 \\
\hline 92.5 & 5 & 0.99316449 & 0.00682051 & 0 & 0.00001500 & 0.00001500 \\
\hline 111 & 5 & 0.99099006 & 0.00898001 & 0 & 0.00002993 & 0.00002993 \\
\hline 129.5 & 6 & 0.98872753 & 0.01122701 & 0 & 0.00004547 & 0.00004547 \\
\hline 148 & 7 & 0.98692163 & 0.01302049 & 0 & 0.00005788 & 0.00005788 \\
\hline 166.5 & 8 & 0.98584007 & 0.01409461 & 0 & 0.00006532 & 0.00006532 \\
\hline 185 & 9 & 0.98475970 & 0.01516754 & 0 & 0.00007276 & 0.00007276 \\
\hline
\end{tabular}

Through-out this thesis attention is focused on the GSOSR as the basic unit commitment criterion. In certain special cases additional 
criteria are considered. It should be clearly recognized, however, that the probabilities of the normal and the alert states can not be calculated using a capacity outage probability table and therefore the computing time required for this method is more than that needed for the basic PJM method. In order to reduce the CPU time, the required number of generating units for a specified risk is first determined using a capacity outage table. The probabilities associated with the different system operating states are calculated for the committed units. If a specified normal state probability is not satisfied, it is obtained in the second step by adding further generating units.

\section{Comparison of the Proposed Probabilistic Technique with the PJM Method}

The concepts of the basic probabilistic method designated as the PJM method were illustrated in detail in Chapter 2. On the basis of the PJM method, unit commitment should be such that the unit commitment risk is less than or equal to a specified value. For a given load and set of committed units, system performance can be identified, using this method as being in either the comfort or at risk domains. The system operating domains are shown in Figure 3.3a. In the comfort domain the operating capacity is greater than the load, whereas in the risk domain it is less than or equal to the load. In the PJM method there is no information on the degree of system comfort. Unit commitment risk and its complementary value, i.e. probability of system comfort, are the only information available to the system operator. 
Deterministic criteria are easier for the system operator to understand than a risk index determined using probabilistic techniques. In order to alleviate the difficulty in interpreting the risk index and provide more applicable information for the system operator, deterministic considerations can be included in the probabilistic assessment.

The main advantage of the proposed technique compared to the PJM method is that it combines deterministic considerations with probabilistic indices to monitor the system well-being. This combination is achieved by recognizing that the system operating states created by incorporating the system deterministic criteria can be categorized as being healthy, marginal or at risk. These system operating divisions are shown in Figure 3.3b and can be quantified using the system operating state probabilities. A system operates in the healthy zone (normal state) when it has enough margin to withstand the deterministic criterion, i.e. any single unit outage. In the marginal zone(alert state) the system no longer has sufficient margin that it can withstand the loss as specified by the deterministic criterion. In the risk zone (emergency and extreme emergency states) the system load is greater than or equal to the operating capacity. The healthy and marginal zones both reside in the comfort domain as shown in Figure 3.3. The risk domain is identical in both cases. 


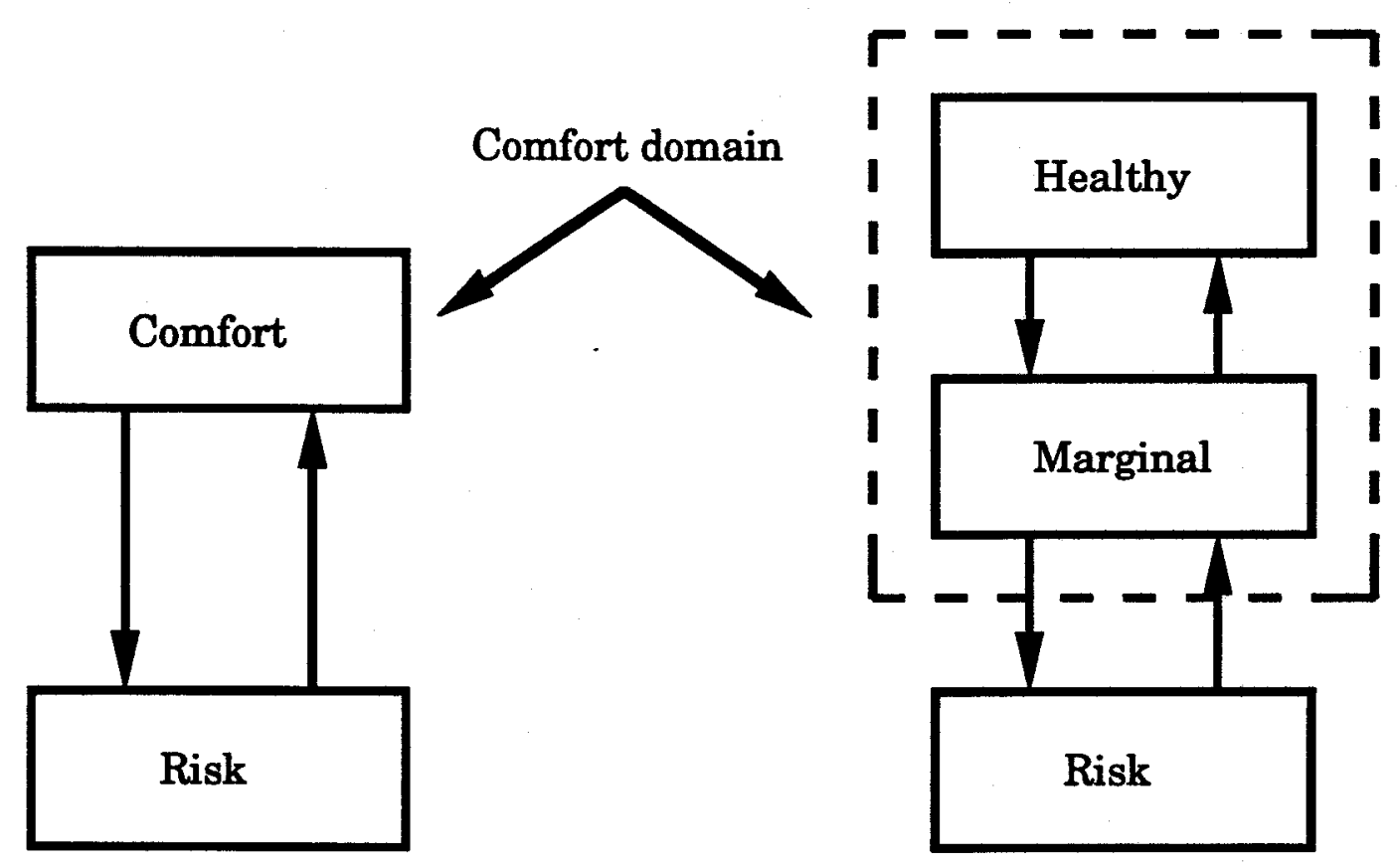

(a)

(b)

Figure 3.3: System Operating Domains.

It can be concluded that the proposed technique provides more information to the power system operator than that available from the basic PJM method. This information not only informs the operator of the system risk but, more importantly, provides information on the degree of system well-being which can not be achieved using the basic PJM method. The system well-being is increased by scheduling or committing additional generating unit(s). If the system operates with a high probability in the marginal zone, this is a warning to the system operator to start up additional unit(s) to push the system into the healthy zone. 


\subsection{Load Forecast Uncertainty}

An important activity in power system operation is to predict the hourly load variation within a short period of time, typically 24 hours. In practice, the future system load is usually predicted based on past experience and weather forecasts. There is a general relationship between the future actual load, the previous system load and the weather forecast. It is extremely unlikely that the forecast load will be the same as the actual load and therefore there is a degree of uncertainty in the forecast value. The best way to describe this uncertainty is in terms of a probability distribution. The parameters of the probability distribution can be estimated from recorded data. Load forecast uncertainty can be reasonably described by a normal distribution [3]. The distribution mean is the forecast load and the standard deviation is obtained from previous forecasts. The normal distribution can be divided into class intervals whose number depends upon the accuracy required. The area of each class represents the probability of the load being the class interval mid-value [3].

Figure 3.4 shows a normal distribution discritized into seven class intervals. In the seven-step normal distribution it is assumed that the distribution beyond \pm 3.5 standard deviations is negligible. In this thesis, a seven-step normal distribution is used whenever load forecast uncertainty is considered. The effect of uncertainty in load forecasting can be included in the unit commitment and in the probabilities of the different operating states. The method and evaluation procedure is examined in the next section. 
Probabilities given by indicated area

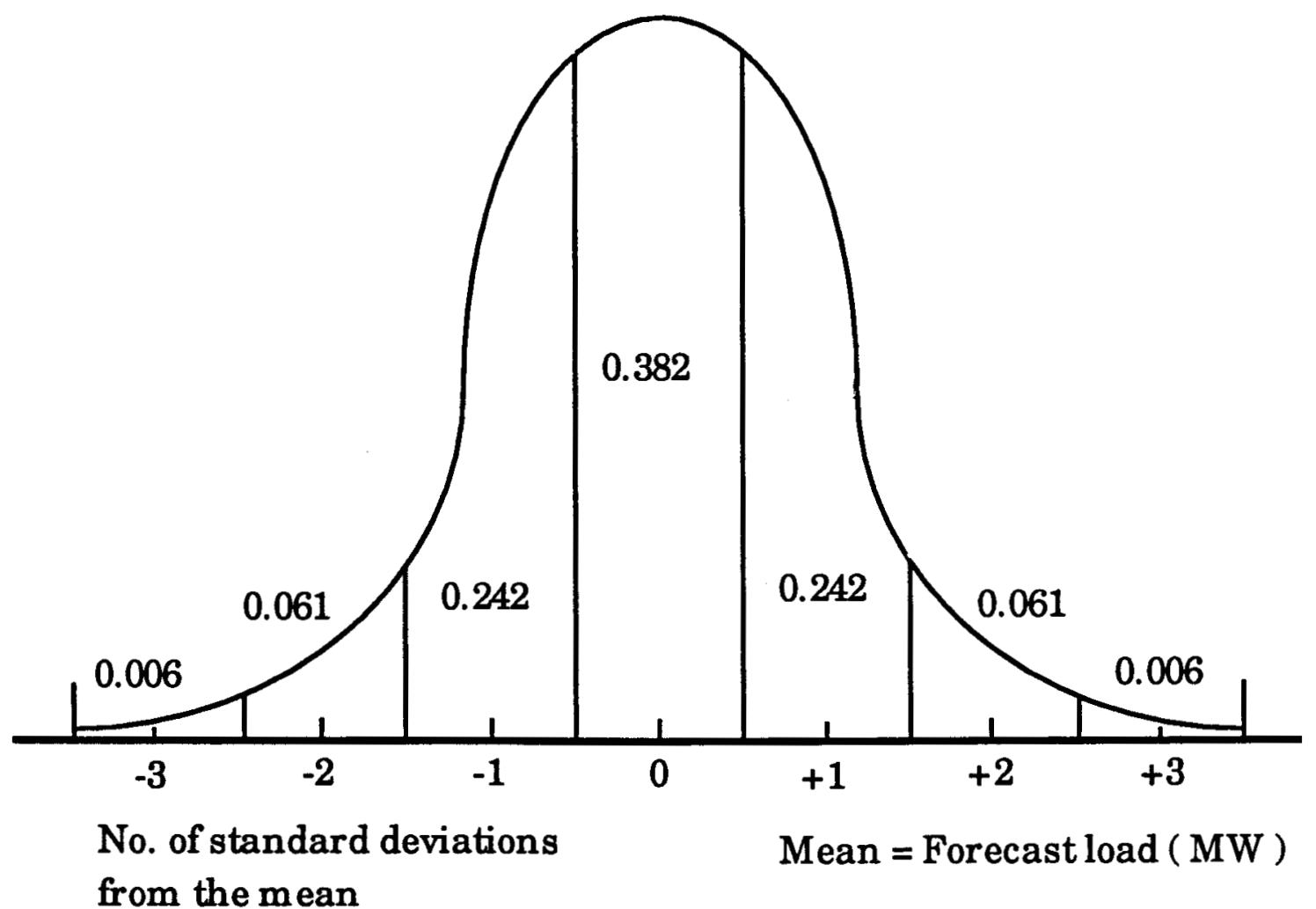

Figure 3.4: Seven-step Approximation of the Normal Distribution of Uncertainty in Load Forecasting.

\subsection{Selected Studies}

The concepts explained in the previous section have been applied to the Roy Billinton Test System(RBTS). The required number of units and the probabilities associated with the different system operating states depend on many factors such as system lead time, system load, size of the various generating units, generating units failure rate and acceptable risk level. In this analysis, effects of lead time and peak load variation on the unit commitment, GSOSR and the system operating state probabilities are considered. Some of the other factors influencing reliability are load 
forecast uncertainty and derating states suffered by generating units in the system. To recognize the effect of these two factors, the following cases have been considered:

Case 1: Base case

Case 2: Including derated states

Case 3: Including load forecast uncertainty

Case 4: Including both derated state and load forecast uncertainty.

Case 1 is the base case and all further cases are variations from this base. The number of generators to be committed for a particular load level are taken from a priority unit loading order table. The priority order list of the generating units for the RBTS is shown in Table 2.1 .

\subsubsection{Effect of Lead Time Variation}

In the studies illustrated in this section, it is assumed that the system peak load does not change with time and additional generating units are made available within the same lead time. In a practical power system, the generating units have various lead times. Considering units with different lead times can be illustrated using an area risk curve which is discussed in the next chapter.

\subsubsection{Base Case}

In this case, each generating unit is represented by a two-state model as shown in Figure 2.2, which includes an operating state and a failed 
state. The repair process is neglected in determining the time dependent availabilities and unavailabilities of the generating units. The probability of the load forecast error is also assumed to be zero.

The number of committed units, system operating state probabilities and corresponding GSOSR for a load of $60 \%$ (111 MW) of the peak load of 185 MW in the RBTS are shown in Table 3.3. The system lead time varies from 0.5 hour to 15 hours. The unit commitment is made using a specified risk value of 0.001 . The number of committed units for a lead time of 0.5 hour is 4. The system should commit its 5 th unit in addition to the four already committed units, when the lead time is increased to 1 hour. The number of committed units is unaffected as the lead time increases from 1 hour to 15 hours.

Table 3.3: Unit Commitment and System Operating State Probabilities (Base Case).

\begin{tabular}{|c|c|c|c|c|c|c|}
\hline $\begin{array}{c}\text { Lead } \\
\text { Time } \\
\text { [Hr] }]\end{array}$ & $\begin{array}{c}\text { No.of } \\
\text { units }\end{array}$ & Normal & Alert & $\begin{array}{c}\text { Emer- } \\
\text { gency }\end{array}$ & $\begin{array}{c}\text { Extreme } \\
\text { Emergency }\end{array}$ & GSOSR \\
\hline 0.5 & 4 & 0 & 0.99921255 & 0 & 0.00078745 & 0.00078745 \\
\hline 1 & 5 & 0.99774168 & 0.00225645 & 0 & 0.00000188 & 0.00000188 \\
\hline 2 & 5 & 0.99548725 & 0.00450525 & 0 & 0.00000749 & 0.00000749 \\
\hline 3 & 5 & 0.99323672 & 0.00674643 & 0 & 0.00001685 & 0.00001685 \\
\hline 4 & 5 & 0.99099008 & 0.00897999 & 0 & 0.00002993 & 0.00002993 \\
\hline 5 & 5 & 0.98874732 & 0.01120595 & 0 & 0.00004673 & 0.00004673 \\
\hline 6 & 5 & 0.98650844 & 0.01342432 & 0 & 0.00006724 & 0.00006724 \\
\hline 7 & 5 & 0.98427343 & 0.01563512 & 0 & 0.00009144 & 0.00009144 \\
\hline 8 & 5 & 0.98204230 & 0.01783836 & 0 & 0.00011934 & 0.00011934 \\
\hline 9 & 5 & 0.97981503 & 0.02003405 & 0 & 0.00015092 & 0.00015092 \\
\hline 10 & 5 & 0.97759162 & 0.02222220 & 0 & 0.00018618 & 0.00018618 \\
\hline 15 & 5 & 0.96653229 & 0.03305046 & 0 & 0.00041725 & 0.00041725 \\
\hline
\end{tabular}


The results are presented in Figures 3.6 to 3.8. These figures present the impact of each state for all four cases. In the figures the following abbreviations are used: "[D]" represents derated state (Case 2), "[LFU]" represents load forecast uncertainty (Case 3) and "[D \& LFU]" represents the effects of both derated states and load forecast uncertainty (Case 4). It can be seen that as the lead time increases, the probability of the normal state decreases, whereas the probabilities of the alert and the extreme emergency state increase.

Four units are committed to service at the $111 \mathrm{MW}$ load level to satisfy the GSOSR of 0.001 . The committed capacity in this case is $120 \mathrm{MW}$. If one of the committed units is removed from service, the load must be curtailed, therefore the probability of the normal state is zero, and the probability of the alert state is $\mathbf{0 . 9 9 9 2 1 2 5 5}$. If at least one of the units is out of service, the system will be in the extreme emergency state. The probability of being in this state is 0.00078745 . From the total 16 possible contingency states of the 4 committed units, none of them are associated with the normal state. Only one of them, i.e. all committed units are in service, lies in the alert state. The 15 remaining contingencies cause the system to be in the extreme emergency state.

The probability of the normal state in Table 3.3 increases as the lead time is increased from 0.5 hour to 1 hour and the probabilities of the alert and the extreme emergency states decrease. The reason for this is that the number of committed units increases from 4 to 5 . The probability associated with the emergency state is zero, because there is no event for which the available generating capacity is exactly equal to the load. Therefore, at this 
load level the GSOSR is equal to the probability of the extreme emergency state.

\subsubsection{2: Inclusion of Derated States Into the Analysis}

In Case 1, all the units are represented by a two-state model. In order to recognize that large thermal units can operate in one or more derated states, the two $40 \mathrm{MW}$ thermal units, i.e. units number 4 and 5, are represented by a three-state model [28]. This representation is shown in Figure 3.5.

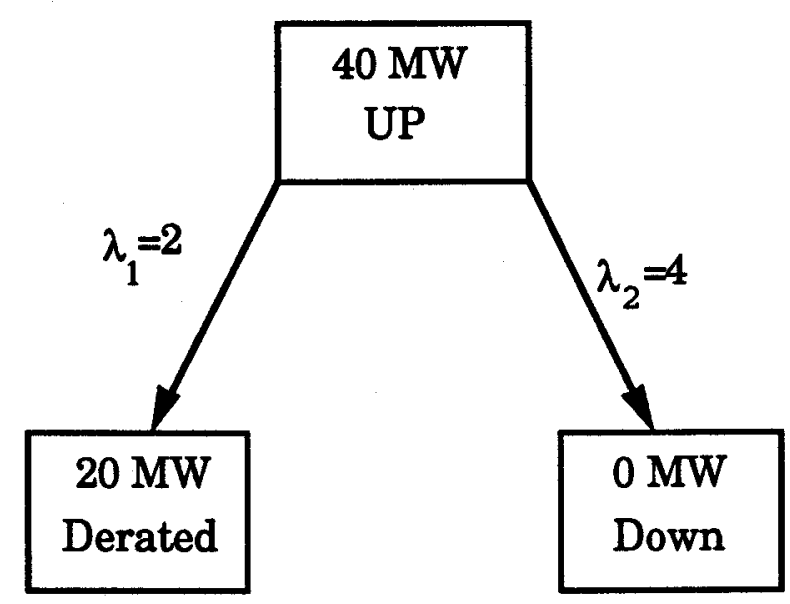

Figure 3.5: Three State-model of the 40 MW Thermal Units.

Table 3.4 shows the unit commitment, system operating state probabilities and the corresponding GSOSR for a load of $111 \mathrm{MW}$ and different lead times. The results are presented in Figures 3.6 to 3.8.

The number of possible generating unit contingency states increases by considering derated or partial outages. The corresponding probabilities of the different system operating states are therefore changed. In this 

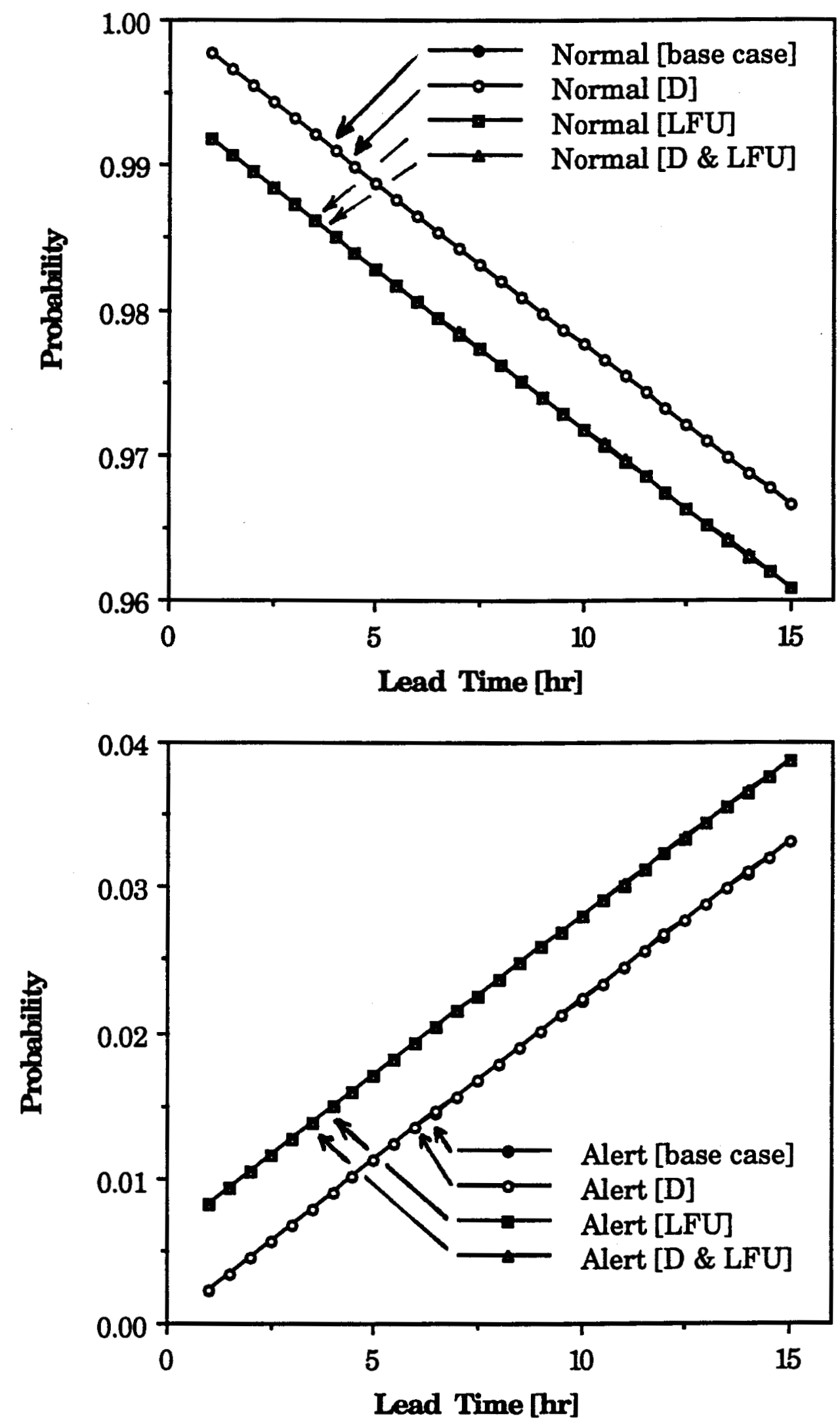

Figure 3.6: Variation of Probabilities of the Normal and Alert States with Lead Time. 

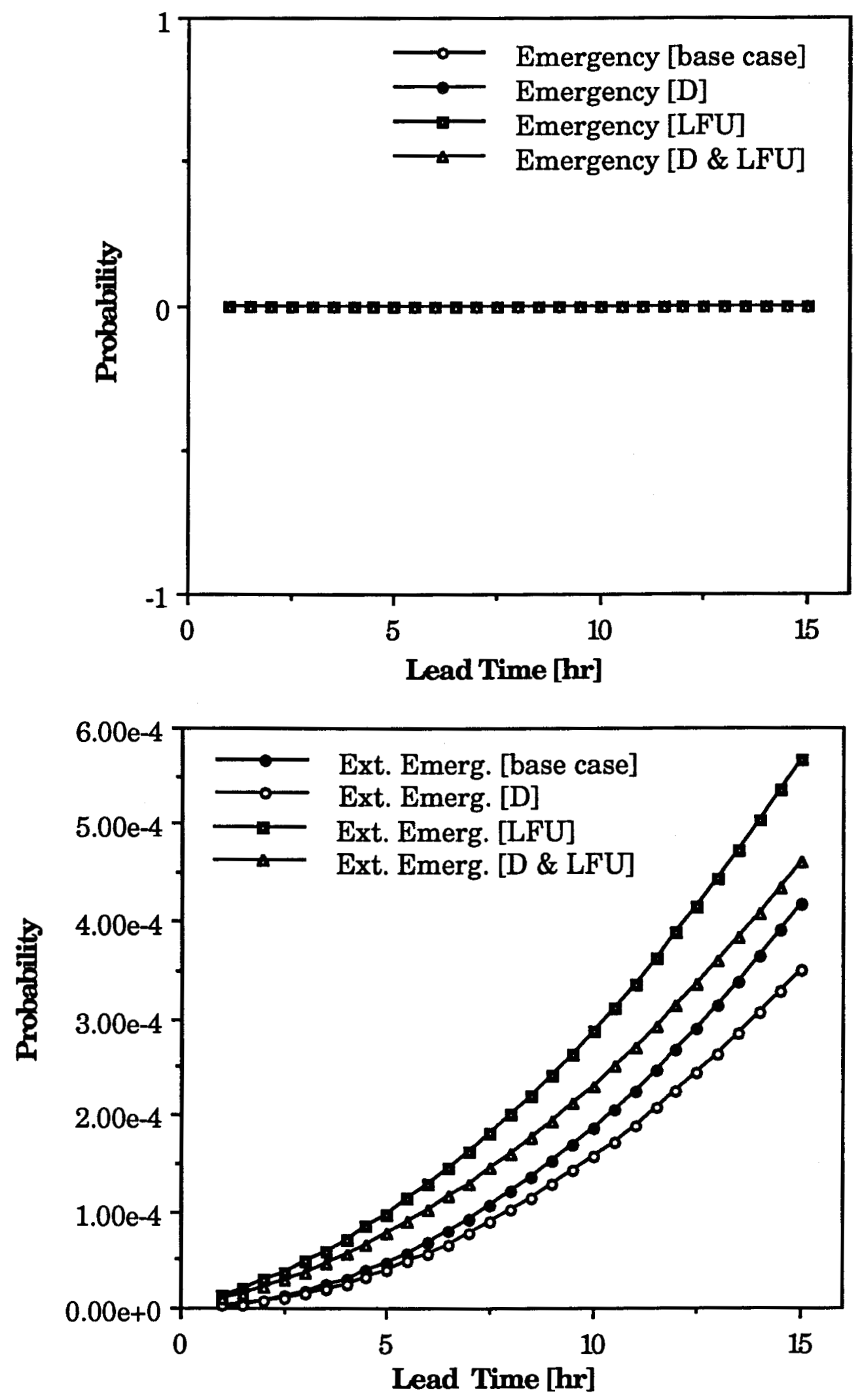

Figure 3.7: Variation of Probabilities of the Emergency and Extreme Emergency States with Lead Time. 


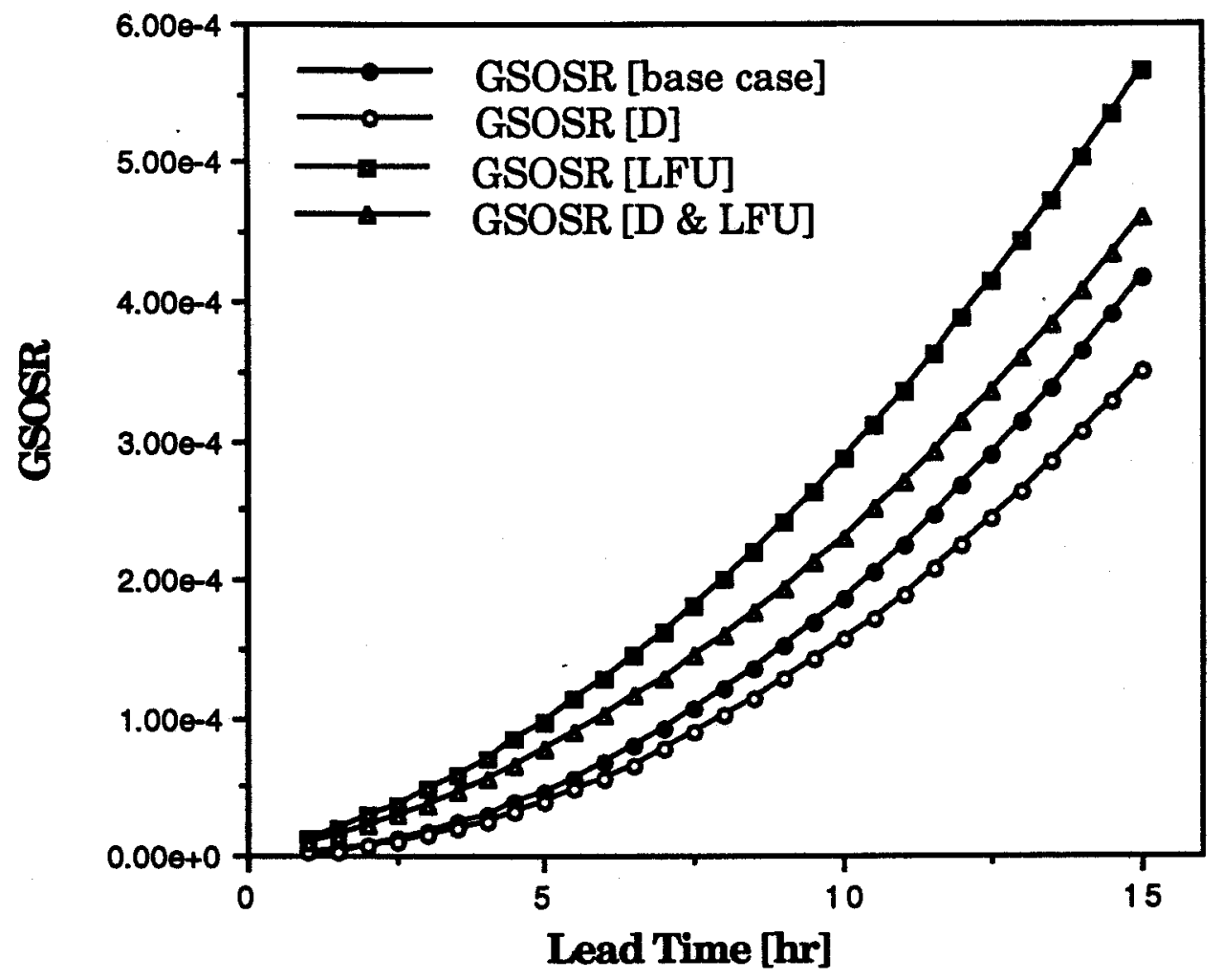

Figure 3.8: Variation of the GSOSR with Lead Time.

system, the system operating state probabilities are identical to those of Case 1 at the lead time of 0.5 hour. The reason for this is that although the number of contingencies increases from 16 to 24 , only the first contingency state, i.e. all committed units are in service with full capacity, belongs to the alert state. The remaining contingencies are located in the extreme emergency state. The probability of the first contingency state does not change, by considering derated states. For lead times of 1 hour to 15 hours and 5 committed units, the probabilities of the normal state are identical to those of the base case. This is due to the fact that with 5 committed units and a load level of $111 \mathrm{MW}$, the first contingency state containing all five units at full capacity resides in the normal state. The probability of this contingency state is identical to that of the base case. 
Table 3.4: Unit Commitment and System Operating State Probabilities Considering the Effects of Derated States (Case 2).

\begin{tabular}{|c|c|c|c|c|c|c|}
\hline $\begin{array}{c}\text { Lead } \\
\text { Time } \\
{[\mathrm{Hr}]}\end{array}$ & $\begin{array}{c}\text { No.of } \\
\text { units }\end{array}$ & Normal & Alert & $\begin{array}{c}\text { Emer- } \\
\text { gency }\end{array}$ & $\begin{array}{c}\text { Extreme } \\
\text { Emergency }\end{array}$ & GSOSR \\
\hline 0.5 & 4 & 0 & 0.99921255 & 0 & 0.00078745 & 0.00078745 \\
\hline 1 & 5 & 0.99774168 & 0.00225675 & 0 & 0.00000157 & 0.00000157 \\
\hline 2 & 5 & 0.99548725 & 0.00450646 & 0 & 0.00000629 & 0.00000629 \\
\hline 3 & 5 & 0.99323672 & 0.00674914 & 0 & 0.00001414 & 0.00001414 \\
\hline 4 & 5 & 0.99099008 & 0.00898481 & 0 & 0.00002512 & 0.00002512 \\
\hline 5 & 5 & 0.98874732 & 0.01121346 & 0 & 0.00003922 & 0.00003922 \\
\hline 6 & 5 & 0.98650844 & 0.01343513 & 0 & 0.00005643 & 0.00005643 \\
\hline 7 & 5 & 0.98427343 & 0.01564981 & 0 & 0.00007676 & 0.00007676 \\
\hline 8 & 5 & 0.9820423 & 0.01785752 & 0 & 0.00010018 & 0.00010018 \\
\hline 9 & 5 & 0.97981503 & 0.02005827 & 0 & 0.00012671 & 0.00012671 \\
\hline 10 & 5 & 0.97759162 & 0.02225207 & 0 & 0.00015632 & 0.00015632 \\
\hline 15 & 5 & 0.96653229 & 0.03311723 & 0 & 0.00035047 & 0.00035047 \\
\hline
\end{tabular}

The probabilities of the alert state in this study are, however, greater than those of the base case and the probabilities of the extreme emergency state and GSOSR are less than those of Case 1. This is because the number of possible contingencies increases from 32 to 72 due to considering partial capacity outages of the 4th and the 5th units. Some of these contingencies which were previously associated with the extreme emergency now lie in the alert state.

\subsubsection{Inclusion of Load Forecast Uncertainty}

In the studies illustrated in the previous cases, it was assumed that the probability of the actual peak load differing from the forecast peak load 
was zero. Load forecast error is included in the analysis in Case 3. It is assumed that the load forecast deviation in the RBTS is normally distributed using the 7 step histogram shown in Figure 3.4. The standard deviation is assumed to be $4 \%$ of the forecast peak load [30]. The following procedure is utilized to obtain the unit commitment schedule and the probabilities of the different operating states :

Step 1- Units are taken from the priority loading order table, such that the total capacity is greater than or equal to the mean or forecast peak load.

Step 2- The probabilities of the different system operating states are computed for each load level represented by the class interval mid-point of the normal distribution for the given number of committed units, obtained from Step 1. Equivalent probabilities associated with the operating states are then calculated for the forecast peak load using Equation 3.3.

$$
P_{n}=\sum_{i=1}^{m} P_{n}(i) P_{l}(i)
$$

where,

$P_{n} \quad=$ probability of the normal state for the forecast peak load, $P_{n}(i)=$ probability of the normal state for the ith load step, $P_{1}(i)=$ probability of the ith load step

m number of load steps

The probabilities of the alert, the emergency and the extreme emergency states are calculated using the same method. 
Step 3- Calculating GSOSR using $P_{n}$ and $P_{a}$ from Step 2

GSOSR $=1-P_{n}-P_{a}$

If GSOSR $\leq$ (Specified risk)

If GSOSR > (Specified risk)
The unit commitment is acceptable

Add the next unit to the committed units from the priority table and repeat step 2 with the new number of committed units.

Table 3.5 shows the unit commitment for the peak load of $111 \mathrm{MW}$ and the lead time of 0.5 hour using the above procedure. The GSOSR is 0.00678109 with 4 committed units which is greater than the acceptable risk of 0.001 . Therefore, one more unit should be committed. The GSOSR reduces to 0.0000056 with 5 committed units.

Table 3.5: System Operating State Probabilities for a Load Level of $111 \mathrm{MW}$ and a Lead Time of 30 Minutes.

\begin{tabular}{|c|c|c|c|c|c|c|}
\hline \multirow{2}{*}{$\begin{array}{c}\text { No.of } \\
\text { SD }\end{array}$} & \multirow{2}{*}{$\begin{array}{l}\text { Load } \\
\text { Level } \\
\text { [MW] }\end{array}$} & \multirow{2}{*}{$\begin{array}{l}\text { Prob.of } \\
\text { Load } \\
\text { Level }\end{array}$} & \multicolumn{4}{|c|}{ Probability of } \\
\hline & & & Normal & Alert & Emergency & $\begin{array}{c}\text { Extreme } \\
\text { Emergency }\end{array}$ \\
\hline-3 & 97.68 & 0.006 & 0.99914405 & 0.00085571 & 0 & 0.00000023 \\
\hline-2 & 102.12 & 0.061 & 0.99887035 & 0.00112918 & 0 & 0.00000047 \\
\hline-1 & 106.56 & 0.242 & 0.99887035 & 0.00112918 & 0 & 0.00000047 \\
\hline 0 & 111 & 0.382 & 0.99887035 & 0.00112918 & 0 & 0.00000047 \\
\hline 1 & 115.44 & 0.242 & 0.99887035 & 0.00112918 & 0 & 0.00000047 \\
\hline 2 & 119.88 & 0.061 & 0.99887035 & 0.00112918 & 0 & 0.00000047 \\
\hline 3 & 124.32 & 0.006 & 0 & 0.99914405 & 0 & 0.00085595 \\
\hline \multicolumn{3}{|l|}{ Inde: } & 0.99287877 & 0.00711563 & 0 & 0.0000056 \\
\hline
\end{tabular}

$\mathrm{SD}=$ Standard Deviation 
The required number of generating units and system operating state probabilities for a load level of $111 \mathrm{MW}$ and different lead times are shown in Table 3.6 and presented in Figures 3.6 to 3.8. Including the load forecast uncertainty in the analysis makes a considerable change in the probabilities of the different operating states and GSOSR. In contrast with the results of Case 2, the probability of the normal state decreases and the probabilities of the alert and the extreme emergency states increase in this case. It should be noted that the inclusion of load forecast uncertainty in unit commitment results in a considerable increase in the required calculations and hence in the CPU time.

Table 3.6: Unit Commitment and System Operating State Probabilities for Different Lead Times and with Load Forecast Uncertainty (Case 3).

\begin{tabular}{|c|c|c|c|c|c|c|}
\hline $\begin{array}{c}\text { Lead } \\
\text { Time } \\
\text { [Hr] }\end{array}$ & $\begin{array}{c}\text { No.of } \\
\text { units }\end{array}$ & Normal & Alert & $\begin{array}{c}\text { Emer- } \\
\text { gency }\end{array}$ & $\begin{array}{c}\text { Extreme } \\
\text { Emergency }\end{array}$ & GSOSR \\
\hline 0.5 & 5 & 0.99287877 & 0.00711563 & 0 & 0.00000560 & 0.00000560 \\
\hline 1 & 5 & 0.99175851 & 0.00822937 & 0 & 0.00001213 & 0.00001213 \\
\hline 2 & 5 & 0.98952088 & 0.01045117 & 0 & 0.00002795 & 0.00002795 \\
\hline 3 & 5 & 0.98728710 & 0.01266542 & 0 & 0.00004747 & 0.00004747 \\
\hline 4 & 5 & 0.98505718 & 0.01487214 & 0 & 0.00007067 & 0.00007067 \\
\hline 5 & 5 & 0.98283111 & 0.01707134 & 0 & 0.00009755 & 0.00009755 \\
\hline 6 & 5 & 0.98060888 & 0.01926303 & 0 & 0.00012809 & 0.00012809 \\
\hline 7 & 5 & 0.97839049 & 0.02144722 & 0 & 0.00016229 & 0.00016229 \\
\hline 8 & 5 & 0.97617593 & 0.02362394 & 0 & 0.00020013 & 0.00020013 \\
\hline 9 & 5 & 0.97396520 & 0.02579318 & 0 & 0.00024161 & 0.00024161 \\
\hline 10 & 5 & 0.97175830 & 0.02795498 & 0 & 0.00028673 & 0.00028673 \\
\hline 15 & 5 & 0.96078096 & 0.03865259 & 0 & 0.00056645 & 0.00056645 \\
\hline
\end{tabular}




\subsubsection{Inclusion of Both Derated States and Load Forecast Uncertainty}

Table 3.7 shows the results when the effects of both derated states and load forecast uncertainty are considered. The system peak load is $111 \mathrm{MW}$ and a specified risk of 0.001 is selected. The results are either the same as those of Case 3 or between those of Case 2 and Case 3. The probabilities associated with the extreme emergency state are lower than those of Case 3 and greater than those of Case 2. The probabilities of the normal and the alert states are, however, larger than those of Case 3.

The calculated system reliability is increased by including derated states and decreased by considering load forecast uncertainty. Therefore, using GSOSR as the criterion, Case 3 is the worst case and Case 2 is the best one.

\subsubsection{Effect of Peak Load Variation}

The studies presented in the previous section are based on a constant load. The system load, however, varies with time and utilization of a constant load as the single system load parameter does not recognize the hourly variability. In the previous studies the load was fixed in $111 \mathrm{MW}$ and the lead time varied. In this study, the lead time is fixed in 4 hours and the load is varied. The load is changed from $50 \mathrm{MW}$ to $185 \mathrm{MW}$ in steps of $1 \mathrm{MW}$. The effects of including derated states and load forecast uncertainty are also examined. 
Table 3.7: Unit Commitment and System Operating State Probabilities Considering the Effects of both Derated States and Load Forecast Uncertainty (Case 4).

\begin{tabular}{|c|c|c|c|c|c|c|}
\hline $\begin{array}{c}\text { Lead } \\
\text { Time } \\
{[\mathrm{Hr}]}\end{array}$ & $\begin{array}{c}\text { No.of } \\
\text { units }\end{array}$ & Normal & Alert & $\begin{array}{c}\text { Emer- } \\
\text { gency }\end{array}$ & $\begin{array}{c}\text { Extreme } \\
\text { Emergency }\end{array}$ & GSOSR \\
\hline 0.5 & 5 & 0.99288014 & 0.00711570 & 0 & 0.00000416 & 0.00000416 \\
\hline 1 & 5 & 0.99176124 & 0.00822967 & 0 & 0.00000909 & 0.00000909 \\
\hline 2 & 5 & 0.98952634 & 0.01045237 & 0 & 0.00002129 & 0.00002129 \\
\hline 3 & 5 & 0.98729529 & 0.01266812 & 0 & 0.00003659 & 0.00003659 \\
\hline 4 & 5 & 0.98506807 & 0.01487694 & 0 & 0.00005499 & 0.00005499 \\
\hline 5 & 5 & 0.9828447 & 0.01707882 & 0 & 0.00007647 & 0.00007647 \\
\hline 6 & 5 & 0.98062516 & 0.01927379 & 0 & 0.00010104 & 0.00010104 \\
\hline 7 & 5 & 0.97840946 & 0.02146186 & 0 & 0.00012869 & 0.00012869 \\
\hline 8 & 5 & 0.97619757 & 0.02364303 & 0 & 0.00015940 & 0.00015940 \\
\hline 9 & 5 & 0.97398951 & 0.02581731 & 0 & 0.00019318 & 0.00019318 \\
\hline 10 & 5 & 0.97178526 & 0.02798473 & 0 & 0.00023001 & 0.00023001 \\
\hline 15 & 5 & 0.96082109 & 0.03871912 & 0 & 0.00045979 & 0.00045979 \\
\hline
\end{tabular}

The number of units required for a specified GSOSR of 0.001 has been calculated for the different load levels. The system operating state probabilities and corresponding GSOSR were calculated and are presented in Figures 3.9 to 3.11. The required number of generating units increases as the load increases. For a given number of committed units, the probability of the normal state decreases as the load increases. The probability of the alert and extreme emergency states increase as the load increases. The reason for this is that some of the probability associated with the normal state at the lower load levels transfers to the alert or extreme emergency states as the system load increases. In other words, some of the contingencies located in the normal state at low load levels move to the alert or extreme emergency states as the load increases. The probability of the 
emergency state is zero for all load levels between $50 \mathrm{MW}$ and $185 \mathrm{MW}$ except for nine specific load levels.

As noted earlier, the GSOSR decreases with the inclusion of generating unit partial outages. The number of committed units for this system is identical to the case where derated states are not considered. The required computation time increases with the inclusion of derated states in the analysis. 

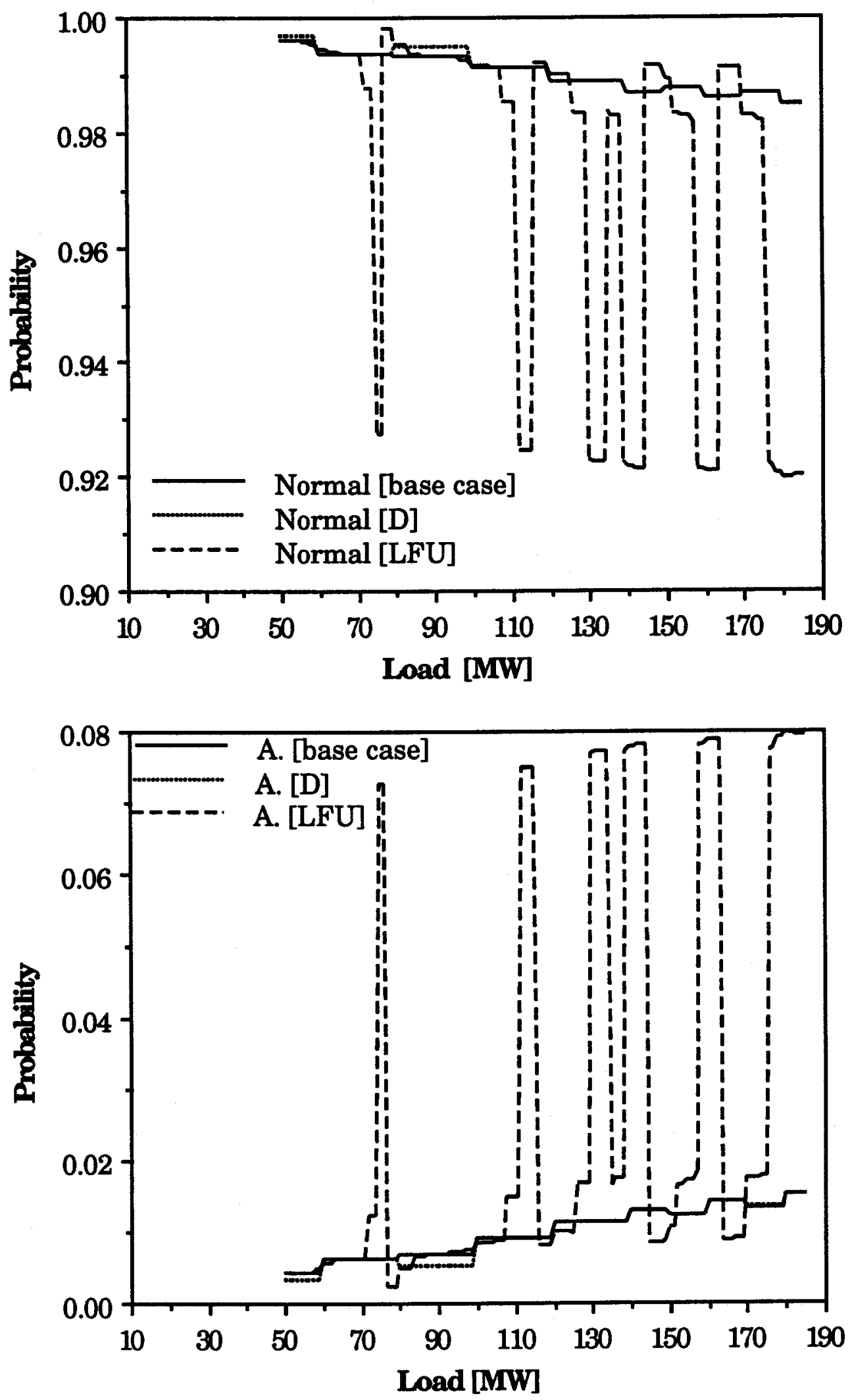

Figure 3.9: Probabilities of the Normal and Alert States. 

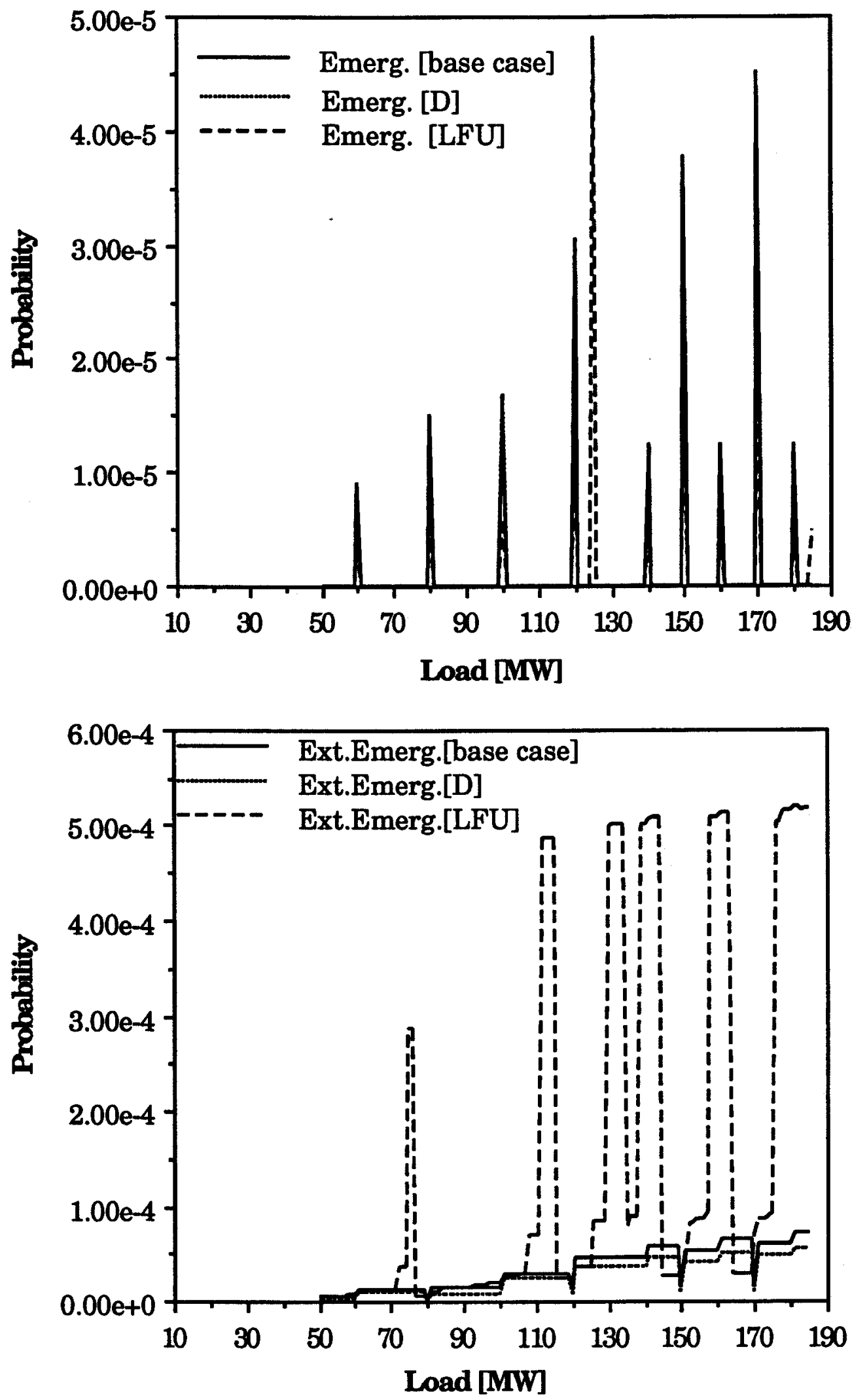

Figure 3.10: Probabilities of the Emergency and Extreme Emergency States. 


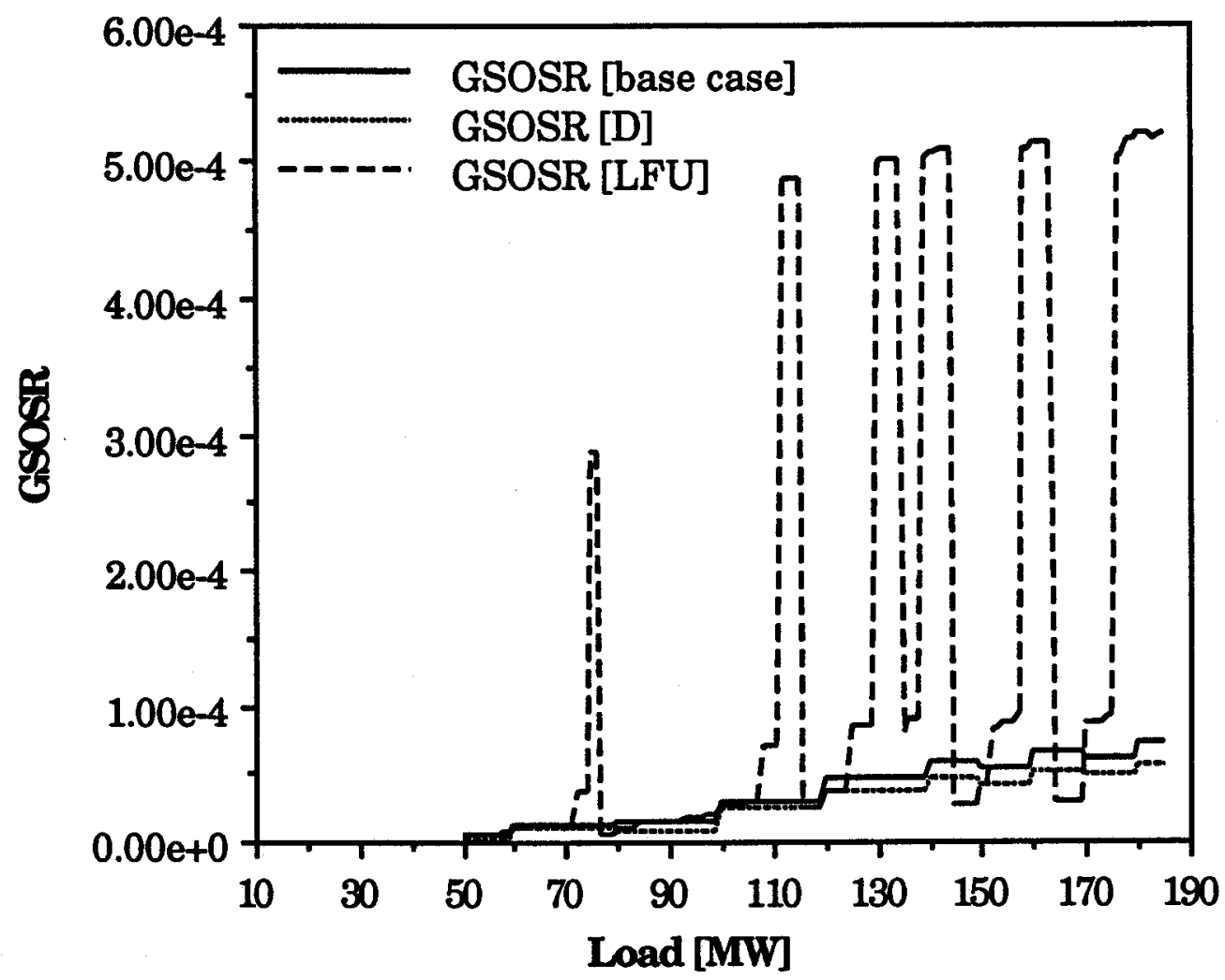

Figure 3.11: Variation of the GSOSR with the System Peak Load.

The number of committed units and the system operating state probabilities are extremely sensitive to load forecast uncertainty. The required number of units and probabilities associated with the different operating states are calculated using the procedure explained in Subsection 3.6.1.3. The inclusion of load forecast uncertainty in the analysis results in units being committed earlier or at lower load levels than would occur without uncertainty. The number of committed units increases from 4 to 5 at the $80 \mathrm{MW}$ load level when the load forecast error is zero and at the 77 MW load level when load forecast uncertainty is included. Figure 3.12 shows the required number of committed units for different peak loads. 


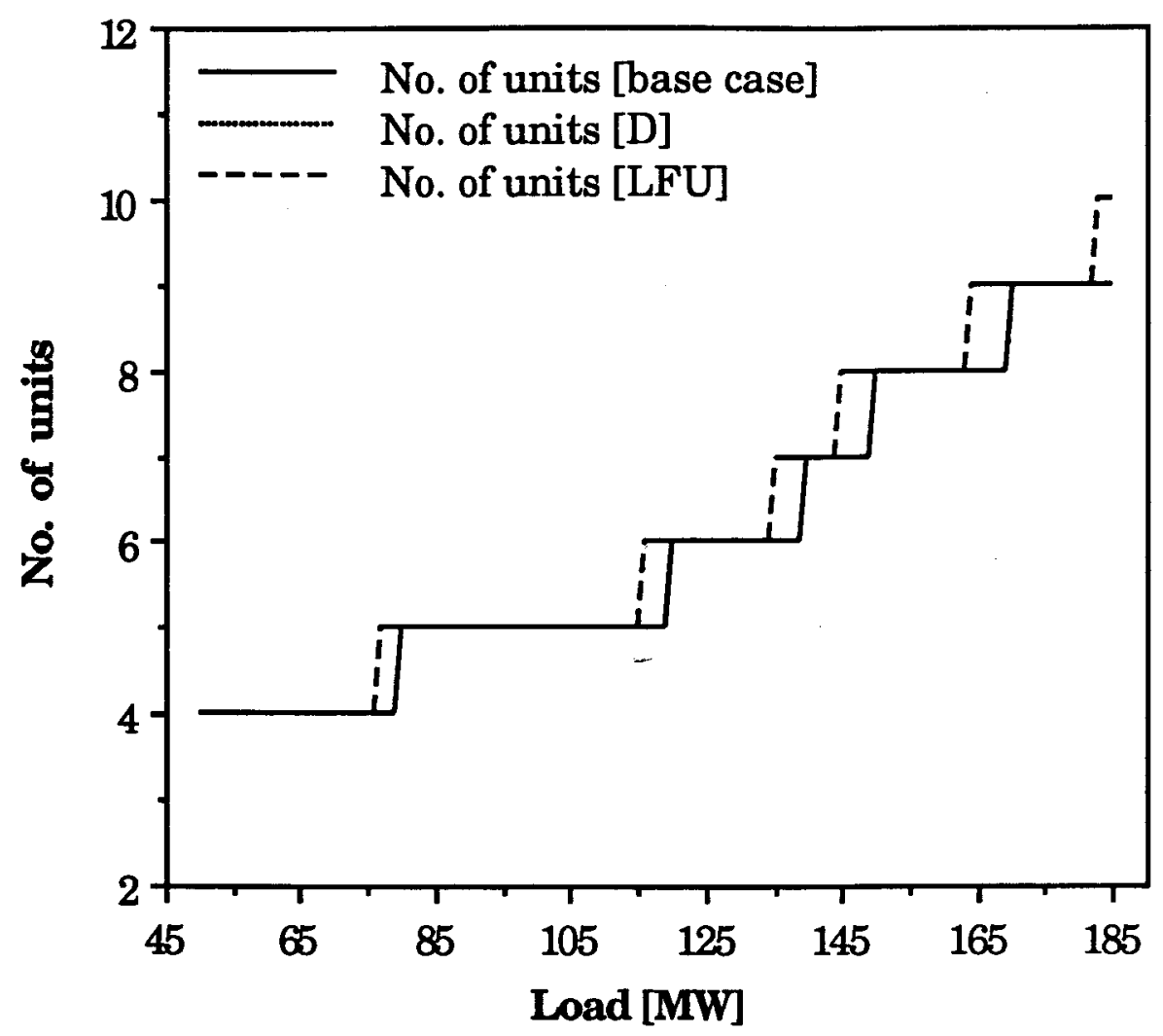

Figure 3.12: Effect of Peak Load Variation on the Number of Committed Units.

\subsubsection{Sensitivity Analysis}

In the previous cases in which the load forecast uncertainty was considered, it was assumed that the standard deviation is $4 \%$. In practice, however, it can vary quite considerably during the hours of a day or a season of a year. In order to illustrate the effect of different standard deviations on the system operating state probabilities and the GSOSR, consider the RBTS with a forecast load of $111 \mathrm{MW}$ and a lead time of 4 hours. Table 3.8 shows the results for a standard deviation varying from 0 to $10 \%$ of the forecast load. The results are also presented in Figures 3.13 and 3.14, where it can be seen that for a given number of committed units, 
the probability of the normal state decreases and the system risk increases as the load forecast uncertainty increases. The probability of the normal state increases as the standard deviation increases from $8 \%$ to $9 \%$ due to the fact that one more unit is committed at the standard deviation of $9 \%$. The variation in the reliability indices with load forecast uncertainty clearly indicates the need for accurate and comprehensive forecasting techniques.

Table 3.8: Effect of Variation in Standard Deviation.

\begin{tabular}{|c|c|c|c|c|c|c|}
\hline \multirow{2}{*}{$\begin{array}{c}\text { SD } \\
{[\%]}\end{array}$} & \multirow{2}{*}{$\begin{array}{c}\text { No.of } \\
\text { units }\end{array}$} & Normal & Alert & $\begin{array}{c}\text { Emer- } \\
\text { gency }\end{array}$ & $\begin{array}{c}\text { Extreme } \\
\text { Emergency }\end{array}$ & GSOSR \\
\hline 0 & 5 & 0.99099008 & 0.00897999 & 0 & 0.00002993 & 0.00002993 \\
\hline 1 & 5 & 0.99099008 & 0.00897999 & 0 & 0.00002993 & 0.00002993 \\
\hline 2 & 5 & 0.99099008 & 0.00897999 & 0 & 0.00002993 & 0.00002993 \\
\hline 3 & 5 & 0.98504414 & 0.01488510 & 0 & 0.00007076 & 0.00007076 \\
\hline 4 & 5 & 0.98505718 & 0.01487214 & 0 & 0.00007067 & 0.00007067 \\
\hline 5 & 5 & 0.92473943 & 0.07477567 & 0 & 0.00048490 & 0.00048490 \\
\hline 6 & 5 & 0.92473943 & 0.07477567 & 0 & 0.00048490 & 0.00048490 \\
\hline 7 & 5 & 0.92473943 & 0.07477567 & 0 & 0.00048490 & 0.00048490 \\
\hline 8 & 5 & 0.92473943 & 0.07477567 & 0 & 0.00048490 & 0.00048490 \\
\hline 9 & 6 & 0.98631294 & 0.01362285 & 0 & 0.00006421 & 0.00006421 \\
\hline 10 & 6 & 0.98795752 & 0.01198189 & 0 & 0.00006059 & 0.00006059 \\
\hline
\end{tabular}



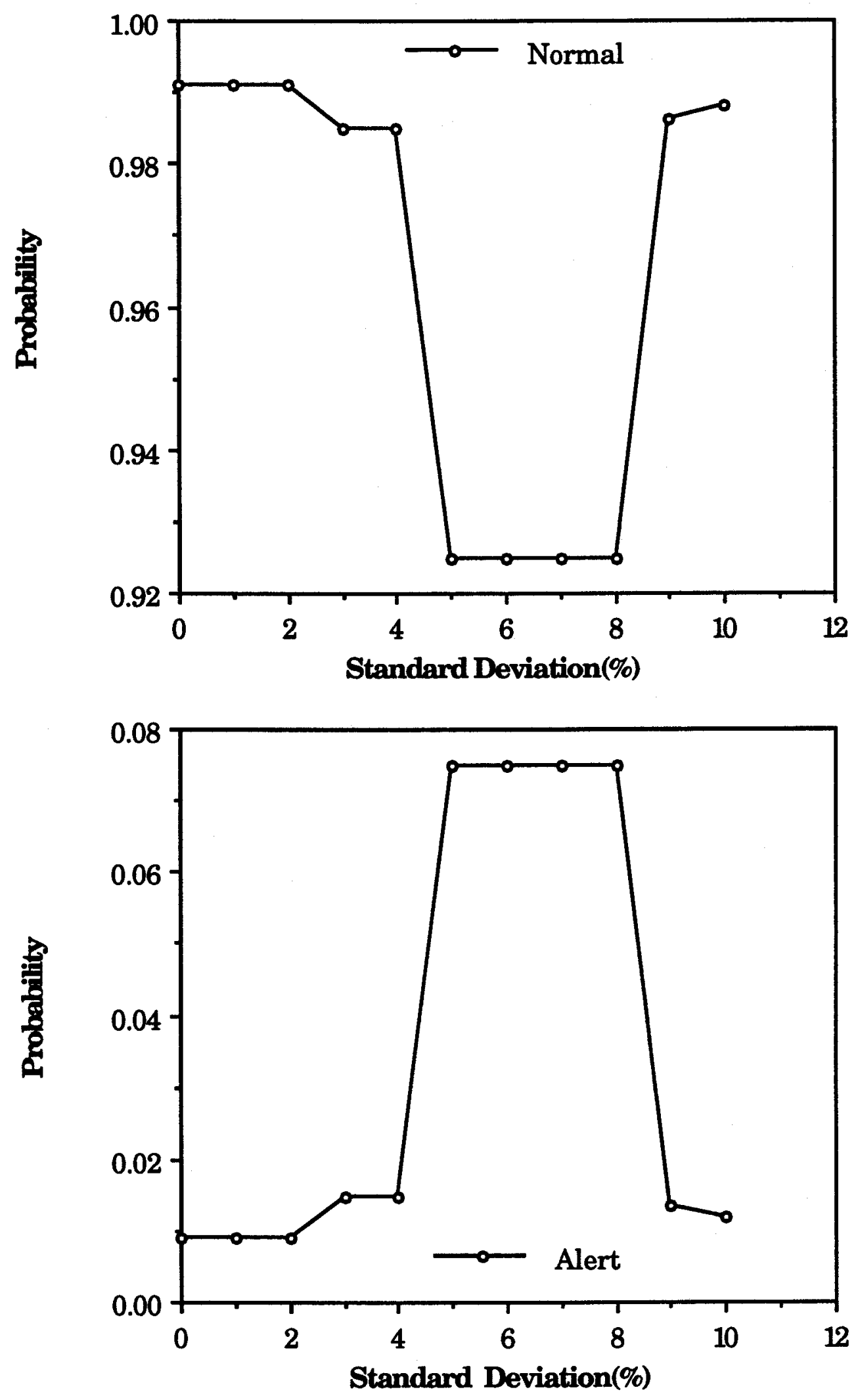

Figure 3.13: Probabilities of the Normal and Alert States with Standard Deviation. 

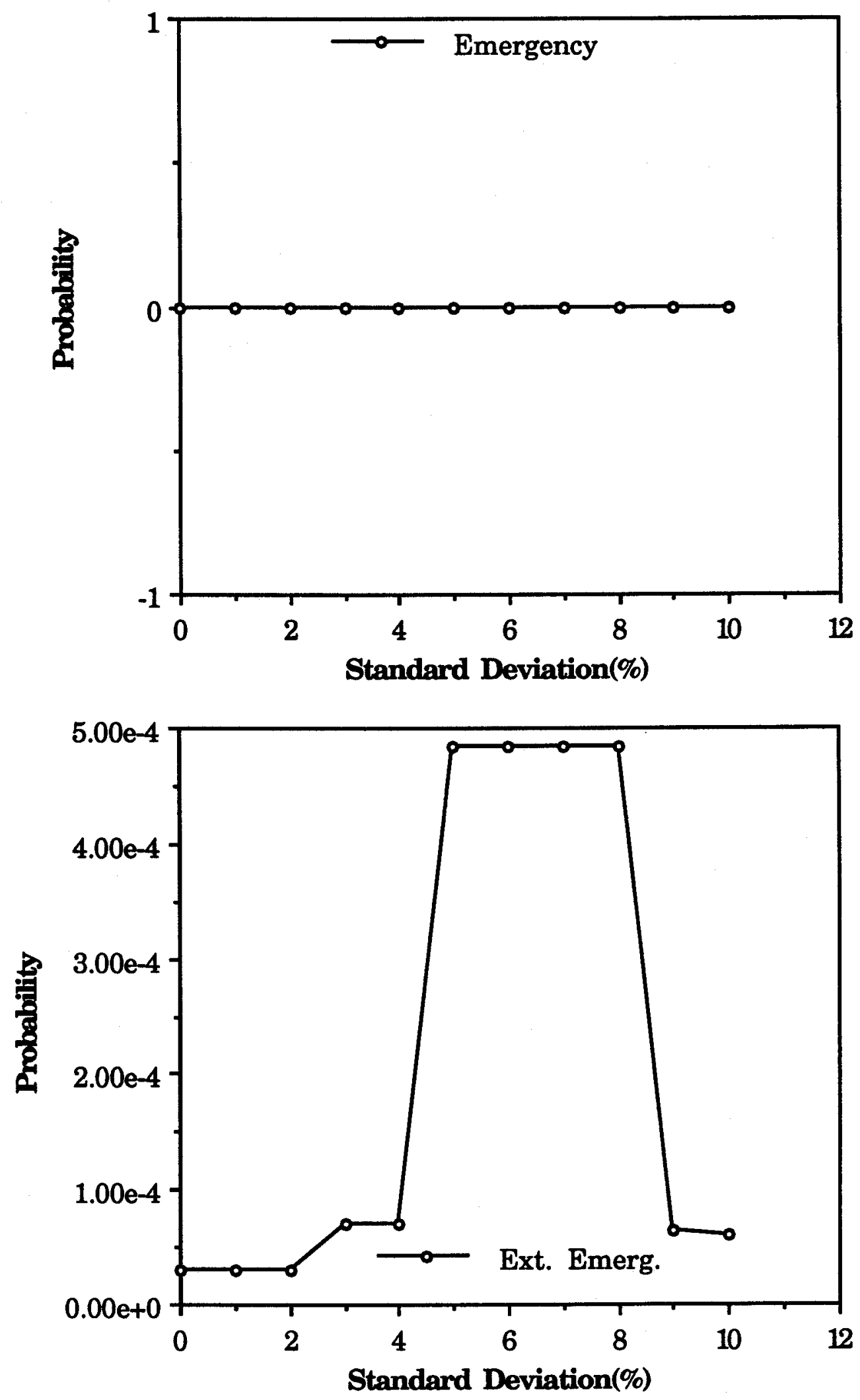

Figure 3.14: Probabilities of the Emergency and Extreme Emergency States with Standard Deviation. 


\subsection{Summary}

A new probabilistic technique for HL I operating reserve assessment is illustrated in this chapter. The framework of system operating states proposed in Reference [18] has been extended and redefined in order to make it applicable to HLI operating reserve evaluation. The state definitions are structured to include deterministic criteria used by many operating utilities. Utilization of these operating states to assess operating reserve requirments should alleviate some of the difficulty encountered in interpreting the risk index and should provide useful and comprehensive information for the system operator.

The basic PJM method is compared with the proposed technique in this chapter. Using the PJM method, system performance is identified as being either in the comfort or in the risk domain. Operating system health, margin and risk zones are presented and defined in this chapter using system operating states. The technique presented provides the opportunity for the system operator to quantify the degree of system wellbeing in addition to the system risk. The degree of system comfort is quantified using the healthy and marginal zones. This quantification can not be achieved using the basic PJM method.

The Generating System Operating State Risk (GSOSR) is defined in this chapter as the probability of residing in an undesirable system operating state. This risk index is identical to the unit commitment risk obtained using the basic PJM method. The generating units are committed to the system at a particular load level in order to satisfy specified operating 
criterion. This criterion could be a specified GSOSR or a specified probability of the system being in the healthy zone (normal state).

The application of the proposed technique is illustrated using the RBTS. The study results presented illustrate the effect of variation in lead time and peak load on the required number of units, GSOSR and system operating state probabilities. The effects of derated states and load forecast uncertainty are also illustrated in this chapter.

The lead time is assumed to be equal for all system generating units in the studies reported in this chapter. This lead time could be different for different units depending on the type and size of the units. The aspect of considering units with different lead times is discussed in the next chapter. 


\section{OPERATING RESERVE ASSESSMENT CONSIDERING STAND-BY UNITS}

\subsection{Introduction}

A power system operator must constantly assess the required spinning capacity in order to operate the system as securely and as economically as possible. Security is achieved by maintaining extra operating capacity at all times. This extra capacity can be in the form of spinning reserve or in a stand-by mode [31]. A generally accepted definition of spinning reserve is that this is the rotating capacity in excess of the system load which is synchronized and immediately available to take up load. Non-synchronized or stand-by generation can be generally categorized as; rapid start and hot reserve units. Generating units are usually committed for a specified time period during which additional generation can be made available after a time delay. This time delay is one of the most important parameters in the assessment of operating reserve and is known as the lead time. The lead time required before a generating unit can be put into service depends on a number of factors including the type of unit in question. The delay time associated with a thermal generating unit could be

several hours [10]. Gas turbine peaking units and hydraulic equipment can usually be made available in a relatively short time as compared to that 
required for more conventional thermal or nuclear generating capacity. Gas turbine and hydraulic units are therefore usually classified as rapid start units. The delay time of thermal units can also be reduced, by maintaining the boilers in a hot state. Units in this operating mode are usually available within an hour, and are known as hot reserve units.

In an operating reserve assessment, it is often assumed that sufficient additional generation is always available and that it is only a matter of time before this additional generation can be brought into service. In the studies described in Chapter 3 , it is assumed that all additional generating units are available with the same lead time. The analysis becomes somewhat more complex when the generating units available to pick up load are not associated with a single lead time. The effect of rapid start and hot reserve units can be incorporated in the operating reserve assessment using the concept of area risk curves [13]. A procedure has been developed to determine the required number of units for a given load level and the probabilities associated with the different system operating states. The impact on the system operating state probabilities of varying the rapid start and hot reserve units are also presented in this chapter.

\subsection{Area Risk Curves}

Evaluation of the risk at HL I for a specified time into the future can be depicted using area risk curves [3]. A possible area risk curve for a system with no stand-by unit is shown in Figure 4.1, where $F(R)$ is the risk function. The area under the curve at any particular point is dependent upon two factors, the available generation and the load level. The area risk 
curve in Figure 4.1 shows the total system risk $\left(\mathrm{T}_{r}\right)$ or the probability of the on-line generation just carrying or failing to carry the load during a lead time of $t_{a}$.

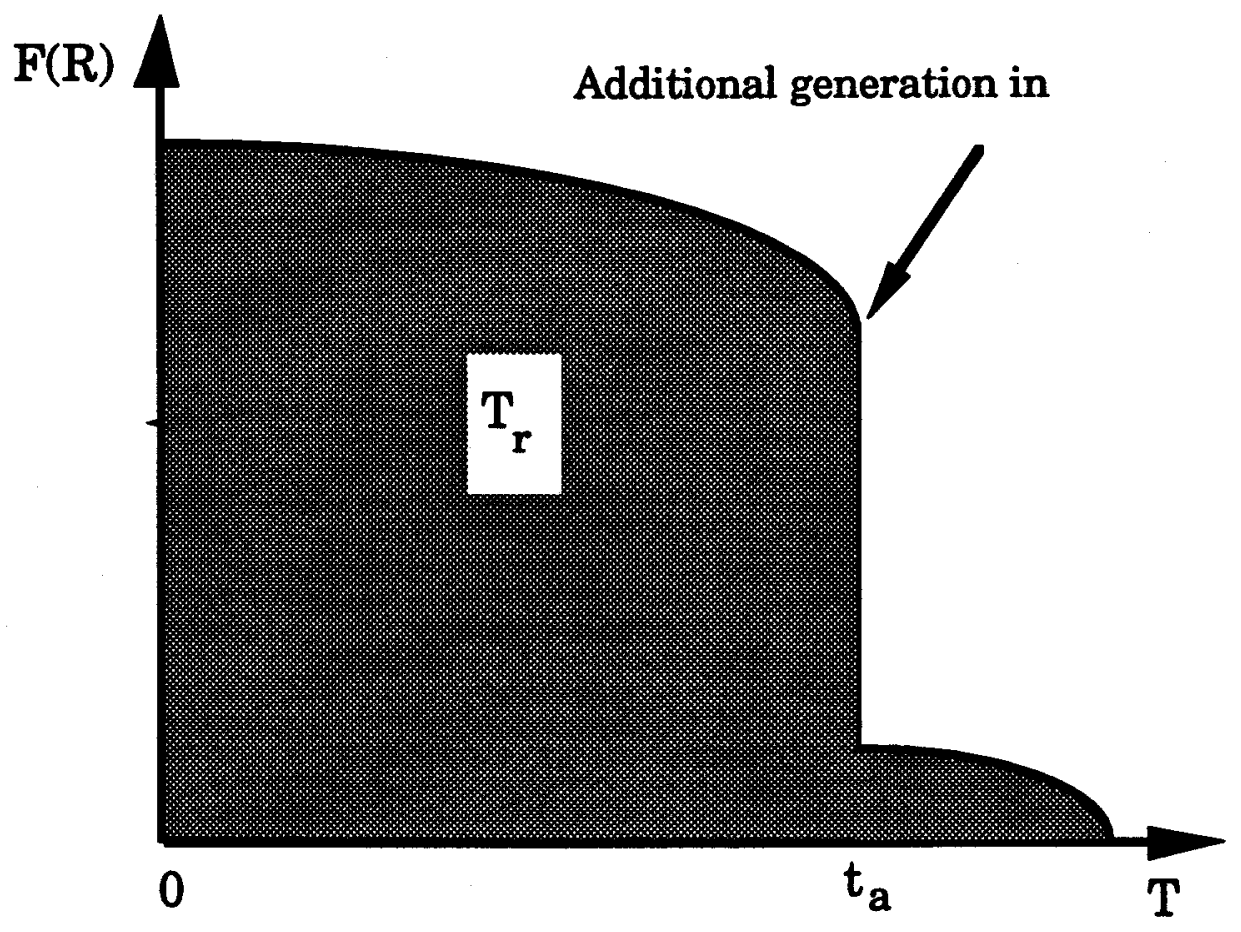

Figure 4.1: Area Risk Curve Without Stand-by Units.

The GSOSR, number of committed units and the system operating state probabilities are affected by including rapid start and hot reserve units in the analysis. Figure 4.2 shows a typical area risk curve for a system with rapid start and hot reserve units. 


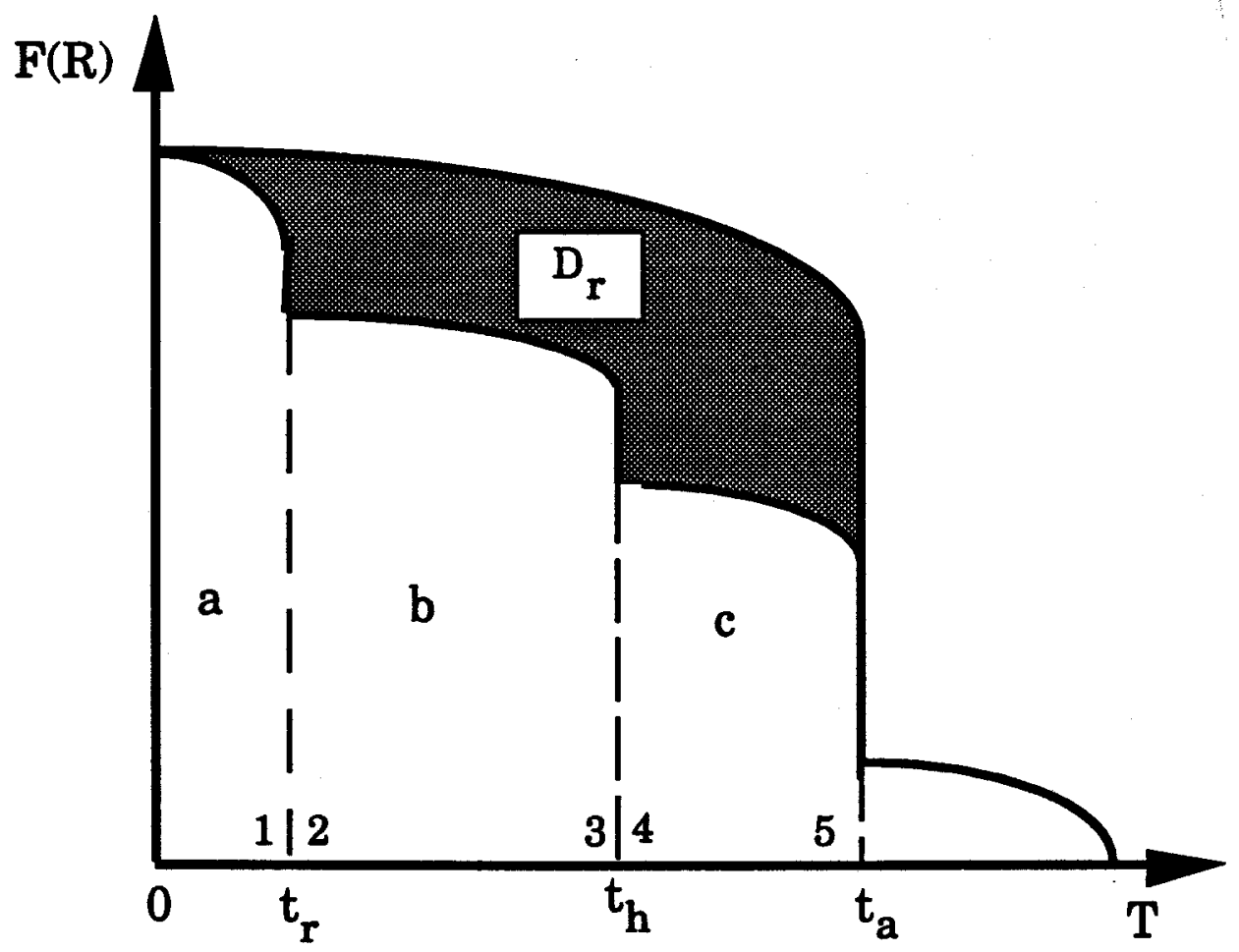

Figure 4.2: Area Risk Curve with Rapid Start and Hot Reserve Units.

Where,

$t_{\mathrm{r}}=$ time to start rapid start units,

$t_{h}=$ time to start hot reserve units into service,

$t_{a}=$ lead time of conventional thermal units,

$\mathrm{D}_{\mathbf{r}}=$ Decreased risk ( shaded area ).

It can be seen by comparing the two curves shown in Figures 4.1 and 4.2 , that the inclusion of stand-by units decreases the total risk to a new value depending on the capacity of the rapid start and hot reserve units. The total risk decreases by $D_{r}$ as shown by the shaded area in Figure 4.2 . 


\subsection{Computing Technique}

The GSOSR and the system operating state probabilities for the entire lead time can be calculated using the following relations :

$$
\begin{aligned}
& \operatorname{GSOSR}_{e q}=R_{a}+R_{b}+R_{c} \\
& \mathrm{GSOSR}_{\mathrm{eq}}=\mathrm{GSOSR}_{1}+\left(\mathrm{GSOSR}_{3}-\mathrm{GSOSR}_{2}\right)+\left(\mathrm{GSOSR}_{5}-\mathrm{GSOSR}_{4}\right) \\
& R_{\mathrm{a}}=\left(\mathrm{P}_{\mathrm{em1} 1}+\mathrm{P}_{\mathrm{ex1}}\right) \text {, } \\
& R_{\mathrm{b}}=\left(P_{\mathrm{em} 3}+P_{\mathrm{ex} 3}\right)-\left(P_{\mathrm{em} 2}+P_{\mathrm{ex} 2}\right), \\
& R_{c}=\left(P_{e m 5}+P_{e x 5}\right)-\left(P_{e m 4}+P_{e x 4}\right), \\
& \text { GSOSR }_{e q}=\left(P_{e m 1}+P_{e x 1}\right)+\left(P_{e m 3}+P_{e x 3}\right)-\left(P_{e m 2}+P_{e x 2}\right)+ \\
& \left(P_{e m 51}+P_{e x 5}\right)-\left(P_{e m 4}+P_{e x 4}\right) \text {, } \\
& =\left(P_{\mathrm{em} 1}+\mathrm{P}_{\mathrm{em} 3}-\mathrm{P}_{\mathrm{em} 2}+\mathrm{P}_{\mathrm{em} 5}-\mathrm{P}_{\mathrm{em} 4}\right)+ \\
& \left(P_{e x 1}+P_{e x 3}-P_{e x 2}+P_{e x 5}-P_{e x 4}\right) \text {, } \\
& =\mathrm{P}_{\text {emeq }}+\mathrm{P}_{\text {exeq }} \\
& \mathrm{P}_{\mathrm{emeq}}=\left(\mathrm{P}_{\mathrm{em} 1}+\mathrm{P}_{\mathrm{em} 3}-\mathrm{P}_{\mathrm{em} 2}+\mathrm{P}_{\mathrm{em} 5}-\mathrm{P}_{\mathrm{em} 4}\right) \text {, } \\
& P_{\text {exeq }}=\left(P_{e x 1}+P_{e x 3}-P_{e x 2}+P_{e x 5}-P_{e x 4}\right) .
\end{aligned}
$$


Where,

GSOSR $_{1}, \mathrm{P}_{\mathrm{em} 1}$ and $\mathrm{P}_{\mathrm{ex} 1}$ : Risk level and probabilities of the emergency and extreme emergency states, calculated at on-line capacity alone for the time period $\left(0, t_{r}\right)$.

GSOSR $_{2}, \mathrm{P}_{\mathrm{em} 2}$ and $\mathrm{P}_{\mathrm{ex} 2}$ : Risk level and probabilities of the emergency and extreme emergency states, calculated at on-line capacity + rapid start capacity at $\left(0, t_{r}\right)$.

GSOSR $_{3}, \mathrm{P}_{\mathrm{em} 3}$ and $\mathrm{P}_{\mathrm{ex} 3}$ : Risk level and probabilities of the emergency and extreme emergency states, calculated at on-line capacity + rapid start capacity at $\left(0, t_{h}\right)$.

GSOSR $_{4}, \mathrm{P}_{\mathrm{em} 4}$ and $\mathrm{P}_{\mathrm{ex} 4}$ : Risk level and probabilities of the emergency and extreme emergency states, calculated at on-line capacity + rapid start capacity + hot reserve capacity at $\left(0, t_{h}\right)$.

GSOSR $_{5}, P_{\text {em5 }}$ and $P_{\text {ex5 }}$ : Risk level and probabilities of the emergency and extreme emergency states, calculated at on-line capacity + rapid start capacity + hot reserve capacity at $\left(0, t_{a}\right)$.

$\mathrm{GSOSR}_{\text {eq }}$ : The equivalent generating system operating state risk for the entire lead time when stand-by units are included.

$\mathrm{P}_{\mathrm{emeq}}$ :The equivalent probability of the emergency state, 
$P_{\text {exeq }}$ : The equivalent probability of the extreme emergency state.

$P_{\text {neq }}$ and $P_{\text {aeq }}$ are defined using Equations 4.7 and 4.8:

$$
\begin{aligned}
& T_{r}=1-P_{n}-P_{a}, \\
& D_{r}=T_{r}-G S O S R_{e q}, \\
& P_{\text {neq }}=P_{n}\left(1+D_{r}\right)+T_{r} * D_{r} \text {, } \\
& P_{a e q}=P_{a}\left(1+D_{r}\right), \\
& \operatorname{GSOSR}_{\mathrm{eq}}=1-\mathrm{P}_{\mathrm{neq}}-\mathrm{P}_{\mathrm{aeq}} \text {, }
\end{aligned}
$$

and

$$
P_{n e q}+P_{a e q}+P_{e m e q}+P_{\text {exeq }}=1
$$

Where,

$\mathrm{D}_{\mathbf{r}}$ : Decreased risk due to including stand-by units,

$T_{\mathbf{r}}$ : Total risk for the same number of committed units and the same load level without considering stand-by units.

$P_{n}$ : Probability of the normal state for the same number of committed units, but without stand-by units, 
$P_{a}$ : Probability of the alert state for the same number of committed units, but without stand-by units.

$P_{n e q}:$ The equivalent probability of the normal state,

$P_{\text {aeq }}$ : The equivalent probability of the alert state,

Unit commitment is usually done such that the GSOSR $_{\text {eq }}$ is less than or equal to a specified value. Once the number of committed units is determined, the total risk $\left(T_{r}\right)$ is calculated for the same number of committed units but without stand-by units. Using the total risk and GSOSR $_{\text {eq }}$, the decreased risk and therefore $P_{\text {neq }}$ and $P_{\text {aeq }}$ can be calculated.

\subsection{Modeling of Stand-by Units}

\subsubsection{Rapid-start Unit Model}

One of the most important requirements necessary for a meaningful quantitative reliability evaluation of a power system is correct modeling of its basic components. In the basic two-state and three-state models presented in Section 2.2, it was assumed that once a unit is called for service, the probability of failing to come into operation is zero. This is not generally true in the case of rapid start units and therefore the possibility of their failure to start must be included. A convenient and realistic model [31] for a rapid start unit is shown in Figure 4.3. The various transition rates can be obtained from the number of transitions between the states divided by the residence times in the various states [32]. 


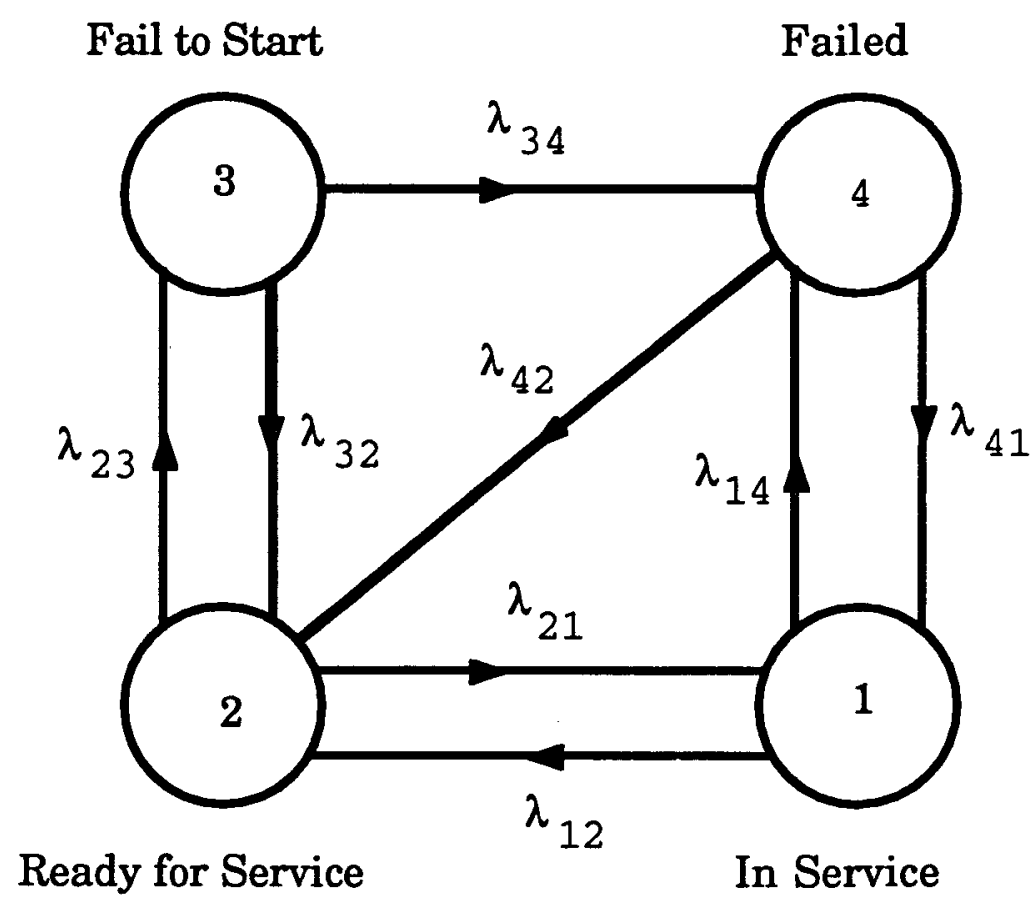

Figure 4.3: Four-state Model for Rapid Start Units.

The time dependent state probabilities can be evaluated using a matrix multiplication [3] technique. This is a very powerful method for obtaining time dependent probabilities of complex systems and is illustrated using the model of Figure 4.3.

$$
[P(t)]=[P(0)][P]^{n}
$$

Where,

$[P(t)]=$ vector of state probabilities at time $t$,

$[P(0)]=$ vector of initial probabilities,

[P] = stochastic transitional probability matrix,

n = number of time steps used in the discretisation process. 
The stochastic transitional probability matrix for the model shown in Figure 4.3 is as follows:

$$
[\mathrm{P}]=\left[\begin{array}{cccc}
1-\left(\lambda_{12}+\lambda_{14}\right) \Delta \mathrm{t} & \lambda_{12} \Delta \mathrm{t} & 0 & \lambda_{14} \Delta \mathrm{t} \\
\lambda_{21} \Delta \mathrm{t} & 1-\left(\lambda_{21}+\lambda_{23}\right) \Delta \mathrm{t} & \lambda_{23^{\Delta t}} & 0 \\
0 & \lambda_{32} \Delta \mathrm{t} & 1-\left(\lambda_{32}+\lambda_{34}\right) \Delta \mathrm{t} & \lambda_{34} \Delta \mathrm{t} \\
\lambda_{41^{\Delta t}} & \lambda_{42} \Delta \mathrm{t} & 0 & 1-\left(\lambda_{41}+\lambda_{42}\right) \Delta \mathrm{t}
\end{array}\right]
$$

The number of matrix multiplications, i.e. $n$, is equal to the time of interest $t$ divided by the time interval $\Delta t$. During the start-up time, a unit is not able to take up load and resides in the ready-for-service state with a probability of unity. However, at the time when the unit may contribute to the system generation, the unit can be in either state 1 or state 4 . Therefore, the vector of initial probabilities is:

$$
[P(0)]=\left[\begin{array}{llll}
P_{1}(0) & 0 & 0 & P_{4}(0)
\end{array}\right]
$$

where,

$$
\begin{aligned}
& \mathrm{P}_{4}(0)=\frac{\text { total number of times unit failed to take up load }}{\text { total number of starts }} \\
& \mathrm{P}_{4}(0)=\frac{\lambda_{23}}{\lambda_{23}+\lambda_{21}}
\end{aligned}
$$

and

$$
P_{1}(0)=1-P_{4}(0)
$$

The probability of finding the unit on outage given that a demand has 
occurred is given by [3] :

$$
\begin{aligned}
& \mathrm{P}(\text { down })=\frac{\mathrm{P}_{3}(\mathrm{t})+\mathrm{P}_{4}(\mathrm{t})}{\mathrm{P}_{1}(\mathrm{t})+\mathrm{P}_{3}(\mathrm{t})+\mathrm{P}_{4}(\mathrm{t})}, \\
& \mathrm{P}(\mathrm{UP})=1-\mathrm{P}(\text { down }) .
\end{aligned}
$$

\subsubsection{Hot Reserve Unit Model}

When a thermal unit is removed from service it can be left in one of two states; hot reserve and cold reserve. In a cold reserve state, both the unit and its boiler are completely shut down [3]. In a hot reserve state, however, the boiler is maintained in a banked state. If some generation is required when a thermal unit is hot, it can be brought into service relatively quickly compare to the time required when the unit is in the cold state. A hot reserve unit can be represented by a five-state model [3] as shown in Figure 4.4.

The time dependent state probabilities can be calculated using the same technique described in the previous section. The vector of initial probabilities is [3]:

$$
[P(0)]=\left[\begin{array}{lllll}
P_{1}(0) & 0 & 0 & P_{4}(0) & 0
\end{array}\right]
$$

where,

$$
\mathrm{P}_{4}(0)=\frac{\lambda_{23}}{\lambda_{23}+\lambda_{21}},
$$




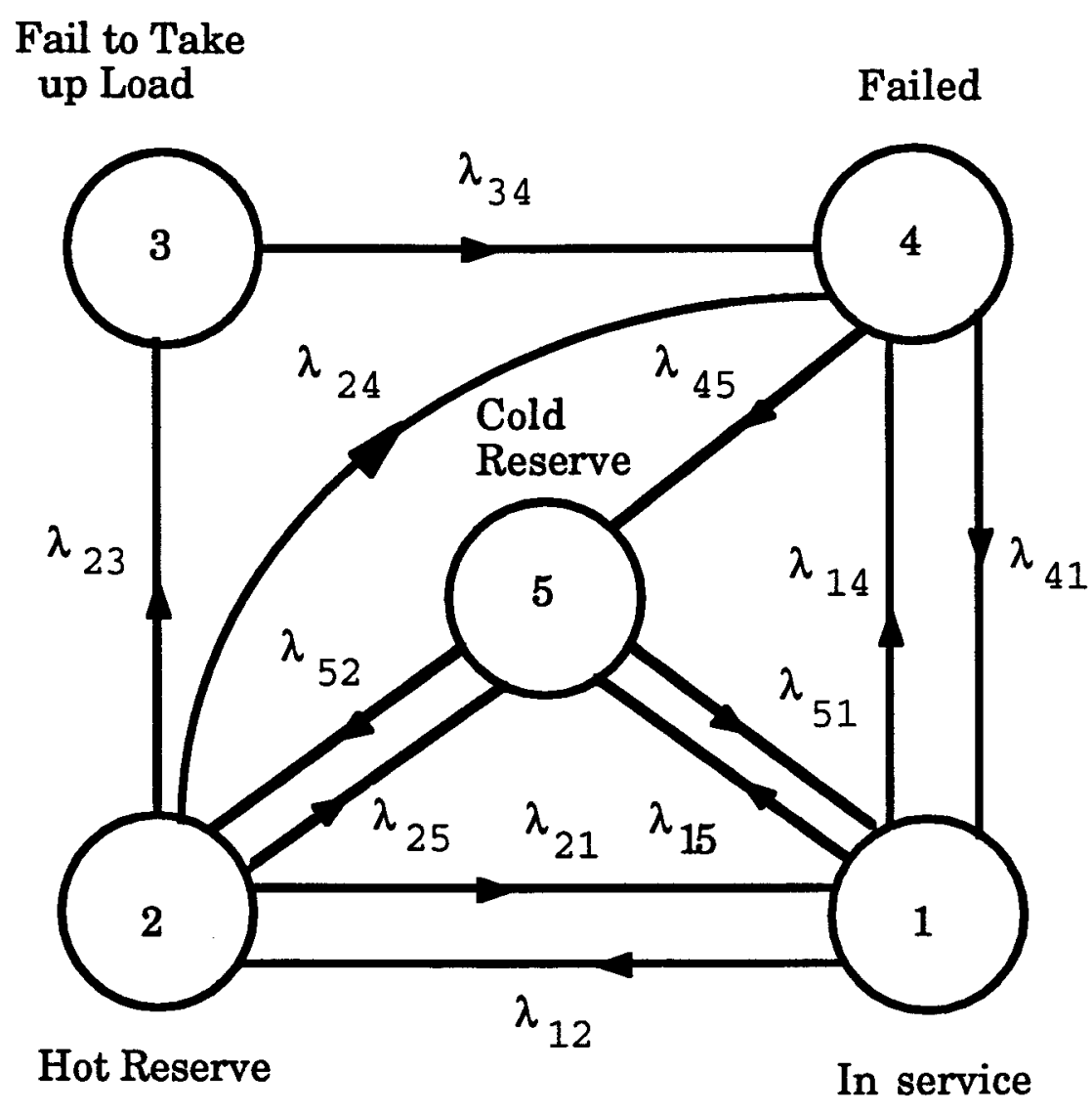

Figure 4.4: Five-state Model for Hot Reserve Units.

and,

$$
P_{1}(0)=1-P_{4}(0)
$$

The probability of finding the unit on outage given that a demand has occurred is given by [3]:

$$
\begin{aligned}
& P(\text { down })=\frac{P_{3}(t)+P_{4}(t)+P_{5}(t)}{P_{1}(t)+P_{3}(t)+P_{4}(t)+P_{5}(t)}, \\
& P(U P)=1-P(\text { down }) .
\end{aligned}
$$




\subsection{Application to the RBTS}

The concepts developed in the previous sections have been applied to the RBTS. A computer program has been written using the computation technique explained in Section 4.3 to include rapid start and hot reserve units in an operating study. The on-line operating capacity was taken from the priority unit loading order list shown in Table 2.1. The system has a number of gas turbine units with a capacity of $10 \mathrm{MW}$ [28]. In addition to the rapid start units, it is assumed that the system has a number of $40 \mathrm{MW}$ hot reserve units. The rapid start and hot reserve units can be brought into service after 10 minutes and 1 hour respectively. The corresponding transition rates of the rapid start and hot reserve units are shown in Table 4.1.

Table 4.1: Transition Rates( occ/hr) of the Rapid Start and Hot Reserve Unit.

\begin{tabular}{|c|c|c|c|c|}
\hline \multicolumn{3}{|c|}{$\begin{array}{l}\text { Rapid Start Unit : } \\
\text { Capacity = } 10 \mathrm{MW}\end{array}$} & \multicolumn{2}{|c|}{ Lead Time $=10$ minutes } \\
\hline$\lambda_{11}=0$ & $\lambda_{12}=0.005$ & $\lambda_{13}=0$ & \multicolumn{2}{|l|}{$\lambda_{14}=0.03$} \\
\hline$\lambda_{21}=0.0033$ & $\lambda_{22}=0$ & $\lambda_{23}=0.0008$ & \multicolumn{2}{|l|}{$\lambda_{24}=0$} \\
\hline$\lambda_{31}=0$ & $\lambda_{32}=0$ & $\lambda_{33}=0$ & \multicolumn{2}{|l|}{$\lambda_{34}=0.025$} \\
\hline$\lambda_{41}=0.015$ & $\lambda_{42}=0.025$ & $\lambda_{43}=0$ & \multicolumn{2}{|l|}{$\lambda_{44}=0$} \\
\hline \multicolumn{3}{|c|}{$\begin{array}{l}\text { Hot Reserve Unit : } \\
\text { Capacity }=40 \mathrm{MW}\end{array}$} & \multicolumn{2}{|c|}{ Lead Time $=60$ minutes } \\
\hline$\lambda_{11}=0$ & $\lambda_{12}=0.024$ & $\lambda_{13}=0$ & $\lambda_{14}=0.008$ & $\lambda_{15}=0$ \\
\hline$\lambda_{21}=0.02$ & $\lambda_{22}=0$ & $\lambda_{23}=0.00002$ & $\lambda_{24}=0$ & $\lambda_{25}=0$ \\
\hline$\lambda_{31}=0$ & $\lambda_{32}=0$ & $\lambda_{33}=0$ & $\lambda_{34}=0.03$ & $\lambda_{35}=0$ \\
\hline$\lambda_{41}=0.035$ & $\lambda_{42}=0$ & $\lambda_{43}=0$ & $\lambda_{44}=0$ & $\lambda_{45}=0.025$ \\
\hline$\lambda_{51}=0.003$ & $\lambda_{52}=0.0025$ & $\lambda_{53}=0$ & $\lambda_{54}=0$ & $\lambda_{55}=0$ \\
\hline
\end{tabular}




\subsubsection{Unit Commitment for a Specified GSOSR}

The required number of committed generating units and the system operating state probabilities at selected load levels are shown in Tables 4.2 and 4.3. The system load varies from $40 \%$ to $100 \%$ of the $185 \mathrm{MW}$ peak load. The acceptable risk level is assumed to be 0.001 . A unit commitment is considered to be acceptable if the GSOSR is less than or equal to this value. The system lead time is assumed to be 4 hours. The results presented in Table 4.2 are for a system with no stand-by units. Table 4.3 shows the results assuming that the system has one rapid start and one hot reserve unit in addition to those units in Table 2.1.

It can be seen from Tables 4.2 and 4.3 that by adding rapid start and hot reserve units to the system the required number of committed units either decreases or remains unchanged. The number of committed units for a load level of $74 \mathrm{MW}$ decreases from 4 to 3 . The unit commitment remains unchanged for some of the load levels even with one rapid start and one hot reserve unit. The corresponding system risk, however, decreases due to the availability of the stand-by units.

The effect of including rapid start and hot reserve units on the number of committed units for different load levels is shown in Figure 4.5. The system peak load is varied from $50 \mathrm{MW}$ to $185 \mathrm{MW}$ in steps of $5 \mathrm{MW}$. It can be seen by comparing the base case with no stand-by units to the cases with stand-by equipment that the number of committed units generally decreases. 
Table 4.2: Unit Commitment and System Operating State Probabilities Without Stand-by Units.

\begin{tabular}{|c|c|c|c|c|c|c|}
\hline $\begin{array}{c}\text { Load } \\
\text { Level } \\
{[\mathrm{MW}]}\end{array}$ & $\begin{array}{c}\text { No.of } \\
\text { units }\end{array}$ & Normal & Alert & Emergency & $\begin{array}{c}\text { Extreme } \\
\text { Emergency }\end{array}$ & GSOSR \\
\hline 74 & 4 & 0.99371256 & 0.00627470 & 0 & 0.00001274 & 0.00001274 \\
\hline 92.5 & 5 & 0.99316449 & 0.00682051 & 0 & 0.00001500 & 0.00001500 \\
\hline 111 & 5 & 0.99099006 & 0.00898001 & 0 & 0.00002993 & 0.00002993 \\
\hline 129.5 & 6 & 0.98872753 & 0.01122701 & 0 & 0.00004547 & 0.00004547 \\
\hline 148 & 7 & 0.98692163 & 0.01302049 & 0 & 0.00005788 & 0.00005788 \\
\hline 166.5 & 8 & 0.98584007 & 0.01409461 & 0 & 0.00006532 & 0.00006532 \\
\hline 185 & 9 & 0.98475970 & 0.01516754 & 0 & 0.00007276 & 0.00007276 \\
\hline
\end{tabular}

Table 4.3: Unit Commitment and System Operating State Probabilities Including one Rapid Start and one Hot Reserve Unit.

\begin{tabular}{|c|c|c|c|c|c|c|}
\hline $\begin{array}{c}\text { Load } \\
\text { Level } \\
\text { [MW] }\end{array}$ & $\begin{array}{c}\text { No.of } \\
\text { units }\end{array}$ & Normal & Alert & Emergency & $\begin{array}{c}\text { Extreme } \\
\text { Emergency }\end{array}$ & GSOSR \\
\hline 74 & 3 & 0.00000917 & 0.99901211 & 0 & 0.00097872 & 0.00097872 \\
\hline 92.5 & 5 & 0.99317809 & 0.00682060 & 0 & 0.00000131 & 0.00000131 \\
\hline 111 & 5 & 0.99101710 & 0.00898026 & 0 & 0.00000264 & 0.00000264 \\
\hline 129.5 & 5 & 0.00004237 & 0.99932049 & 0 & 0.00063715 & 0.00063715 \\
\hline 148 & 6 & 0.00004243 & 0.99931926 & 0 & 0.00063831 & 0.00063831 \\
\hline 166.5 & 8 & 0.98589958 & 0.01409546 & 0 & 0.00000496 & 0.00000496 \\
\hline 185 & 9 & 0.98482582 & 0.01516856 & 0 & 0.00000563 & 0.00000563 \\
\hline
\end{tabular}

4.5.2. Unit Commitment for a Specified GSOSR and a Specified Normal State Probability

The operating objective might be to operate the system within an acceptable level of normal state probability in addition to satisfying a specified risk. Once a specified risk is satisfied, the number of committed 


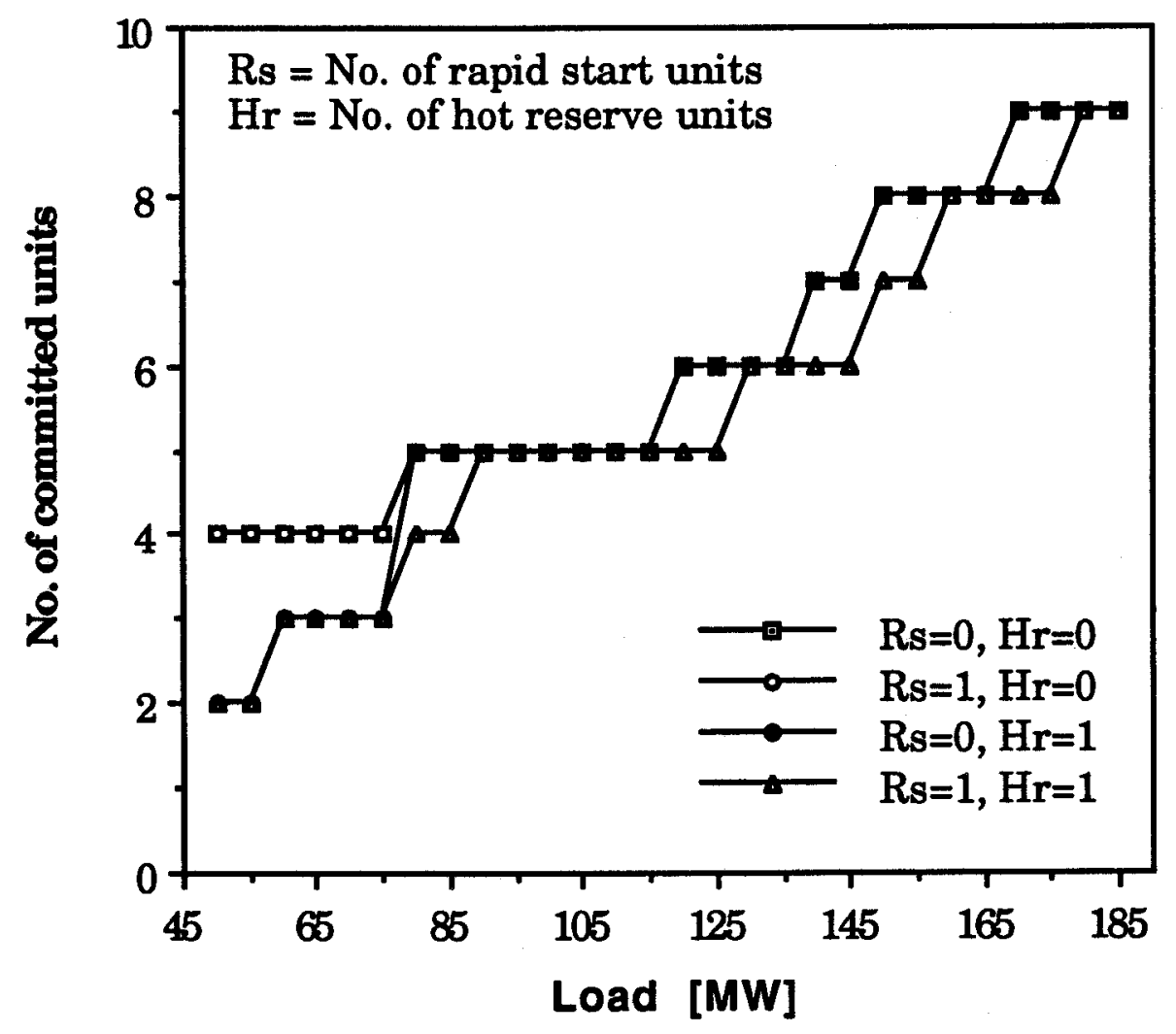

Figure 4.5: Variation of Number of Required Units Versus Load.

units may or may not satisfy the acceptable normal state probability. Table 4.4 shows the results when the system including one rapid start and one hot reserve unit is required to satisfy both criteria. A unit commitment is considered to be acceptable if the GSOSR is less than or equal to 0.001 and the probability of the normal state is greater than or equal to 0.9 . In comparison with the results shown in Table 4.3 , it can be seen that the number of committed units increases when the system is required to meet an acceptable normal state probability in addition to a specified risk. For this system, the number of committed units for different load levels are the same as those shown in Table 4.2 in which the system has no stand-by units and a single specified risk of 0.001 is utilized. 
Table 4.4: Unit Commitment and System Operating State Probabilities Including one Rapid Start and one Hot Reserve Unit with Multiple Criteria.

\begin{tabular}{|c|c|c|c|c|c|c|}
\hline $\begin{array}{c}\text { Load } \\
\text { Level } \\
\text { [MW] }\end{array}$ & $\begin{array}{c}\text { No.of } \\
\text { units }\end{array}$ & Normal & Alert & Emergency & $\begin{array}{c}\text { Extreme } \\
\text { Emergency }\end{array}$ & GSOSR \\
\hline 74 & 4 & 0.99372411 & 0.00627477 & 0 & 0.00000111 & 0.00000111 \\
\hline 92.5 & 5 & 0.99317809 & 0.00682060 & 0 & 0.00000131 & 0.00000131 \\
\hline 111 & 5 & 0.99101710 & 0.00898026 & 0 & 0.00000264 & 0.00000264 \\
\hline 129.5 & 6 & 0.98877054 & 0.01122750 & 0 & 0.00000197 & 0.00000197 \\
\hline 148 & 7 & 0.98697452 & 0.01302119 & 0 & 0.00000430 & 0.00000430 \\
\hline 166.5 & 8 & 0.98589958 & 0.01409546 & 0 & 0.00000496 & 0.00000496 \\
\hline 185 & 9 & 0.98482582 & 0.01516856 & 0 & 0.00000563 & 0.00000563 \\
\hline
\end{tabular}

From the results presented in Tables $4.2,4.3$ and 4.4 it can be concluded that a system will have a high probability of being in the normal state if it has sufficient spinning reserve to tolerate any single unit outage. Stand-by units do not increase this ability, since they are in a stand-by mode at the decision time of $t=0$. In other words, the system operator should curtail some part of the load for at least a time period equal to the lead time of the rapid start units, if certain on-line capacity is removed from service and the system is operating initially in the alert state.

\subsubsection{Effect on the System Operating States and GSOSR of Increasing the Number of Rapid Start and Hot Reserve Units}

In order to realize the effect of including stand-by units on the probabilities of the different system operating states another study was conducted in which the system peak load was fixed at $130 \mathrm{MW}$ for an operating capacity of $180 \mathrm{MW}$ ( 6 units). The effect on the system operating 
state probabilities and GSOSR of different amounts of rapid start and hot reserve generation at a total lead time of 4 hours is shown in Tables 4.5 and 4.6, and graphically presented in Figures 4.6 to 4.8 .

It can be seen that for a given number of rapid start units, the probabilities of the normal and alert states increases when one hot reserve unit is added. The probability of the normal state with only one rapid start unit is 0.98872753 and by adding one hot reserve unit this probability increases to 0.98876850 . When the second and the third hot reserve units are added it changes to 0.98876963 and 0.98876966 respectively. The GSOSR and the probabilities associated with the emergency and extreme emergency states decrease by increasing the number of rapid start and hot reserve units.

For this system it is evident that the probabilities of the system operating states and GSOSR are unaffected by having more than two hot reserve units. The reason for this is that by adding two hot reserve units, the area between $t_{h}$ and $t_{a}$ in the area risk curve becomes very small and decreasing this area by including more than two hot reserve units is negligible.

Looking at Figures 4.6, 4.7 and 4.8 for the case with no hot reserve units it can be seen that the indices are almost unaffected by adding more than seven rapid start units. The reason for this is that the area between $t_{r}$ and $t_{a}$ becomes negligible compare to the area between $t=0$ to $t_{r}$ in the area risk curve when more than seven rapid start units are included. 
Table 4.5: System Operating State Probabilities for Different Numbers of Rapid Start Units and no Hot Reserve Units.

\begin{tabular}{|c|c|c|c|c|c|c|}
\hline \multirow[b]{2}{*}{ NRS } & \multirow[b]{2}{*}{ NHR } & \multicolumn{4}{|c|}{ Probability of } & \multirow[b]{2}{*}{ GSOSR } \\
\hline & & Normal & Alert & Emergency & $\begin{array}{c}\text { Extreme } \\
\text { Emergency }\end{array}$ & \\
\hline 1 & 0 & 0.98872753 & 0.01122701 & 0.00002255 & 0.00002292 & 0.00004547 \\
\hline 2 & 0 & 0.98874407 & 0.01122719 & 0.00001163 & 0.00001711 & 0.00002874 \\
\hline 3 & 0 & 0.98875260 & 0.01122729 & 0.00001060 & 0.00000951 & 0.00002011 \\
\hline 4 & 0 & 0.98876038 & 0.01122738 & 0.00000784 & 0.00000440 & 0.00001224 \\
\hline 5 & 0 & 0.98876613 & 0.01122745 & 0.00000457 & 0.00000185 & 0.00000642 \\
\hline 6 & 0 & 0.98876949 & 0.01122748 & 0.00000227 & 0.00000076 & 0.00000303 \\
\hline 7 & 0 & 0.98877116 & 0.01122750 & 0.00000101 & 0.00000033 & 0.00000134 \\
\hline 8 & 0 & 0.98877190 & 0.01122751 & 0.00000042 & 0.00000017 & 0.00000059 \\
\hline 9 & 0 & 0.98877221 & 0.01122751 & 0.00000017 & 0.00000011 & 0.00000028 \\
\hline
\end{tabular}

NRS $=$ Number of Rapid Start units

NHR = Number of Hot Reserve units

Table 4.6: System Operating State Probabilities for Different Numbers of Rapid Start Units and one Hot Reserve Unit.

\begin{tabular}{|c|c|c|c|c|c|c|}
\hline \multirow[b]{2}{*}{ NRS } & \multirow[b]{2}{*}{ NHR } & \multicolumn{4}{|c|}{ Probability of } & \multirow[b]{2}{*}{ GSOSR } \\
\hline & & Normal & Alert & Emergency & $\begin{array}{c}\text { Extreme } \\
\text { Emergency }\end{array}$ & \\
\hline 1 & 1 & 0.98876850 & 0.01122747 & 0.00000206 & 0.00000197 & 0.00000403 \\
\hline 2 & 1 & 0.98877008 & 0.01122749 & 0.00000093 & 0.00000150 & 0.00000243 \\
\hline 3 & 1 & 0.98877079 & 0.01122750 & 0.00000092 & 0.00000080 & 0.00000171 \\
\hline 4 & 1 & 0.98877149 & 0.01122751 & 0.00000063 & 0.00000037 & 0.00000100 \\
\hline 5 & 1 & 0.98877197 & 0.01122751 & 0.00000033 & 0.00000019 & 0.00000051 \\
\hline 6 & 1 & 0.98877223 & 0.01122751 & 0.00000014 & 0.00000012 & 0.00000026 \\
\hline 7 & 1 & 0.98877234 & 0.01122752 & 0.00000006 & 0.00000009 & 0.00000015 \\
\hline 8 & 1 & 0.98877238 & 0.01122752 & 0.00000002 & 0.00000008 & 0.00000010 \\
\hline 9 & 1 & 0.98877240 & 0.01122752 & 0.00000001 & 0.00000008 & 0.00000009 \\
\hline
\end{tabular}



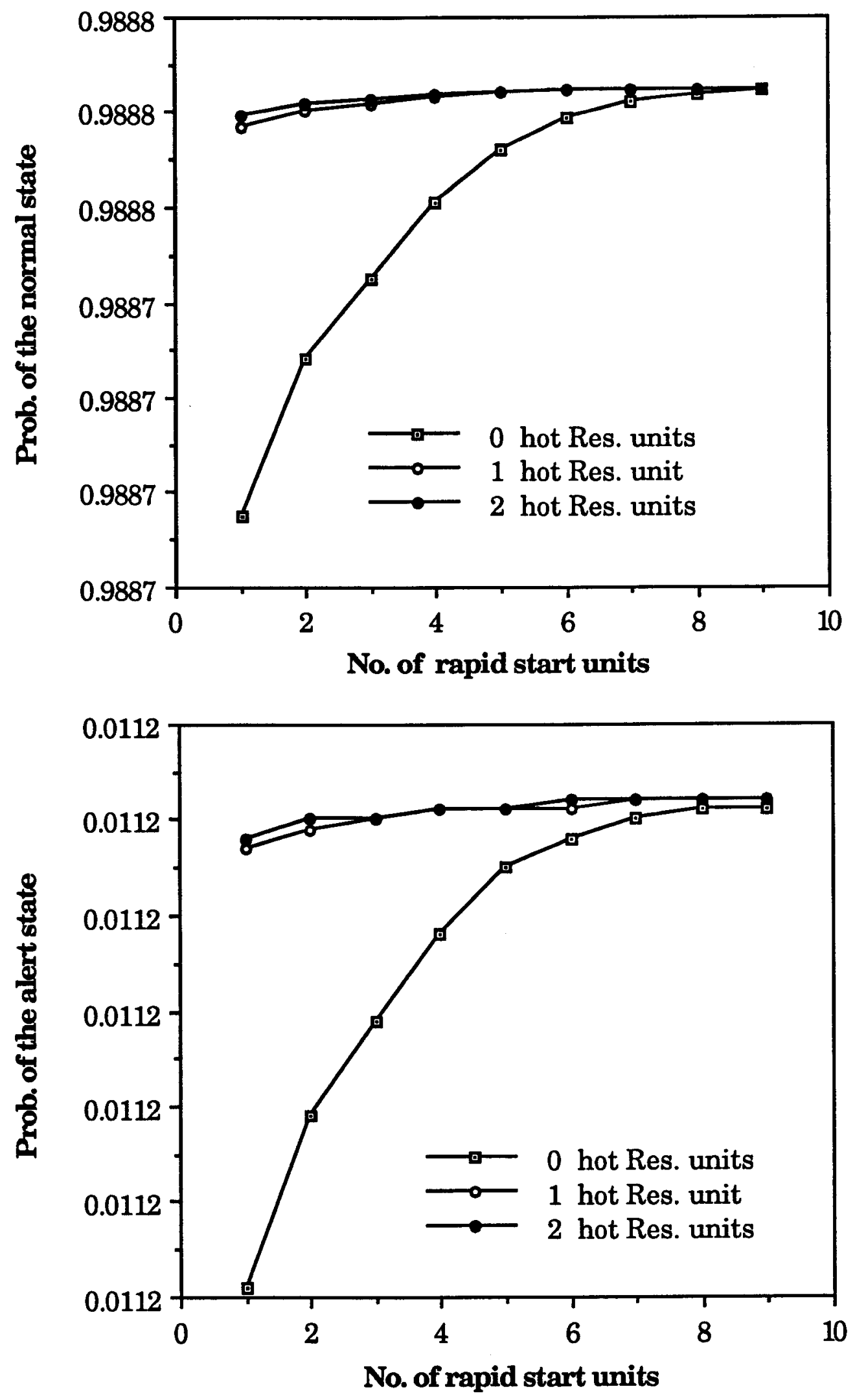

Figure 4.6: Probabilities of the Normal and Alert States. 

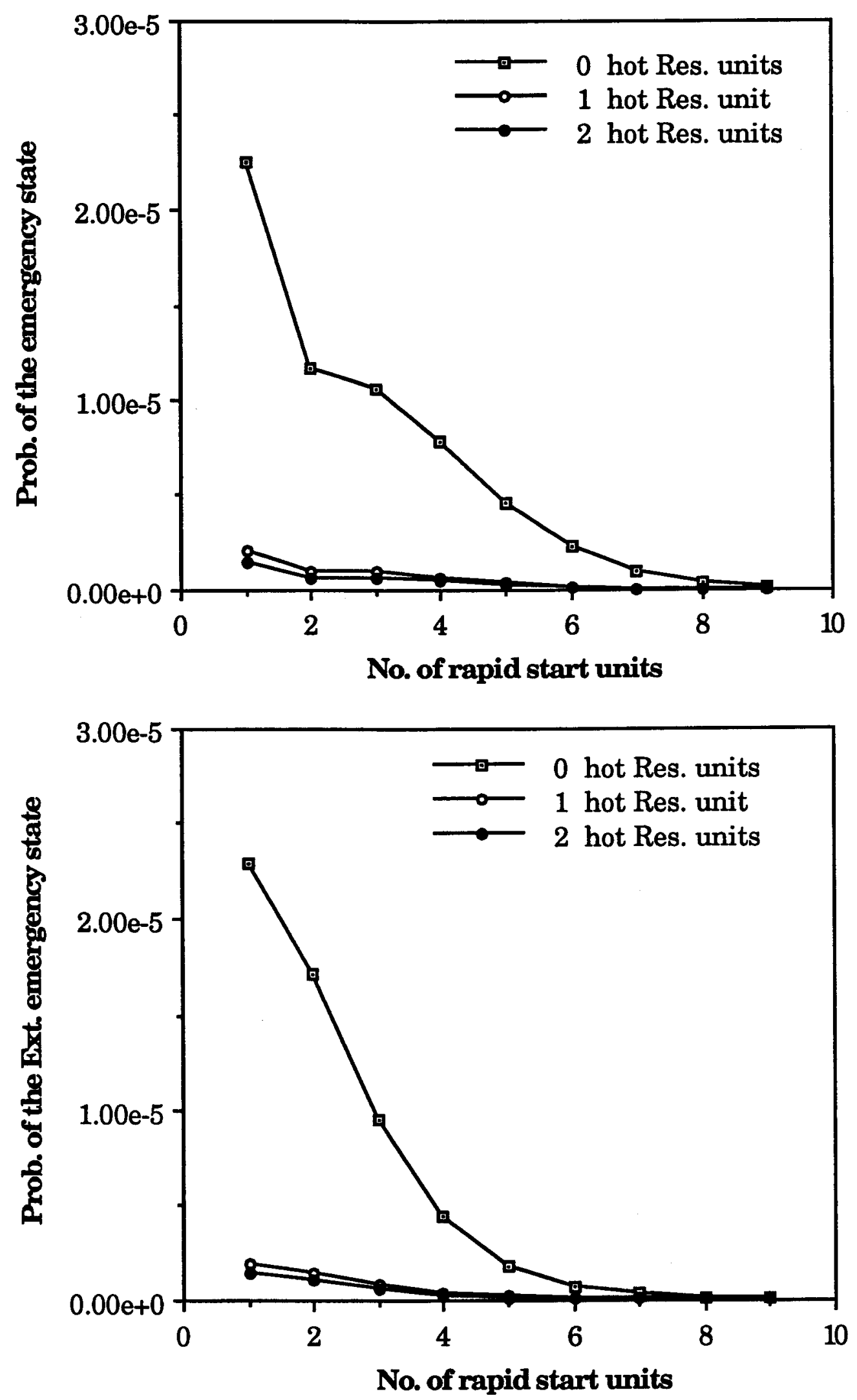

Figure 4.7: Probabilities of the Emergency and Extreme Emergency States. 


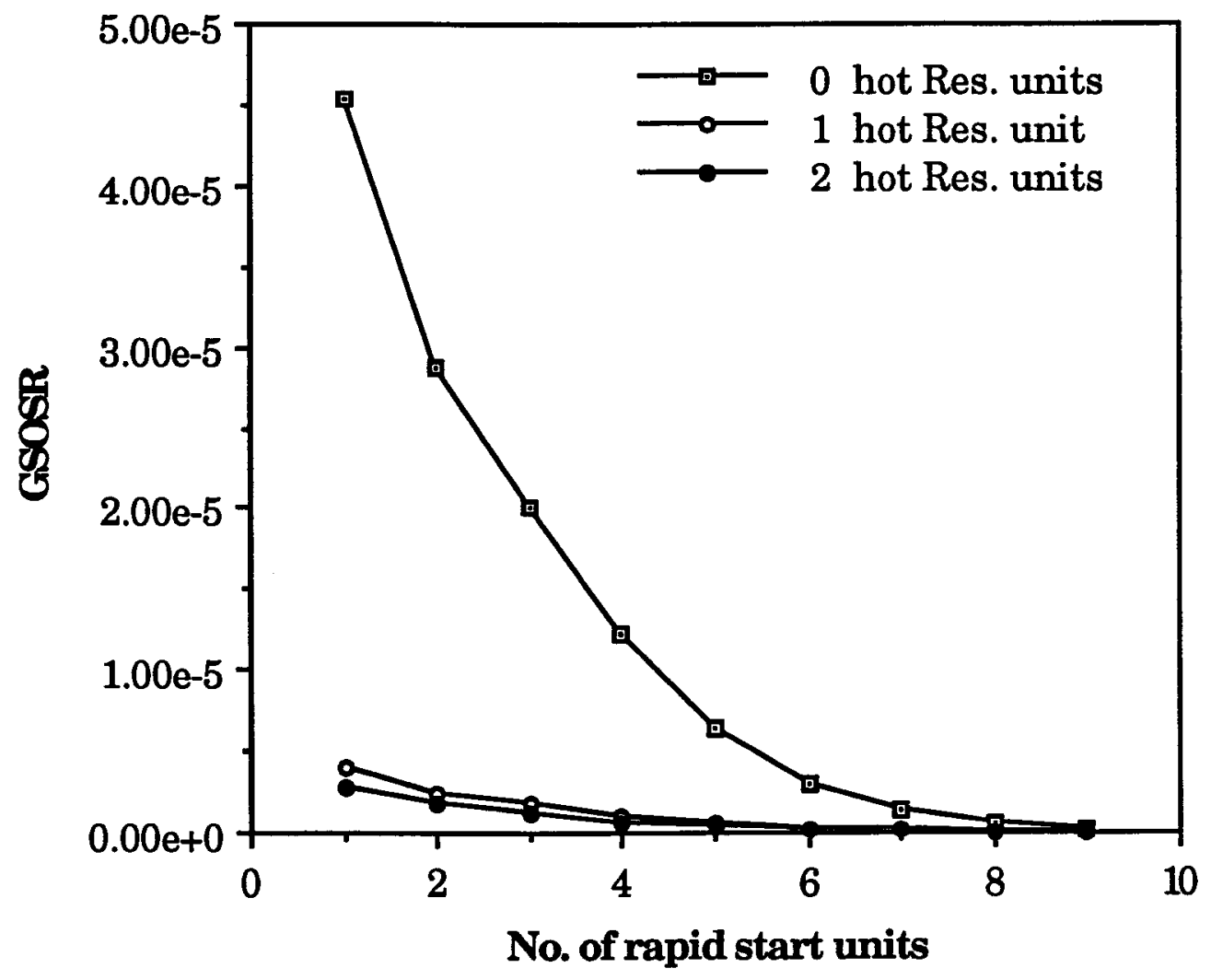

Figure 4.8: Variation of GSOSR with Number of Rapid Start Units.

\subsection{Postponable Outages}

When a unit is removed from service due to equipment failure, it can be either removed immediately or the removal postponed for a certain limited period of time. The conventional definition of a forced outage includes both sudden and deferrable or non-sudden unit removal from service [33]. The concept of both sudden and deferred unit removal from service does not pose any difficulty in a planning study but causes some problems when considering operating reserve evaluation. In practice, many of the failures that occur can be tolerated for a short period of time and the removal of the unit for repair can be postponed [3]. In these cases, the unit may still be capable of production if it is considered necessary to the 
system. This is obviously not true for all unit failures as some failures require immediate unit removal.

\subsubsection{Model and Evaluation Technique for Postponable Outages}

In the conventional two-state generating unit model described in Section 2.2, it is assumed that once a unit is declared failed it is not available for production. The two-state model has been modified [33] to include postponable outages as shown in Figure 4.9.

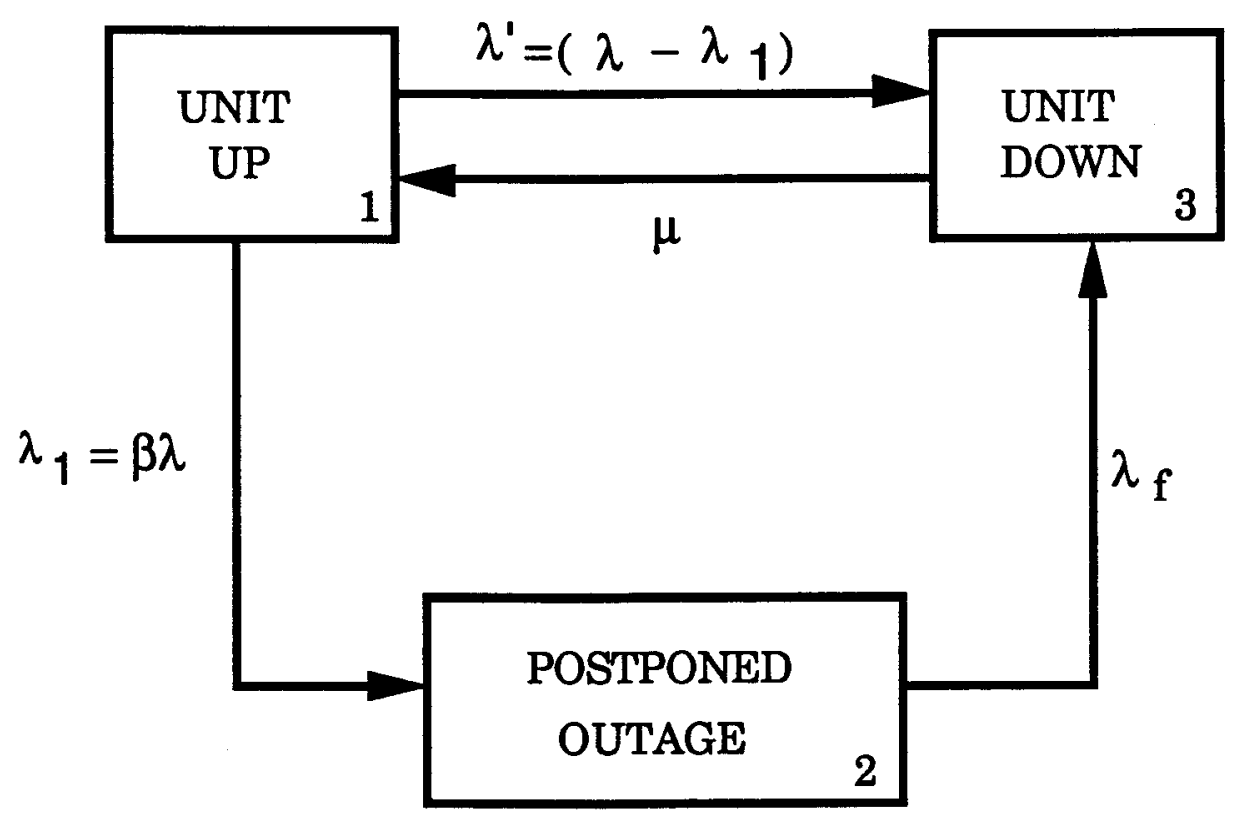

Figure 4.9: Postponable Outage Model.

Where,

$\lambda_{1}=$ Rate of outages that can be postponed,

$\lambda^{\prime}=$ Rate of outages that can not be postponed, 
$\lambda=$ Total failure rate $=\lambda^{\prime}+\lambda_{1}$,

$\lambda_{\mathrm{f}}=$ Rate at which postponed outages are forced into the

'Failed and Removed from service' state, $\beta=$ Proportion of $\lambda$ that can be postponed $=\frac{\lambda_{1}}{\lambda}$.

The time dependent state probabilities can be calculated using a set of simultaneous differential equations .

$$
\left[\begin{array}{lll}
\mathrm{P}_{1}^{\prime}(\mathrm{t}) & \mathrm{P}_{2}^{\prime}(\mathrm{t}) & \mathrm{P}_{3}^{\prime}(\mathrm{t})
\end{array}\right]=\left[\begin{array}{lll}
\mathrm{P}_{1}(\mathrm{t}) & \mathrm{P}_{2}(\mathrm{t}) & \mathrm{P}_{3}(\mathrm{t})
\end{array}\right]\left[\begin{array}{ccc}
-\left(\lambda^{\prime}+\lambda_{1}\right) & \lambda_{1} & \lambda^{\prime} \\
0 & -\lambda_{\mathrm{f}} & \lambda_{\mathrm{f}} \\
\mu & 0 & -\mu
\end{array}\right]
$$

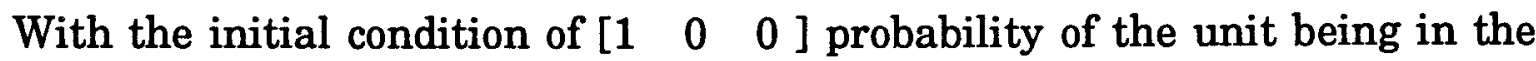
down state is :

$$
\mathrm{P}(\text { down })=\frac{\lambda^{\prime} \lambda_{\mathrm{f}}+\lambda_{1} \lambda_{\mathrm{f}}}{\alpha \gamma}+\frac{\lambda^{\prime} \lambda_{\mathrm{f}}+\lambda_{1} \lambda_{\mathrm{f}}-\alpha \lambda^{\prime}}{\alpha(\alpha-\gamma)} \mathrm{e}^{-\alpha \mathrm{t}}-\frac{\lambda^{\prime} \lambda_{\mathrm{f}}+\lambda_{1} \lambda_{\mathrm{f}}-\gamma \lambda^{\prime}}{\gamma(\alpha-\gamma)} \mathrm{e}^{-\gamma \mathrm{t}} .
$$

Where,

$$
\begin{aligned}
& \alpha=1 / 2\left[\left(\lambda^{\prime}+\lambda_{1}+\mu+\lambda_{f}\right)-\left\{\left(\lambda^{\prime}+\lambda_{1}+\mu+\lambda_{f}\right)^{2}-4\left(\mu \lambda_{f}+\lambda^{\prime} \lambda_{f}+\lambda_{1} \lambda_{f}+\lambda_{1} \mu\right)\right\}^{1 / 2}\right], \\
& \gamma=1 / 2\left[\left(\lambda^{\prime}+\lambda_{1}+\mu+\lambda_{f}\right)-\left\{\left(\lambda^{\prime}+\lambda_{1}+\mu+\lambda_{f}\right)^{2}-4\left(\mu \lambda_{f}+\lambda^{\prime} \lambda_{f}+\lambda_{1} \lambda_{f}+\lambda_{1} \mu\right)\right\}^{1 / 2}\right] .
\end{aligned}
$$

If $\alpha t<<1$ and $\gamma t<<1$ then [3],

$$
P(\text { down }) \cong \lambda^{\prime} t=(\lambda-\beta \lambda) t \cong(1-\beta) \lambda t=\text { Modified O.R.R. }
$$


Since $\beta$ is between zero and 1, the modified O.R.R is less than the original O.R.R . $\beta=0$ corresponds to the usual two-state unit model and $\beta=1$ corresponds to the case where all forced outages can be postponed[33].

\subsubsection{Results for the RBTS}

In order to illustrate the evaluation of the GSOSR and the system operating state probabilities when some outages are postponed, the concepts have been applied to the RBTS . The RBTS has 4 thermal units, $2 * 40 \mathrm{MW}$, $1 * 20 \mathrm{MW}$ and $1 * 10 \mathrm{MW}$. The concept of outage postponability is usually applied to large units. In this system, it is assumed that the two $40 \mathrm{MW}$ thermal units can have some of their outages postponed with different values of $\beta$. These two $40 \mathrm{MW}$ units are the fourth and the fifth units, according to the priority loading order table.

The number of units required for a load level of $130 \mathrm{MW}$ and a specified GSOSR of 0.001 is shown in Table 4.7 for different values of $\beta$. The lead time for all generating units is assumed to be 4 hours. The system operating state probabilities are shown in Table 4.7, and are presented in Figures 4.10 to 4.12 . The required number of generating units is 6 and does not change as $\beta$ increases from 0 to 1 . It can be seen from the results that as $\beta$ increases, the probability of the normal state increases and the probabilities of the alert, the emergency and the extreme emergency states decrease. The GSOSR decreases as $\beta$ increases. 
Table 4.7: Unit Commitment and System Operating State Probabilities for Different Values of $\beta$.

\begin{tabular}{|c|c|c|c|c|c|c|}
\hline & \multirow{2}{*}{$\beta$} & \begin{tabular}{c} 
No.of \\
\cline { 5 - 7 }
\end{tabular} & Normal & Alert & Emergency & $\begin{array}{c}\text { Extreme } \\
\text { Emergency }\end{array}$ \\
\hline 0 & 6 & 0.98872753 & 0.01122701 & 0 & 0.00004547 & 0.00004547 \\
\hline 0.1 & 6 & 0.98927086 & 0.01068828 & 0 & 0.00004087 & 0.00004087 \\
\hline 0.2 & 6 & 0.98981434 & 0.01014925 & 0 & 0.00003641 & 0.00003641 \\
\hline 0.3 & 6 & 0.99035797 & 0.00960993 & 0 & 0.00003211 & 0.00003211 \\
\hline 0.4 & 6 & 0.99090175 & 0.00907030 & 0 & 0.00002795 & 0.00002795 \\
\hline 0.5 & 6 & 0.99144568 & 0.00853038 & 0 & 0.00002394 & 0.00002394 \\
\hline 0.6 & 6 & 0.99198975 & 0.00799017 & 0 & 0.00002008 & 0.00002008 \\
\hline 0.7 & 6 & 0.99253398 & 0.00744965 & 0 & 0.00001637 & 0.00001637 \\
\hline 0.8 & 6 & 0.99307836 & 0.00690884 & 0 & 0.00001281 & 0.00001281 \\
\hline 0.9 & 6 & 0.99362288 & 0.00636773 & 0 & 0.00000939 & 0.00000939 \\
\hline 1 & 6 & 0.99416756 & 0.00582632 & 0 & 0.00000612 & 0.00000612 \\
\hline
\end{tabular}

Table 4.8 shows the same indices when load forecast uncertainty is considered with a standard deviation of $4 \%$. The results are presented in Figures 4.10 to 4.12. It can be seen from Figures 4.10, 4.11 and 4.12 that for a given value of $\beta$ the incorporation of load forecast uncertainty causes the probability of the normal state to decrease and the probabilities of the alert and extreme emergency states to increase. 
Table 4.8: Unit Commitment and System Operating State Probabilities for Different Values of $\beta$ with Load Forecast Uncertainty.

\begin{tabular}{|c|c|c|c|c|c|c|}
\hline & \multirow{2}{*}{$\beta$} & No.of & Normal & Alert & Emergency & $\begin{array}{c}\text { Extreme } \\
\text { Emergency }\end{array}$ \\
\cline { 5 - 8 } & units & & & & 0 & \\
\hline 0 & 6 & 0.92277973 & 0.07672158 & 0 & 0.00049869 & 0.00049869 \\
\hline 0.1 & 6 & 0.92328682 & 0.07625519 & 0 & 0.00045800 & 0.00045800 \\
\hline 0.2 & 6 & 0.92379405 & 0.07578853 & 0 & 0.00041743 & 0.00041743 \\
\hline 0.3 & 6 & 0.92430142 & 0.07532160 & 0 & 0.00037699 & 0.00037699 \\
\hline 0.4 & 6 & 0.92480893 & 0.07485440 & 0 & 0.00033667 & 0.00033667 \\
\hline 0.5 & 6 & 0.92531658 & 0.07438693 & 0 & 0.00029649 & 0.00029649 \\
\hline 0.6 & 6 & 0.92582436 & 0.07391920 & 0 & 0.00025644 & 0.00025644 \\
\hline 0.7 & 6 & 0.92633229 & 0.07345120 & 0 & 0.00021651 & 0.00021651 \\
\hline 0.8 & 6 & 0.92684036 & 0.07298293 & 0 & 0.00017671 & 0.00017671 \\
\hline 0.9 & 6 & 0.92734856 & 0.07251440 & 0 & 0.00013704 & 0.00013704 \\
\hline 1 & 6 & 0.92785691 & 0.07204559 & 0 & 0.00009750 & 0.00009750 \\
\hline
\end{tabular}

\subsection{Summary}

The delay time associated with additional generating units is quite variable and dependent upon many factors. The most important, however, is the type of additional generation available. Operating reserve assessment including rapid start and hot reserve units is illustrated in this chapter. A matter of concern when dealing with rapid start units is the possibility of their failure to start. A state space model used for such units taking this possibility into account is also presented in this chapter. The effect of rapid start and hot reserve units on the required number of committed generating units and system operating state probabilities are illustrated. 

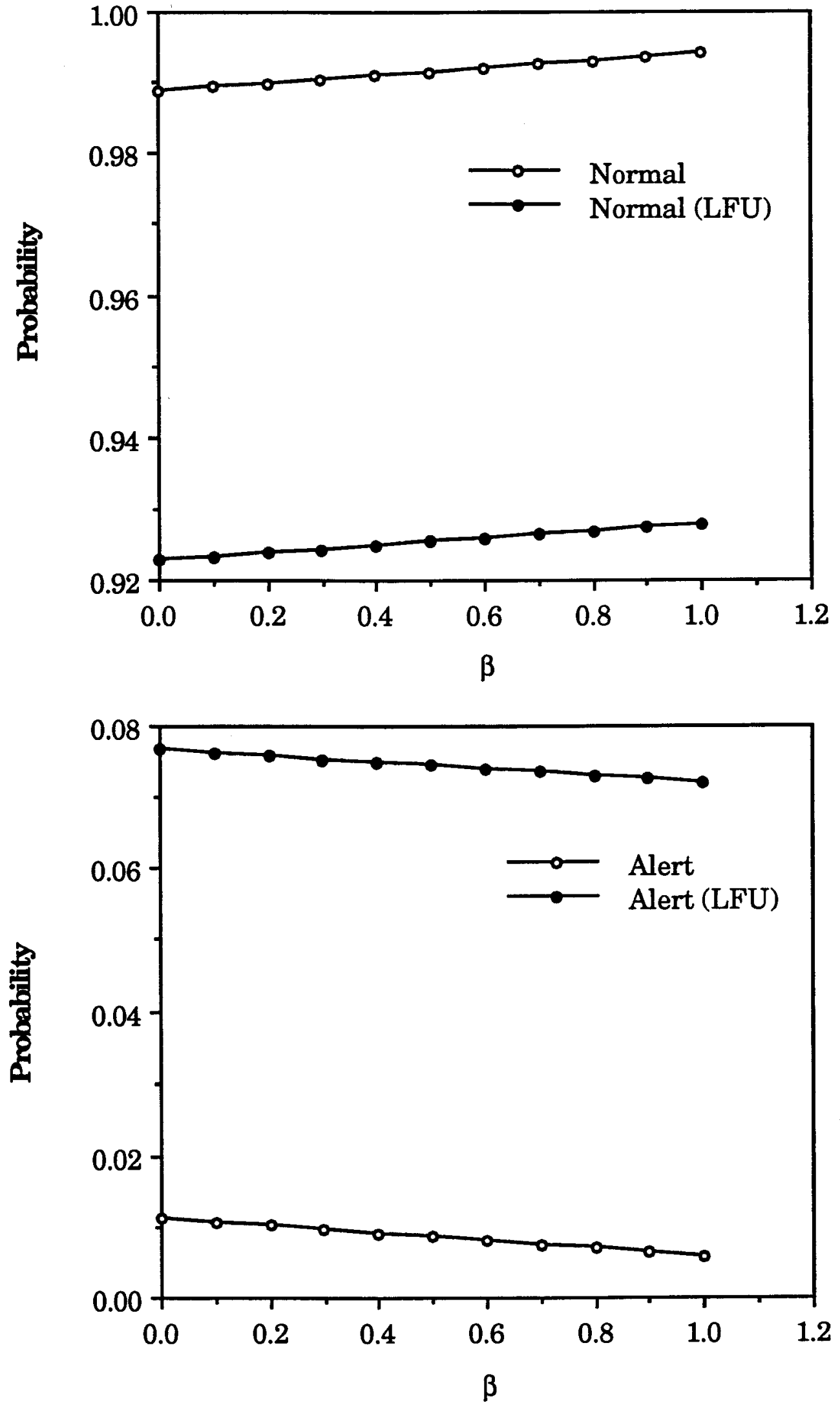

Figure 4.10: Variation of Normal and Alert State Probabilities with $\beta$. 

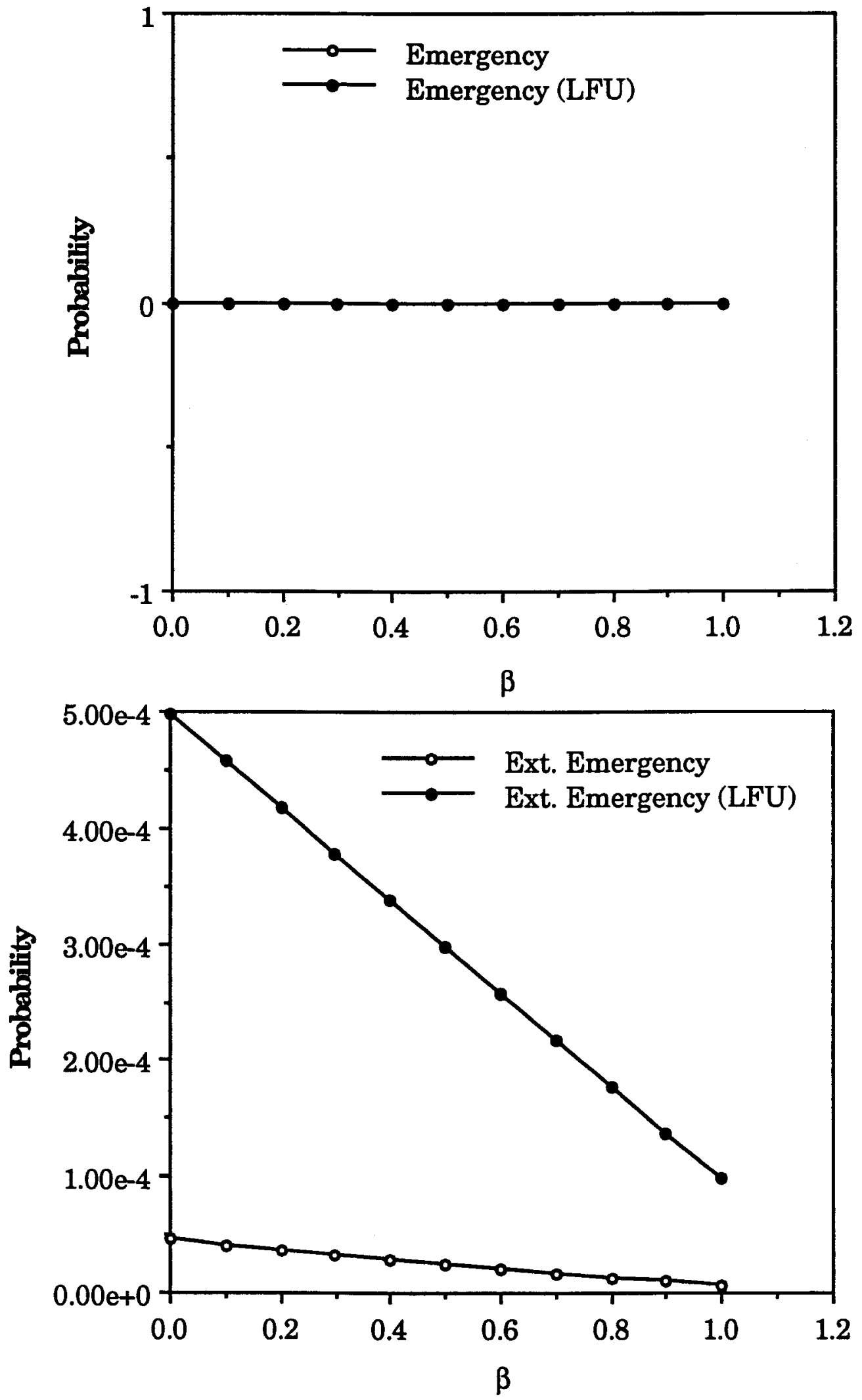

Figure 4.11: Variation of Emergency and Extreme emergency State Probabilities with $\beta$. 


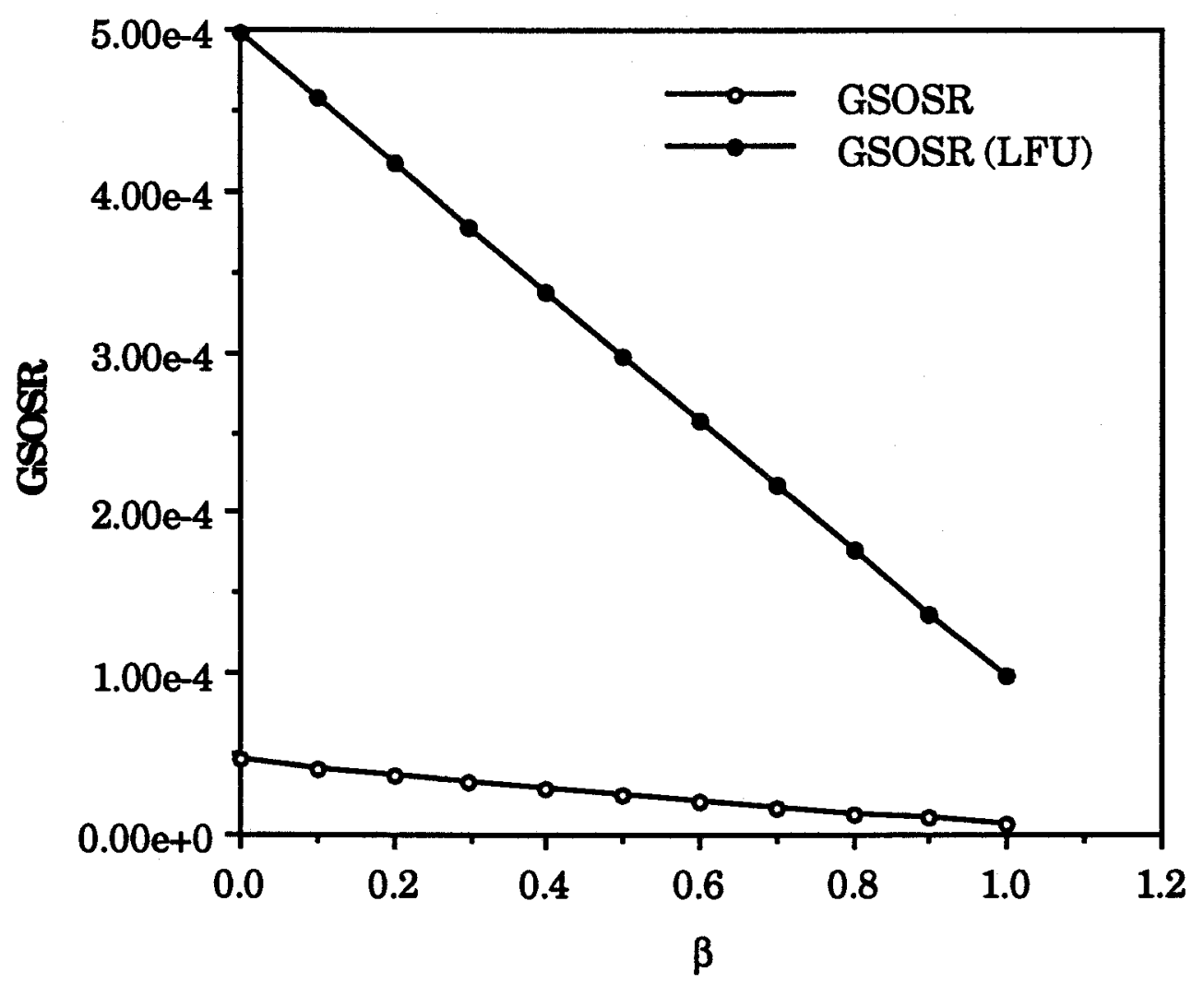

Figure 4.12: Variation of GSOSR with $\beta$.

The conventional definition of a forced outage includes both sudden unit removals from service and those for which the unit can continue for a relatively short period of time. The various degrees of urgency associated with forced unit removal from service is usually considered using postponability codes or classes of forced outages. The effects of various degrees of postponability on the system operating states and the GSOSR are discussed in this chapter.

The availability of stand-by units can alleviate the system risk. The system load could however be such that the specified risk can not be satisfied even after including all available rapid start and hot reserve units. In this case, some part of the system load could be curtailed to reduce the 
system risk. Consideration of interruptible load as a part of operating reserve is discussed in the next chapter. 


\section{OPERATING RESERVE ASSESSMENT CONSIDERING INTERRUPTIBLE LOADS}

\subsection{Introduction}

Adequate operating reserve is required in an electric power system in order to maintain a desired level of reliability through a given period of time. There is a wide range of available approaches to maintaining operating reserve. Operating reserve can be generally divided into two classes, unit reserve and system reserve [17]. Generating unit operating reserve may be in the form of synchronized and non-synchronized units such as rapid start or hot reserve units. Some utilities include system reserve in the form of interruptible loads in their operating reserve. Unit reserve was discussed in the previous chapters. It was found that, the availability of rapid start and hot reserve units can alleviate the system risk. Interruptible loads can also be used to perform a similar function.

In addition to generating capacity adjustments, some utilities have loads which can be curtailed within a specified period of time. This time which is called the interruptible load lead time, is the maximum allowable time within which the load should be curtailed. In order to keep the unit commitment risk within a specified value, it may be necessary to interrupt 
some portion of the load, at the time of peak load. It may also be necessary to curtail some load due to the sudden outage of one or more operating units [34]. It is usually assumed that, a utility has prior knowledge regarding the various loads that can be interrupted with minimum or no penalty. The magnitude of curtailable load and the corresponding time of interruption depend on the agreements between the utility and its consumers. The cost associated with interruption may be lower for some loads than that for other loads and consumers may be willing to have their loads interrupted if necessary, provided that there are economic benefits [34].

Units are usually committed such that a specified risk is satisfied for a given firm load. The total generating capacity in operation is usually greater than the firm load. Therefore, with this number of committed units, the system can carry additional load or additional interruptible load on top of its firm load without violating the specified risk [35]. The system may or may not operate at the normal state, however with this set of additional load/interruptible load, if it operates initially at this state when all the load is firm load.

The effect of interruptible loads can be incorporated in operating reserve assessment using the concept of area risk curves [34]. The technique and evaluation procedure are discussed in this chapter. The effects on the system risk and operating state probabilities of variation in the magnitude of interruptible loads and the corresponding lead times are also illustrated. 


\subsection{Evaluation Technique}

In a practical power system, generating units are committed for a specified time period during which additional generation can be made available. The lead time required before a generating unit can be put into service, depends on a number of factors including the unit type in question. The delay time associated with a thermal generating unit could be several hours [10]. Stand-by units can usually be made available in a relatively short time as compared to more conventional units. The system risk can be reduced by including stand-by units in the analysis as shown in Chapter 4. The system load could however be such that, the specified risk can still not be satisfied after including all the available stand-by units. The risk in this situation can be alleviated by curtailing some part of the load [35].

The effect of interruptible loads on the GSOSR and the system operating state probabilities can be illustrated using the area risk concept [34]. A typical area risk curve for a system with an interruptible load is shown in Figure 5.1 where,

$t_{i}=$ Time of load interruption,

$t_{\mathrm{a}}=$ Time required to bring additional unit into service,

$\mathrm{D}_{\mathbf{r}}=$ Decreased risk 


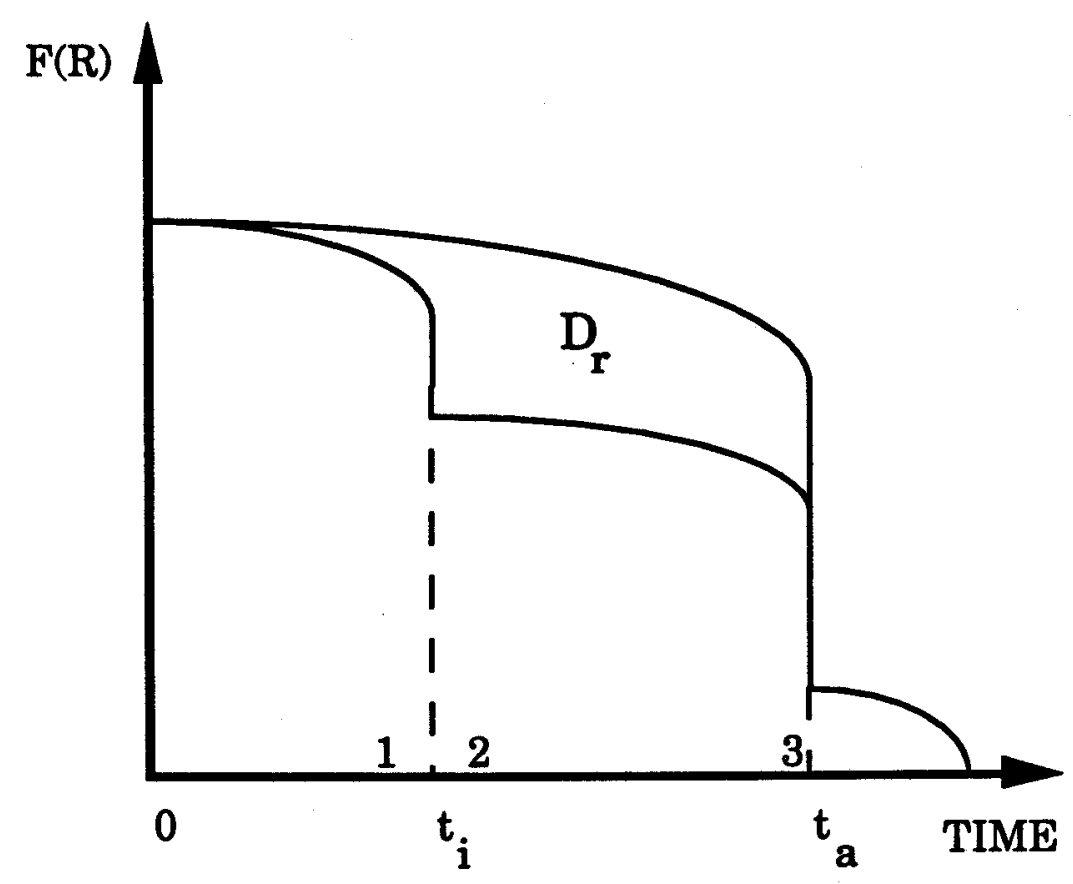

Figure 5.1: Area Risk Curve for Load Interruption.

The total load which is the summation of the firm load and the interruptible load is supplied in the period 0 to $t_{i}$. In the next period $t_{i}$ to $t_{a}$ only the firm load remains. At time $t_{i}$, LI MW of load is interrupted and the risk contribution decreases. The interruptible load is considered as a load variation for computational purposes [34]. Figure 5.2 shows the system load and total spinning capacity when interruptible load is considered as a load variation. The total spinning capacity is constant during the system lead time, 0 to $t_{a}$. The system load, however, changes from the total load in the period $0-t_{i}$ to the firm load in the period $t_{i}-t_{a}$. It is possible to represent interruptible load as an equivalent generating unit with zero failure rate [34]. Such a representation is shown in Figure 5.3. 


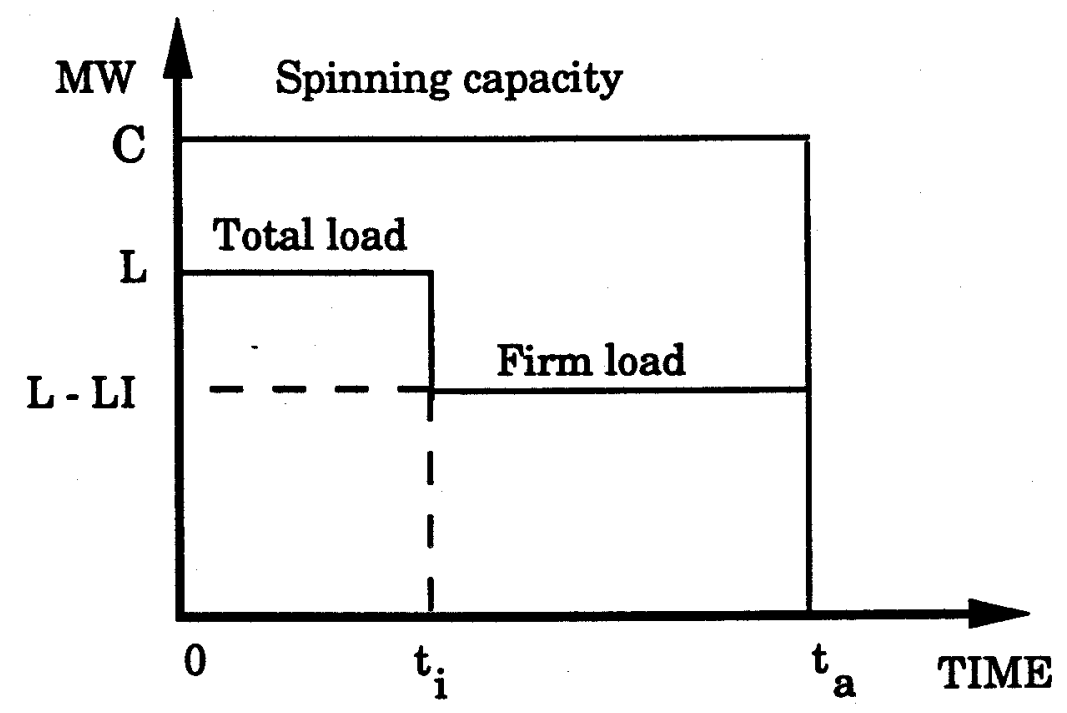

Figure 5.2: Equivalent Load Approach for Load Interruption.

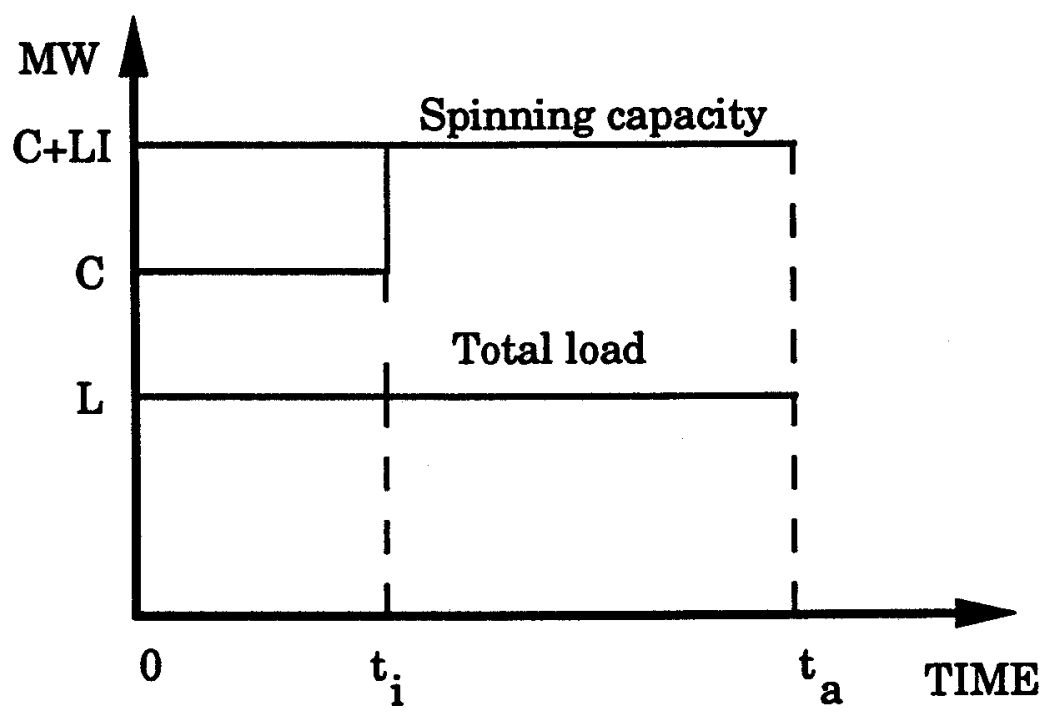

Figure 5.3: Equivalent Unit Approach for Load Interruption.

Where,

LI : Load interruption,

L : Total load. 
The system operating state probabilities and the GSOSR for the entire lead time can be evaluated using a similar technique to that utilized for rapid start and hot reserve units. The following equations can be used to evaluate the actual GSOSR and the system operating state probabilities:

$$
\begin{aligned}
& \text { GSOSR }_{\mathrm{eq}}=\text { GSOSR }_{1}+\text { GSOSR }_{3}-\text { GSOSR }_{2} \\
& \begin{aligned}
\text { GSOSR }_{\mathrm{eq}} & =\left(P_{\mathrm{em} 1}+P_{\mathrm{ex} 1}\right)+\left(P_{\mathrm{em} 3}+P_{\mathrm{ex} 3}\right)-\left(P_{\mathrm{em} 2}+P_{\mathrm{ex} 2}\right) \\
& =\left(P_{\mathrm{em} 1}+P_{\mathrm{em} 3}-P_{\mathrm{em} 2}\right)+\left(P_{\mathrm{ex} 1}+P_{\mathrm{ex} 3}-P_{\mathrm{ex} 2}\right)
\end{aligned} \\
& P_{\mathrm{emeq}}=\left(P_{\mathrm{em} 1}+P_{\mathrm{em} 3}-P_{\mathrm{em} 2}\right) \\
& P_{\text {exeq }}=\left(P_{\mathrm{ex} 1}+P_{\mathrm{ex} 3}-P_{\mathrm{ex} 2}\right)
\end{aligned}
$$

Where,

GSOSR $_{1}, \mathrm{P}_{\mathrm{em} 1}$ and $\mathrm{P}_{\mathrm{ex} 1}=$ Risk level and probabilities of the emergency and extreme emergency states, calculated at on-line capacity with total load at time period $\left(0, t_{i}\right)$.

GSOSR $_{2}, P_{\mathrm{em} 2}$ and $\mathrm{P}_{\mathrm{ex} 2}=$ Risk level and probabilities of the emergency and extreme emergency states, calculated at on-line capacity with firm load at time period $\left(0, t_{\mathbf{i}}\right)$.

GSOSR $_{3}, \mathrm{P}_{\mathrm{em} 3}$ and $\mathrm{P}_{\mathrm{ex} 3}=$ Risk level and probabilities of the emergency and extreme emergency states, calculated at on-line capacity with firm load at time period $\left(0, t_{a}\right)$. 
GSOSR $_{\text {eq }}=$ The equivalent generating system operating state risk for the entire lead time when interruptible load is included.

$P_{\text {emeq }}=$ The equivalent probability of the emergency state,

$P_{\text {exeq }}=$ The equivalent probability of the extreme emergency state.

Units are committed in such a way that the GSOSR eq $_{\text {should be less }}$ than or equal a specified GSOSR. Once the number of committed units is adopted, probability of the normal $\left(P_{n}\right)$ and the alert $\left(P_{a}\right)$ states are calculated for the same number of committed units, when the system load is the total load for the period 0 to $t_{a}$. Then, $P_{n e q}$ and $P_{a e q}$ are determined using Equations 5.6 and 5.7.

$$
\begin{aligned}
& T_{r}=1-P_{n}-P_{a} . \\
& D_{r}=T_{r}-G S O S R_{e q} . \\
& P_{n e q}=P_{n}\left(1+D_{r}\right)+T_{r} * D_{r} . \\
& P_{a e q}=P_{a}\left(1+D_{r}\right) . \\
& \text { GSOSR }_{e q}=1-P_{n e q}-P_{a e q} .
\end{aligned}
$$

Where,

$\mathrm{D}_{\mathrm{r}} \quad=$ Decreased risk due to including interruptible load,

$\mathrm{T}_{\mathbf{r}} \quad=$ Total risk $=\mathrm{D}_{\mathbf{r}}+$ GSOSR $_{\mathrm{eq}}$,

$P_{n e q}=$ The equivalent probability of the normal state,

$P_{\text {aeq }}=$ The equivalent probability of the alert state, 
$P_{n}=$ Probability of the normal state for the same number of committed units, the total load and without including interruptible load,

$\mathrm{P}_{\mathrm{a}} \quad=$ Probability of the alert state for the same number of committed units, the total load and without including interruptible load,

Total load = Firm load + Interruptible load

\subsection{Unit Commitment}

The number of generators to be committed for a particular load level are taken from a merit loading order table. In order to illustrate the effect of interruptible load on the GSOSR and the system operating state probabilities the concepts developed in the previous section were applied to the RBTS. It is assumed that the system has the ability to interrupt $10 \mathrm{MW}$ of its load within a time delay of 10 minutes.

The required number of generating units and the system operating state probabilities are shown in Table 5.1. The system peak load varies from $110 \mathrm{MW}$ to $185 \mathrm{MW}$ in steps of $5 \mathrm{MW}$ and the system lead time is assumed to be 4 hours. A unit commitment is acceptable if the GSOSR is less than or equal to 0.001 .

Table 5.2 shows the number of committed units for three different cases. Column 2, i.e. Case 1, shows the required number of committed units when the interruptible load is not included and a single specified 
GSOSR of 0.001 should be satisfied. In Case 2, the unit commitment criterion is the same as Case 1 , however the interruptible load is also included. In Case 3, the unit commitment is considered to be acceptable if the GSOSR is less than or equal to 0.001 and the normal state probability is greater than or equal to 0.9 . The effect of interruptible load is also considered in the last case.

Table 5.1: Unit Commitment and System Operating State Probabilities Considering Interruptible Load.

\begin{tabular}{|c|c|c|c|c|c|c|}
\hline $\begin{array}{l}\text { Load } \\
\text { Level } \\
\text { [MW] }\end{array}$ & $\begin{array}{c}\text { No.of } \\
\text { units }\end{array}$ & Normal & Alert & Emergency & $\begin{array}{c}\text { Extreme } \\
\text { Emergency }\end{array}$ & GSOSR \\
\hline 110 & 5 & 0.99099006 & 0.00898001 & 0.00001490 & 0.00001503 & 0.00002993 \\
\hline 115 & 5 & 0.99099006 & 0.00898001 & 0 & 0.00002993 & 0.00002993 \\
\hline 120 & 5 & 0.00004457 & 0.99964019 & 0.00028531 & 0.00002993 & 0.00031524 \\
\hline 125 & 5 & 0.00004457 & 0.99964019 & 0 & 0.00031524 & 0.00031524 \\
\hline 130 & 6 & 0.98872753 & 0.01122701 & 0.00003038 & 0.00001509 & 0.00004547 \\
\hline 135 & 6 & 0.98872753 & 0.01122701 & 0 & 0.00004547 & 0.00004547 \\
\hline 140 & 6 & 0.00004453 & 0.99962471 & 0.00028529 & 0.00004547 & 0.00033076 \\
\hline 145 & 6 & 0.00004453 & 0.99962471 & 0 & 0.00033076 & 0.00033076 \\
\hline 150 & 7 & 0.00004444 & 0.99961240 & 0.00029766 & 0.00004549 & 0.00034315 \\
\hline 155 & 7 & 0.00004444 & 0.99961240 & 0 & 0.00034315 & 0.00034315 \\
\hline 160 & 8 & 0.98585228 & 0.01409478 & 0.00003773 & 0.00001520 & 0.00005294 \\
\hline 165 & 8 & 0.98585228 & 0.01409478 & 0 & 0.00005294 & 0.00005294 \\
\hline 170 & 8 & 0.00004446 & 0.99960495 & 0.00029765 & 0.00005294 & 0.00035059 \\
\hline 175 & 8 & 0.00004446 & 0.99960495 & 0 & 0.00035059 & 0.00035059 \\
\hline 180 & 9 & 0.98477189 & 0.01516773 & 0.00004511 & 0.00001527 & 0.00006038 \\
\hline 185 & 9 & 0.98477189 & 0.01516773 & 0 & 0.00006038 & 0.00006038 \\
\hline
\end{tabular}

From the results shown in Table 5.2, it can be seen that the number of committed units for a load level of $120 \mathrm{MW}$ decreases from 6 to 5 in the second case by including the $10 \mathrm{MW}$ interruptible load. In Case 3, the 
system is required to meet an acceptable normal state probability in addition to a specified risk. Therefore, the sixth unit must be committed in addition to the 5 already committed to satisfy both criteria. In general, it can be concluded that the probability of the normal state does not improve considerably by including interruptible loads in the analysis. The number of committed units is not affected by including interruptible loads, if a high probability of the normal state is required.

Table 5.2: Number of Committed Units for Three Different Cases.

\begin{tabular}{|c|c|c|c|}
\hline \multirow{2}{*}{$\begin{array}{c}\text { Load } \\
{[\mathrm{MW}]}\end{array}$} & \multicolumn{3}{|c|}{ Number of committed units } \\
\cline { 2 - 4 } & Case 1 & Case 2 & Case 3 \\
\hline 110 & 5 & 5 & 5 \\
\hline 115 & 5 & 5 & 5 \\
\hline 120 & 6 & 5 & 6 \\
\hline 125 & 6 & 5 & 6 \\
\hline 130 & 6 & 6 & 6 \\
\hline 135 & 6 & 6 & 6 \\
\hline 140 & 7 & 6 & 7 \\
\hline 145 & 7 & 6 & 7 \\
\hline 150 & 8 & 7 & 8 \\
\hline 155 & 8 & 7 & 8 \\
\hline 160 & 8 & 8 & 8 \\
\hline 165 & 8 & 8 & 8 \\
\hline 170 & 9 & 8 & 9 \\
\hline 175 & 9 & 8 & 9 \\
\hline 180 & 9 & 9 & 9 \\
\hline 185 & 9 & 9 & 9 \\
\hline
\end{tabular}

Case 1 : GSOSR $\leq 0.001$

Case 2 : GSOSR 0.001

$10 \mathrm{MW}$ interruptible load

Case 3 : GSOSR $\leq 0.001, P_{\text {neq }} \geq 0.9 \quad 10 \mathrm{MW}$ interruptible load 


\subsection{Effect of Variation in the Available Interruptible Load}

The required operating reserve is a function of the available capacity, the system load and the system lead time. Some portion of this operating reserve can be in the form of interruptible load if available. The magnitude of the required spinning reserve decreases with an increase in the interruptible load. A generation system with a higher interruptible load than that of another generation system, therefore, requires less spinning reserve than the other system, provided that the system load and other parameters are identical in both systems.

Consider a load level of $160 \mathrm{MW}$ for the RBTS. The system lead time is assumed to be 4 hours and a specified GSOSR of 0.001 is selected. The interruptible load was changed from 0 to $35 \mathrm{MW}$ with a corresponding lead time of 10 minutes. Table 5.3 shows the number of committed units and the system operating state probabilities. It can be seen that the required spinning capacity decreases from $210 \mathrm{MW}$, i.e. 8 units, for no interruptible load to $190 \mathrm{MW}$, i.e. 7 units, when the system has the ability to interrupt 15 MW of load. It also decreases to $180 \mathrm{MW}$, i.e. 6 units, when an interruptible load of $25 \mathrm{MW}$ is available.

In order to illustrate the effect of interruptible load variation on the system operating state probabilities, consider a system load of $160 \mathrm{MW}$ with a fixed spinning capacity of $210 \mathrm{MW}$, i.e. 8 units. The results are shown in Table 5.4 and presented in Figures 5.4 to 5.6. It can be seen that the probabilities of the normal and the alert states increase very slighty but are virtually unchanged as the interruptible load increases. The probability of 
the extreme emergency state and the GSOSR decrease by increasing the interruptible load.

Table 5.3: Unit Commitment and System Operating State Probabilities for a Load Level of $160 \mathrm{MW}$ with Variable Interruptible Load Capability.

\begin{tabular}{|c|c|c|c|c|c|c|}
\hline $\begin{array}{c}\text { Int. } \\
\text { Load } \\
{[\mathrm{MW}]}\end{array}$ & $\begin{array}{c}\text { No.of } \\
\text { units }\end{array}$ & Normal & Alert & Emergency & $\begin{array}{c}\text { Extreme } \\
\text { Emergency }\end{array}$ & GSOSR \\
\hline 0 & 8 & 0.98584007 & 0.01409461 & 0.00001241 & 0.00005291 & 0.00006532 \\
\hline 5 & 8 & 0.98585228 & 0.01409478 & 0.00000002 & 0.00005291 & 0.00005294 \\
\hline 10 & 8 & 0.98585228 & 0.01409478 & 0.00003773 & 0.0000152 & 0.00005294 \\
\hline 15 & 7 & 0.00004455 & 0.99961228 & 0.00000001 & 0.00034315 & 0.00034316 \\
\hline 20 & 7 & 0.00004455 & 0.99961228 & 0.0000124 & 0.00033076 & 0.00034316 \\
\hline 25 & 6 & 0.00012124 & 0.99936162 & 0.00018638 & 0.00033076 & 0.00051714 \\
\hline 30 & 6 & 0.00012124 & 0.99936162 & 0.00018638 & 0.00033076 & 0.00051714 \\
\hline 35 & 6 & 0.00012124 & 0.99936162 & 0.00018638 & 0.00033076 & 0.00051714 \\
\hline
\end{tabular}

Table 5.4: System Operating State Probabilities for a Load Level of $160 \mathrm{MW}$ and Spinning Capacity of $210 \mathrm{MW}$ Considering Variable Interruptible Load Capability.

\begin{tabular}{|c|c|c|c|c|c|c|}
\hline $\begin{array}{c}\text { Int. } \\
\text { Load } \\
\text { [MW] }\end{array}$ & $\begin{array}{c}\text { No.of } \\
\text { units }\end{array}$ & Normal & Alert & Emergency & $\begin{array}{c}\text { Extreme } \\
\text { Emergency }\end{array}$ & GSOSR \\
\hline 0 & 8 & 0.98584007 & 0.01409461 & 0.00001241 & 0.00005291 & 0.00006532 \\
\hline 5 & 8 & 0.98585228 & 0.01409478 & 0.00000002 & 0.00005291 & 0.00005294 \\
\hline 10 & 8 & 0.98585228 & 0.01409478 & 0.00003773 & 0.00001520 & 0.00005294 \\
\hline 15 & 8 & 0.98588946 & 0.01409531 & 0.00000002 & 0.00001520 & 0.00001522 \\
\hline 20 & 8 & 0.98588946 & 0.01409531 & 0.00000009 & 0.00001513 & 0.00001522 \\
\hline 25 & 8 & 0.98588953 & 0.01409531 & 0.00000002 & 0.00001513 & 0.00001516 \\
\hline 30 & 8 & 0.98588953 & 0.01409531 & 0.00001494 & 0.00000021 & 0.00001516 \\
\hline 35 & 8 & 0.98590424 & 0.01409552 & 0.00000002 & 0.00000021 & 0.00000023 \\
\hline
\end{tabular}



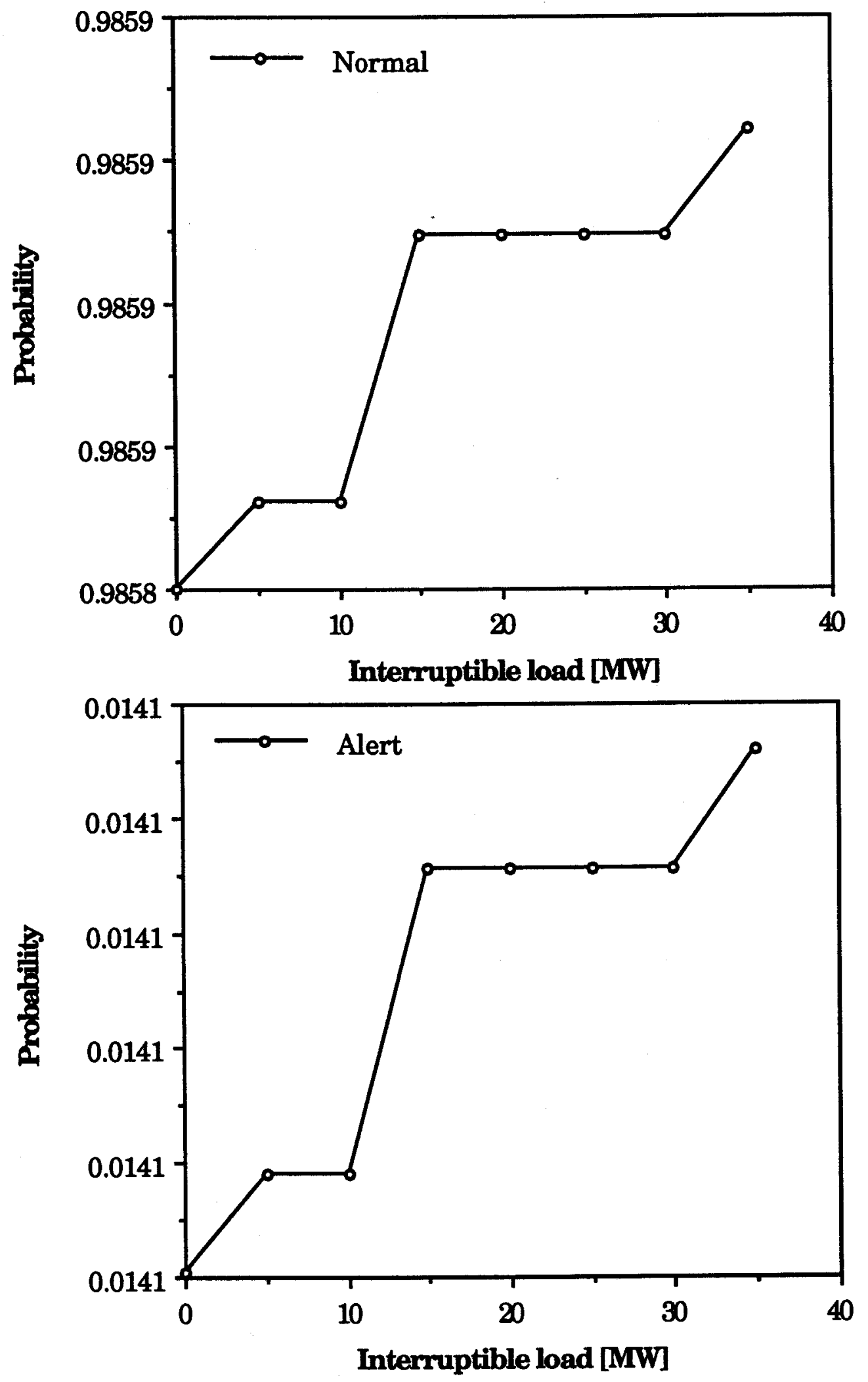

Figure 5.4: Probabilities of the Normal and Alert States with the Magnitude of Interruptible Load. 

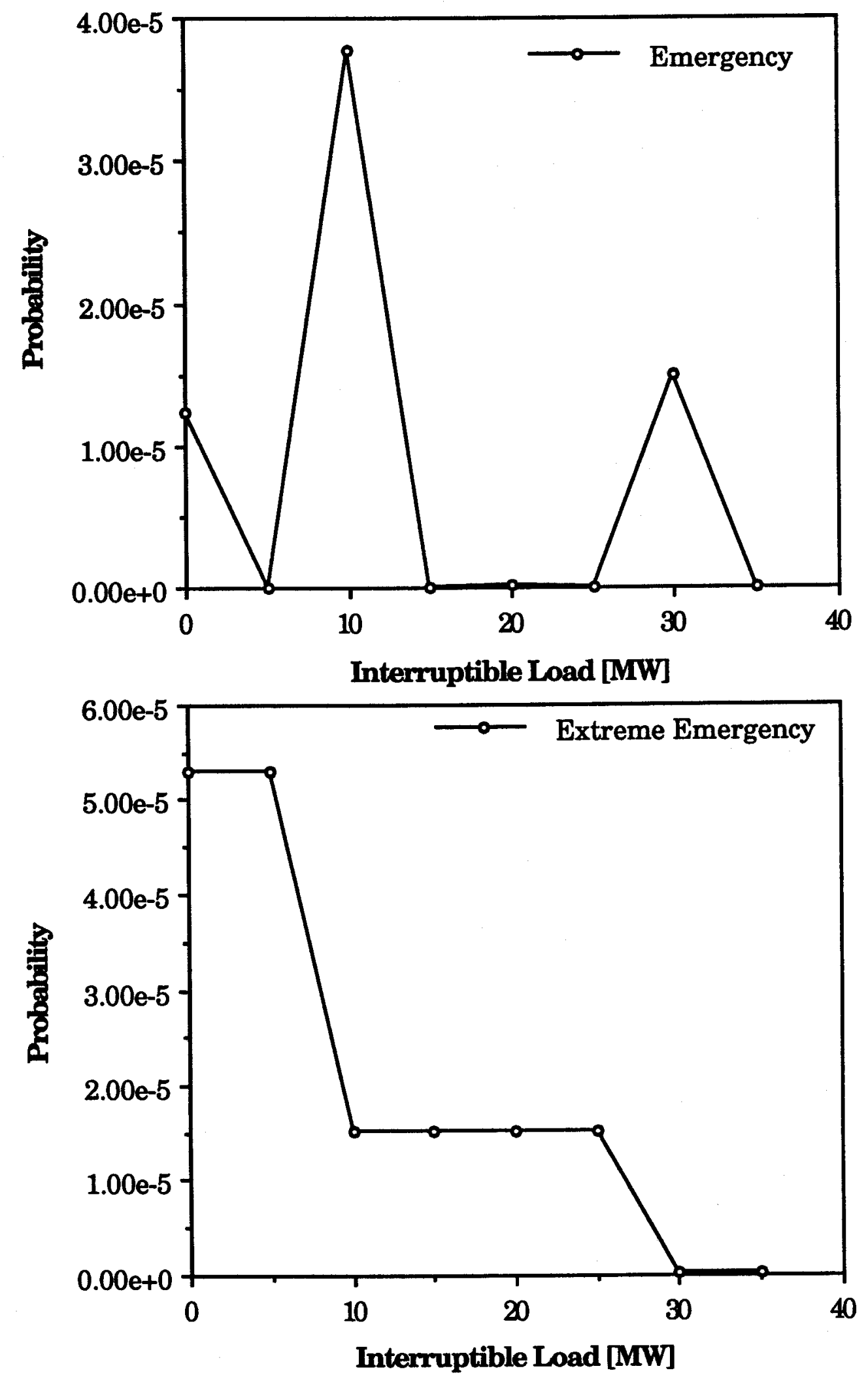

Figure 5.5: Probabilities of the Emergency and Extreme Emergency States with the Magnitude of Interruptible Load. 


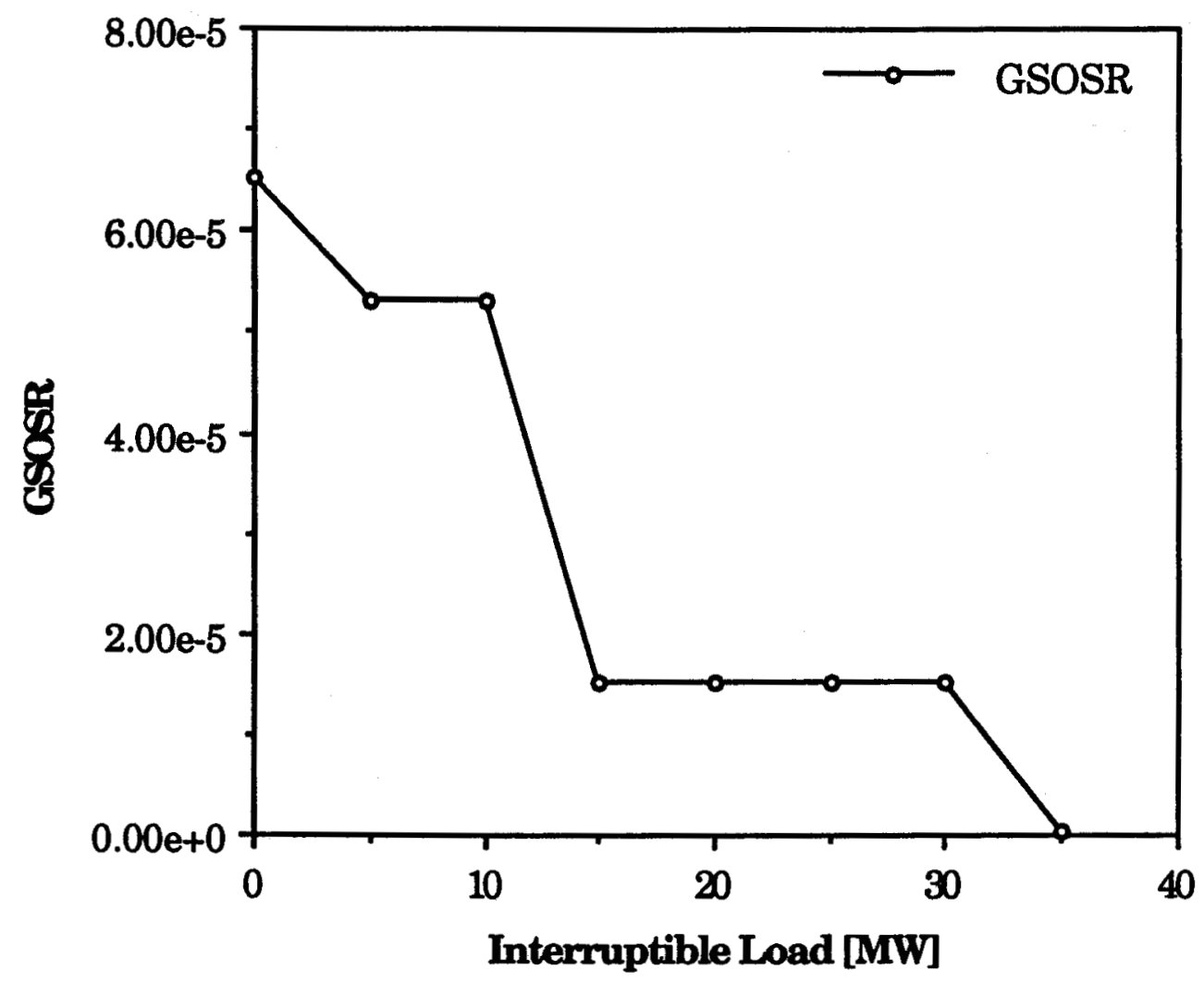

Figure 5.6: Variation of the GSOSR with the Magnitude of Interruptible Load.

\subsection{Effect of Variation in the Lead Time of Interruptible Load}

In the presence of a given amount of interruptible load, the magnitude of the required spinning capacity is also a function of interruptible load lead time. The time for load interruption depends on the agreement between the consumer and the utility. The required spinning reserve usually decreases with a decrease in interruptible load lead time. For two identical systems, the probability of the normal state in the system with a lower interruptible load lead time is higher than that of the other system, provided that the magnitude of the interruptible loads is identical in both systems. 
Table 5.5 shows the unit commitment and the system operating state probabilities in the RBTS for a load level of $160 \mathrm{MW}$ and a system lead time of 4 hours. The specified GSOSR is assumed to be 0.001 for the study in this section. In this study the interruptible load is fixed at $10 \mathrm{MW}$ and the corresponding lead time is varied from 10 to 90 minutes. The results are presented in Figures 5.7 to 5.9 .

It can be seen from the results that as the interruptible load lead time increases, the probabilities of the normal and the alert states decrease. However, the probability of the extreme emergency state increases as the interruptible load lead time increases.

Table 5.5: Unit Commitment and System Operating State Probabilities for Various Interruptible Load Lead Times.

\begin{tabular}{|c|c|c|c|c|c|c|}
\hline \multirow[b]{2}{*}{$\begin{array}{l}\mathrm{TI} \\
\mathrm{Min}]\end{array}$} & \multirow[b]{2}{*}{$\begin{array}{l}\text { No.of } \\
\text { units }\end{array}$} & \multicolumn{4}{|c|}{ Probability of } & \multirow[b]{2}{*}{ GSOSR } \\
\hline & & Normal & Alert & Emergency & $\begin{array}{c}\text { Extreme } \\
\text { Emergency }\end{array}$ & \\
\hline 10 & 8 & 0.98585228 & 0.01409478 & 0.00003773 & 0.00001520 & 0.00005294 \\
\hline 20 & 8 & 0.98585222 & 0.01409478 & 0.00003760 & 0.00001540 & 0.00005300 \\
\hline 30 & 8 & 0.98585211 & 0.01409478 & 0.00003738 & 0.00001573 & 0.00005311 \\
\hline 40 & 8 & 0.98585196 & 0.01409478 & 0.00003707 & 0.00001619 & 0.00005326 \\
\hline 50 & 8 & 0.98585177 & 0.01409477 & 0.00003667 & 0.00001679 & 0.00005346 \\
\hline 60 & 8 & 0.98585153 & 0.01409477 & 0.00003618 & 0.00001752 & 0.00005369 \\
\hline 70 & 8 & 0.98585126 & 0.01409477 & 0.0000356 & 0.00001837 & 0.00005398 \\
\hline 80 & 8 & 0.98585094 & 0.01409476 & 0.00003494 & 0.00001936 & 0.0000543 \\
\hline 90 & 8 & 0.98585057 & 0.01409476 & 0.00003419 & 0.00002048 & 0.00005467 \\
\hline
\end{tabular}

$\mathrm{TI}=$ Time of Interruption 

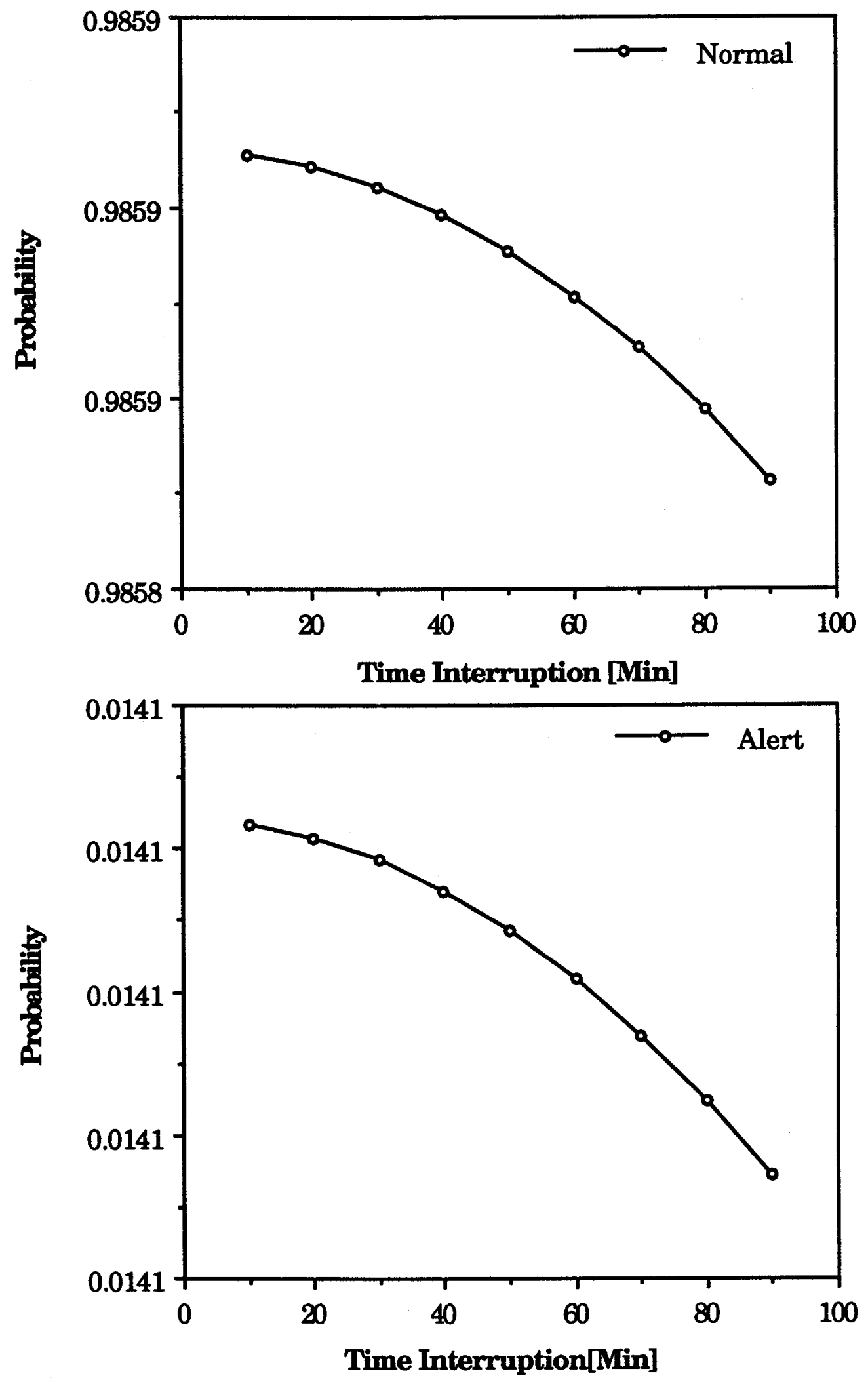

Figure 5.7: Probabilities of the Normal and Alert States with the Interruptible Load Lead Time. 

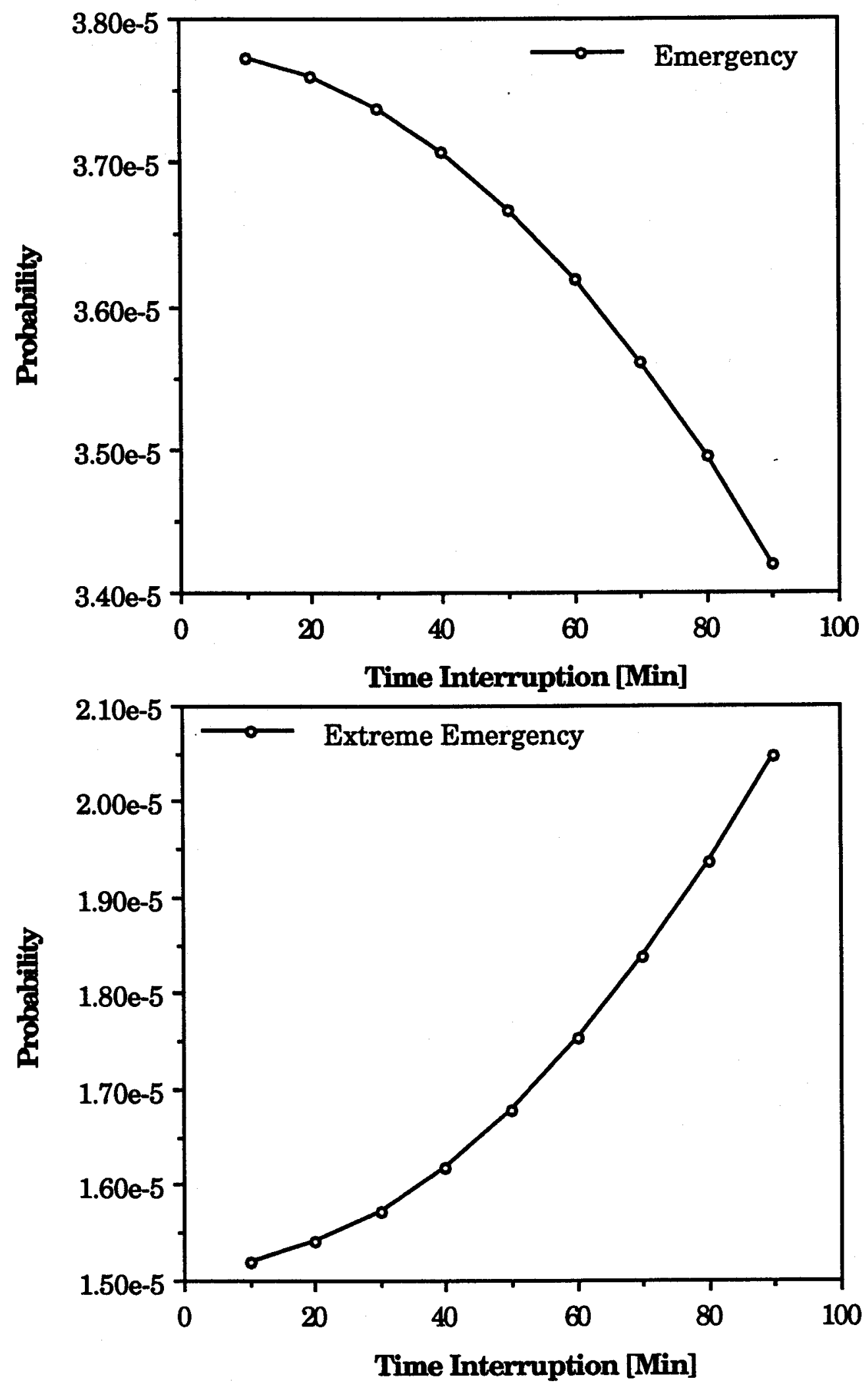

Figure 5.8: Probabilities of the Emergency and Extreme Emergency States with the Interruptible Load Lead Time. 


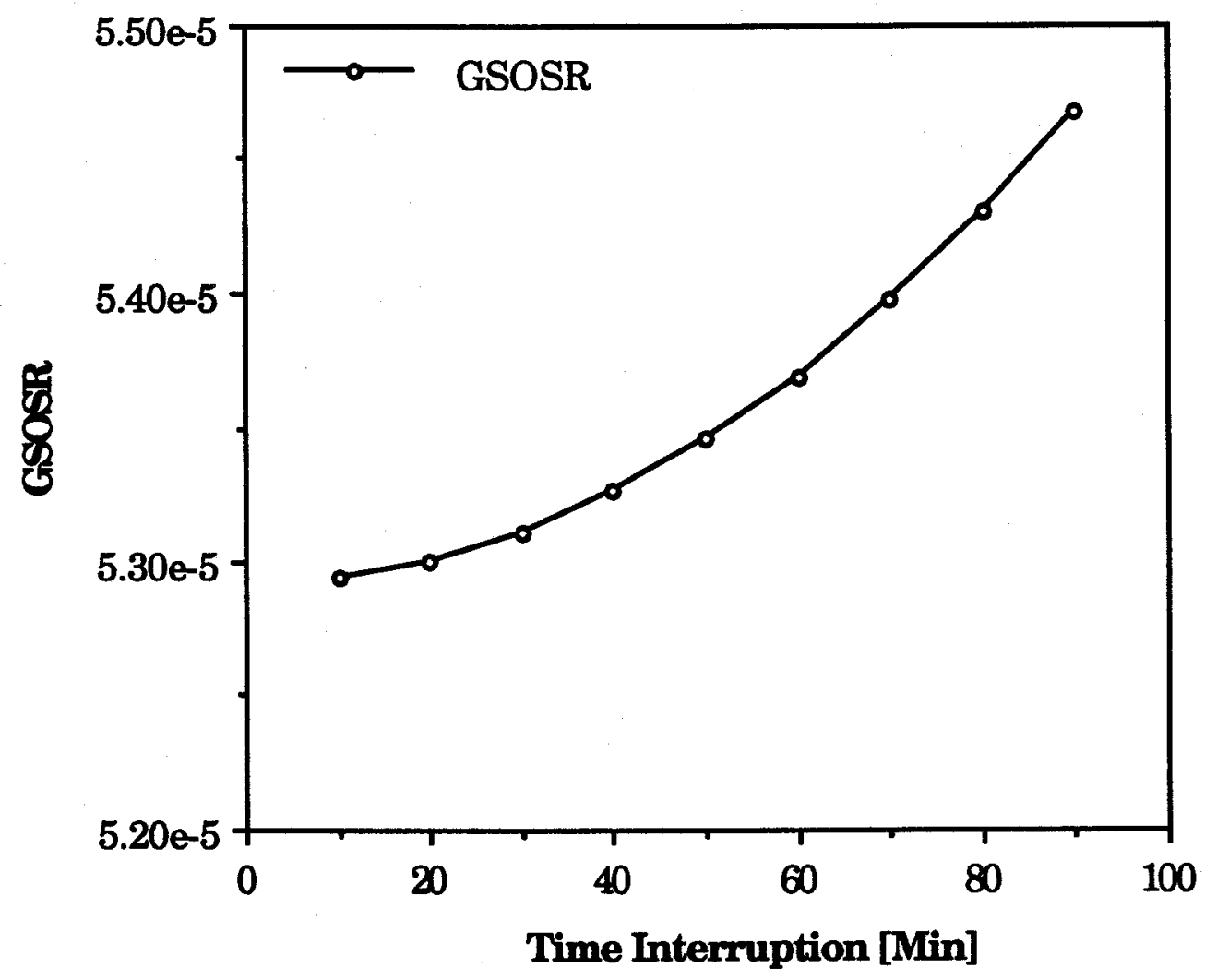

Figure 5.9: Variation of the GSOSR with the Interruptible Load Lead Time.

\subsection{Additional Load/Interruptible Load Carrying Capability of a System}

Generating units are committed to the system at a particular firm load level in order to maintain the risk lower than or equal to a specified value. There is a window between the firm load and the total generating capacity in operation, if the actual GSOSR at the firm load is less than the specified risk. Therefore, the generation system can carry additional load on top of the firm load without requiring any additional units to be committed other than those required to carry the firm load and without violating the unit commitment criterion. The allowable additional load depends on the generating capacity in operation, the firm load and the unit commitment criteria. 
Depending on the extra committed capacity above the firm load, the system can carry additional load for a time period equal to the system lead time or for a certain period less than the system lead time. The additional load which the system can carry on top of the firm load for a period less than the system lead time is designated as additional interruptible load [35]. The additional interruptible load is called additional load when the corresponding time of interruption is equal to the system lead time.

Consider the RBTS with a firm load of $160 \mathrm{MW}$ and a specified risk of 0.001 . It is assumed that additional units are available within 4 hours. The system requires eight committed units to carry the firm load of $160 \mathrm{MW}$. The actual GSOSR at this point is 0.00006532 and the spinning capacity is $210 \mathrm{MW}$. The results for additional load/interruptible load are shown in Table 5.6. The first column shows the total load which is the summation of the firm load and additional/interruptible load. The third column of Table 5.6 shows the additional load or interruptible load that the system can carry on top of the firm load of $160 \mathrm{MW}$. The fourth column shows the lead time of additional load/interruptible load for which the corresponding additional load or interruptible load shown in column three can be carried by the system, without committing any additional generation than that committed to carry the firm load of $160 \mathrm{MW}$ and without violating the system risk.

It can be seen from the results, that the system can carry an additional load of $5 \mathrm{MW}$ on top of the firm load of $160 \mathrm{MW}$ with an actual GSOSR of 0.00006532 . By increasing the load to $170 \mathrm{MW}$, the GSOSR is violated and $10 \mathrm{MW}$ of the load should be curtailed within 32 minutes. If the load is increased to $175 \mathrm{MW}$, to satisfy the specified GSOSR, $15 \mathrm{MW}$ of the 


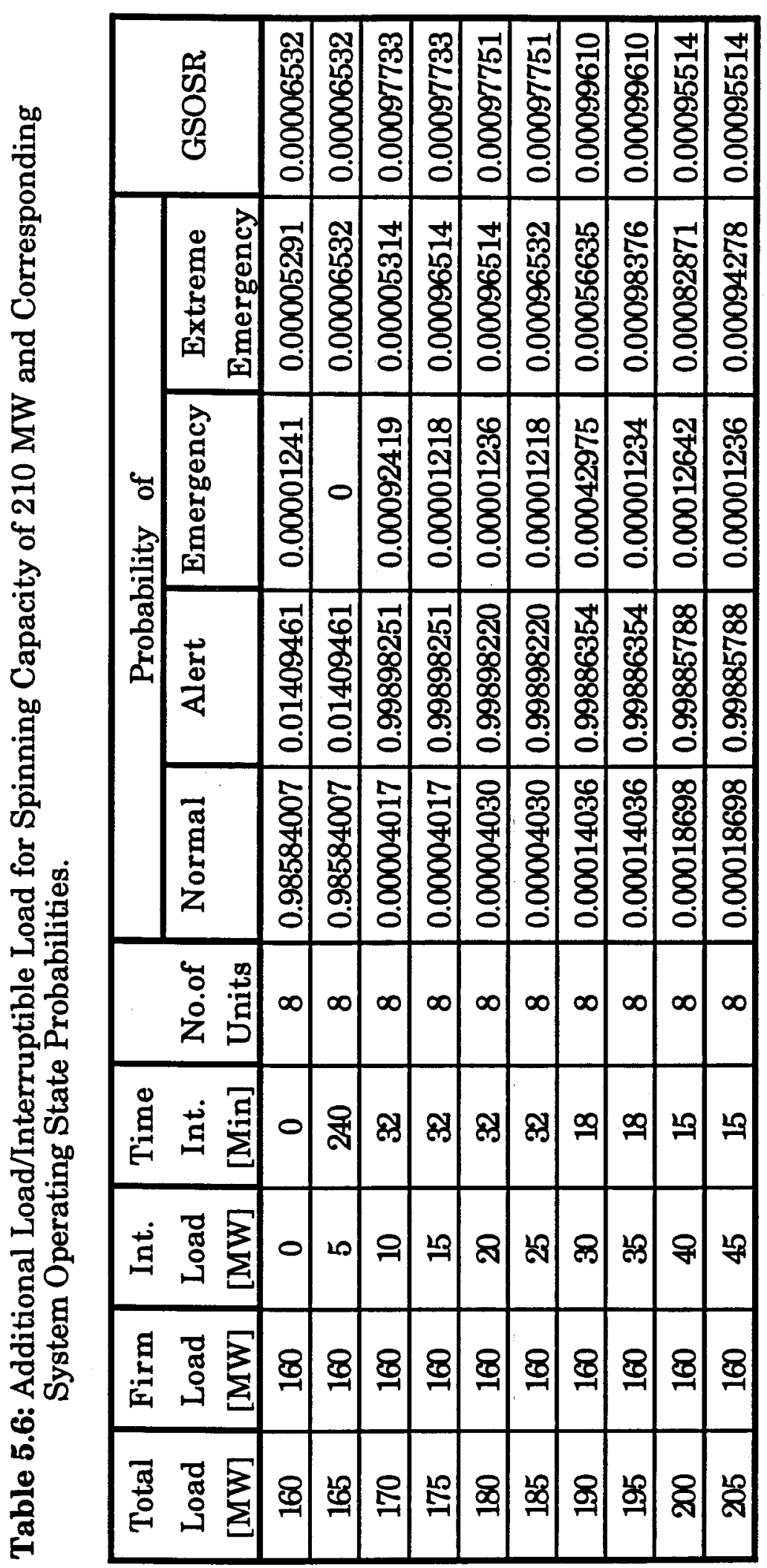


load must be curtailed within 32 minutes. Under this situation the actual GSOSR is 0.00097733 . However, the probability of the normal state decreases to 0.00004017 . If an additional criterion such as a higher probability of the normal state is required, this system can not satisfy the new condition and one more unit has to be committed. With the spinning capacity of $210 \mathrm{MW}$ the system can carry a load of $205 \mathrm{MW}$, provided that $45 \mathrm{MW}$ of the load can be curtailed within 15 minutes to satisfy the specified GSOSR of 0.001 . In this case the actual GSOSR is 0.00095514 . Therefore, as the additional interruptible load is increased, its lead time decreases, i.e. the higher the interruptible load is, the shorter the time period before the load has to be interrupted.

In general, it can be concluded that additional load/interruptible load depends on many factors, from which the unit commitment criterion is the most important. The set of additional load/interruptible loads shown in Table 5.6 is for a firm load of $160 \mathrm{MW}$ when the system should satisfy a single specified risk of 0.001 . If a desired level of probability of the normal state, i.e. 0.9 , is required, this set will be restricted to the first two rows.

\subsection{Comparison of the Effect of Interruptible Loads and Rapid Start Units}

There is an important difference between interruptible loads and rapid start units as there is always some probability of these units not being available when called into service. This is not the case with an interruptible load as once it has been decided to remove the load, the probability of it not occurring is negligible. 
As noted in Chapter 4, the RBTS has a number of rapid start units of $10 \mathrm{MW}$ with a lead time of 10 minutes. In order to compare the effect of interruptible load and rapid start units, it is assumed that there are some interruptible loads that can be interrupted within 10 minutes. Table 5.7 shows the system operating state probabilities when various numbers of rapid start units are included in the analysis. Table 5.8 shows the results when different amounts of interruptible load are included. In both cases the system firm load is assumed to be $160 \mathrm{MW}$. The total spinning capacity is $210 \mathrm{MW}$, i.e. 8 units, and the system lead time is 4 hours. The results are presented in Figures 5.10 to $\mathbf{5 . 1 2}$.

As expected, the probabilities associated with the normal and the alert states when considering interruptible load are greater than those when including rapid start units, provided that the magnitude of interruptible load is equal to the capacity of the rapid start unit(s). The probability of the extreme emergency state and the GSOSR when considering interruptible load are less than those when rapid start units are included in the system.

Table 5.7: System Operating State Probabilities for Different Numbers of Rapid Start Units.

\begin{tabular}{|c|c|c|c|c|c|c|}
\hline \multirow{2}{*}{$\begin{array}{l}\text { No.of } \\
\text { RS } \\
\text { units }\end{array}$} & \multirow[b]{2}{*}{$\begin{array}{l}\text { No.of } \\
\text { units }\end{array}$} & \multicolumn{4}{|c|}{ Probability of } & \multirow[b]{2}{*}{ GSOSR } \\
\hline & & Normal & Alert & Emergency & $\begin{array}{c}\text { Extreme } \\
\text { Emergency }\end{array}$ & \\
\hline 0 & 8 & 0.98584007 & 0.01409461 & 0.00001241 & 0.00005291 & 0.00006532 \\
\hline 1 & 8 & 0.98584913 & 0.01409474 & 0.00003120 & 0.00002493 & 0.00005613 \\
\hline 2 & 8 & 0.98587195 & 0.01409506 & 0.00001532 & 0.00001767 & 0.00003299 \\
\hline 3 & 8 & 0.98588314 & 0.01409522 & 0.00001195 & 0.00000969 & 0.00002164 \\
\hline 4 & 8 & 0.98589186 & 0.01409535 & 0.00000831 & 0.00000448 & 0.00001279 \\
\hline
\end{tabular}


Table 5.8: System Operating State Probabilities for Various Interruptible Load Capabilities.

\begin{tabular}{|c|c|c|c|c|c|c|}
\hline $\begin{array}{c}\text { Int. } \\
\text { Load } \\
\text { [MW] }\end{array}$ & $\begin{array}{c}\text { No.of } \\
\text { units }\end{array}$ & Normal & Alert & Emergency & $\begin{array}{c}\text { Extreme } \\
\text { Emergency }\end{array}$ & GSOSR \\
\hline 0 & 8 & 0.98584007 & 0.01409461 & 0.00001241 & 0.00005291 & 0.00006532 \\
\hline 10 & 8 & 0.98585228 & 0.01409478 & 0.00003773 & 0.00001520 & 0.00005294 \\
\hline 20 & 8 & 0.98588946 & 0.01409531 & 0.00000009 & 0.00001513 & 0.00001522 \\
\hline 30 & 8 & 0.98588953 & 0.01409531 & 0.00001494 & 0.00000021 & 0.00001516 \\
\hline 40 & 8 & 0.98590424 & 0.01409552 & 0.00000005 & 0.00000019 & 0.00000023 \\
\hline
\end{tabular}



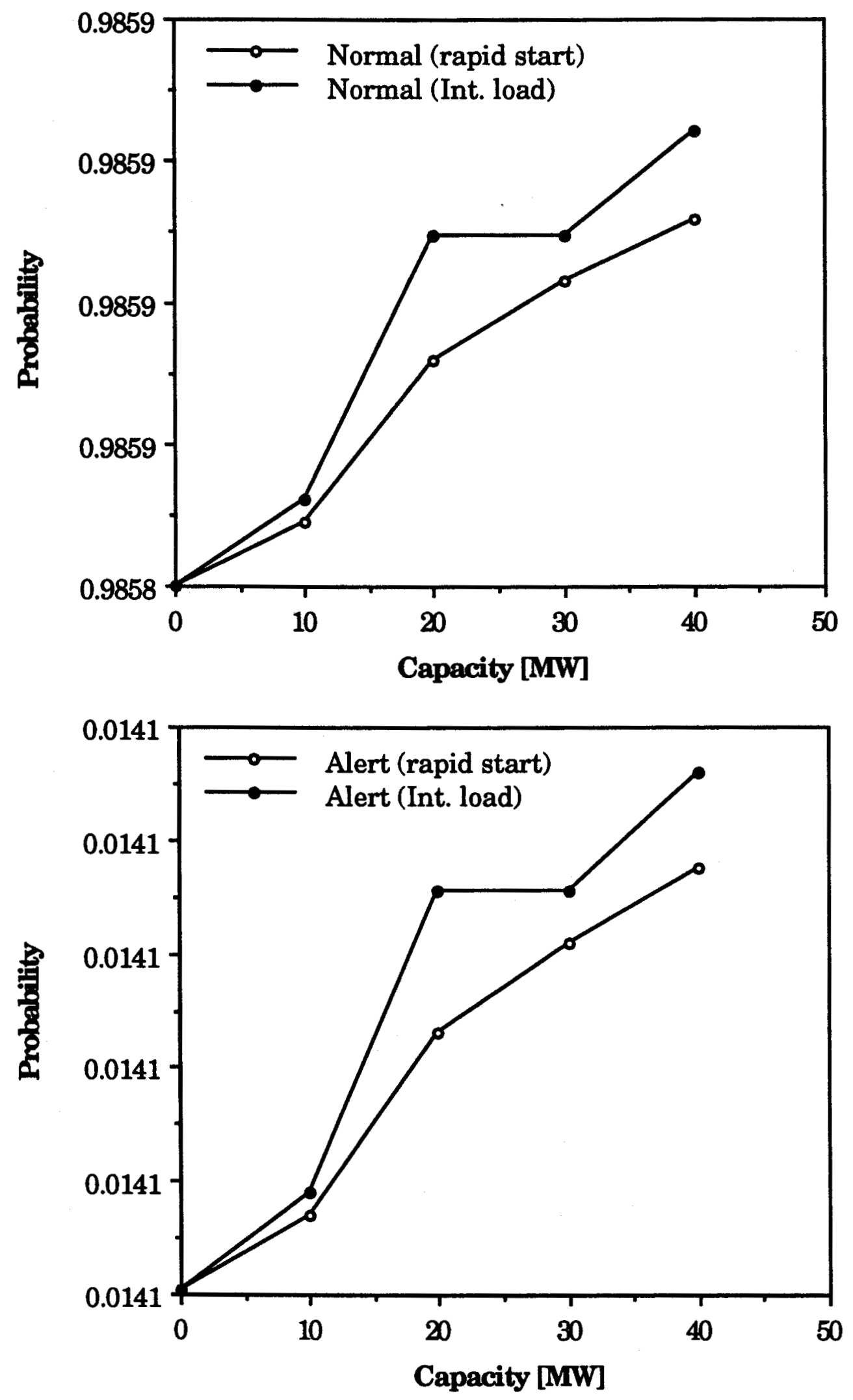

Figure 5.10: Probabilities of the Normal and Alert States. 

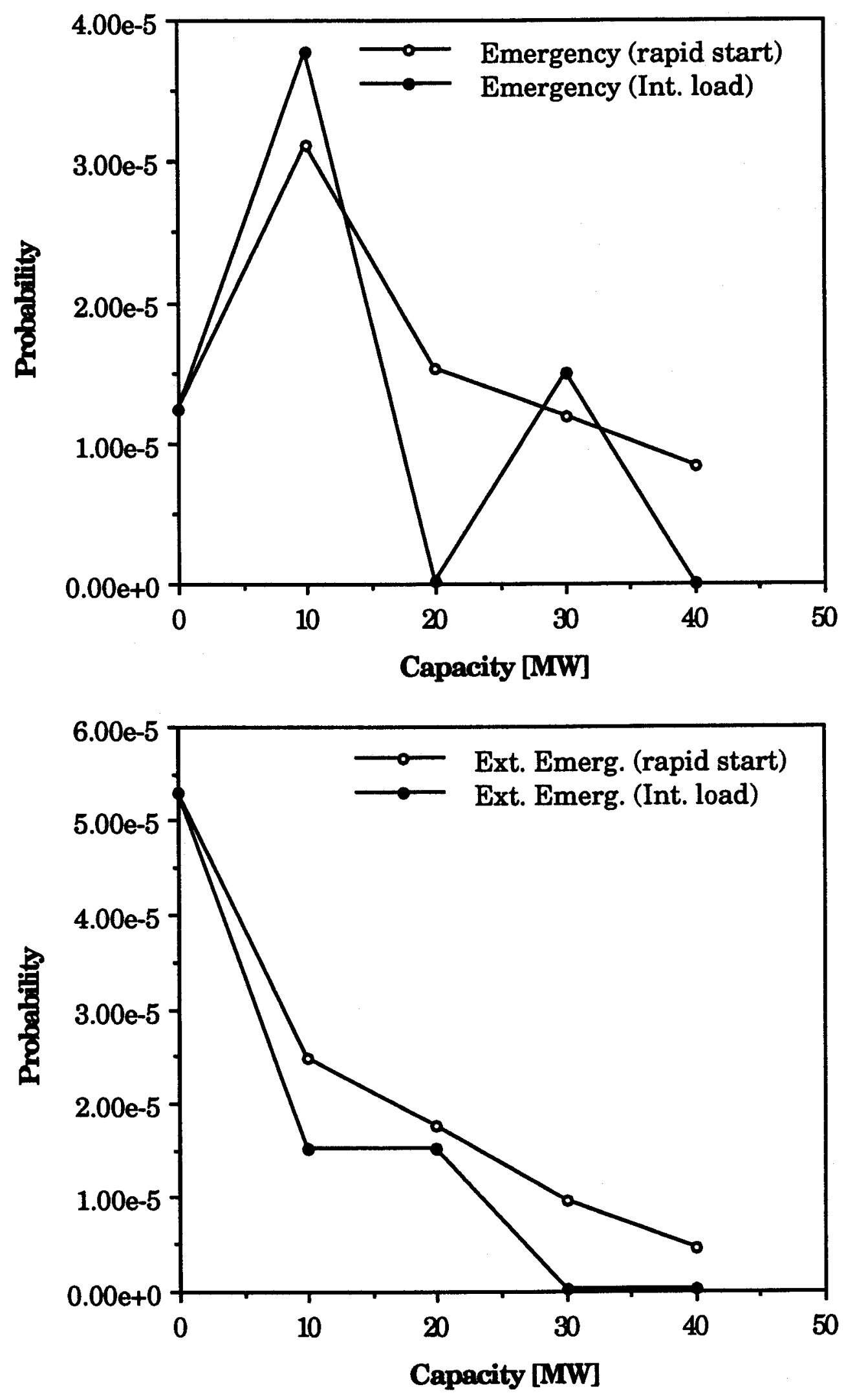

Figure 5.11: Probabilities of the Emergency and Extreme Emergency States. 


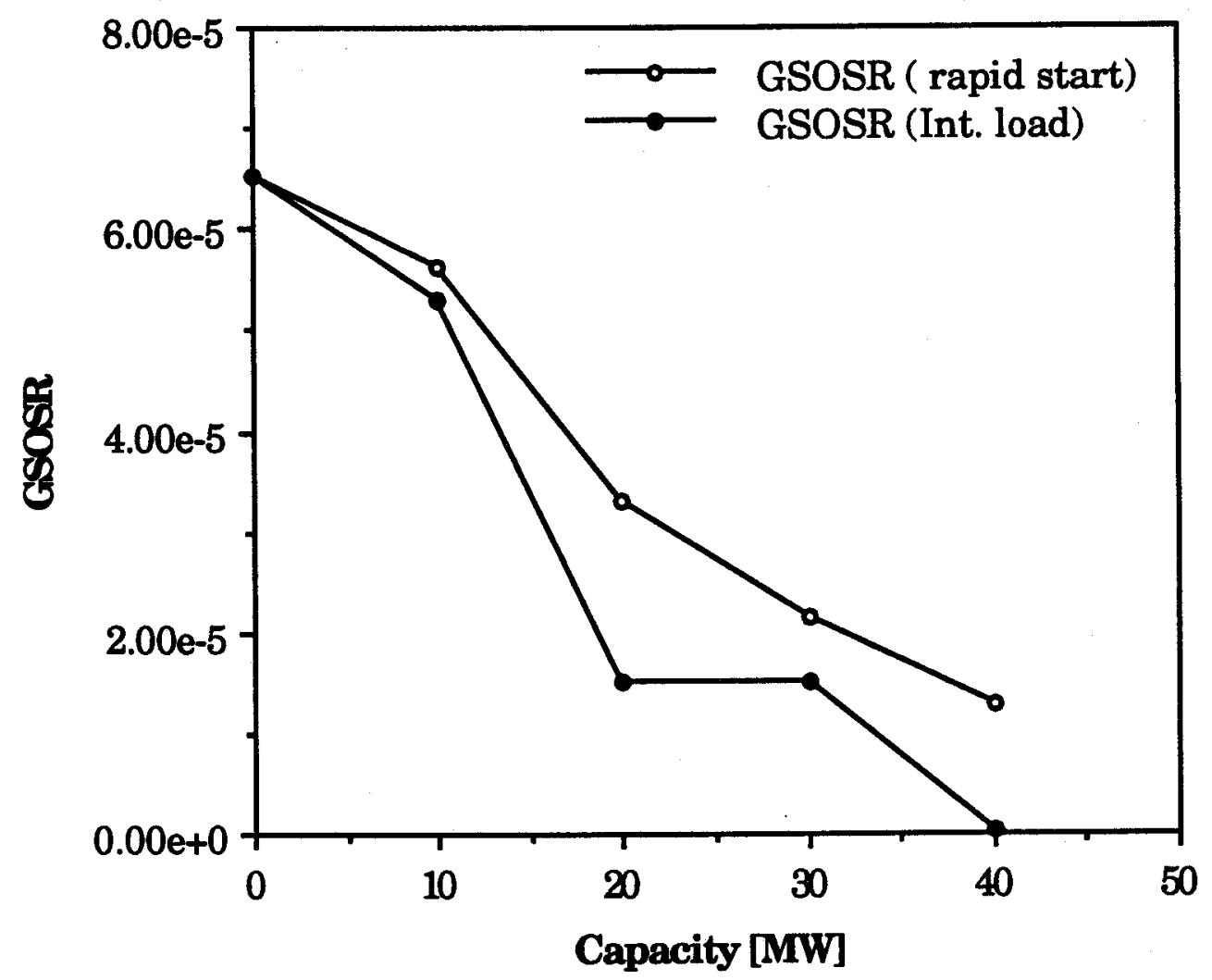

Figure 5.12: Variation of Generating System Operating State Risk.

\subsection{Summary}

The inclusion of interruptible load in operating reserve assessment is illustrated in this chapter. Interruptible loads can be incorporated in operating reserve assessment using the concept of area risk curves. A technique has been developed to determine the required number of generating units for a given load level and a specified unit commitment criterion. This technique is used to evaluate the system operating state probabilities. The GSOSR, the number of committed units and the system operating state probabilities are affected by including interruptible loads. 
The magnitude of interruptible loads and the corresponding time delay before which the load should be curtailed depend on the agreement between the utility and the consumer. It is usually assumed that a utility has prior knowledge regarding the various loads that can be curtailed with minimum penalty. The impact of such load curtailment on the GSOSR, the number of committed units and the system operating state probabilities is illustrated in this chapter. From the results presented in this chapter it can be concluded that if a system initially operates in the alert state, it will not transfer to the normal state by including interruptible load into the analysis.

For a given firm load, units are usually committed in such a way that a specified risk is satisfied. With this number of committed units the system can carry additional load or additional interruptible load on top of its firm load without violating the specified risk. The additional load/interruptible load that a system can carry in addition to a given firm load is evaluated in this chapter.

There is a basic difference between interruptible loads and rapid start units in that there is always a possibility that rapid start units will not be available when called into service. This possibility is negligible for the case of an interruptible load. The impact of these two factors on the probability of different system operating states is compared in this chapter. 


\section{APPLICATION TO THE IEEE-RELIABILITY TEST SYSTEM}

\subsection{Introduction}

Many techniques have been developed for the purpose of conducting power system reliability analysis[20,21,22]. The litrature also contains reference or "test" systems to provide a basis for testing and comparing the results obtained from alternate methods. Two basic reliability test systems, the Institute of Electrical and Electronic Engineering Reliability Test System(IEEE-RTS) [36] and the Roy Billinton Test System(RBTS) [28], have been published. The RBTS is a small power system and is utilized extensively in the reliability research work at the University of Saskatchewan. The system was described in Section 2.5 of Chapter 2. The application of the system operating state concepts in operating reserve assessment and the techniques presented in the previous chapters were illustrated using the RBTS.

The IEEE-RTS is a relatively large power system in which sufficient complexity and detail have been included to make the test system representative of an actual utility system. The IEEE-RTS is used to demonstrate the application of system operating state concepts in operating 
reserve assessment in this chapter.

\subsection{Description of the IEEE-Reliability Test System (IEEE-RTS)}

The single line diagram of the IEEE-RTS is shown in Figure 6.1. This 24 bus system was established by an IEEE Task Force in 1979 [36]. This system has 10 generator buses, 10 load buses, 38 transmission lines and 5 transformers. The total number of generating units is 32 , ranging from 12 MW to $400 \mathrm{MW}$. The total system generation is $3405 \mathrm{MW}$ and the annual peak load is $2850 \mathrm{MW}$. The generation data for the IEEE-RTS is given in Table 6.1. The results presented in this chapter utilize the main concepts developed and illustrated in the previous chapters.

Table 6.1: Generation Unit Data for the IEEE-RTS.

\begin{tabular}{|c|c|c|c|}
\hline $\begin{array}{c}\text { Priority } \\
\text { loading } \\
\text { order }\end{array}$ & $\begin{array}{c}\text { Unit } \\
\text { size } \\
{[\mathrm{MW}]}\end{array}$ & $\begin{array}{c}\text { Unit } \\
\text { type }\end{array}$ & $\begin{array}{c}\text { Failure } \\
\text { rate } \\
{[\mathrm{f} / \mathrm{Yr}]}\end{array}$ \\
\hline 14 & 50 & Hydro & 4.42 \\
\hline $5-6$ & 400 & Nuclear & 7.96 \\
\hline 7 & 350 & Thermal & 7.62 \\
\hline $8-10$ & 197 & Thermal & 9.22 \\
\hline $11-14$ & 155 & Thermal & 9.13 \\
\hline $15-17$ & 100 & Thermal & 7.3 \\
\hline $18-21$ & 76 & Thermal & 4.47 \\
\hline $22-26$ & 12 & Thermal & 2.98 \\
\hline $27-30$ & 20 & Thermal & 19.47 \\
\hline $31-32$ & 50 & Hydro & 4.47 \\
\hline
\end{tabular}




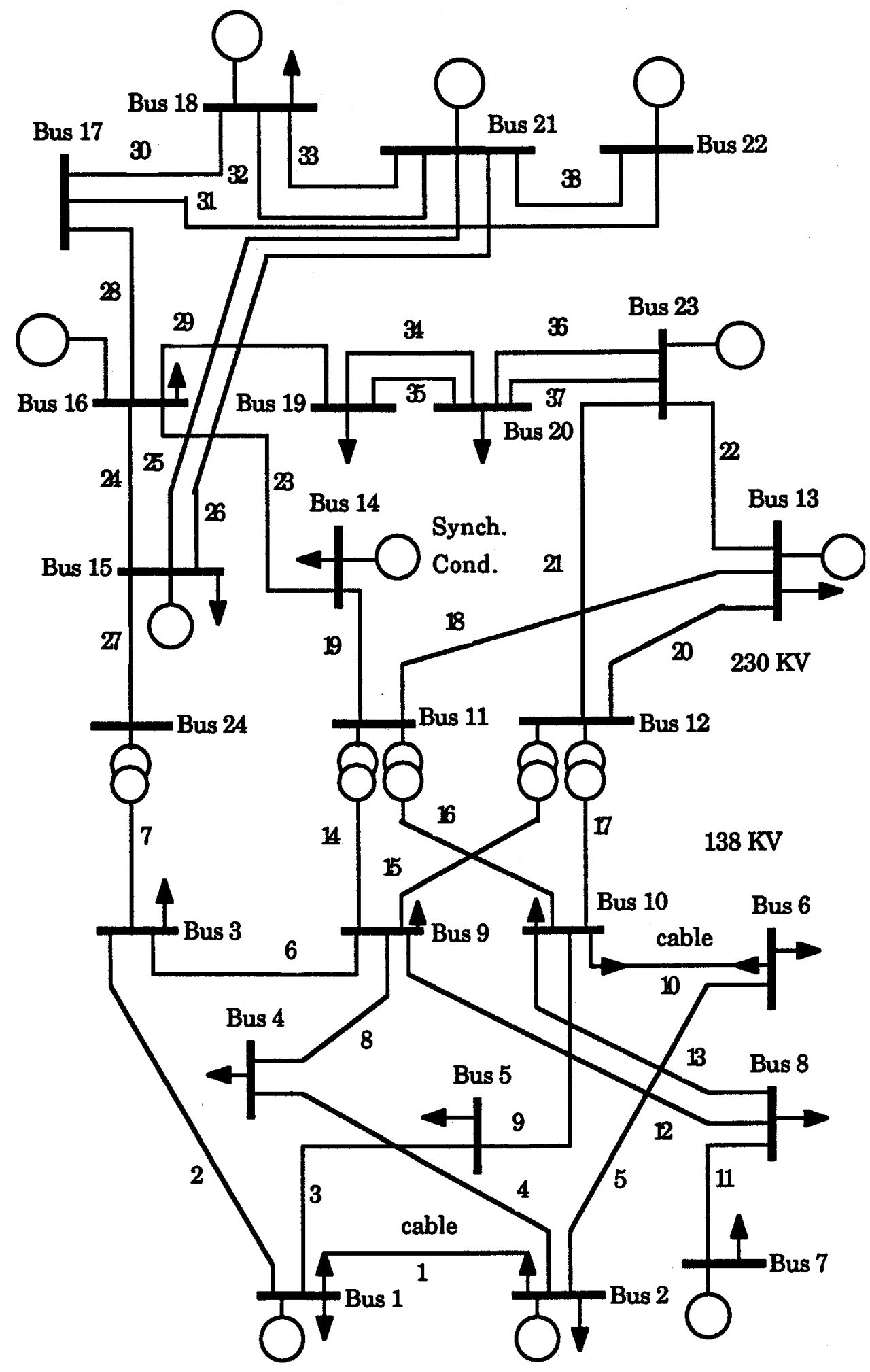

Figure 6.1: Single Line Diagram of the IEEE-RTS. 


\subsection{Unit Commitment for the Hourly Peak Load}

The number of generating units to be committed for a particular load level are taken from the priority loading order list shown in Table 6.1. Table 6.2 shows the hourly peak loads on Monday during week \#51 of the IEEERTS. The number of committed units and the system operating state probabilities during the 24 hour scheduling period are also presented in Table 6.2. The system lead time is assumed to be 4 hours and a specified risk of 0.001 is selected as a unit commitment criterion for the study in this section. The system peak load changes from 1564 to 2651 MW during the 24 hours, and the required number of committed units varies from 11 to 20 . With this commitment schedule, the system is not only able to satisfy the specified risk of 0.001 but also satisfies a normal state probability of 0.9 .

\subsection{Effect of Lead Time Variation}

The required spinning reserve is dependent on the system load, generating unit failure rates, lead time and allowable risk level. Table 6.3 shows the required number of units and the system operating state probabilities for a load level of $1995 \mathrm{MW}$, i.e. $70 \%$ of the peak load of 2850 MW. The system lead time varies from 0.5 hour to 15 hours. The number of committed units is 13 when the lead time changes from 0.5 to 6 hours. However, as the lead time increases to 7 hours the required number of committed units becomes 14 . The system must commit 15 units for a lead time of 15 hours in order to keep the GSOSR less than or equal to the specified risk of 0.001 . 
Table 6.2: Unit Commitment and system Operating State Probabilities for the Hourly Peak Load Variations in a 24 Hours Scheduling Period.

\begin{tabular}{|c|c|c|c|c|c|c|c|}
\hline \multirow[b]{2}{*}{$\mathrm{Hr}$} & \multirow[b]{2}{*}{$\begin{array}{l}\text { Load } \\
\text { [MW] }\end{array}$} & \multirow[b]{2}{*}{$\begin{array}{l}\text { No.of } \\
\text { units }\end{array}$} & \multicolumn{4}{|c|}{ Probability of } & \multirow[b]{2}{*}{ GSOSR } \\
\hline & & & Normal & Alert & $\begin{array}{l}\text { Emer- } \\
\text { gency }\end{array}$ & $\begin{array}{c}\text { Extreme } \\
\text { Emergency }\end{array}$ & \\
\hline 1 & 1776 & 12 & 0.96869579 & 0.03104299 & 0 & 0.00026121 & 0.00026121 \\
\hline 2 & 1670 & 11 & 0.96494533 & 0.03478018 & 0 & 0.00027449 & 0.00027449 \\
\hline 3 & 1590 & 11 & 0.97277482 & 0.02702243 & 0 & 0.00020275 & 0.00020275 \\
\hline 4 & 1564 & 11 & 0.97277482 & 0.02702243 & 0 & 0.00020275 & 0.00020275 \\
\hline 5 & 1564 & 11 & 0.97277482 & 0.02702243 & 0 & 0.00020275 & 0.00020275 \\
\hline 6 & 1590 & 11 & 0.97277482 & 0.02702243 & 0 & 0.00020275 & 0.00020275 \\
\hline 7 & 1961 & 13 & 0.95691649 & 0.04272146 & 0 & 0.00036206 & 0.00036206 \\
\hline 8 & 2279 & 16 & 0.95424218 & 0.04536093 & 0 & 0.00039689 & 0.00039689 \\
\hline 9 & 2518 & 18 & 0.94150399 & 0.05796269 & 0 & 0.00053332 & 053332 \\
\hline 10 & 2544 & 19 & 0.94718293 & 0.05236784 & 0 & 0.00044923 & 0.00044923 \\
\hline 11 & 2544 & 19 & 0.94718293 & 0.05236784 & 0 & 0.00044923 & 0.00044923 \\
\hline 12 & 2518 & 18 & 0.94150399 & 0.05796269 & 0 & 0.00053332 & 0.00053332 \\
\hline 13 & 2518 & 18 & 0.94150399 & 0.05796269 & 0 & 0.00053332 & 0.00053332 \\
\hline 14 & 2518 & 18 & 0.94150399 & 0.05796269 & 0 & 0.00053332 & 0.00053332 \\
\hline 15 & 2465 & 18 & 0.94912017 & 0.05044509 & 0 & 0.00043474 & 0.00043474 \\
\hline 16 & 2491 & 18 & 0.94150399 & 0.05797024 & 0 & 0.00052577 & 0.00052577 \\
\hline 17 & 2624 & 20 & 0.94524964 & 0.05428648 & 2.80E-07 & 0.0004636 & 0.00046387 \\
\hline 18 & 2651 & 20 & 0.93766452 & 0.06178092 & 0 & 0.00055457 & 0.00055457 \\
\hline 19 & 2651 & 20 & 0.93766452 & 0.06178092 & 0 & 0.00055457 & 0.00055457 \\
\hline 20 & 2544 & 19 & 0.94718293 & 0.05236784 & $\underline{0}$ & 0.00044923 & 0.00044923 \\
\hline 21 & 2412 & 17 & 0.94342961 & 0.05605883 & $\underline{0}$ & 0.00051156 & 0.00051156 \\
\hline 22 & 2200 & 15 & 0.95743363 & 0.0421928 & 0 & 0.00037357 & 0.00037357 \\
\hline 23 & 1935 & 13 & 0.96465735 & 0.03503723 & 0 & 0.00030542 & 0.00030542 \\
\hline 24 & 1670 & 11 & 0.96494533 & 0.03478018 & 0 & 0.00027449 & 0.00027449 \\
\hline
\end{tabular}


Table 6.3: Unit Commitment and System Operating State Probabilities for Different Lead Times When the System Load is 1995 MW.

\begin{tabular}{|c|c|c|c|c|c|c|}
\hline $\begin{array}{c}\text { Lead } \\
\text { Time } \\
\text { [Hr] }\end{array}$ & $\begin{array}{c}\text { No.of } \\
\text { units }\end{array}$ & Normal & Alert & Emergency & $\begin{array}{c}\text { Extreme } \\
\text { Emergency }\end{array}$ & GSOSR \\
\hline 0.5 & 13 & 0.99451896 & 0.00547531 & 0 & 0.00000573 & 0.00000573 \\
\hline 1 & 13 & 0.98906549 & 0.01091162 & 0 & 0.00002288 & 0.00002288 \\
\hline 2 & 13 & 0.97824074 & 0.02166803 & 0 & 0.00009123 & 0.00009123 \\
\hline 3 & 13 & 0.96752474 & 0.03227069 & 0 & 0.00020458 & 0.00020458 \\
\hline 4 & 13 & 0.95691649 & 0.04272104 & 0 & 0.00036247 & 0.00036247 \\
\hline 5 & 13 & 0.94641501 & 0.05302054 & 0 & 0.00056446 & 0.00056446 \\
\hline 6 & 13 & 0.93601931 & 0.06317060 & 0 & 0.00081008 & 0.00081008 \\
\hline 7 & 14 & 0.95908842 & 0.04050073 & 0 & 0.00041085 & 0.00041085 \\
\hline 8 & 14 & 0.95325079 & 0.04621054 & 0 & 0.00053867 & 0.00053867 \\
\hline 9 & 14 & 0.94741667 & 0.05189902 & 0 & 0.00068431 & 0.00068431 \\
\hline 10 & 14 & 0.94158662 & 0.05756545 & 0 & 0.00084793 & 0.00084793 \\
\hline 15 & 15 & 0.95496327 & 0.0443071 & 0 & 0.00072963 & 0.00072963 \\
\hline
\end{tabular}

The unit commitment with load forecast uncertainty is shown in Table 6.4. The system load has a load forecast uncertainty of $4 \%$ of the forecast mean, and the load distribution is approximated by seven discrete steps as noted in Section 3.5. The number of units that must be committed varies between 13 and 16 . With 15 committed units, the system is unable to satisfy its risk for a lead time of 15 hours, when load forecast uncertainty is included. In this situation, the sixteenth unit should be committed to satisfy the risk.

In order to illustrate the effect of the lead time on the system operating state probabilities, another study was conducted in which the number of on-line units was fixed at 13 . The total spinning capacity is 2406 
Table 6.4: Unit Commitment and System Operating State Probabilities for Different Lead Times and a Load Level of $1995 \mathrm{MW}$ with Load Forecast Uncertainty.

\begin{tabular}{|c|c|c|c|c|c|c|}
\hline $\begin{array}{c}\text { Lead } \\
\text { Time } \\
\text { [Hr] }\end{array}$ & \multirow{2}{*}{$\begin{array}{c}\text { No.of } \\
\text { units }\end{array}$} & Normal & Alert & Emergency & $\begin{array}{c}\text { Extreme } \\
\text { Emergency }\end{array}$ & GSOSR \\
\hline 0.5 & 13 & 0.68763649 & 0.31193452 & 0 & 0.00042899 & 0.00042899 \\
\hline 1 & 13 & 0.68428774 & 0.31484563 & 0 & 0.00086663 & 0.00086663 \\
\hline 2 & 14 & 0.98161931 & 0.01830497 & 0 & 0.00007572 & 0.00007572 \\
\hline 3 & 14 & 0.97545021 & 0.02440350 & 0 & 0.00014630 & 0.00014630 \\
\hline 4 & 14 & 0.96929570 & 0.03046553 & 0 & 0.00023877 & 0.00023877 \\
\hline 5 & 14 & 0.96315610 & 0.03649069 & 0 & 0.00035321 & 0.00035321 \\
\hline 6 & 14 & 0.95703172 & 0.04247862 & 0 & 0.00048966 & 0.00048966 \\
\hline 7 & 14 & 0.95092285 & 0.04842896 & 0 & 0.00064819 & 0.00064819 \\
\hline 8 & 14 & 0.94482978 & 0.05434137 & 0 & 0.00082885 & 0.00082885 \\
\hline 9 & 15 & 0.96509102 & 0.03449434 & 0 & 0.00041464 & 0.00041464 \\
\hline 10 & 15 & 0.96111194 & 0.03837244 & 0 & 0.00051562 & 0.00051562 \\
\hline 15 & 16 & 0.9719262 & 0.02769202 & 0 & 0.00038178 & 0.00038178 \\
\hline
\end{tabular}

MW and the system load is held at $1995 \mathrm{MW}$. The system operating state probabilities are shown in Table 6.5 and presented in Figures 6.2 and 6.3.

From Figures 6.2 and 6.3 , it can be seen that as the lead time increases, the probability of the normal state decreases. The probability of the normal state decreases from 0.99451896 to 0.84706093 when the system lead time is increased from 0.5 hours to 15 hours. The probabilities of the alert and extreme emergency states however, increase as the lead time increases. The probabilities of the emergency state for all lead times are zero. This is due to the fact that there is no event for which the available generating capacity is exactly equal to the load. 
Table 6.6 shows the results for the same number of committed units when load forecast uncertainty is also included. For a given lead time, the probability of the normal state decreases when load forecast uncertainty is included. However, the probabilities of the alert and the extreme emergency states increase. The probability of the normal state for a lead time of 4 hours decreases from 0.95691649 with zero load forecast uncertainty to 0.664502 with $4 \%$ load forecast uncertainty.

Table 6.5: System Operating State Probabilities for a Load Level of 1995 MW when the Number of Committed Units is Fixed at 13.

\begin{tabular}{|c|c|c|c|c|c|c|}
\hline $\begin{array}{c}\text { Lead } \\
\text { Time } \\
\text { [Hr] }\end{array}$ & $\begin{array}{c}\text { No.of } \\
\text { units }\end{array}$ & Normal & Alert & Emergency & $\begin{array}{c}\text { Extreme } \\
\text { Emergency }\end{array}$ & GSOSR \\
\hline 0.5 & 13 & 0.99451896 & 0.00547531 & 0 & 0.00000573 & 0.00000573 \\
\hline 1 & 13 & 0.98906549 & 0.01091162 & 0 & 0.00002288 & 0.00002288 \\
\hline 2 & 13 & 0.97824074 & 0.02166803 & 0 & 0.00009123 & 0.00009123 \\
\hline 3 & 13 & 0.96752474 & 0.03227069 & 0 & 0.00020458 & 0.00020458 \\
\hline 4 & 13 & 0.95691649 & 0.04272104 & 0 & 0.00036247 & 0.00036247 \\
\hline 5 & 13 & 0.94641501 & 0.05302054 & 0 & 0.00056446 & 0.00056446 \\
\hline 6 & 13 & 0.93601931 & 0.06317060 & 0 & 0.00081008 & 0.00081008 \\
\hline 7 & 13 & 0.92572843 & 0.07317266 & 0 & 0.00109891 & 0.00109891 \\
\hline 8 & 13 & 0.91554141 & 0.08302811 & 0 & 0.00143047 & 0.00143047 \\
\hline 9 & 13 & 0.90545729 & 0.09273836 & 0 & 0.00180435 & 0.00180435 \\
\hline 10 & 13 & 0.89547511 & 0.10230480 & 0 & 0.00222009 & 0.00222009 \\
\hline 15 & 13 & 0.84706093 & 0.14802750 & 0 & 0.00491157 & 0.00491157 \\
\hline
\end{tabular}



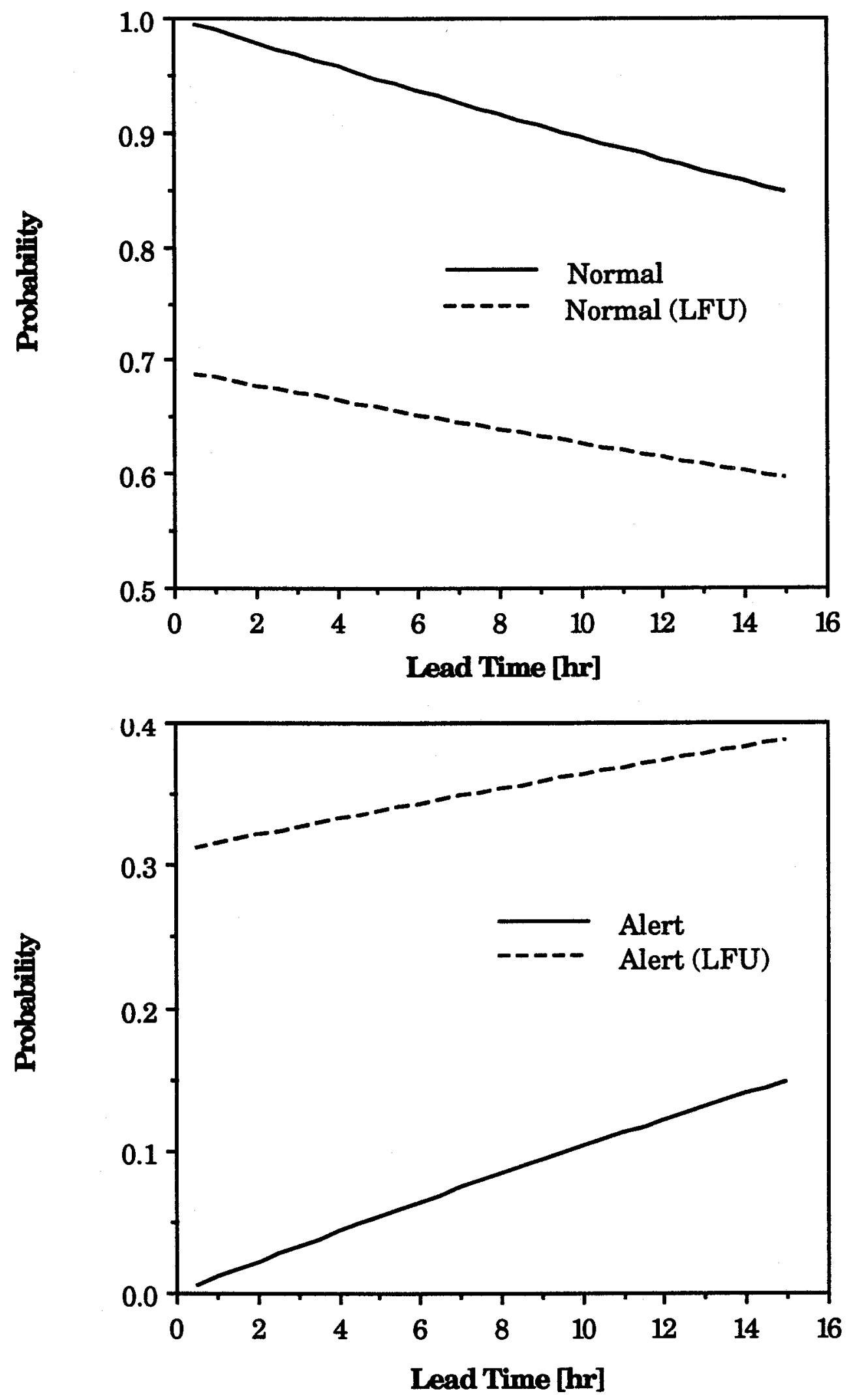

Figure 6.2: Probabilities of the Normal and Alert States with Lead Time. 

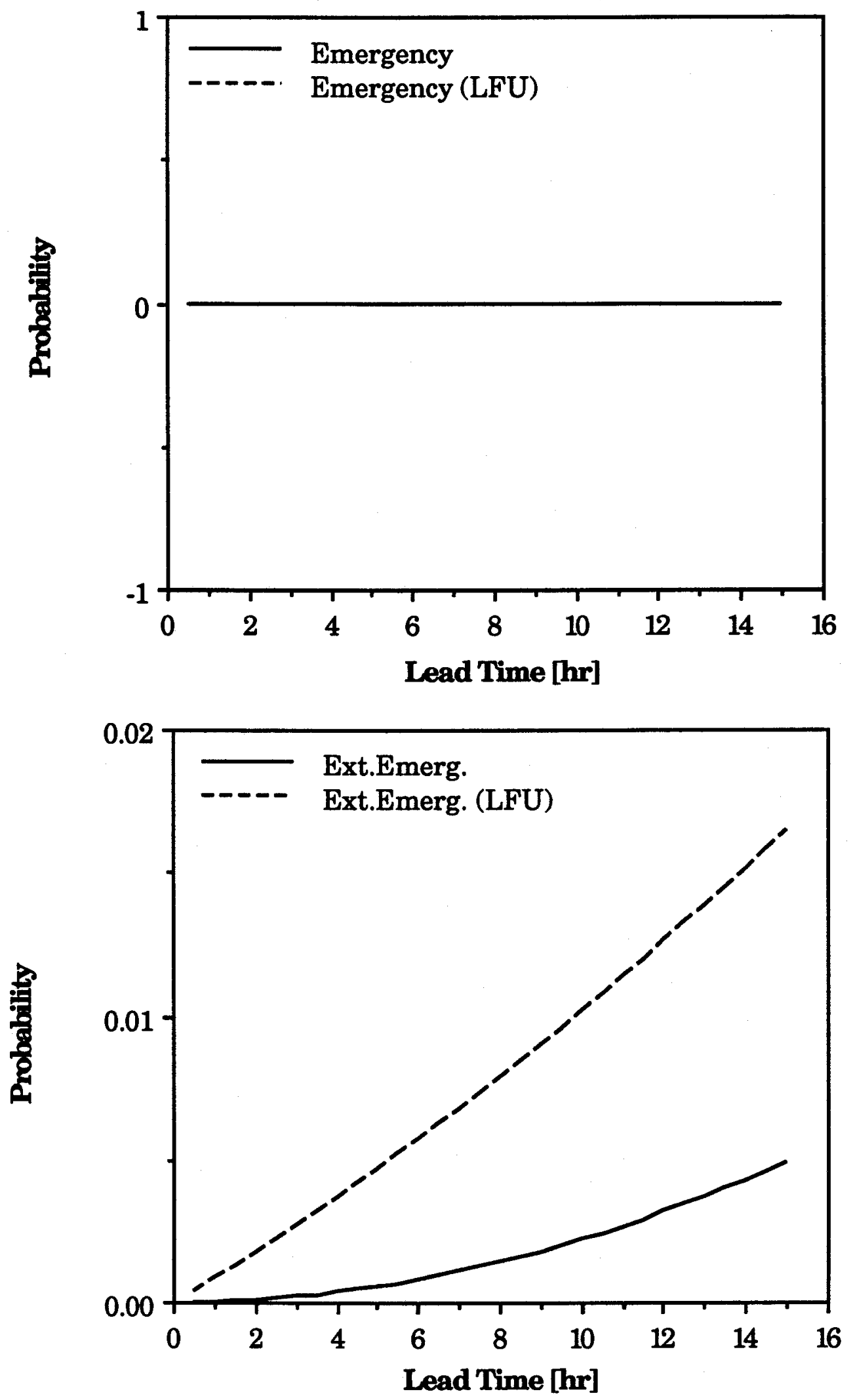

Figure 6.3: Probabilities of the Emergency and Extreme Emergency States with Lead Time. 
Table 6.6: System Operating State Probabilities for a Load Level of 1995 MW When the Number of Committed Units is Fixed at 13 and with Load Forecast Uncertainty.

\begin{tabular}{|c|c|c|c|c|c|c|}
\hline $\begin{array}{c}\text { Lead } \\
\text { Time } \\
\text { [Hr] }\end{array}$ & $\begin{array}{c}\text { No.of } \\
\text { units }\end{array}$ & Normal & Alert & Emergency & $\begin{array}{c}\text { Extreme } \\
\text { Emergency }\end{array}$ & GSOSR \\
\hline 0.5 & 13 & 0.68763649 & 0.31193452 & 0 & 0.00042899 & 0.00042899 \\
\hline 1 & 13 & 0.68428774 & 0.31484563 & 0 & 0.00086663 & 0.00086663 \\
\hline 2 & 13 & 0.67763429 & 0.32059803 & 0 & 0.00176767 & 0.00176767 \\
\hline 3 & 13 & 0.67103920 & 0.32625801 & 0 & 0.00270279 & 0.00270279 \\
\hline 4 & 13 & 0.66450200 & 0.33182639 & 0 & 0.00367161 & 0.00367161 \\
\hline 5 & 13 & 0.65802225 & 0.33730397 & 0 & 0.00467378 & 0.00467378 \\
\hline 6 & 13 & 0.65159950 & 0.34269155 & 0 & 0.00570895 & 0.00570895 \\
\hline 7 & 13 & 0.64523329 & 0.34798994 & 0 & 0.00677677 & 0.00677677 \\
\hline 8 & 13 & 0.63892319 & 0.35319992 & 0 & 0.00787689 & 0.00787689 \\
\hline 9 & 13 & 0.63266875 & 0.35832229 & 0 & 0.00900896 & 0.00900896 \\
\hline 10 & 13 & 0.62646955 & 0.36335782 & 0 & 0.01017263 & 0.01017263 \\
\hline 15 & 13 & 0.59628685 & 0.3872601 & 0 & 0.01645304 & 0.01645304 \\
\hline
\end{tabular}

\subsection{Effect of Peak Load Variation}

In order to demonstrate the effect of peak load variation on the system operating state probabilities, the lead time in this study is fixed at 4 hours and the system peak load is varied. The peak load level is varied from $40 \%$ to $100 \%$ of the annual peak load of $2850 \mathrm{MW}$ in steps of $10 \%$.

Table 6.7 shows the number of committed units and the system operating state probabilities for the selected load levels when the specified GSOSR is 0.001 . The results are presented in Figures 6.4 to 6.6. The number of units that must be committed varies between 8 and 28 . 
Table 6.7: Unit Commitment and System Operating State Probabilities for Different Load Levels.

\begin{tabular}{|c|c|c|c|c|c|c|}
\hline $\begin{array}{l}\text { Load } \\
\text { Level } \\
\text { [MW] }\end{array}$ & $\begin{array}{c}\text { No.of } \\
\text { units }\end{array}$ & Normal & Alert & Emergency & $\begin{array}{c}\text { Extreme } \\
\text { Emergency }\end{array}$ & GSOSR \\
\hline 1140 & 8 & 0.97719573 & 0.02266299 & 0 & 0.00014127 & 0.00014127 \\
\hline 1425 & 10 & 0.97684725 & 0.02298005 & 0 & 0.00017271 & 0.00017271 \\
\hline 1710 & 12 & 0.96871937 & 0.03104789 & 0 & 0.00023273 & 0.00023273 \\
\hline 1995 & 13 & 0.95691649 & 0.04272104 & 0 & 0.00036247 & 0.00036247 \\
\hline 2280 & 16 & 0.95424218 & 0.04536093 & 0 & 0.00039689 & 0.00039689 \\
\hline 2565 & 19 & 0.93958229 & 0.05987774 & 0 & 0.00053997 & 0.00053997 \\
\hline 2850 & 28 & 0.91916923 & 0.08011214 & 0 & 0.00071863 & 0.00071863 \\
\hline
\end{tabular}

Table 6.8 shows the number of required generating units and the system operating state probabilities for the selected load levels when load forecast uncertainty is also included. The results are presented in Figures 6.4 to 6.6. The number of committed units for the case with load forecast uncertainty is either equal to or greater than that of the case with zero load forecast error and varies from 9 to 32 . The required number of generating units for a $100 \%$ peak load, i.e. $2850 \mathrm{MW}$, is 28 when load forecast error is zero, whereas all 32 units must be committed for this load level when the forecast load has standard deviation of $4 \%$ of the forecast mean. 

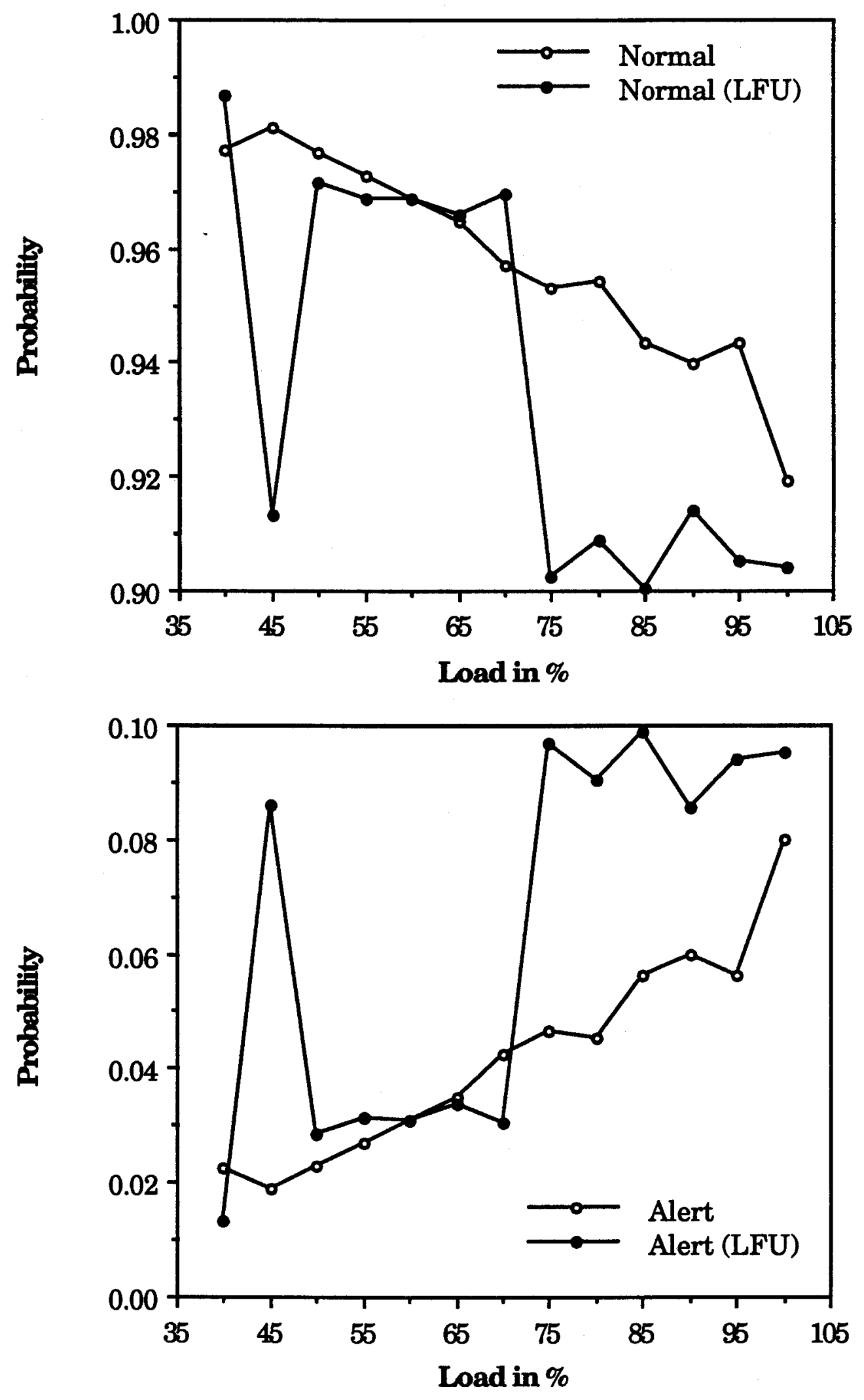

Figure 6.4: Probabilities of the Normal and Alert States with Peak Load. 

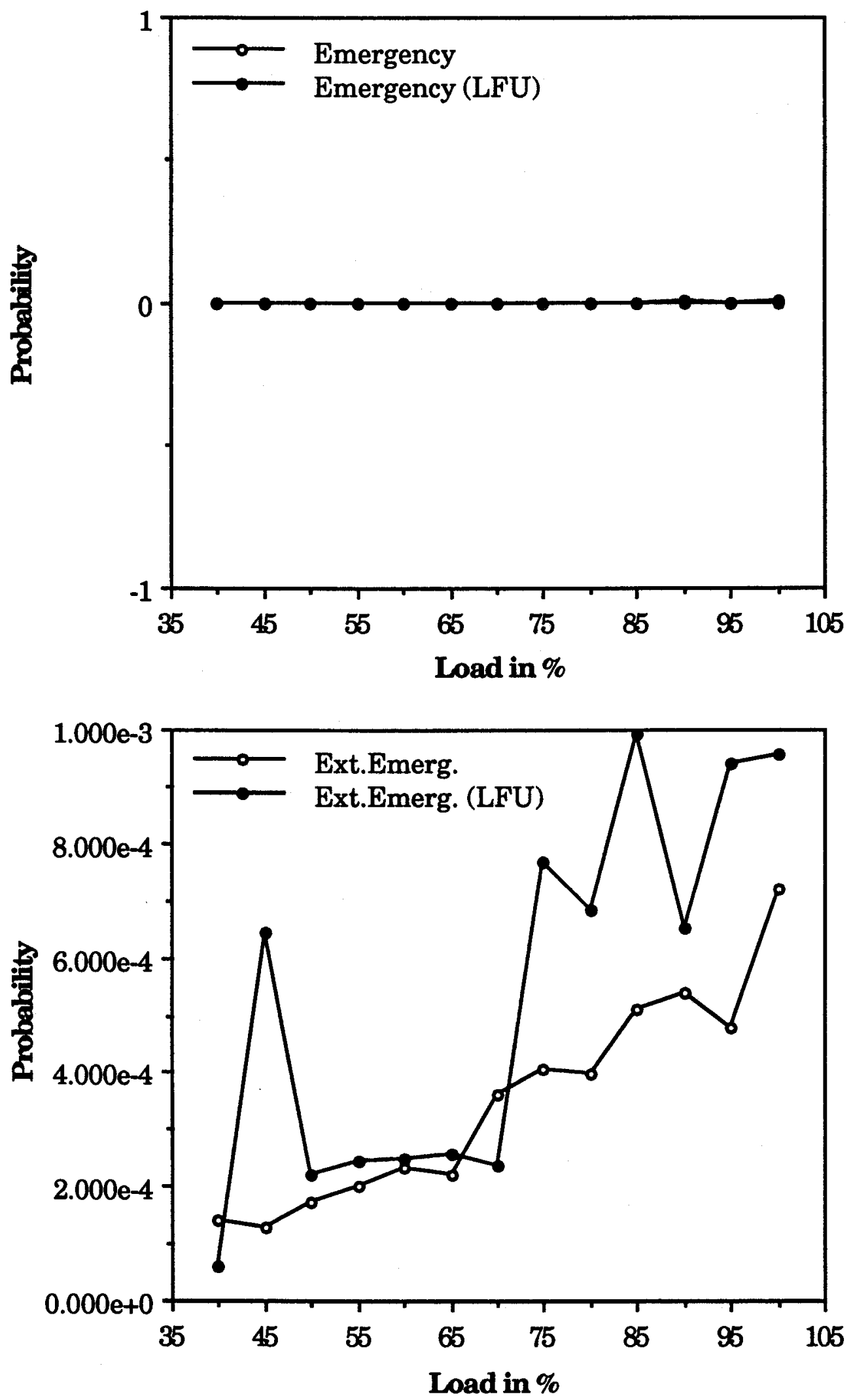

Figure 6.5: Probabilities of the Emergency and Extreme Emergency States with Peak Load. 

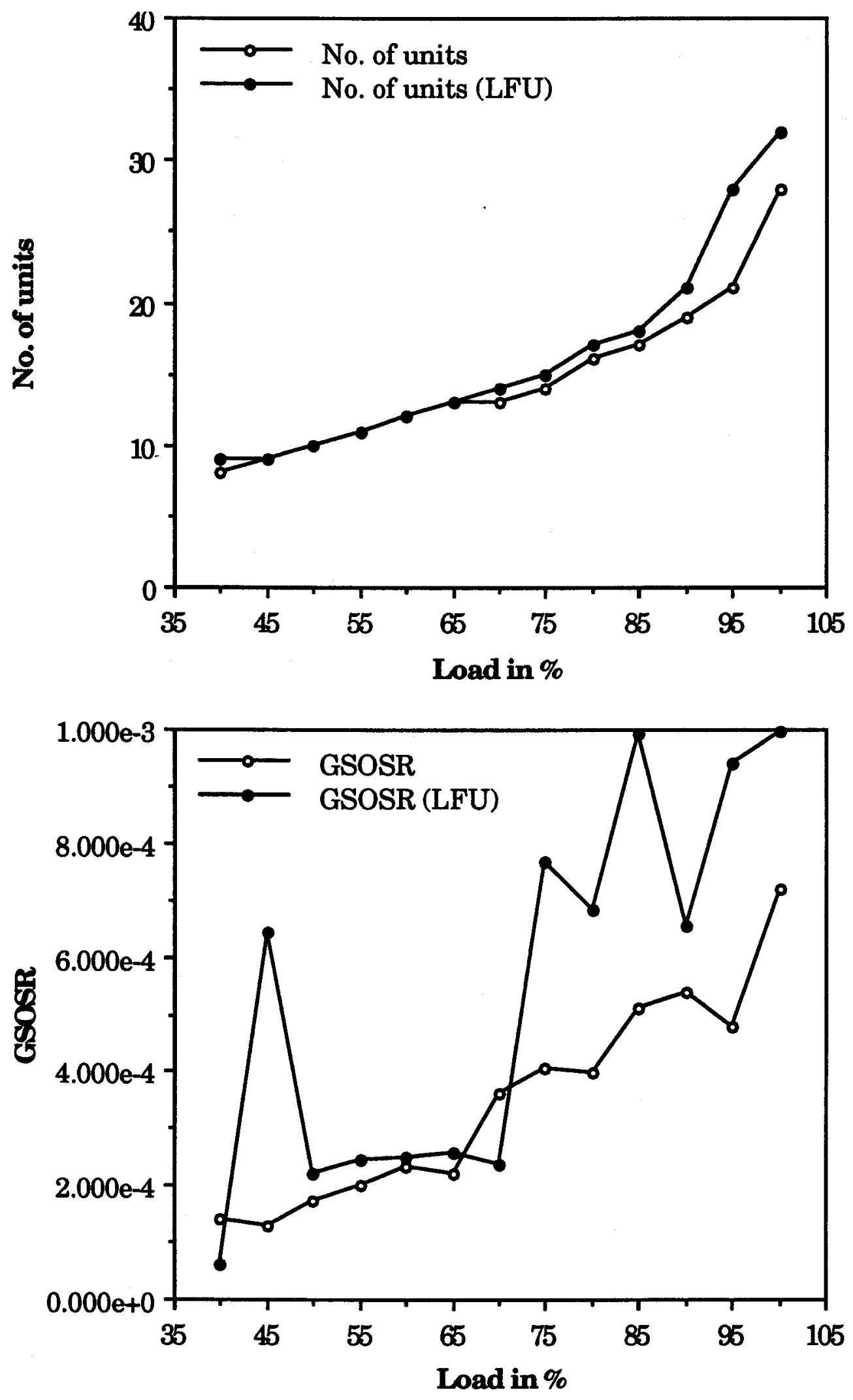

Figure 6.6: Variation of the Number of Required Generating Units and the GSOSR with Peak Load. 
Table 6.8: Unit Commitment and System Operating State Probabilities for Different Load Levels Considering Load Forecast Uncertainty.

\begin{tabular}{|c|c|c|c|c|c|c|}
\hline $\begin{array}{l}\text { Load } \\
\text { Level } \\
\text { [MW] }\end{array}$ & $\begin{array}{c}\text { No.of } \\
\text { units }\end{array}$ & Normal & Alert & Emergency & $\begin{array}{c}\text { Extreme } \\
\text { Emergency }\end{array}$ & GSOSR \\
\hline 1140 & 9 & 0.98668326 & 0.01325726 & 0 & 0.00005949 & 0.00005949 \\
\hline 1425 & 10 & 0.97132486 & 0.02845462 & 0 & 0.00022052 & 0.00022052 \\
\hline 1710 & 12 & 0.96870474 & 0.03104591 & 0 & 0.00024935 & 0.00024935 \\
\hline 1995 & 14 & 0.96929570 & 0.03046553 & 0 & 0.00023877 & 0.00023877 \\
\hline 2280 & 17 & 0.90898406 & 0.09033203 & 0 & 0.00068390 & 0.00068390 \\
\hline 2565 & 21 & 0.91390819 & 0.08543915 & 0.00000009 & 0.00065257 & 0.00065266 \\
\hline 2850 & 32 & 0.90398142 & 0.09502260 & 0.00004193 & 0.00095405 & 0.00099598 \\
\hline
\end{tabular}

\subsection{Effect of Inclusion of Rapid Start and Hot Reserve Units}

The system risk can be alleviated by including stand-by units in the operating reserve assessment. It was assumed that in addition to the capacity shown in Table 6.1 there are several $25 \mathrm{MW}$ gas turbine units [37] and several $100 \mathrm{MW}$ hot reserve units available to the IEEE-RTS. The number varies with the case under consideration. The gas turbine and hot reserve units can be called into operation after lead times of 10 minutes and 1 hour respectively. The corresponding transition rates of the rapid start and hot reserve units are taken from Table 4.1 of Chapter 4.

Table 6.9 shows the number of units that must be committed for different load levels when the system has one rapid start and one hot reserve unit in addition to those units in Table 6.1. The system lead time is assumed to be 4 hours and the specified risk is considered to be 0.001 . The GSOSR and the system operating state probabilities were determined using 
the procedure explained in Section 4.3 of Chapter 4. For a given load level, the required spinning reserve usually reduces by adding stand-by units to the system. The unit commitment for some of the load levels remains unchanged even with one rapid start and one hot reserve unit. The corresponding GSOSR, however, decreases due to the availability of the stand-by capacity.

In order to illustrate the effect of including stand-by units on the system operating state probabilities, another study was conducted in which the system peak load was fixed at 1995 MW for an operating capacity of 2406 MW (13 units), assuming that various numbers of rapid start and hot reserve units are available.

Table 6.9: Unit Commitment and System Operating State Probabilities with one Rapid Start and one Hot reserve Unit.

\begin{tabular}{|c|c|c|c|c|c|c|}
\hline $\begin{array}{l}\text { Load } \\
\text { Level } \\
\text { [MW] }\end{array}$ & $\begin{array}{c}\text { No.of } \\
\text { units }\end{array}$ & Normal & Alert & Emergency & $\begin{array}{c}\text { Extreme } \\
\text { Emergency }\end{array}$ & GSOSR \\
\hline 1140 & 8 & 0.97724740 & 0.02266419 & 0 & 0.00008841 & 0.00008841 \\
\hline 1425 & 10 & 0.97696578 & 0.02298283 & 0 & 0.00005138 & 0.00005138 \\
\hline 1710 & 11 & 0.00004817 & 0.99907192 & 0 & 0.00087992 & 0.00087992 \\
\hline 1995 & 13 & 0.95700364 & 0.04272493 & 0 & 0.00027143 & 0.00027143 \\
\hline 2280 & 15 & 0.00004813 & 0.99896070 & 0 & 0.00099117 & 0.00099117 \\
\hline 2565 & 19 & 0.93990792 & 0.05989848 & 0 & 0.00019360 & 0.00019360 \\
\hline 2850 & 28 & 0.91953272 & 0.08014379 & 0.00000002 & 0.00032347 & 0.00032349 \\
\hline
\end{tabular}

Table 6.10 shows the system operating state probabilities when the system has various numbers of rapid start units and no hot reserve unit. The number of rapid start units varies from 1 to 10 . Tables 6.11 and 6.12 
show the results when the system has various numbers of rapid start units and one or two hot reserve units respectively. The results are presented in Figures 6.7 and 6.8. It can be seen from the results that for a given number of rapid start units, the probabilities of the normal and the alert states increase when the number of hot reserve units is increased. For this system, it is evident that no benefit is derived by having more than 3 hot reserve units. The indices are virtually unaffected by adding more than 10 rapid start units. The reason for this is that stand-by units do not contribute during the total period of the system lead time and only marginally affect the total risk in the area risk curve.

Table 6.10: System Operating State Probabilities with Different Numbers of Rapid Start Units and no Hot Reserve Units.

\begin{tabular}{|c|c|c|c|c|c|c|}
\hline \multirow[b]{2}{*}{ NRS } & \multirow[b]{2}{*}{ NHR } & \multicolumn{4}{|c|}{ Probability of } & \multirow[b]{2}{*}{ GSOSR } \\
\hline & & Normal & Alert & Emergency & $\begin{array}{c}\text { Extreme } \\
\text { Emergency }\end{array}$ & \\
\hline 1 & 0 & 0.95691649 & 0.04272104 & 0 & 0.00036247 & 0.00036247 \\
\hline 2 & 0 & 0.95694647 & 0.04272238 & 0 & 0.00033115 & 0.00033115 \\
\hline 3 & 0 & 0.95696196 & 0.04272307 & 0 & 0.00031496 & 0.00031496 \\
\hline 4 & 0 & 0.95698036 & 0.04272389 & 0 & 0.00029574 & 0.00029574 \\
\hline 5 & 0 & 0.95699522 & 0.04272456 & 0 & 0.00028022 & 0.00028022 \\
\hline 6 & 0 & 0.95702505 & 0.04272589 & 0 & 0.00024907 & 0.00024907 \\
\hline 7 & 0 & 0.95706187 & 0.04272753 & 0 & 0.00021060 & 0.00021060 \\
\hline 8 & 0 & 0.95710095 & 0.04272927 & 0 & 0.00016977 & 0.00016977 \\
\hline 9 & 0 & 0.95713812 & 0.04273093 & 0 & 0.00013095 & 0.00013095 \\
\hline 10 & 0 & 0.95716901 & 0.04273231 & 0 & 0.00009868 & 0.00009868 \\
\hline
\end{tabular}

NRS = Number of Rapid Start units NHR = Number of Hot Reserve units 
Table 6.11: System Operating State Probabilities with Different Numbers of Rapid Start Units and One Hot Reserve Unit.

\begin{tabular}{|c|c|c|c|c|c|c|}
\hline \multirow[b]{2}{*}{ NRS } & \multirow[b]{2}{*}{ NHR } & \multicolumn{4}{|c|}{ Probability of } & \multirow[b]{2}{*}{ GSOSR } \\
\hline & & Normal & Alert & Emergency & $\begin{array}{c}\text { Extreme } \\
\text { Emergency }\end{array}$ & \\
\hline 1 & 1 & 0.95700364 & 0.04272493 & 0 & 0.00027143 & 0.00027143 \\
\hline 2 & 1 & 0.95706891 & 0.04272784 & 0 & 0.00020324 & 0.00020324 \\
\hline 3 & 1 & 0.95710284 & 0.04272936 & 0 & 0.00016780 & 0.00016780 \\
\hline 4 & 1 & 0.95714063 & 0.04273104 & 0 & 0.00012833 & 0.00012833 \\
\hline 5 & 1 & 0.95717075 & 0.04273239 & 0 & 0.00009686 & 0.00009686 \\
\hline 6 & 1 & 0.95719135 & 0.04273331 & 0 & 0.00007534 & 0.00007534 \\
\hline 7 & 1 & 0.95720379 & 0.04273386 & 0 & 0.00006234 & 0.00006234 \\
\hline 8 & 1 & 0.95721156 & 0.04273421 & 0 & 0.00005423 & 0.00005423 \\
\hline 9 & 1 & 0.95721672 & 0.04273444 & 0 & 0.00004884 & 0.00004884 \\
\hline 10 & 1 & 0.95722119 & 0.04273464 & 0 & 0.00004418 & 0.00004418 \\
\hline
\end{tabular}

Table 6.12: System Operating State Probabilities with Different Numbers of Rapid Start and Two Hot Reserve Units.

\begin{tabular}{|c|c|c|c|c|c|c|}
\hline \multirow[b]{2}{*}{ NRS } & \multirow[b]{2}{*}{ NHR } & \multicolumn{4}{|c|}{ Probability of } & \multirow[b]{2}{*}{ GSOSR } \\
\hline & & Normal & Alert & Emergency & $\begin{array}{c}\text { Extreme } \\
\text { Emergency }\end{array}$ & \\
\hline 1 & 2 & 0.95719359 & 0.04273341 & 0 & 0.00007300 & 0.00007300 \\
\hline 2 & 2 & 0.95719944 & 0.04273367 & 0 & 0.00006689 & 0.00006689 \\
\hline 3 & 2 & 0.95720226 & 0.04273379 & 0 & 0.00006395 & 0.00006395 \\
\hline 4 & 2 & 0.95720575 & 0.04273395 & 0 & 0.00006030 & 0.00006030 \\
\hline 5 & 2 & 0.95720845 & 0.04273407 & 0 & 0.00005748 & 0.00005748 \\
\hline 6 & 2 & 0.95721542 & 0.04273438 & 0 & 0.00005020 & 0.00005020 \\
\hline 7 & 2 & 0.95722414 & 0.04273477 & 0 & 0.00004108 & 0.00004108 \\
\hline 8 & 2 & 0.95723316 & 0.04273517 & 0 & 0.00003167 & 0.00003167 \\
\hline 9 & 2 & 0.95724131 & 0.04273554 & 0 & 0.00002315 & 0.00002315 \\
\hline 10 & 2 & 0.95724777 & 0.04273583 & 0 & 0.00001641 & 0.00001641 \\
\hline
\end{tabular}



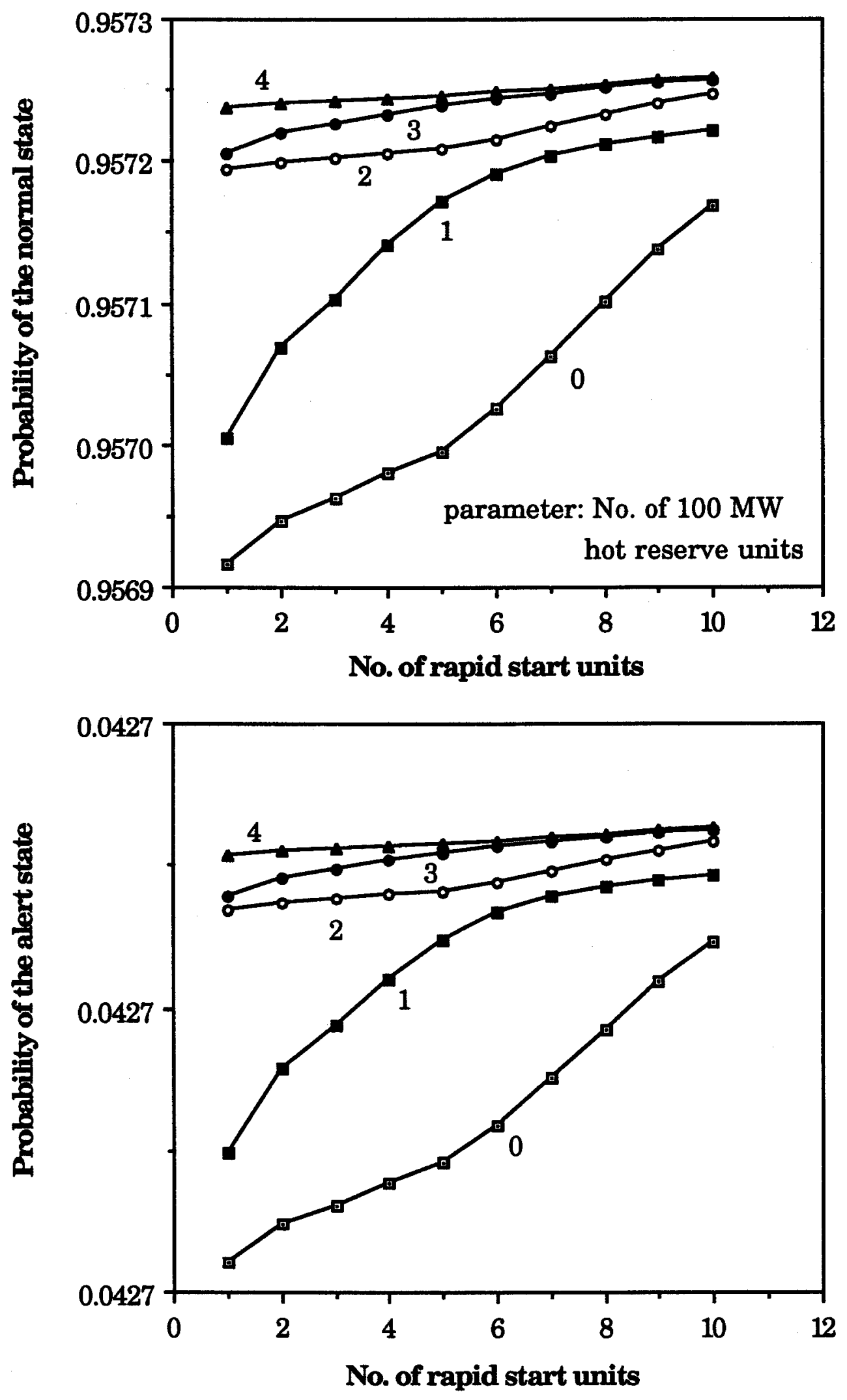

Figure 6.7: Probabilities of the Normal and Alert States with Rapid Start Units. 

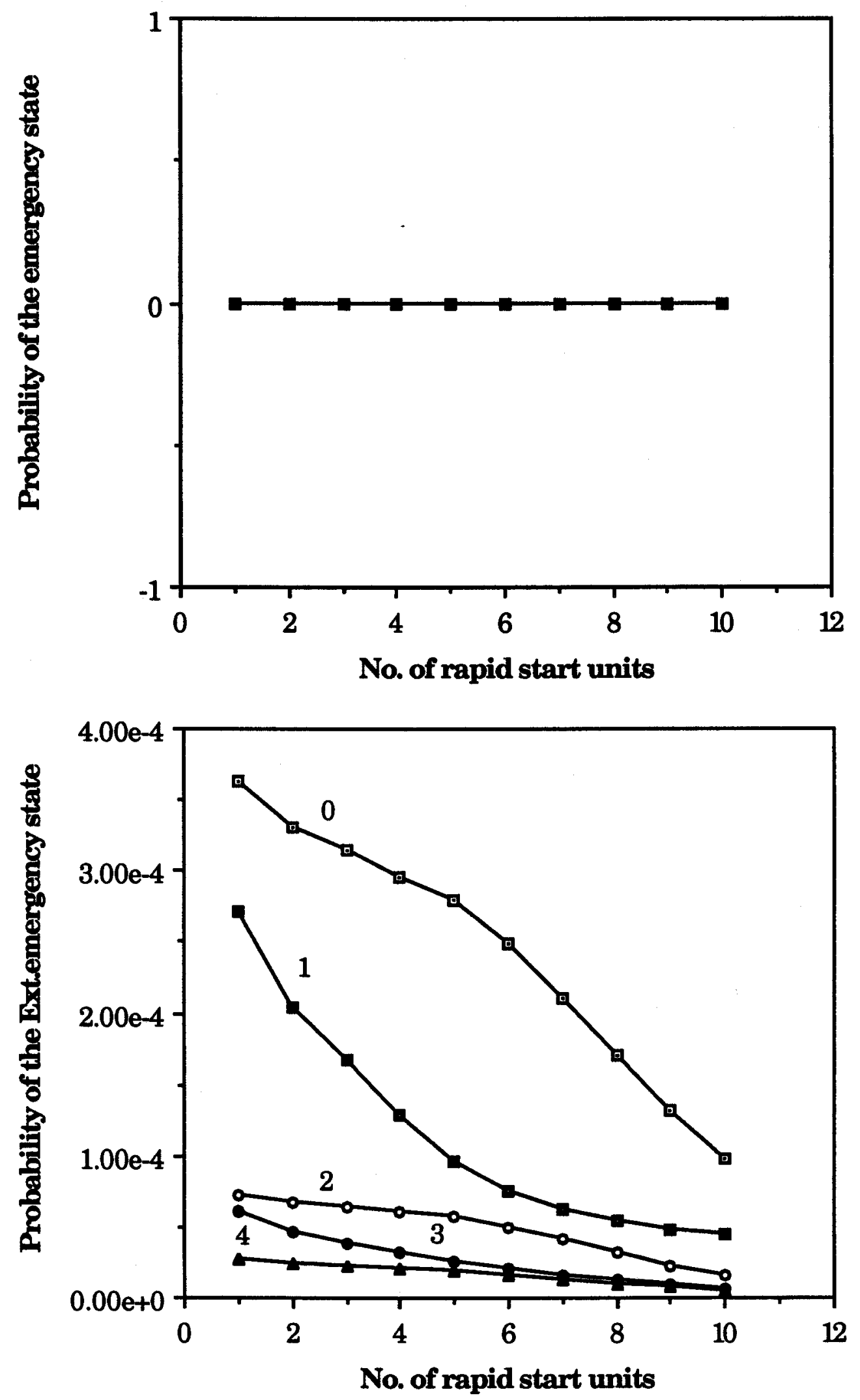

Figure 6.8: Probabilities of the Emergency and Extreme Emergency States with Rapid Start Units. 


\subsection{Effect of Outage Postponability}

The IEEE-RTS has 24 thermal units ranging from $12 \mathrm{MW}$ to $350 \mathrm{MW}$. In this system, it is assumed that $1 * 350 \mathrm{MW}$ and $3 * 197 \mathrm{MW}$ thermal units can have some of their outages postponed with different values of $\beta$. Table 6.13 shows the priority loading order and the corresponding failure rates of these units, taken from Table 6.1.

Table 6.13: Data for Considering Postponable Outage Units.

\begin{tabular}{|c|c|c|c|}
\hline $\begin{array}{c}\text { Priority } \\
\text { loading } \\
\text { order }\end{array}$ & $\begin{array}{c}\text { Unit } \\
\text { size } \\
{[\mathrm{MW}]}\end{array}$ & $\begin{array}{c}\text { Unit } \\
\text { type }\end{array}$ & $\begin{array}{c}\text { Failure } \\
\text { rate } \\
{[\mathrm{f} / \mathrm{Yr}]}\end{array}$ \\
\hline 7 & 350 & Thermal & 7.62 \\
\hline $8-10$ & 197 & Thermal & 9.22 \\
\hline
\end{tabular}

For a specified GSOSR of 0.001 and a system lead time of 4 hours, the number of committed units and the system operating state probabilities are shown in Table 6.14. The system load is assumed to be $1995 \mathrm{MW}$ and $\beta$ changes from 0 to 1 . The required spinning capacity usually decreases as the degree of postponability, i.e. $\beta$, increases. For this load level, the number of committed units is 13 and does not change as $\beta$ increases. However, the corresponding GSOSR decreases due to inclusion of postponable outages. The IEEE-RTS must commit its 14th unit in addition to the 13 units already committed when load forecast uncertainty is considered with a standard deviation of $4 \%$. The results are shown in Table 6.15 . 
Table 6.14: Unit Commitment and System Operating State Probabilities for Different Values of $\beta$.

\begin{tabular}{|c|c|c|c|c|c|c|}
\hline \multirow[b]{2}{*}{$\beta$} & \multirow[b]{2}{*}{$\begin{array}{l}\text { No.of } \\
\text { units }\end{array}$} & \multicolumn{4}{|c|}{ Probability of } & \multirow[b]{2}{*}{ GSOSR } \\
\hline & & Normal & Alert & Emergency & $\begin{array}{c}\text { Extreme } \\
\text { Emergency }\end{array}$ & \\
\hline 0 & 13 & 0.95691649 & 0.04272104 & 0 & 0.00036247 & 0.00036247 \\
\hline 0.1 & 13 & 0.95846525 & 0.04119631 & 0 & 0.00033844 & 0.00033844 \\
\hline 0.2 & 13 & 0.96001589 & 0.03966885 & 0 & 0.00031527 & 0.00031527 \\
\hline 0.3 & 13 & 0.96156840 & 0.03813864 & 0 & 0.00029296 & 0.00029296 \\
\hline 0.4 & 13 & 0.96312279 & 0.03660569 & 0 & 0.00027152 & 0.00027152 \\
\hline 0.5 & 13 & 0.96467907 & 0.03506999 & 0 & 0.00025094 & 0.00025094 \\
\hline 0.6 & 13 & 0.96623722 & 0.03353155 & 0 & 0.00023123 & 0.00023123 \\
\hline 0.7 & 13 & 0.96779726 & 0.03199035 & 0 & 0.00021239 & 0.00021239 \\
\hline 0.8 & 13 & 0.96935918 & 0.03044641 & 0 & 0.00019441 & 0.00019441 \\
\hline 0.9 & 13 & 0.97092298 & 0.02889971 & 0 & 0.00017730 & 0.00017730 \\
\hline 1 & 13 & 0.97248868 & 0.02735026 & 0 & 0.00016106 & 0.00016106 \\
\hline
\end{tabular}

Table 6.15: Unit Commitment and System Operating State Probabilities for Different Values of $\beta$ Considering Load Forecast Uncertainty.

\begin{tabular}{|c|c|c|c|c|c|c|}
\hline \multirow{2}{*}{$\beta$} & \multirow{2}{*}{$\begin{array}{c}\text { No.of } \\
\text { units }\end{array}$} & Normal & Alert & Emergency & $\begin{array}{c}\text { Extreme } \\
\text { Emergency }\end{array}$ & \multirow{2}{*}{ GSOSR } \\
\hline 0 & 14 & 0.96929570 & 0.03046553 & 0 & 0.00023877 & 0.00023877 \\
\hline 0.1 & 14 & 0.97048614 & 0.02929050 & 0 & 0.00022337 & 0.00022337 \\
\hline 0.2 & 14 & 0.97167757 & 0.02811418 & 0 & 0.00020825 & 0.00020825 \\
\hline 0.3 & 14 & 0.97287001 & 0.02693658 & 0 & 0.00019341 & 0.00019341 \\
\hline 0.4 & 14 & 0.97406345 & 0.02575770 & 0 & 0.00017885 & 0.00017885 \\
\hline 0.5 & 14 & 0.97525789 & 0.02457754 & 0 & 0.00016457 & 0.00016457 \\
\hline 0.6 & 14 & 0.97645334 & 0.02339609 & 0 & 0.00015057 & 0.00015057 \\
\hline 0.7 & 14 & 0.97764979 & 0.02221336 & 0 & 0.00013685 & 0.00013685 \\
\hline 0.8 & 14 & 0.97884724 & 0.02102935 & 0 & 0.00012341 & 0.00012341 \\
\hline 0.9 & 14 & 0.98004570 & 0.01984405 & 0 & 0.00011025 & 0.00011025 \\
\hline 1 & 14 & 0.98124516 & 0.01865748 & 0 & 0.00009736 & 0.00009736 \\
\hline
\end{tabular}


In order to demonstrate the effect of various degrees of postponability on the system operating state probabilities with and without load forecast uncertainty another study was conducted in which the number of committed units was fixed at 13 and the indices were calculated for a load level of $1995 \mathrm{MW}$ and $4 \%$ load forecast uncertainty. The results are shown in Table 6.16.

Table 6.16: System Operating State Probabilities for Different Values of $\beta$ and Fixed Number of Units, Considering Load Forecast Uncertainty.

\begin{tabular}{|c|c|c|c|c|c|c|}
\hline & \multirow{2}{*}{$\beta$} & No.of & \multicolumn{5}{|c|}{ Probability of } & \multirow{2}{*}{ GSOSR } \\
\cline { 5 - 7 } & units & & Alert & Emergency & $\begin{array}{c}\text { Extreme } \\
\text { Emergency }\end{array}$ & \\
\hline 0 & 13 & 0.66450200 & 0.33182639 & 0 & 0.00367161 & 0.00367161 \\
\hline 0.1 & 13 & 0.66557011 & 0.33089579 & 0 & 0.00353409 & 0.00353409 \\
\hline 0.2 & 13 & 0.66663951 & 0.32996308 & 0 & 0.00339741 & 0.00339741 \\
\hline 0.3 & 13 & 0.66771019 & 0.32902826 & 0 & 0.00326155 & 0.00326155 \\
\hline 0.4 & 13 & 0.66878216 & 0.32809131 & 0 & 0.00312653 & 0.00312653 \\
\hline 0.5 & 13 & 0.66985541 & 0.32715225 & 0 & 0.00299234 & 0.00299234 \\
\hline 0.6 & 13 & 0.67092996 & 0.32621106 & 0 & 0.00285898 & 0.00285898 \\
\hline 0.7 & 13 & 0.67200579 & 0.32526775 & 0 & 0.00272646 & 0.00272646 \\
\hline 0.8 & 13 & 0.67308291 & 0.32432232 & 0 & 0.00259477 & 0.00259477 \\
\hline 0.9 & 13 & 0.67416133 & 0.32337475 & 0 & 0.00246392 & 0.00246392 \\
\hline 1 & 13 & 0.67524104 & 0.32242506 & 0 & 0.00233390 & 0.0023339 \\
\hline
\end{tabular}

Figures 6.9 and 6.10 show the results of the above three cases. It can be seen as $\beta$ increases, the probability of the normal state increases whereas the probabilities of the alert and extreme emergency states decrease. For a given value of $\beta$ and the same number of committed units, 

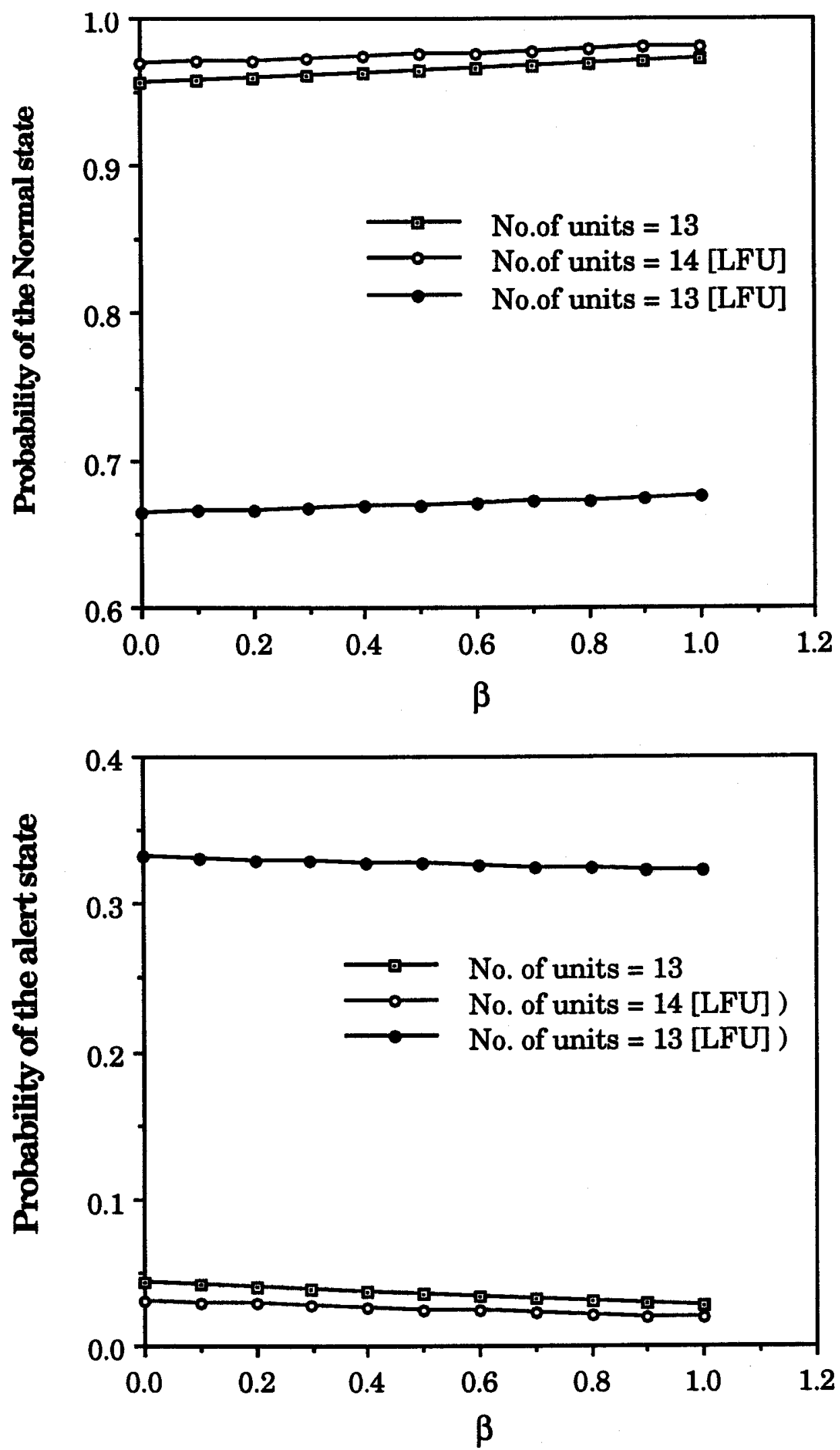

Figure 6.9: Probabilities of the Normal and Alert States with $\beta$. 

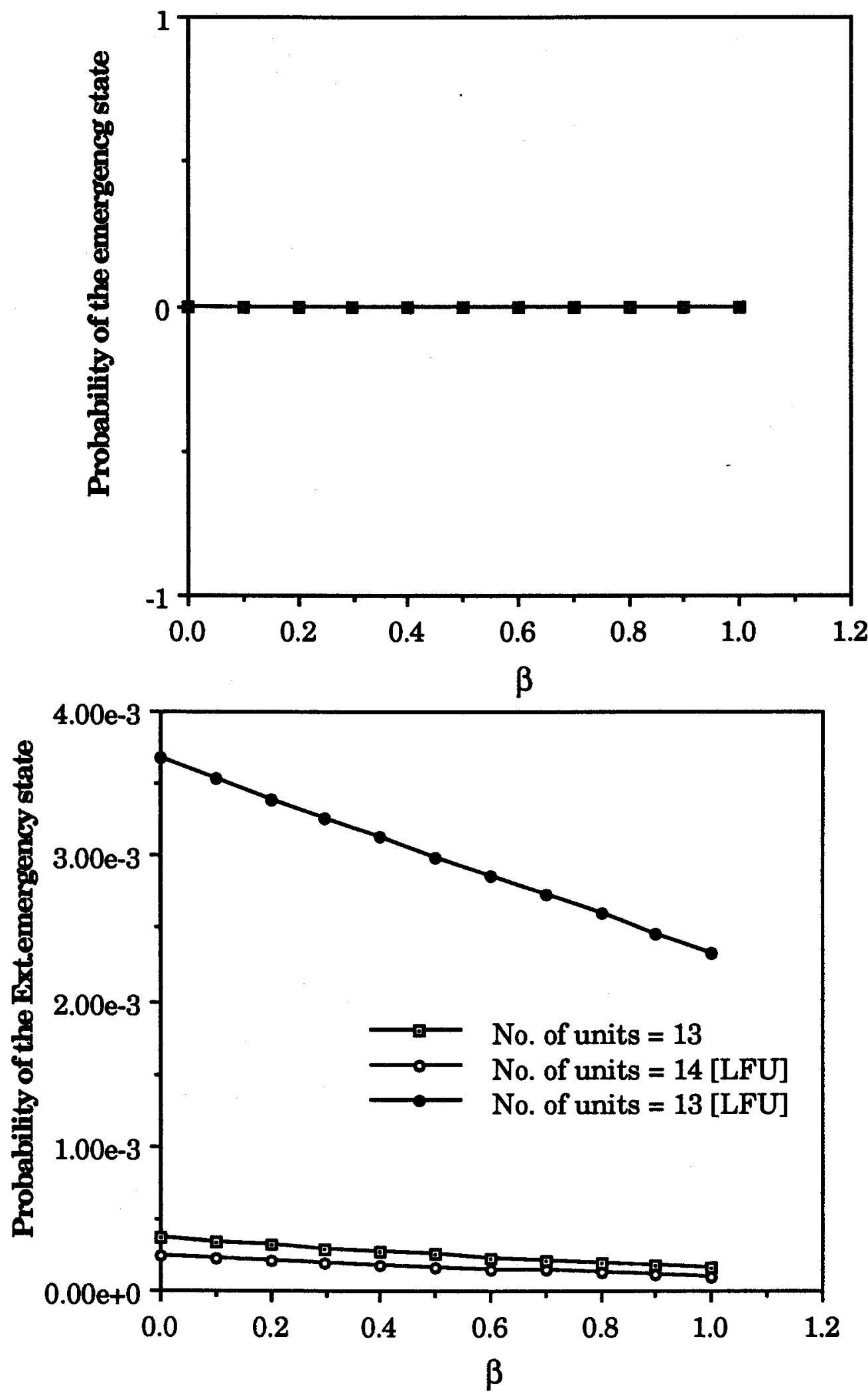

Figure 6.10: Probabilities of the Emergency and Extreme Emergency States with $\beta$. 
the probability of the normal state corresponding to zero load forecast uncertainty is greater than that corresponding to the $4 \%$ load forecast uncertainty.

\section{Effect of Interruptible Loads}

The presence of interruptible loads can affect the GSOSR and the system operating state probabilities. The ability of a system to interrupt its load can be considered as an ability to bring ready reserve into the system depending on the allowable time delay of the load interruption. Two different studies were conducted to incorporate the effect of interruptible load on the system operating state probabilities and number of required units. These studies are, 1) Variation in the magnitude of the interruptible load and 2) Variation in the interruptible load lead time.

In the first study, it was assumed that the IEEE-RTS has the ability to interrupt load ranging from 50 to $140 \mathrm{MW}$ within an allowable lead time of 10 minutes. The system load is assumed to be $1995 \mathrm{MW}$. Table 6.17 shows the number of committed units and the system operating state probabilities when the system lead time is 4 hours and the specified GSOSR is assumed to be 0.001 . The results are presented in Figures 6.11 and 6.12. It can be seen that as the interruptible load increases, the probabilities of the normal and the alert states increase. The probability of the extreme emergency state however decreases. The number of committed units will decrease to 12 , if the magnitude of the interruptible load increases to $150 \mathrm{MW}$. With this number of committed units, the probability of the normal state decreases to 0.00011011 whereas the probability of the alert state increases to 0.99912392 . 
Table 6.17: Effect of the Magnitude of Interruptible Loads on the System Operating State Probabilities.

\begin{tabular}{|c|c|c|c|c|c|c|}
\hline $\begin{array}{c}\text { Int. } \\
\text { load } \\
\text { [MW] }\end{array}$ & $\begin{array}{c}\text { No.of } \\
\text { units }\end{array}$ & Normal & Alert & Emergency & $\begin{array}{c}\text { Extreme } \\
\text { Emergency }\end{array}$ & GSOSR \\
\hline 0 & 13 & 0.95691649 & 0.04272104 & 0 & 0.00036247 & 0.00036247 \\
\hline 50 & 13 & 0.95697093 & 0.04272347 & 0 & 0.00030560 & 0.00030560 \\
\hline 60 & 13 & 0.95697100 & 0.04272347 & 0 & 0.00030553 & 0.00030553 \\
\hline 70 & 13 & 0.95697100 & 0.04272347 & 0 & 0.00030553 & 0.00030553 \\
\hline 80 & 13 & 0.95697100 & 0.04272347 & 0 & 0.00030553 & 0.00030553 \\
\hline 90 & 13 & 0.95697117 & 0.04272348 & 0 & 0.00030535 & 0.00030535 \\
\hline 100 & 13 & 0.95701187 & 0.04272530 & 0 & 0.00026283 & 0.00026283 \\
\hline 110 & 13 & 0.95701187 & 0.04272530 & 0 & 0.00026283 & 0.00026283 \\
\hline 120 & 13 & 0.95701187 & 0.04272530 & 0 & 0.00026283 & 0.00026283 \\
\hline 130 & 13 & 0.95701187 & 0.04272530 & 0 & 0.00026283 & 0.00026283 \\
\hline 140 & 13 & 0.95705299 & 0.04272713 & 0 & 0.00021988 & 0.00021988 \\
\hline
\end{tabular}

In the second study, it was assumed that for a load level of $1995 \mathrm{MW}$, the system has the ability to interrupt $70 \mathrm{MW}$ of load with various time delays from 10 to 90 minutes. The results are shown in Table 6.18 and presented in Figures 6.13 and 6.14. From the figures, it can be seen that the probabilities of the normal and the alert states decrease as the delay time of interruptible load increases, while the probability of the extreme emergency state increases. The probability of the emergency state in both cases is zero and therefore, the GSOSR is equal to the probability of the extreme emergency state. 

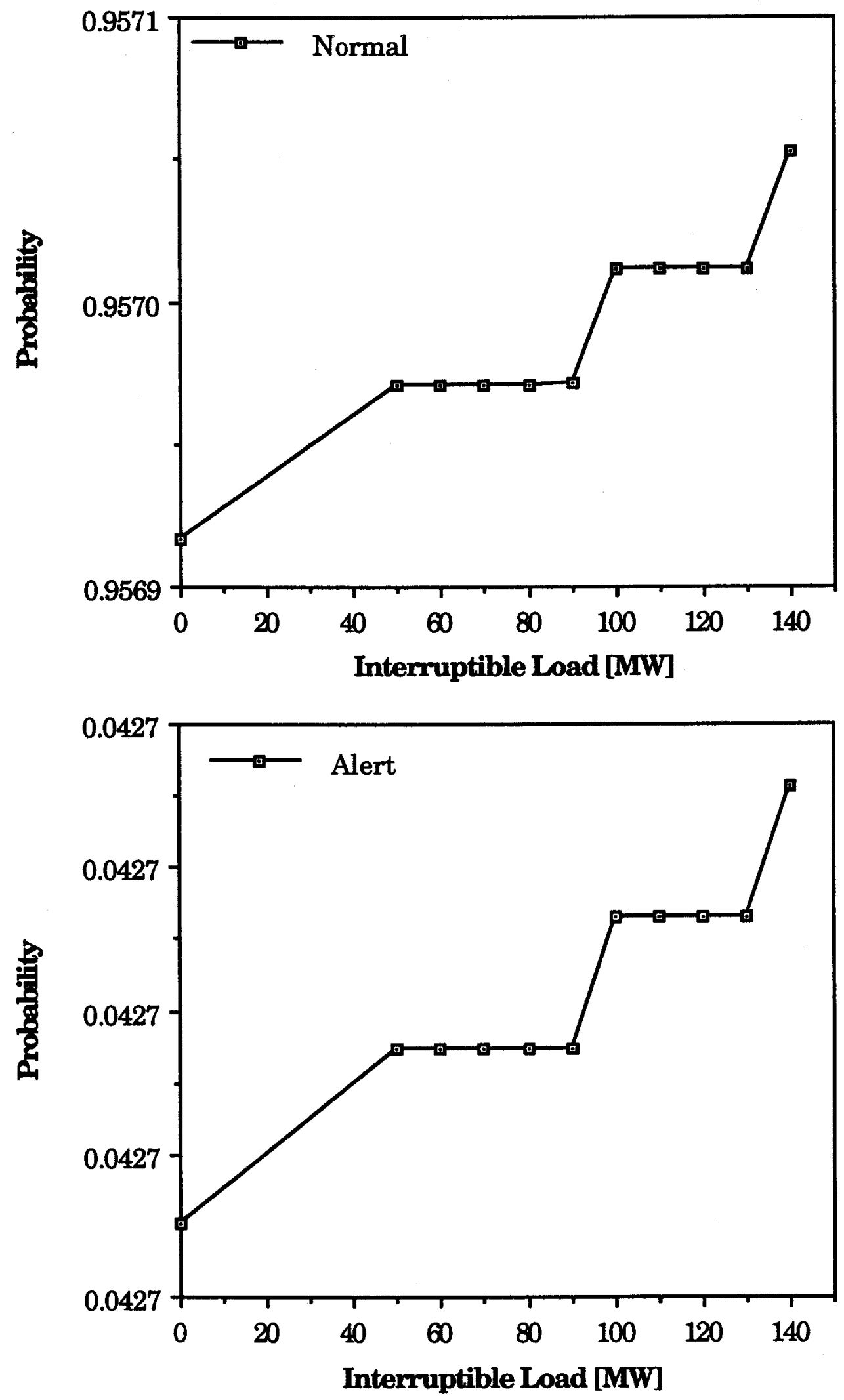

Figure 6.11: Probabilities of the Normal and Alert States with the Magnitude of Interruptible Load. 

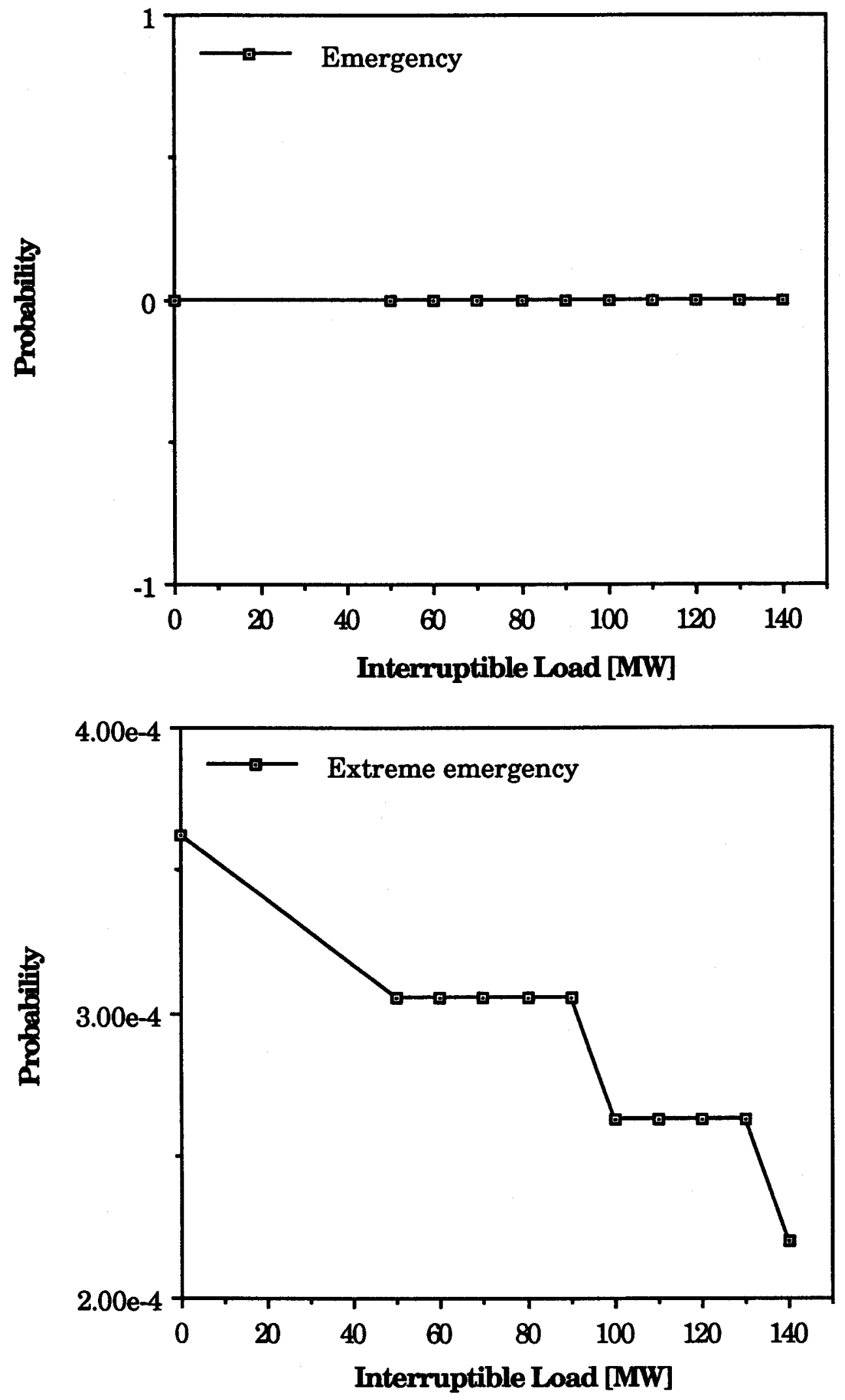

Figure 6.12: Probabilities of the Emergency and Extreme Emergency States with the Magnitude of Interruptible Load. 
Table 6.18: Effect of Interruptible Load Lead time on the System Operating State Probabilities.

\begin{tabular}{|c|c|c|c|c|c|c|}
\hline \multirow[b]{2}{*}{$\begin{array}{c}\text { TI } \\
{[\mathrm{Min}]}\end{array}$} & \multirow[b]{2}{*}{$\begin{array}{l}\text { No.of } \\
\text { units }\end{array}$} & \multicolumn{4}{|c|}{ Probability of } & \multirow[b]{2}{*}{ GSOSR } \\
\hline & & Normal & Alert & Emergency & $\begin{array}{c}\text { Extreme } \\
\text { Emergency }\end{array}$ & \\
\hline 10 & 13 & 0.9569710 & 0.04272347 & $\underline{0}$ & 0.00030553 & 0.00030553 \\
\hline 20 & 13 & 0.95697071 & 0.04272346 & 0 & 0.00030583 & 0.00030583 \\
\hline 30 & 13 & 0.95697022 & 0.04272344 & 0 & 0.00030634 & 0.00030634 \\
\hline 40 & 13 & 0.95696954 & 0.04272341 & 0 & 0.00030705 & 0.00030705 \\
\hline 50 & 13 & 0.95696867 & 0.04272337 & 0 & 0.00030796 & 0.00030796 \\
\hline 60 & 13 & 0.95696761 & 0.04272332 & 0 & 0.00030907 & 0.00030907 \\
\hline 70 & 13 & 0.95696636 & 0.04272327 & 0 & 0.00031038 & 0.00031038 \\
\hline 80 & 13 & 0.95696491 & 0.0427232 & 0 & 0.00031188 & 0.00031188 \\
\hline 90 & 13 & 0.95696328 & 0.04272313 & 0 & 0.00031359 & 0.00031359 \\
\hline
\end{tabular}

\section{9: Summary}

Reliability test systems provide useful references for testing and comparing alternate techniques for power system reliability evaluation. The techniques based on utilising the system operating states in operating reserve assessment have been applied to the IEEE-RTS. Most of the studies conducted are similar to those performed on the RBTS and described in the previous chapters. Application to the IEEE-RTS, however, illustrates the utilization of the developed concepts on a relatively large size system which has similar features to actual operating systems. The effects of lead time and load variation on unit commitment and the system operating state probabilities are presented. Results are also shown for studies which considered additional factors, such as load forecast uncertainty, stand-by and hot reserve units, postponable outages and interruptible loads. 

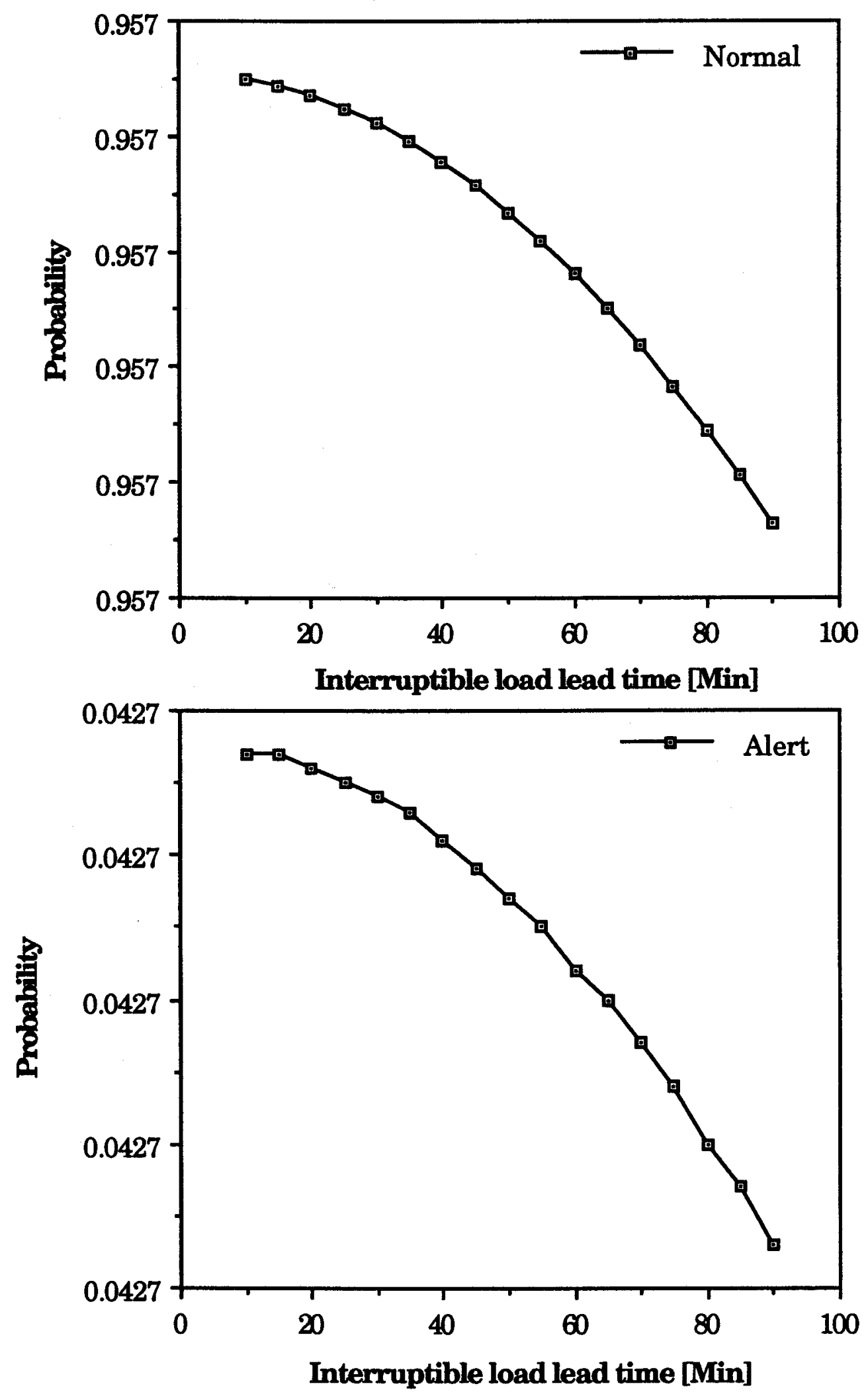

Figure 6.13: Probabilities of the Normal and Alert States with Interruptible Load Lead Time. 

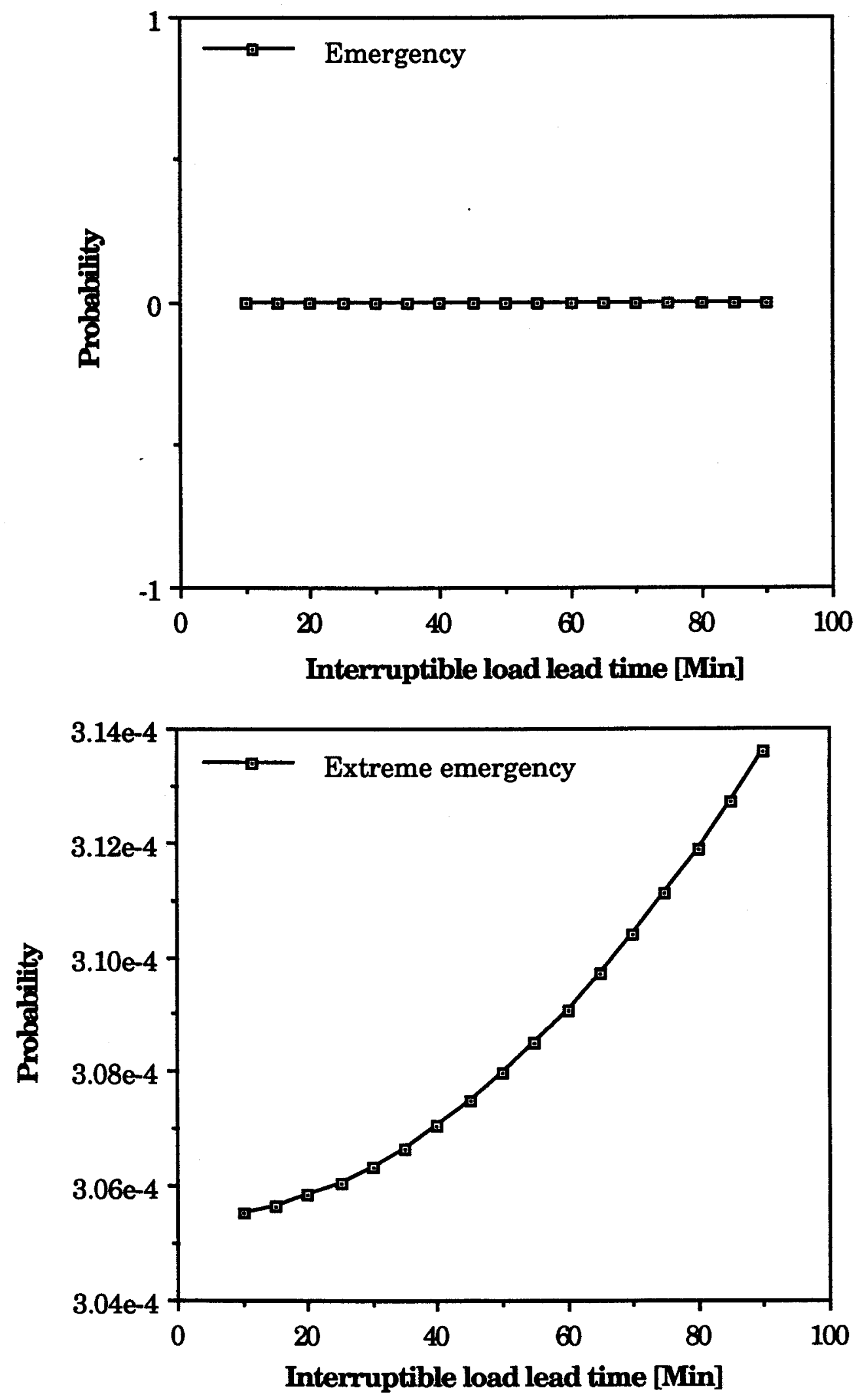

Figure 6.14: Probabilities of the Emergency and Extreme Emergency States with Interruptible Load Lead Time. 


\section{SUMMARY AND CONCLUSIONS}

Operating reserve assessment is normally done using deterministic approaches. The most common deterministic criterion dictates a reserve margin equal to the size of the largest unit or to some percentage of the peak load. The essential weakness of deterministic approaches is that they do not assess the actual system risk and ignore the probabilistic or stochastic nature of system behavior and component failures. Probabilistic techniques, however, provide a more comprehensive and realistic evaluation of the operating reserve by incorporating the stochastic nature of system components. A new probabilistic technique for HL I operating reserve assessment is proposed and illustrated in this thesis. The concepts of the basic probabilistic technique known as the PJM method are illustrated in Chapter 2. On the basis of the PJM method, unit commitment should be such that the risk is less than or equal to a specified value. System performance for a given load and set of committed units can be identified using this method, as being in either the comfort or at risk domains. In the comfort domain, the operating capacity is greater than the load, while in the risk domain it is less than or equal to the load. The only information available to the system operator is the unit commitment risk and its complementary value, i.e. probability of system comfort. The main disadvantages of this method are the restricted information it provides and the associated difficulty in interpreting the information by the system 
operator.

A new probabilistic technique is illustrated in this thesis which overcomes these difficulties associated with the PJM method. In this approach, the generation system is classified into different system operating states designated as normal, alert, emergency and extreme emergency. This technique combines deterministic considerations with probabilistic indices to monitor the system well-being. This combination is achieved by recognizing that the system operating states created by incorporating the system deterministic criteria can be categorized as being healthy, marginal and at risk. These divisions are defined as the system operating zones and quantified by the system operating state probabilities. The basic principles of the new probabilistic technique are developed and discussed in Chapter 3. Operating system health, margin and risk zones are presented and defined in this chapter. It is believed that the proposed technique provides more information to the power system operator than that available from the basic PJM method. This information not only informs the operator of the system risk but, more importantly, provides information on the degree of system well-being, which can not be achieved using the PJM method.

A procedure has been developed to quantify the system operating states in terms of the probability of finding the system in the defined states. No constraint is violated or load curtailed in either the normal or the alert states. A system operating objective is therefore to operate the system with a high probability of being in these two states. The summation of the two probabilities of the normal and the alert states provides an assessment of 
the favorable conditions associated with the system. The complement of the sum of these two state probabilities is considered as a basic risk index in Chapter 3. This risk factor has been designated as the Generating System Operating State Risk (GSOSR). This index risk is identical to the unit commitment risk obtained in the PJM method. Generating units are committed to the system at a particular load level in order to satisfy specified operating criteria. These criteria could be a specified GSOSR or a specified probability of the normal state or both. It is shown that the number of committed units increases when a system is required to meet an acceptable normal state probability in addition to a specified risk.

The priority loading order for the generating units is used to commit units in service or to remove units from service depending on the load levels. The number of units that must be committed and the system operating state probabilities depend on many factors, such as the system lead time, the system load, the generating unit failure rates and the unit commitment criterion. The effects of lead time and peak load on the required number of committed units, the GSOSR and the system operating state probabilities are presented in Chapter 3. It was found that the probability of the normal state decreases as the lead time increases while the GSOSR increases as the lead time increases.

The uncertainty associated with forecasting the system load is an important factor in operating reserve evaluation. The best way to describe this uncertainty is in terms of a probability distribution. Load forecast uncertainty is reasonably described by a normal distribution in which the mean is the forecast load and the standard deviation is some fraction of the 
forecast load. Derated states suffered by generating units is another factor which influences operating reserve in a practical system. The proposed probabilistic technique can include both load forecast uncertainty and derated states in the assessment of system operating reserve. The impact of these two factors on the system operating state probabilities is also illustrated and discussed in Chapter 3.

The delay time associated with additional generating units is quite variable and is dependent upon many factors. The most important, however, is the type of unit in question. Stand-by units can usually be made available in a relatively short time as compared to that required for more conventional thermal units. Operating reserve assessment including rapid start and hot reserve units is illustrated in Chapter 4. The effect of rapid start and hot reserve units can be incorporated in operating reserve assessment using the concept of area risk curves. A procedure has been developed to determine the system operating state probabilities for the entire lead time. It was found that the system risk decreases by including stand-by units in the system. The results also show that the system can not transfer to the normal state by including rapid start and hot reserve units, if it is operating initially in the alert state.

The conventional definition of a forced outage includes both sudden unit removal from service and those failure events for which the unit can continue to operate for a relatively short period of time. The various degrees of urgency associated with forced unit removal from service is usually considered using postponability codes or classes of forced outages. The effect on the system operating state probabilities and GSOSR of various 
degrees of postponability are also discussed in Chapter 4. The results show that the system risk decreases by increasing the degree of postponability.

The inclusion of interruptible loads in operating reserve assessment in a system is illustrated in Chapter 5 . The effect of interruptible load can be incorporated in operating reserve assessment using the area risk curve technique. For computational purposes, interruptible load can be considered as a load variation or as an equivalent generating unit with a failure rate equal to zero. It is generally recognized that interruptible load can alleviate the system risk. The magnitude of interruptible load and corresponding time of interruption depend on the agreements between the utility and its consumers. The effect of variation in the available interruptible load and the corresponding lead time on the GSOSR and system operating state probabilities are also illustrated in Chapter 5.

Units are usually committed such that for a given firm load a specified risk is satisfied. The total generating capacity in operation must be equal to or greater than the firm load. The generation system, therefore, may be able to carry additional load or additional interruptible load on top of its firm load without violating the specified risk and without requiring any additional units to be committed other than those required to satisfy the firm load. The set of additional load/interruptible load depends on the generating capacity in operation, the firm load and the unit commitment criterion.

Two reliability test systems are utilized in this thesis in order to illustrate the proposed techniques. The results obtained by using the RBTS 
are illustrated in Chapters 2,3,4 and 5. In order to illustrate the applicability of the proposed techniques to a relatively large practical system, similar studies were conducted using the IEEE-RTS and those results are presented in Chapter 6.

The concepts proposed in this thesis extend the quantitative indices and techniques available for operating reserve assessment and should prove useful in providing the system operator with additional information on the wellbeing of the system. 


\section{REFERENCES}

1. Billinton, R., Allan, R. N., "Power System Reliability in Perspective" , IEE Electronics and Power, pp. 231-236, March 1984.

2. Singh, C., Billinton, R., "System Reliability Modeling and Evaluation", Hutchinson of London/1977.

3. Billinton, R. and Allan, R. N., Reliability Evaluation of Power Systems, Longman (London, England)/Plenum press, 1984.

4. Billinton, R. "Criteria Used by Canadian Utilities in the Planning and Operation of Generating Capacity", IEEE Transactions on Power Apparatus and Systems, Vol. 3, No. 4, pp. 1488-1493, November 1988.

5. Shoults, R. R., Chang, S. K., Helmick, S., Grady, W. M., "A Practical Approach to Unit Commitment, Economic Dispatch and Savings Allocation For Multiple-Area Pool Operation With Import/Export Constraints", IEEE Transactions on Power Apparatus and Systems, Vol. PAS-99, No. 2, pp. 625-633 March/April 1980.

6. Kerr, R. H., Scheidt, J. L., Fontana, A. J. and Wiley, J. K., "Unit Commitment", IEEE Transactions on Power Apparatus and Systems", Vol. PAS-85, No.5, pp. 417-421, May 1966.

7. Lowery, P. G., "Generating Unit Commitment by Dynamic Programming", IEEE Transactions on Power Apparatus and Systems, Vol. PAS-85, No.5, pp. 422-426, May 1966.

8. Happ, H. H., Johson, R. C. and Wright, W. J., "Large Scale HydroThermal Unit Commitment-method and Results", IEEE Transactions on Power Apparatus and Systems, Vol. PAS-90, No. 5, pp. 1373-1382, May/June 1971.

9. Allan, R. N., "Probabilistic Methods Applied to Electric Power Systems - Are They Worth?", Third International Conference on Probabilistic Methods Applied to Electric Power Systems, PM PAS 91, July 3, 1991.

10. Billinton, R., Chowdhury, N. A., "Operating Reserve Assessment in Interconnected Generating Systems", IEEE Transactions on Power Apparatus and Systems, Vol. PAS-3, No. 4, pp. 1479-1487, November 1988. 
11. Ansine, L. T., Burke, R. E., Casey, J. E., Holgate, R., John, R. S. and Stewart, H. G., "Application of Probability Method to the Determination of Spinning Reserve Requirements for the Pennsylvania - New Jersey - Maryland Interconnection", IEEE Transactions on Power Apparatus and Systems, Vol. PAS-68, pp. 726-735, October 1963.

12. Leffler, L. G., Chambliss, R. J., Cucchi, G. A., Reppen, N. d., Ringlee, R. J. "Operating Reserve and Generation Risk Analysis for the PJM Interconnection", IEEE Transactions on Power Apparatus and Systems, Vol. PAS-94, No. 2, pp. 396-407, March/April 1975.

13. Billinton, R., Jain, A. V., "The Effect of Rapid Start and Hot Reserve Units in Spinning Reserve Studies", IEEE Transaction on Power Apparatus and Systems, Vol. PAS-91, No. 2, pp. 511-516, March/April 1972.

14. Patton, A. D., "Short-term Reliability Calculation", IEEE Transactions on Power apparatus and systems, Vol. PAS-89, No. 4, pp. 509-521, April 1970.

15. Patton, A. D., "A Probability Method for Bulk Power System Security Assessment: I-Basic Concepts" IEEE Transactions on Power Apparatus and Systems, Vol. PAS-91, pp. 54-61, January/February 1972.

16. Patton, A. D., "A Probability Method for Bulk Power System Security Assessment: II-Development of Probability Models for Normallyoperating Components", IEEE Transaction on Power Apparatus and Systems, Vol. PAS-91, pp. 2480-5, November/December 1972.

17. Nish, J. I. and Millar, N. A., "Generation System Operating Reserve Assessment Practices used by Canadian Utilities", Electrical Association, Power System Planning and Operation Section, Spring Meeting 1984.

18. Final Report, "Composite-System Reliability Evaluation: Phase 1 Scooping Study ", Tech. report EPRI EL-5290, Project 2581-1, December 1987.

19. Fink, L. K. and Carlsen, K., "Operating Under Stress and Strain", IEEE Spectrum, pp. 48-53, March 1978.

20. IEEE Committee Report, "Bibliography on the Application of Probability Methods in Power System Reliability Evaluation, 19711977", IEEE Transactions on Power Apparatus and Systems, Vol. PAS-97, No. 6, pp. 2235-2242, November/December 1978. 
21. Allan, R. N., Billinton, R. and Lee, S. H. "Bibliography on the Application of Probability Methods in Power System Reliability Evaluation, 1977-1982", IEEE Transactions on Power Apparatus and Systems, PAS-103, pp. 275-282, No. 2, February 1984.

22. Allan, R. N., Billinton, R., Shahidehpour, S. M. and Singh, C. "Bibliography on the Application of Probability Methods in Power System Reliability Evaluation, 1982-87", IEEE Transactions on Power Apparatus and Systems, Vol. 3, No. 4, pp. 1555-1564, November 1988.

23. Billinton, R. and Allan, R. N., Reliability Evaluation Of Engineering System - Concepts and Techniques, Longmans(England)/ Plenum Press, New York, 1983.

24. Billinton, R., Jain, A. V., "Unit Derating Levels in Spinning Reserve Studies", IEEE Transactions on Power Apparatus and Systems, Vol. PAS-90, No. 4, pp. 1677-86, July/August 1971.

25. Biggerstaff, B. E. and Jackson, T. M., "The Markov Process As a Means of Determining Generating Unit State Probabilities For Use in Spinning Reserve Application", IEEE Transactions on Power Apparatus and Systems, Vol. Pas-88, No. 4, April 1969.

26. Billinton, R., Discussion on Reference 25.

27. Chowdhury, N. A. and Billinton, R., "Unit Commitment in Interconnected Generating Systems Using a Probabilistic Technique", IEEE Transactions on Power Apparatus and Systems, Vol. 5, No.4, pp. 1231-1238, November 1990.

28. Billinton, R., Kumar, S., Chowdhury, N. A., et al. , "A Reliability Test System For Educational Purposes-Basic Data", IEEE Transactions on Power Apparatus and Systems, Vol.4, No. 4, pp. 1238-1244, November 1989.

29. Billinton, R. and Khan, E., "A Security Based Approach to Composite Power System Reliability Evaluation", IEEE Transactions on Power Apparatus and Systems, Vol. PWRS-7, No. 1, pp. 65-71, February 1992.

30. Chowdhury, N. A., Billinton, R., "A Reliability Test System For Educational Purposes - Spinning Reserve Studies in Isolated and Interconnected Systems", IEEE/PES 1991 Summer meeting, paper No. 91 SM 309-5 PWRS.

31. Allan, R. N., Nunes, R. A. F., "Modeling of Stand-by Generating Units in Short - Term Reliability Evaluation", IEEE Winter Power Meeting, New York, pp. 1-6, 1979, paper A79006-8. 
32. Billinton, R., "Reliability Models for Generating Unit Peaking Equipment", Canadian Electrical Association, System Planning and Operating Section, CEA Transaction, Vol. II, Part 3, Paper No. 72 5P-140.

33. Billinton, R. and Alam, M., "Outage Postponability Effects in Operating Capacity Reliability Studies", IEEE Winter Power Meeting, New York, pp. 1-7, January/February 1978, Paper A78064-8.

34. Billinton, R., Chowdhury, N. A., "Operating Benefits of Interruptible Loads", Presented at the 1988 Spring Meeting of Canadian Electrical Association/Power System Planning and Operating Section, Montreal, Quebec, March 16-21 1988.

35. Chowdhury, N. A., Billinton, R., "Interruptible Load Carrying Capability of a Generation System", IEEE paper No. 88 SM 652-0, Presented at the IEEE/PES Summer Meeting , Portland, Oregon, July 24-29 1988.

36. IEEE Committee Report, "IEEE Reliability Test System", IEEE Transactions on Power Apparatus and Systems, Vol. PAS-98, No. 6, pp. 2047-2054, November/December 1979.

37. Allan, R. N., Billinton, R., Abdel-Gawad, N. M. K., "The IEEE Reliability Test System-Extension to and Evaluation of the Generating System", IEEE Transactions on Power Apparatus and Systems, Vol. PWRS-1, No. 4, pp. 1-7, November 1986. 